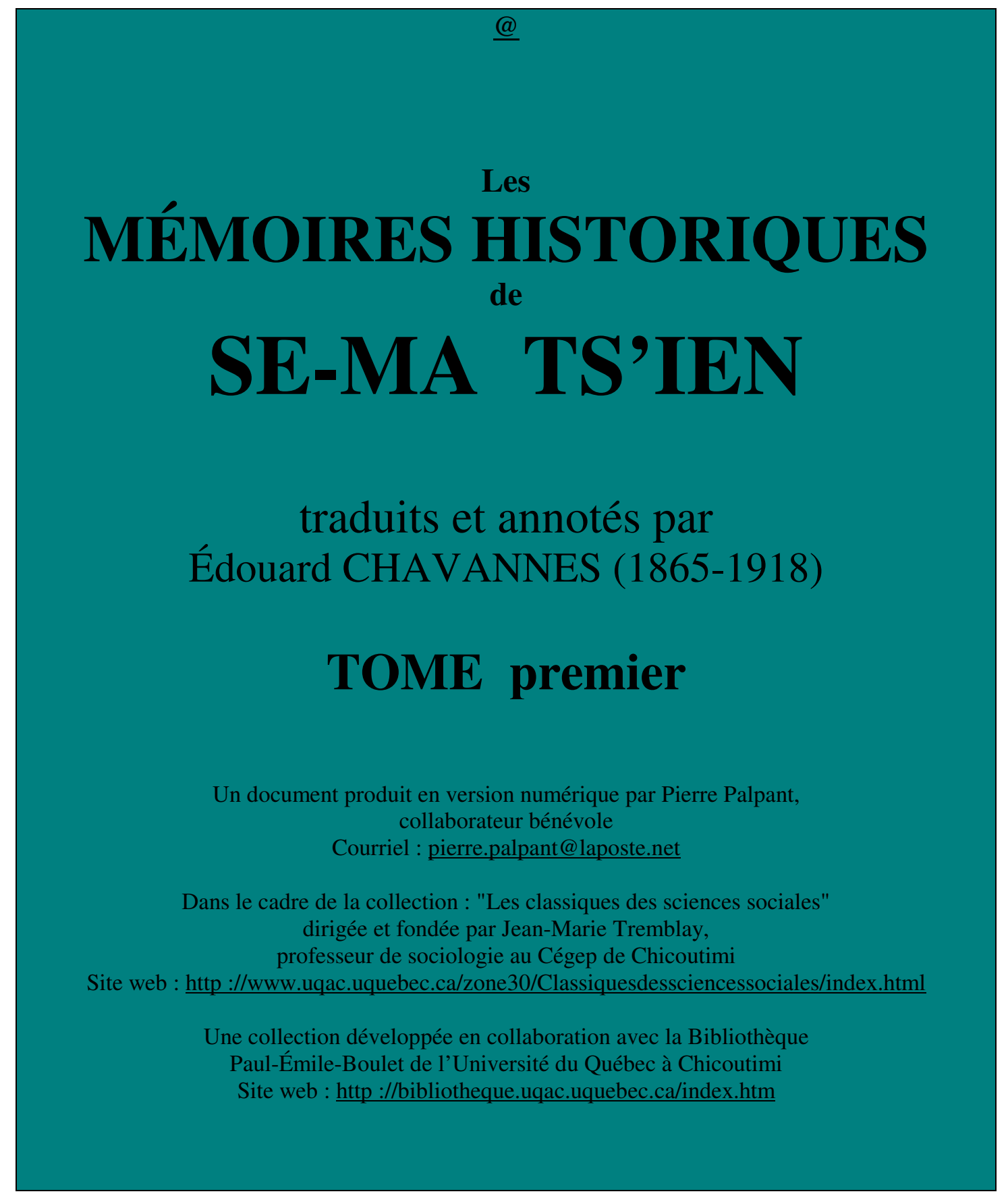


Un document produit en version numérique par Pierre Palpant, collaborateur bénévole, Courriel : pierre.palpant@laposte.net

à partir de :

\section{Les Mémoires historiques de Se-ma Ts’ien, Tome premier,}

\section{traduits et annotés par Edouard CHAVANNES (1865-1918)}

Librairie d'Amérique et d'Orient Adrien Maisonneuve, Paris, 1967.

Polices de caractères utilisée : Times, 10 et 12 points.

Mise en page sur papier format LETTRE (US letter), 8.5 x 11'.

Édition complétée le 30 novembre 2004 à Chicoutimi, Québec. 


\section{T A B LE DES M A T I ÈRES}

Annales principales des Trois Souverains, par Se-ma Tcheng, (commencement $d u$ huitième siècle de notre ère), avec notes.

\section{Première section : Annales principales}

Chapitre premier. - Les cinq empereurs.

Chapitre II. - Les Hia.

Chapitre III. - Les $Y$ n.

Chapitre IV. - Les Tcheou.

$\underline{\text { Notes }:-C h a p i t r e s ~: ~} \underline{\mathrm{I}}-\underline{\mathrm{II}}-\underline{\mathrm{III}}-\underline{\mathrm{IV}}$. 


\title{
ANNALES PRINCIPALES
}

\section{DES TROIS SOUVERAINS}

\author{
PAR \\ SE-MA TCHENG (101)
}

- 3 T'ai-hao Pao-hi $(\underline{102})$ avait pour nom de clan $(\underline{103})$ Fong. Succédant à ${ }_{5}$ Soei-jen $\left(\frac{104}{)}\right)$ il continua le Ciel et régna.

[ $(\underline{105})$ Sa mère s'appelait Hoa-siu $(\underline{106})$; elle marcha dans les empreintes de pas d'un géant $\left(\frac{107}{)}\right)$ auprès du marais de Lei $\left(\frac{108}{)}\right.$; et c'est à la suite de cela qu'elle enfanta $P$ 'ao-hi à Tch'eng-ki $\left(\frac{109}{)}\right)$. Il avait un corps de serpent et une tête d'homme $(\underline{110})$.]

${ }_{6}$ Il eut une vertu sainte.

[ (111) Levant la tête, il contempla les figures qui se trouvent dans le ciel ; baissant la tête, il contempla les formes qui sont sur la terre. - Autour de lui il contempla les bigarrures des oiseaux et des animaux, ainsi que ce qui convient au sol $(\underline{112})$. - Au près, il prit en considération toutes les parties de son corps ; au loin, il prit en considération tous les êtres. Il fut le premier à tracer les huit trigrammes $(\underline{113})$ grâce auxquels il pénétra l'efficace des esprits divins et grâce auxquels il sépara par classes les natures des êtres.]

Il inventa les textes écrits pour remplacer l'institution des cordes nouées $(\underline{114})$.

- 7 Puis le premier il régla le mariage de la femme et celui de l'homme et du don des deux peaux de bêtes il fit un rite $(\underline{115})$.

[ $(116)$ Il tressa des filets et des rets pour enseigner la chasse et la pêche] et c'est pourquoi on l'appela Fou-hi. Il éleva des animaux domestiques pour la cuisine et c'est pourquoi on l'appela $P$ 'ao-hi $(\underline{117})$.

Il eut le présage favorable d'un dragon ; il appela les fonctionnaires de noms de dragons en leur donnant le titre d'officiers -dragons $(\underline{118})$.

${ }_{8}$ Il fit un luth de trente-cinq cordes $(\underline{119})$.

Il régna par la vertu du bois. Il dirigea son attention sur les ordonnances du printemps ; c'est pourquoi le Livre des Changements $(\underline{120})$ dit : "L'emper eur apparaît au signe Tchen »; et le Livre des Ordonnances mensuelles $\left(\frac{121}{)}\right)$ à l'article du premier mois du printemps, dit : «L'empereur qui y préside est T'ai-hao. » C'est exact. 
Il eut sa capitale à Tch'en $(\underline{122})$.

- 9 Il alla dans l'est accomplir la cérémonie fong $(\underline{123})$ sur le T'ai -chan $(\underline{124})$.

II fut au pouvoir onze années, puis mourut.

Lors de la période Tch'oen-ts'ieou (125), on comptait parmi ses descendants (les princes de) Jen, Sou, Siu-kiu et Tchoan-yu, qui tous étaient issus du clan Fong (126).

Niu-koa $\left(\frac{127}{)}\right)$ appartenait aussi au clan Fong; il avait un corps de $\bullet{ }_{10}$ serpent et une tête d'homme. Il eut une vertu divine et sainte. Il eut le pouvoir à la place de Fou-hi. Il prit l'appellation de Niu-hi. Il ne changea ni n'inventa rien ; il fit seulement les tuyaux de l'instrument de musique appelé cheng $\left({ }^{128}\right)$. Le Livre des Changements ne parle donc pas de lui. Il ne cadre pas avec le cycle quinaire $(\underline{129})$.

Une autre tradition dit que Niu-koa régna aussi par la vertu du bois ; il était en effet le descendant de Fou-hi et, comme plusieurs générations s'étaient écoulées entre eux deux, le métal, puis le bois avaient réapparu à leur tour; le cycle était terminé et recommençait de nouveau. Cette tradition loue spécialement Niu-koa à cause de ses grands mérites et le met au rang des trois souverains ; il y aurait donc eu deux rois qui possédèrent la vertu du bois $\left(\frac{130}{}\right)$.

- ${ }_{11}$ Dans les dernières années de Niu-koa, il y eut, parmi les seigneurs, Kong-kong (131) ; se fiant sur son savoir et sur les châtiments, il se fit obéir par la violence, mais il ne fut pas roi légitime, car c'était par l'eau qu ill succédait au bois $(\underline{132})$. Il combattit avec Tchou-yong $(\underline{133})$; il ne fut pas vainqueur ; [ $(\underline{134})$ dans sa colère, il se précipita la tête la première, contre la montagne Pou-tcheou $(\underline{135})$ et la fit tomber. La colonne du ciel se $\bullet{ }_{12}$ rompit et les côtés de la terre se brisèrent.] [ $(\underline{136})$ Niu-koa fondit alors des pierres de cinq couleurs $(\underline{137})$ afin de soutenir le ciel ; il coupa les pattes d'une tortue marine afin de supporter les quatre extrémités de la terre.] Il rassembla de la cendre de roseau pour arrêter les eaux débordées et pour rétablir l'ordre dans la province de $K i(\underline{138})$.

Puis, la terre étant calme et le ciel affermi, il ne changea plus l'a ncien ordre de choses.

Après la mort de Niu-koa, Chen-nong $(\underline{139})$ exerça le pouvoir. Yen-ti Chen-nong était du clan Kiang. Sa mère s'appelait Niu-teng $\left(\frac{140}{)}\right)$. Il arriva qu'une fille de Koa $(\underline{141})$, étant devenue concubine de Chao-tien, fut émue ${ }_{13}$ par un dragon divin et enfanta Yen-ti. Il avait le corps d'un homme et la tête d'un bœuf. Il grandit au bord de la rivière Kiang $(\underline{142})$ et c'est de là que lui vint son nom de clan. Il régna par la vertu du feu; c'est pourquoi on l'appela Yen-ti. Il nomma ses officiers d'après le feu $(\underline{143})$.

[ $(\underline{144})$ Il tailla une pièce de bois pour en faire un soc ; il courba une pièce de bois pour en faire la flèche d'une charrue. L'usage de la charrue et de la houe fut enseigné par lui à la foule des hommes.] II fut le premier qui enseigna le labourage. C'est pourquoi il reçut le titre de Chen-nong. Puis il 
institua le sacrifice de la fin de l'année $(\underline{145})$. Il frappait avec un fouet rouge $\left(\frac{146}{)}\right)$ les herbes et les arbres. Le premier il éprouva les cent espèces de plantes et le premier il trouva les drogues qui guérissent.

Il fit en outre un luth à cinq cordes.

[ ( $(477)$ Il enseigna aux hommes à tenir le marché au milieu du jour et, une - ${ }_{14}$ fois les échanges faits, à se retirer ; chacun obtint de la sorte ce dont il avait besoin] $(\underline{148})$.

Ensuite il multiplia les huit trigrammes et en fit les soixante-quatre hexagrammes $(\underline{149})$.

Il commença par avoir sa capitale à Tch'en (150), puis il résida à K’iu-feou (151). Il mourut après avoir été au pouvoir cent vingt années, Il fut enterré à Tch'ang -cha $(\underline{152})$.

Chen-nong vint d'abord de la montagne Lié $(\underline{153})$. C'est pourquoi Tso $(\underline{154})$ - ${ }_{15}$ dit : «Le fils de Lié-chan s'appela Tchou. »On l'appelle aussi Li-chan et c'est ainsi que les Rites $(\underline{155})$ disent : «Li-chan eut l'empire. »

Chen-nong prit une fille de la famille Pen-choei, qui s'appelait T’ing -pa et en fit sa femme. Il en eut un fils qui fut l'empereur Ngai; Ngai engendra l'empereur $K^{\prime} o$; K'o engendra l'empereur $Y u$-wang. En tout il se passa huit générations et cinq cent trente années $(\underline{156})$ et alors Hien-yuen $(\underline{157})$ arriva au pouvoir.

Parmi ses descendants il y eut Tcheou, Fou, Kan, Hiu, Hi, Lou, Ts'i, Ki, I, Hiang, Chen, $\mathrm{Lu}$, qui tous étaient issus du clan Kiang $(\underline{158})$.

• ${ }_{16}$ Ils furent tous seigneurs ; quelques-uns d'entre eux furent envoyés pour gouverner les quatre montagnes $\left(\frac{159}{2}\right)$. Au temps de la dynastie Tcheou, le marquis de Fou et le comte de Chen furent les sages conseillers du roi ( $(160)$. $T$ ' $i$ et Hiu furent des seigneurs autonomes $(\underline{161})$; ils fournirent un hégémon au royaume du milieu $(\underline{162})$.

- ${ }_{17}$ Comme la vertu de l'homme saint $(\underline{163})$ avait été abondante, étendue et grande, sa fortune et sa postérité furent florissantes et durèrent longtemps.

Une autre tradition explique les trois souverains en disant que les souverains du ciel, les souverains de la terre et les souverains de l'homm e sont les trois souverains $\left(\frac{164}{)}\right)$. C'est donc l'époque primitive où le ciel et la terre se séparèrent et où pour la première fois il y eut des princes et des sujets. Ce que rapporte l'Appendice au Tableau $\left(\frac{165}{}\right)$, on ne $\bullet_{18}$ peut le rejeter en bloc ; c'est pourquoi je mentionne cette tradition à la suite de la précédente.

Lorsque le ciel et la terre furent constitués pour la première fois, il y eut les souverains du ciel qui comptèrent douze représentants $(\underline{166})$. Calmes et immuables, ils ne se livraient à aucune action et les mœurs se perfectionnaient d'elles-mêmes. Ils régnaient par la vertu du bois. Le calcul des années se faisait au moyen de la constellation Ché-t’i $(\underline{167})$. Ils étaient douze frères qui régnèrent chacun dix-huit mille années. 
Les souverains de la terre comptèrent onze représentants. Ils régnèrent par la vertu du feu. Ils furent onze membres de la même famille. Ils furent florissants auprès des montagnes Hiong-eul $\left(\frac{168}{)}\right)$ et Long-men. Chacun d'eux aussi régna dix-huit mille années.

• ${ }_{19}$ Les neuf souverains de l'homme $(\underline{169})$, montés sur des chars de nuages attelés de six êtres ailés $\left(\frac{170}{}\right)$, sortirent de Kou-k'eou $(\underline{171})$. — Ils étaient neuf frères qui se divisèrent le commandement des neuf provinces $\left(\frac{172}{2}\right)$. Chacun d'eux éleva une ville murée. En tout ils ré gnèrent pendant cent cinquante générations, soit quarante-cinq mille six cents années.

Après les souverains de l'homme, il y eut les cinq Dragons ( $(\underline{173})$, puis Soeijen (174), Ta-t’ing ( $\left.{ }^{175}\right)$, Po-hoang, Tchong-yang, Kiuen-siu, Li-lou, $\bullet_{20}$ Li-lien, Ho-siu, Ts'oen-lou, Hoen-toen (176), Hao-yng, Yeou-tch'ao, Tchou-siang, Ko-t'ien, Yn-k'ang, Ou-hoai. Ce sont là les noms de ceux qui, après les trois souverains, eurent l'empire. Cependant, comme les monuments écrits ne le rappellent pas, on ne sait pas la durée des règnes de ces familles, ni leurs généalogies, ni le lieu où elles eurent leur capitale.

Cependant les Poésies de Han $\left(\frac{177}{)}\right)$ estiment que depuis l'antiquité ceux qui firent la cérémonie fong sur le T'ai-chan et la cérémonie chan sur le mont Leang-fou $\left(\frac{178}{(179)}\right.$ furent au nombre de plus de dix mille personnes, Tchong-ni $\left(\frac{179}{}\right)$ vit ce témoignage, mais ne put les connaître tous. Koan-tse de son côté dit $(\underline{180})$ :

- Autrefois, il y eut soixante-douze personnes qui firent la cérémonie fong sur le T'ai-chan. Ceux que moi, I-ou $(\underline{181})$, je connais, sont au nombre de douze.

En tête de sa liste, il y a Ou-hoai. Mais avant $O u$-hoai et après les souverains du ciel, le calcul des années est illimité et insondable.

Comment les souverains et les rois s'élevaient et comment ils l'an nonçaient $\left(\frac{182}{)}\right.$, c'est ce que les anciens écrits ont perdu et on ne saurait le bien exposer. Est-ce à dire toutefois qu'il n'y eut ni empereurs ni rois ?

Or un appendice $(\underline{183})$ du Tch'oen ts 'ieou dit :

«Depuis la grande $\bullet_{21}$ séparation $(\underline{184})$ jusqu’à la prise du lin $\left(\frac{185}{)}\right.$, il y eut en tout trois millions deux cent soixante-seize mille années $(\underline{186})$; elles se divisent en dix périodes appelées $k i$ qui, réunies, comprennent les années de soixante-dix mille six cents générations $\left(\frac{187}{}\right)$. La première de ces périodes s'appelle la pé riode des neuf têtes $(\underline{188})$; la seconde s'appelle la période des cinq dragons; la troisième s'appelle la période Ché-t $i$; la quatrième s'appelle la période Ho-ngo ; la cinquième s'appelle la période Lien-t'ong ; la sixième s'appelle la période Sia-ming ; la septième s'appelle la période Sieou-fei; la huitième s'appelle la période Hoei-t'i ; la neuvième s'ap pelle la période Chan-t'ong ; la dixième s'appelle la période Lieou-ki. 
- ${ }_{22}$ Or la période Lieou-ki doit correspondre à l'époque de Hoang-ti $\left(\frac{189}{)}\right)$. J'ai déterminé l'intervalle compris d ans les neuf autres périodes et c'est ainsi que, j’ai fait des Annales supplémentaires en rédigeant ici cet exposé. 


\section{MÉMOIRES HISTORIQUES \\ de \\ SE-M A T S'I E N}

PREMIÈRE SECTION

ANNALES PRINCIPALES 


\section{CHAPITRE PREMIER}

\section{PREMIÈRES ANNALES PRINCIPALES LES CINQ EMPEREURS (101)}

${ }_{25}$ [ ( $(\underline{102})$ Hoang-ti $(\underline{103})$ était fils de Chao-tien $]\left(\frac{104}{)}\right)$. Son nom de $\bullet_{26}$ famille était Kong-suen $(\underline{105}) ; \bullet$ son nom personnel [était Hien-yuen $(\underline{106})$. Dès sa naissance il eut une puissance surnaturelle; dès sa tendre enfance $\left(\frac{107}{)}\right)$ il sut parler; dès sa jeunesse, sa vertu s'exerça partout avec promptitude; adolescent, il fut bon et perspicace; homme fait $\left(\frac{108}{)}\right)$, il eut une intelligence ouverte].

$\mathrm{Au}$ temps de Hien-yuen, les descendants de Chen-nong (109) s'étaient pervertis; les seigneurs se prenaient $\bullet_{27}$ des territoires les uns aux autres et se battaient; ils opprimaient les cent familles. Or Chen-nong ne pouvait les réduire $\left(\frac{110}{}\right)$. Alors Hien-yuen s'exerça au maniement du bouclier et de la lance afin de soumettre ceux qui ne rendaient pas hommage à la cour; les seigneurs vinrent tous avec respect et obéissance. Cependant Tch'e-yeou ( $\left.{ }^{111}\right)$ était le plus terrible et restait invincible.

- 28 Yen-ti voulut empiéter sur les droits des seigneurs; les seigneurs se réfugièrent tous auprès de Hien-yuen. Hien-yuen alors fit appel à toute son énergie et leva des soldats ; [ $(\underline{112})$ il se rendit maître des cinq influences $(\underline{113})$; il mit en terre les cinq semences $\left(\frac{114}{}\right)$; il fit du bien aux dix mille tribus et gouverna les quatre côtés. Il dressa des ours, des léopards, des panthères, des lynx et des tigres $(\underline{115})$ et il s'en servit lors de la bataille qu’il livra à $\bullet_{29}$ Yen-ti (116) dans la campagne de Pan-k'iuen (117). Il soutint trois combats et finit par avoir gain de cause.]

Tch'e-yeou fit des troubles; il n'obéit pas aux ordres impériaux. Alors Hoang-ti appela aux armes les seigneurs et livra bataille à Tch'e-yeou dans la campagne de Tchouo-Lou (118). Il s'empara donc de Tch'e-yeou et le mit à mort.

Puis les seigneurs élevèrent tous Hien-yuen au rang de Fils du ciel; il remplaça Chen-nong; ce fut Hoang-ti.

Ceux qui dans le monde ne se soumirent pas à lui, Hoang-ti les poursuivit et les dompta ; ceux qui se tinrent calmes, il les laissa aller. Il fit des percées dans les montagnes; il ouvrit des routes. Il n'a vait pas un moment pour se reposer en paix. A l'est, il alla jusqu'à la mer ; il monta sur la montagne Hoan $(\underline{119})$ et sur le $\bullet_{30}$ Tai-tsong $(\underline{120})$. A l'ouest, il alla jusqu'au mont Kong-t'ong (121) et monta sur le Ki-t'eou ( $(22)$. Au sud, il alla jusqu'au 
Kiang $\left(\frac{123}{}\right)$ et gravit les monts Hiong et Siang. Au nord, il repoussa les Hiun-yu (124).

- Il vérifia les insignes sur la montagne Fou $(\underline{125})$. Puis il s'établit au pied du Tchouo-lou $\left(\frac{126}{)}\right)$. Il se déplaçait çà et là et n'avait pas de résidence fixe $(\underline{127})$; ses soldats formaient un campement pour le protéger.

Quant aux noms de fonctions, il se servit des nuées et $\bullet_{32}$ appela nuées ses officiers $\left(\frac{128}{1}\right)$. Il institua les grands surintendants de gauche et de droite pour surveiller les dix mille tribus. Les dix mille tribus vécurent en paix. Puis les (sacrifices aux) génies et aux dieux, aux montagnes et aux fleuves, et les cérémonies fong et chan furent multipliés par lui. Il entra en possession du trépied précieux ; il compta d'avance les jours en faisant des supputations au moyen de l'achillée $(\underline{129})$.

Il leva en dignité Fong-heou, Li-mou, Tch'ang-sien et Ta hong et les chargea de gouverner le peuple $(\underline{130})$.

- 33 [ ( $\underline{131}$ ) Il se conforma aux nombres du ciel et de la terre, aux explications de la vie et de la mort,] aux raisons subtiles du calme et du trouble $(\underline{132})$.

-: [Aux époques voulues il planta les cent espèces de céréales, d'herbes et d'arbres. Il favorisa le développe ment des oiseaux, des quadrupèdes, des insectes et des reptiles. Il établit partout l'ordre pour le soleil, la lune, les étoiles, les syzygies de conjonction $(\underline{133})$, pour les flots de la mer, pour la terre, les pierres, les métaux et le jade. Il n'épargna aucune peine à son cœur, à sa force, à ses oreilles et à ses yeux. Il régla l'usage de l'eau, du feu ( $\underline{134})$, du bois et de toutes choses.]

- 34 Il eut l'heureux présage de la vertu de la terre ; c'est pourquoi son surnom fut Hoang-ti ( $\underline{135})$.

Hoang-ti eut vingt-cinq fils ; ceux qui eurent des noms de clans furent au nombre de quatorze $\left(\frac{136}{)}\right)$. [ $\left(\frac{137}{)}\right.$ Hoang-ti demeura sur la colline de Hien-yuen (138) ; il se maria avec une femme de Si-Ling (139) qui n'est autre que ${ }_{35}$ Lei-tsou $\left(\frac{140}{}\right)$. Lei-tsou fut première entre les femmes de Hoang-ti $\left(\frac{141}{}\right)$.]

Elle enfanta deux fils; les descendants de tous deux possédèrent l'empire $\left({ }^{142}\right)$. L'un d'eux s'appelait Hiuen-hiao; il n'est autre que T'sing-yang; T'sing-yang alla s'établir sur les bords de la rivière Kiang $\left({ }^{143}\right)$. Le second fils $\bullet_{36}$ s'appelait Tch'ang-i; [il alla s'établir sur les bords de la rivière $J o\left({ }^{144}\right)$. Tch'ang- $i$ épousa une femme des montagnes de Chou qui s'appelait Tch'ang p'ou $(\underline{145})$ ] et qui enfanta Kao-yang. Kao-yang eut une vertu sainte. Hoang-ti mourut et fut enterré sur la montagne Kiao $(\underline{146})$. Son $\bullet_{37}$ petit-fils, Kao-yang, qui était le fils de Tch'ang-i, prit le pouvoir. Ce fut l'empereur Tchoan-hiu.

L'empereur Tchoan-hiu, qui n'est autre que Kao-yang, [ ( $\left.{ }^{147}\right)$ était petit-fils de Hoang-ti et fils de Tch'ang- $i$. Il était calme et profond dans ses desseins. Son intelligence était claire et étendue et il comprenait tout. Il cultivait les 
plantes de la manière qui convient à la terre. Il agissait suivant les saisons pour se conformer au ciel. Il s'appuyait sur les mânes et les dieux pour fixer la justice $(\underline{148})$. Il dirigeait les influences afin d'apprendre aux êtres à se perfectionner. Il accomplissait les sacrifices avec pureté et sincérité.]

[Au nord, il alla jusqu'à Yeou-Ling $(\underline{149})$; au sud, il alla jusqu'au Kiao-tche $\left(\frac{150}{)}\right)$; à l'ouest, il alla jusqu'au ${ }_{38}$ Leou-cha $(\underline{151})$; à l'est, il alla jusqu'au P'an-mou $(\underline{152})$.

Les êtres en mouvement et ceux qui sont en repos, les dieux, petits et grands, les choses qu'éclairent le soleil et la lune, tout, sans exception, fut calme et docile.]

- ${ }_{39}$ L'empereur Tchoan-hiu engendra un fils qui s’appela $K^{\prime}$ iong-chan (153).

Tchoan-hiu mourut (154). Alors le petit-fils de Hiuen-hiao, Kao-sin, prit le pouvoir ; ce fut l'empereur K'ou.

Kao-sin, qui fut l'empereur Kou $\left(\frac{155}{5}\right)$, était arrière-petit-fils de Hoang-ti. Son père s'appelait Kiao-ki; le père de Kiao-ki s'appelait Hiuen-hiao ; le père de Hiuen-hiao s'appelait Hoang-ti. Hiuen-hiao, puis Kiao-ki, n'eurent ni l'un ni l'autre l'empire. Mais Kao-sin obtint la dignité impériale (156). Kao-sin était neveu ( $\underline{157}$ ) de Tchoan-hiu.

- ${ }_{40}$ Dès sa naissance [ $(\underline{158})$ Kao-sin fut divin et merveilleux ; il dit lui-même quel était son nom. Sa libéralité universelle favorisait tous les êtres. Il ne pensait pas à lui-même. Il avait l'ouïe fine et connaissait les choses éloignées ; il avait la vue perçante et discernait les moindres détails. il se conformait à l'ordre établi par le ciel. Il savait quels étaient les besoins du peuple. Il était bon et cependant majestueux, bienveillant et cependant digne de confiance.] - [Il s'appliquait à bien se conduire et l'empire lui obéissait. Il recueillait les productions de la terre et en usait avec mesure. Il gouvernait et instruisait les dix mille tribus ; il leur était utile et leur donnait des conseils. Il observait le soleil et la lune pour les recevoir et les accompagner $(\underline{159})$. Il comprenait les mânes et les dieux $(\underline{160})$ et les servait avec respect.

Son air était très imposant ; sa vertu était fort haute ;

Il agissait aux temps opportuns; son habillement était celui des fonctionnaires.]

L'empereur Kou était ferme et juste et il embrassait le monde entier. [ $\left(\frac{161}{6}\right)$ Tout ce qu'éclairent le soleil et la lune, tout ce qu'atteignent le vent et la pluie, se soumit à lui sans exception.]

L'empereur K'ou épousa une femme de Tch'en-fong $(\underline{162}) . \bullet_{41}$ Elle mit au monde Fang-hiun (163).

L'empereur Kou épousa une femme de Tsiu-tse ; elle enfanta Tche (164). 
L'empereur $\operatorname{Kou}\left(\frac{165}{)}\right)$ mourut et l'empereur Tche prit le $\bullet_{42}$ pouvoir à sa place ; il ne fut pas bon; il mourut. - Son frère cadet, Fang-hiun, prit alors le pouvoir ; ce fut l'em pereur Yao $(\underline{166})$.

Celui qui fut l'empereur Yao n'est autre que Fang-hiun. [ ( $(\underline{167})$ Sa bonté fut comme celle du ciel; son savoir fut comme celui d'un dieu. De près, il apparaissait comme le soleil; de loin, comme une nuée $\left(\frac{168}{)}\right)$ Quoique puissant, il n'était pas arrogant ; quoique élevé en dignité, il n'était pas méprisant. Il portait un bonnet $(\underline{169})$ jaune et un vêtement d'une seule couleur. Son char était rouge ; il montait sur un cheval blanc.]

$\bullet_{43}\left[\left(\frac{170}{)}\right)\right.$ Il savait mettre en lumière et favoriser les talents $(\underline{171})$.

Par l'amour qu'il eut pour ses parents a ux neuf degrés (172),

Les neuf degrés de parenté furent en harmonie ;

Il distingua $(\underline{173})$ et dirigea les cent fonctionnaires $(\underline{174})$,

Et les cent fonctionnaires furent éclairés et intelligents $(\underline{175})$.

Il maintint la concorde entre les dix mille tribus.

- Puis il ordonna à $H i$ et à $H o\left(\frac{176}{)}\right)$ d'observer avec $\bullet_{44}$ attention le ciel majestueux et d'appliquer les méthodes du calcul au soleil, à la lune, aux constellations et aux syzygies de conjonction, puis dindiquer avec soin au peuple les saisons.

Il ordonna spécialement au cadet des $H i$ de demeurer chez les $Y u$ - $i\left(\frac{177}{)}\right)$, dans le lieu appelé Vallée du Soleil levant, pour y suivre avec attention le lever du soleil et déterminer et promulguer partout ce qu'il faut faire au printemps $(\underline{178})$. Le jour moyen $(\underline{179})$ et les constellations Niao $(\underline{180}) \bullet_{45}$ servent à fixer le milieu du printemps. Le peuple alors se disperse $(\underline{181})$; les oiseaux et les bêtes nourrissent ou sont petits $(\underline{182})$.

Il ordonna en outre au plus jeune des $\mathrm{Hi}$ de demeurer à Nan-kiao $(\underline{183})$ pour déterminer et promulguer les $\bullet_{46}$ occupations de l'été $(\underline{184})$ et avec soin les faire parvenir à leur but $(\underline{185})$. Le jour le plus long $(\underline{186})$ et les constellations Ho servent à fixer le milieu de l'été. La population alors $(\underline{187}) \bullet_{47}$ continue (à se disperser) ; (les plumes et les poils) des oiseaux et des bêtes deviennent rares et changent $(\underline{188})$.

Il ordonna en outre au cadet des Ho de demeurer dans le territoire de l'ouest, au lieu appelé Vallée de l'Obscurité, pour suivre avec attention le coucher du soleil et déterminer et promulguer ce qui s'achève en automne. La nuit moyenne $\left(\frac{189}{)}\right)$ et la constellation Hiu $(\underline{190})$ servent à fixer le milieu de l'automne. La population a une vie calme et paisible. Les oiseaux et les bêtes se couvrent de plumes et de poils renouvelés $(\underline{191})$.

Il ordonna en outre au plus jeune des $H o$ de demeurer dans la région du nord, au lieu appelé la Résidence $\bullet_{48}$ sombre, pour déterminer et surveiller le moment où les êtres se cachent $(\underline{192})$. Le jour le plus court et la constellation Mao $\left(\frac{193}{)}\right)$, servent à fixer le milieu de l'hiver. La popu lation se tient alors au chaud $(\underline{194})$; les plumes et les poils des oiseaux et des bêtes s'épaississent. 
- 49 - L'année a trois cent soixante-six jours; par le moyen du mois intercalaire $(\underline{195})$ on détermine $(\underline{196})$ les quatre saisons. En conformité avec cela on ordonne les cent fonctions et tous les travaux sont florissants $(\underline{197})$.

Yao dit :

— Qui est capable de continuer ces choses ?

Fang-ts'i dit : intelligent.

Yao dit : lui.

- Hélas, il est méchant et querelleur; on ne peut se servir de

Yao dit encore :

- Qui en est capable?

Hoan-teou dit :

- Kong-kong $(\underline{198})$ a multiplié et répandu $\bullet_{50}$ ses actions méritoires en tous lieux; on peut se servir de lui.

Yao dit :

- Kong-kong est un beau parleur; mais quand on le met à l'œuvre il est mauvais ; il a l'air d'être respectueux, mais il méprise le ciel. C'est impos sible.

Yao dit encore :

— Oh ! (chefs des) quatre montagnes $(\underline{199}), \bullet_{51}$ la vaste étendue des eaux débordées s'élève jusqu'au ciel ; l’immense nappe entoure les montagnes et submerge les collines. A cause de cela le peuple de la plaine est dans l'affliction. Y a-t-il quelqu'un que je puisse charger d'y mettre bon ordre ?

Tous dirent :

- Koen $(\underline{200})$ est capable.

Yao dit :

- Koen enfreint mes ordres et il est funeste à ses collègues. C'est impossi ble.

Les (chefs des quatre) montagnes dirent :

- Il n'y en a plus d'autres (201). Essayez-le et si vous ne pouvez pas vous servir de lui, vous le renverrez.

Alors Yao écouta l'avis des (chefs des quatre) montagnes et se servit de Koen. Pendant neuf ans $(\underline{202})$ celui-ci travailla à son service, mais sans succès. 
Yao dit :

- Oh! (chefs des) quatre montagnes, j'ai été au pouvoir soixante-dix années. Vous êtes capables d'observer le décret céleste $(\underline{203})$; succédez-moi dans ma $\bullet_{52}$ dignité.

Les (chefs des quatre) montagnes répondirent : impériale.

Yao dit :

- Cherchez partout quelqu'un à me proposer, peu importe qu'il soit élevé en dignité et qu'il soit mon parent ou qu'il vive à l'écart, caché et méconnu.

L'assemblée tout entière dit alors à Yao :

- Il y a un homme non marié (204) qui est au nombre des gens du peuple $(\underline{205})$; il s'appelle Yu Choen $(\underline{206})$.

${ }_{53}$ Yao dit : est-il ?

— C'est bien ! j'ai entendu parler de lui. Quelle sorte d'homme

Les (chefs des quatre) montagnes dirent :

- C'est le fils d'un aveugle $(\underline{207})$. Son père était pervers; sa mère était trompeuse ; son frère cadet était insolent. Il a su les faire rentrer dans l'ordre par sa piété filiale ; il les a graduellement amenés à bien agir et à ne pas se porter vers les choses mauvaises.

Yao dit :

— Je le mettrai à l'essai.

Alors Yao lui donna en mariage ses deux filles $(\underline{208})$, pour observer quelle était sa vertu dans la manière dont il se comporterait envers ses deux filles. Choen, dans les lieux qu'arrosent les rivières Koei et Joei $\left(\frac{209}{}\right)$, dirigea et rendit ${ }_{54}$ humbles ces deux femmes $(\underline{210})$, en sorte qu'elles observèrent les rites des épouses (211).]

Yao trouva cela fort bien; il chargea donc ensuite $\bullet_{55}$ Choen [ $(\underline{212})$ de mettre avec soin l'ordre dans les cinq règles et les cinq règles $(\underline{213})$ purent être observées. Puis il (Choen) fut investi de toutes les cent fonctions (14 $)$ et les cent fonctions eurent leur rang en leur temps. - \# Il reçut les hôtes aux quatre portes ; ceux qui venaient aux quatre portes $(\underline{215})$ étaient pénétrés de respect.] Les seigneurs et les étrangers qui arrivaient de loin pour être reçus étaient attentifs à leurs devoirs.

Yao envoya Choen [ (1ㅡ) dans la forêt de la montagne] $(\underline{217}), \bullet_{56}$ parmi les cours d'eau et les marais ; [il y eut un vent violent, du tonnerre et de la pluie,] mais Choen poursuivit sa route [sans se laisser troubler (218).] 
Yao estima cette conduite sage ; il manda Choen et lui dit :

- Les entreprises que vous avez projetées ont abouti; vos paroles ont pu produire des œuvres méritoires ; voici la troisième année $(\underline{219})$. Montez à la dignité d'empereur.

Choen s'excusa en alléguant son peu de mérite et ne se réjouit pas $(\underline{220})$.

Le premier jour du premier mois, Choen reçut l'abdi cation (de Yao) dans le (temple de) Wen-tsou.] Wen-tsou était l'aïeul à la cinquième génération de Yao $(\underline{221})$.

- ${ }_{58}$ Alors l'empereur Yao étant vieux chargea Choen de le suppléer dans l'exercice du gouvernement qui appartient au Fils du ciel, afin de voir quel était le décret du ciel (222).

$[(\underline{223}) \bullet$ Choen observa donc le mécanisme de l'évol ution et la balance de jade pour vérifier l'accord entre les sept gouvernements $(\underline{224})$. Aussitôt après il fit le sacrifice lei à $\bullet{ }_{59}$ l'Empereur d'en haut $(\underline{225})$, le sacrifice in aux six $\bullet_{61}$ Vénérables $(\underline{226})$, le sacrifice wang $(\underline{227})$ aux montagnes et aux cours d'eau et rendit hommage à tous les dieux $(\underline{228})$. — - Il recueillit les cinq insignes $\left(\frac{229}{)}\right.$; il choisit un mois et un jour $\bullet_{62}$ fastes pour donner audience aux (chefs des) quatre montagnes et aux pasteurs (des peuples) $(\underline{230})$, et leur distribua les insignes.

- Le deuxième mois de l'année, il parcourut les fiefs $(\underline{231})$ dans l'est ; arrivé au Tai-tsong, il alluma un bûcher; il fit le sacrifice wang aux montagnes et aux cours d'eau suivant l'ordre fixé $(\underline{232})$. Puis il donna audience aux chefs de la contrée orientale. Il mit l'accord dans les saisons ${ }_{63}$ et dans les mois et rectifia les jours; il rendit uniformes les tubes musicaux $(\underline{233})$ et les mesures de longueur, de capacité et de poids; il restaura les cinq rites $(\underline{234})$; les cinq (insignes de) jade $(\underline{235})$, les trois pièces de soie $(\underline{236})$, les deux animaux vivants et l'animal mort $(\underline{237})$ lui furent apportés $\bullet_{64}$ en offrande; quant aux cinq instruments $(\underline{238})$, lorsque tout fut fini il les rendit.

Le cinquième mois $(\underline{239})$, il parcourut les fiefs dans le sud. Le huitième mois, il parcourut les fiefs dans l'ouest. Le onzième mois, il parcourut les fiefs dans le nord. Toutes (ces inspections) furent comme la première. A son retour, il se rendit aux temples de son grand-père et de son père défunt $(\underline{240})$, et fit le sacrifice rituel d'un taureau.

- ${ }_{65}$ En cinq ans il y avait une inspection des fiefs et quatre réceptions des chefs à la cour $(\underline{241})$. Ils faisaient des rapports complets par leurs paroles ; ils étaient clairement contrôlés par leurs œuvres; ils recevaient des chars et des vêtements pour leurs mérites.

Il institua douze provinces $(\underline{242})$. Il rectifia les cours d'eau.

Il fit des images $(\underline{243})$ pour les châtiments légaux. « On ${ }_{66}$ bannit $(\underline{244})$ ceux qui sont dignes d'une mitigation de peine $(\underline{245})$; il y a les cinq châtiments ; le fouet constitue le châtiment des magistrats ; la verge constitue le châtiment 
des instructeurs $\left(\frac{246}{2}\right)$; l'amende constitue le châtiment des fautes rachetables $(\underline{247})$. Ceux qui pèchent par inadvertance, on leur pardonne ; ceux qui sont endurcis et persistants dans le crime, on leur inflige les châtiments. Soyez sur vos gardes ! soyez sur vos gardes ! c'est par les châti ments qu'on établit le calme. »]

• ${ }_{67}$ Hoan-teou $(\underline{248})$ recommanda Kong-kong. Yao dit :

- C'est impossible, car je l'ai mis à l'essai comme intendant des travaux ; Kong-kong s'est montré mau vais et pervers.

\# Les (chefs des) quatre montagnes proposèrent Koen pour refréner les eaux débordées ; Yao considérait que c'était impossible ; sur l'instante prière des (chefs des quatre) montagnes, il le mit à l'essai ; or il n'eut aucun succès et c'est pourquoi les cent familles ne furent pas à leur aise. San-miao $(\underline{249})$ suscita souvent des troubles dans la province de King, entre le Kiang et le Hoai. Alors Choen revint et parla à l'empereur ; il demanda qu'on [ $(\underline{250})$ exilât Kong-kong sur la colline Yeou $(\underline{251}) \bullet{ }_{68}$ pour réformer $(\underline{252})$ les $\mathrm{Ti}$ du nord, qu'on bannît Hoan-teou sur la montagne Tch'ong ( $\left.{ }^{253}\right)$ pour réformer les Man du sud, qu'on transférât San-miao à San-wei ${ }^{254}$ ) pour réformer les Jong de l'ouest, qu'on laissât périr Koen sur la montagne $Y u(\underline{255})$ pour réformer les $I$ de l'est. Après ces quatre condamnations $(\underline{256})$, il y eut une soumission générale dans l'empire.]

- ${ }_{69}$ Yao était au pouvoir depuis soixante-dix ans quand il trouva Choen; au bout de vingt ans ; étant vieux, il ordonna à Choen d'exercer à sa place le gouvernement du Fils du ciel ; il le présenta au Ciel. [ (257)Yao mourut vingthuit ans en tout $(\underline{258})$ après avoir renoncé au pouvoir. Les cent familles s'affligèrent comme si elles avaient été en deuil d'un père ou d'une mère ; pendant trois ans on ne fit aucune musique en aucun lieu,] car on pensait à Yao.

Yao savait que son fils Tan-tchou $(\underline{259})$ était dégénéré et n'était pas digne qu'on lui remît l'empire ; c'est pourquoi donc, tenant compte des circonstances $(\underline{260})$, il le donna à Choen. En le donnant à Choen, l'empire y trouvait son avantage et c'était un mal pour Tan-tchou; en le donnant à Tan-tchou c'était un mal pour l'empire et Tan-tchou y trouvait son avantage ; Yao dit :

- Je ne me déciderai pas à favoriser un seul homme au détriment de tout l'empire.

Ainsi en définitive il donna l'empire à Choen.

[ ( $\underline{261})$ Après la mort de Yao, quand le deuil de trois ans fut $\bullet_{70}$ terminé, Choen quitta le pouvoir et le céda à Tan-tchou au sud du Nan-ho $(\underline{262})$. Les seigneurs qui venaient rendre hommage n'allèrent pas auprès de Tan-tchou mais allèrent auprès de Choen; ceux qui étaient condamnés à la prison ou avaient des procès n'allèrent pas auprès de Tan-tchou mais allèrent auprès de 
Choen; ceux qui récitaient et chantaient ne célébrèrent pas Tan-tchou mais célébrèrent Choen. Choen dit :

- C'est le Ciel !

Alors il revint à la capitale $(\underline{263})$ et prit la dignité de Fils du ciel.] Ce fut l'empereur Choen.

Yu Choen avait pour nom personnel Tch'ong-hoa $(\underline{264})$. Le ${ }_{71}$ père de Tch'ong-hoa s'appelait Kou-seou; le père de Kou-seou s'appelait Kiao-nieou $(\underline{265})$; le père de Kiao-nieou s'appelait Keou-wang; le père de Keou-wang s'appelait King-k'ang ; le père de King-k'ang s'appelait K'iongchan; le père de K'iong-chan s'appelait l'empereur Tchoan-hiu; le père de Tchoan-hiu s'appelait Tch'ang-i; jusqu'à Choen il y eut sept générations ( $(266)$. A partir de K'iong-chan jusqu'à l'empereur Choen, tous furent sans importance et furent des hommes du commun peuple.

Le père de Choen, Kou-seou, était aveugle; la mère de Choen étant morte (267), il prit une autre femme qui enfanta Siang. Siang était arrogant. Kou-seou aimait le fils de sa seconde femme et cherchait sans cesse à faire périr Choen; Choen lui échappa, mais lorsqu'il commettait quelque faute légère il se soumettait au châtiment. Il servait scrupuleusement son père et sa marâtre ainsi que son frère cadet ; chaque jour il se montrait sincère et attentif et jamais il ne se relâchait.

Choen était un homme de la province de $K i(\underline{268})$.

- ${ }_{72}$ Choen laboura sur la montagne $L i(\underline{269})$; il pêcha dans l'étang de Lei; il façonna des vases d'argile au bord du Fleuve ; il fabriqua diverses sortes d'ustensiles à Cheou-k'ieou $(\underline{270})$; il profita du moment favorable pour aller à Fou-hia (271).

- ${ }_{73}$ Le père de Choen, Kou-seou, était pervers ; sa mère était trompeuse ; son frère cadet, Siang, était insolent, Tous désiraient tuer Choen; Choen était docile, et il ne lui arriva jamais de manquer à la conduite que doit avoir un fils, ni à l'amour fraternel. Quoiqu'ils voulussent le tuer, ils ne purent y arriver ; quand ils cherchaient à l'essayer, ils (frappaient) à côté.

Quand Choen eut vingt ans, il fut renommé pour sa piété filiale ; quand il eut trente ans, l'empereur Yao demanda qui il pourrait employer et les (chefs des) quatre montagnes lui proposèrent tous Yu Choen; alors Yao donna ses deux filles en mariage à Choen pour voir quelle était sa conduite à l'intérieur ; il envoya ses neuf fils demeurer avec lui pour voir quelle était sa conduite à l'extérieur. Choen s'établit dans les lieux qu'ar rosent les rivières Koei et Toei; dans sa conduite privée il agit en tout avec attention; les deux filles de Yao n'osèrent pas se targuer de leur noblesse pour être insolentes $(272)$; elles servirent les parents de Choen et observèrent strictement les devoirs des épouses ; les neuf fils de Yao redoublèrent tous de vertu.

Choen laboura sur la montagne $L i\left(\frac{273}{)}\right.$ : les gens de la montagne $L i$ se firent tous des concessions sur les limites de leurs champs; il pêcha dans 
l'étang de Lei : les gens $\bullet_{74}$ qui étaient sur les rives de l'étang de Lei se firent tous des concessions sur les places de leurs habitations ; il façonna des vases d'argile au bord du Fleuve : les ustensiles fabriqués au bord du Fleuve furent tous sans défauts. Au bout d'un an, dans l'endroit où il habitait, il se formait un village ; au bout de deux ans, il se formait un bourg ; au bout de trois ans, il se formait une ville $(\underline{274})$.

Yao alors gratifia Choen d'un vêtement de toile fine et d'un luth ; il lui fit construire un magasin et un grenier; il lui donna des bœufs et des moutons $(\underline{275})$.

Cependant Kou-seou voulut encore le tuer; il fit monter Choen sur le grenier pour le crépir; d'en bas, Kou-seou mit le feu au grenier pour l'incendier ; Choen alors se servit de deux grands chapeaux de jonc pour protéger sa descente $(276)$; il s'échappa et put ne pas périr. Ensuite Kou-seou envoya derechef Choen creuser un puits; Choen, en creusant le puits, ménagea un orifice secret qui était une issue latérale. Quand Choen fut entré au fond, Kou-seou et Siang jetèrent ensemble de la terre et remplirent le puits ; Choen sortit par l'orifice secret et $\bullet_{75}$ s'échappa. Kou-seou et Siang se réjouirent, pensant que Choen était mort. Siang dit :

- C'est moi qui ai eu l'idée de ce stratagème.

Siang fit un partage avec son père et sa mère et dit alors :

- Les femmes de Choen, filles de Yao, ainsi que son luth, c'est moi, Siang, qui les prendrai. Les boufs, les moutons, le magasin et le grenier je les donne à mon père et à ma mère.

Siang alors s'ét ablit dans la demeure de Choen et joua de son luth. Choen vint le voir. Siang déconcerté et mécontent lui dit :

— Je pensais à Choen et je me trouve plein de joie $(\underline{277})$.

Choen $\bullet{ }_{76}$ répliqua :

— Bien. Ce sont là, j'espère, vos sentiments $(\underline{278})$.

Choen recommença à servir Kou-seou et à aimer son frère cadet et fut sans cesse plein d'égards pour eux.

Alors Yao mit Choen à l'essai dans les cinq règles et les cent fonctions $(\underline{279})$; tout cela fut bien dirigé.

[ $(\underline{280})$ Autrefois Kao-yang $(\underline{281})$ eut huit fils capables; les $\bullet_{77}$ hommes jouirent de leurs bienfaits et les appelèrent les huit Satisfaisants. Kao-sin (ㄹ2) eut huit fils capables : les hommes les appelèrent les huit Excellents. Ces seize familles de génération en génération perfectionnèrent leurs qualités et ne laissèrent pas tomber leur réputation. Lorsque arriva le temps de Yao, Yao ne put point encore les mettre en charge. Choen mit en charge les huit Satisfaisants et les fit présider à la terre souveraine $(\underline{283})$, afin de déterminer les cent occupations ; il n'y eut rien qui n'eût son temps et son rang. Il mit en charge les huit Excellents et leur fit répandre les cinq enseignements $(\underline{284})$ dans les 
quatre directions : les pères furent justes ; les mères furent aimantes ; les frères aînés furent bienveillants ; les frères cadets furent respectueux; les fils furent pieux ; à l'intérieur, ce fut le calme ; à l'extérieur, la perfection.

- Autrefois l'empereur Hong $(\underline{285})$ eut un fils incapable; il faisait disparaître la justice ; il était dissimulé et scélérat ; il se plaisait à se livrer aux pires vices ; le monde l'appe lait Chaos $(\underline{286})$. Chao-hao eut un fils incapable ; il détruisait ${ }_{78}$ la bonne foi et haïssait la sincérité ; il appréciait les discours artificieux et méchants; le monde l'appelait Vau rien-trompeur $(\underline{287})$. Tchoan-hiu eut un fils incapable; il ne pouvait rien apprendre et ne comprenait pas ce qu'on lui disait ; le monde l'appelait Soliveau ( $(288)$. De génération en génération on souffrait de ces trois familles; lorsque arriva le temps de Yao, Yao ne put encore s'en débar rasser. Tsin-yun $(\underline{289})$ eut un fils incapable ; il avait la passion de la boisson et de la bonne chère ; il était avide de richesse ; le monde l'appelait Glouton ; le monde l'avait en horreur et le mettait sur le même pied que les trois criminels $(\underline{290})$. - Choen, allant recevoir les hôtes aux quatre ${ }_{79}$ portes, exila les quatre familles criminelles et les bannit aux quatre frontières, afin de soumettre à la règle les démons (291).] Alors les quatre portes furent ouvertes et on annonça qu'il n'y avait plus de criminels.

Choen (292) entra dans une grande forêt sur la montagne ; il y eut un vent violent, du tonnerre, et de la pluie ; il n'en fut pas troublé. Yao reconnut alors que Choen était digne qu'il lui donnât l'empire. \# Yao étant vieux chargea Choen d'exercer à sa place le gouvernement qui appartient au Fils du ciel et de parcourir les fiefs. Vingt ans après que Choen eut été mis en charge et eut administré les affaires, Yao le chargea de gouverner à sa place. Il gouverna à sa place pendant huit ans et c'est alors que Yao mourut. Lorsque le deuil de trois ans fut terminé, il céda le pouvoir à Tan-tchou. Le monde se réfugia au-

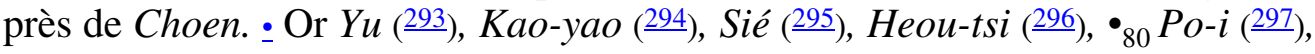
K'oei, Long, Choei $(\underline{298})$, I $(\underline{299})$, P'ong-tsou avaient tous été, dès le temps de Yao, promus à des emplois, mais on n'avait pas encore distingué les attributions des fonctions. Alors [ $(\underline{300})$ Choen se rendit au (temple de) Wen-tsou ( ${ }^{301}$ ). Il tint conseil avec les (chefs des) quatre montagnes pour ouvrir les quatre portes $(\underline{302})$ et percevoir par les oreilles et par $\bullet_{81}$ les yeux tout ce qui se passait dans les quatre directions. Il ordonna aux douze pasteurs $\left.\left(\frac{303}{)}\right)\right]$ de prendre pour règle la vertu de l'empereur $\left(\frac{304}{}\right)$, de pratiquer [la vertu réelle, d'éloigner les hommes artificieux. Alors les bar bares Man et I se soumirent à l'envi.

Choen parla en ces termes aux (chefs des) quatre montagnes :

- Y a-t-il quelqu'un qui puisse me servir avec zèle et illustrer les entreprises de Yao ? Je lui donnerai l'autorité pour qu'il m'aide dans les affaires.

Tous dirent : 
- Le comte $Y u$ est intendant des travaux publics $(\underline{305})$;] il est capable d'illustrer les mérites impériaux.

[Choen dit :

- Ah ! c'est bien. $Y u$, vous réglerez les eaux et les $\bullet_{82}$ terres $\left(\frac{306}{)}\right)$. Ne songez qu'à faire tous vos efforts !

$Y u$ salua et se prosterna et voulut céder la place à $T s i\left(\frac{307}{)}\right)$ à Sié et à $K a O$ yao. Choen dit :

- C'est bien. Allez.

- Choen dit :

- $K^{\prime} i\left(\frac{308}{}\right)$, lorsque au commencement $(\underline{309})$ le peuple aux cheveux noirs était affamé, vous, prince Millet, vous avez semé et transplanté $(\underline{310})$ les cent céréales.

$\cdot{ }_{83}$ Choen dit :

- Les cent familles ne sont pas en bonne harmonie ; les cinq ordres $(\underline{311})$ (de devoirs) ne sont pas observés. Soyez directeur des multitudes $(\underline{312})$ et répandez les cinq enseignements. Ayez soin d'agir avec douceur.

Choen dit :

- Kao-yao, les (barbares) Man et I troublent notre beau pays $(\underline{313})$. Ce sont des voleurs, des assassins, des ennemis et des rebelles $\left(\frac{314}{)}\right.$ ). Soyez chef (de la justice). Pour les cinq châtiments, il $\mathrm{y}$ a ceux qui les subissent et pour les subir, il y a trois lieux déterminés $(\underline{315})$; pour les ${ }_{84}$ cinq bannissements il y a des limites et pour les cinq limites il y a trois emplacements $\left(\frac{316}{16}\right)$. Ce n'est que par le discernement $(\underline{317})$ que vous pourrez mériter la confiance.

Choen dit :

— Qui peut surveiller mes travailleurs?

Tous dirent :

- Choei ( $(\underline{18})$ en est capable.

Alors il nomma Choei intendant des travaux publics $(\underline{319})$.

Choen dit :

- Qui peut surveiller pour moi les lieux hauts et les lieux bas, les herbes et les arbres, les oiseaux $\bullet_{85}$ et les quadrupèdes ?

Tous dirent :

- $I$ en est capable. 
Alors il nomma $I$ intendant des eaux et forêts $(\underline{320})$. $I$ salua et se prosterna et voulut céder la place aux autres ministres ; Tchou, Hou, Hiong et P'i. Choen dit :

— Allez. Faites régner l'harmonie.]

Alors (I) prit pour assistants Tchou, Hou, Hiong et $P ’ i\left(\frac{321}{)}\right)$.

[Choen dit :

- Ah! (chefs des) quatre montagnes ! Y a-t-il quelqu'un qui soit capable de présider à mes trois cérémonies rituelles $(\underline{322})$ ?

Tous dirent :

- Po-i en est capable.

Choen dit :

- Ah! Po-i (23), je vous nomme directeur du temple ancestral $\left(\frac{324}{)}\right)$. Du matin jusqu'au soir $\bullet_{86}$ appliquez-vous à la vigilance. Soyez droit ! appliquez-vous à être pur.

Po-i voulut céder la place à K'oei et à Long. Choen dit :

- C'est bien.

Il nomma K'oei intendant de la musique pour qu'il enseignât aux enfant s des princes $(\underline{325})$ à être inflexibles mais avec douceur, indulgents mais avec énergie, fermes mais sans rigueur, indifférents aux détails mais sans arrogance. La poésie fut l'expression de la pensée ; le chant prolongea cette expression; les notes résultèrent de ces modulations ; les tubes sonores furent d'accord avec les notes; les huit instruments de musique purent être en harmonie et n'empiétèrent pas sur les domaines les uns des autres. L'accord fut établi par là entre les dieux et les hommes $(\underline{326})$. K'oei dit :

- Hé ! je frappe la pierre, je ${ }_{87}$ touche la pierre et les cent animaux dansent tous à l'envi $(\underline{327})$.

Choen dit :

- Long, je redoute fort les paroles calomnieuses et les tromperies corruptrices; elles troublent et effraient mon peuple. Je vous nomme à la charge d'auditeur des paroles ; matin et soir, vous répandrez mes ordres et vous m’en référerez ; veillez à la bonne foi $\left(\frac{328}{2}\right)$.

Choen dit :

- Vous, ces vingt-deux hommes $(\underline{329})$, soyez $\bullet_{88}$ attentifs ; conformez-vous aux temps; observez quels devoirs prescrit le ciel $(\underline{330})$. 
Tous les trois ans il y avait un examen des mérites $(\underline{331})$; au bout de trois examens, on faisait des dégradations et des promotions, des renvois et des nominations. Toutes les tâches furent bien exécutées.

On divisa et on repoussa les San-miao ( $\left(\frac{332}{2}\right)$.]

- Ces vingt-deux hommes accomplirent tous leur tâche. Kao-yao étant chef de la justice, on eut la paix ; dans le peuple, chacun fut soumis et obtint ce qu'il méritait. Po-i présidant aux rites, tous les hommes, du haut en bas (de l'échelle sociale), se firent des concessions. Choei étant directeur des travaux, les cent travailleurs firent tous leurs efforts. I étant intendant des eaux et forêts, les montagnes et les marais furent ouverts (à la culture). ${ }_{89} K^{\prime} i$ étant préposé aux grains, les cent céréales furent abondantes en la saison voulue. Sié étant directeur des multitudes, les cent familles vécurent dans l'amitié et dans l'harmonie. Long étant préposé aux hôtes, les hommes des pays lointains arrivèrent. Les douze pasteurs étant chargés de l'administration, personne dans les neuf provinces n'osa leur désobéir $(\underline{333})$. Mais, c'est $Y u$ dont le mérite fut le plus grand $(\underline{34})$; il ouvrit les neuf montagnes ; il constitua les neuf lacs ; il dirigea le cours des neuf fleuves; il détermina les neuf provinces ; chacune d'elles vint apporter un tribut suivant ce qu'elle devait et n'y trouva aucun désavantage.

Sur un espace de cinq mille $l i$ carrés, (Choen) parvint jusqu'au domaine des terres incultes $(\underline{335})$; au sud, il soumit Kiao-tche et Pei-fa; à l'ouest, les Jong, Si-tche, K'iu-seou, les Ti-k’iang ; au nord les Jong des montagnes, $F a$ et $\mathrm{Si}$-tchen; à l'est, les barbares Tch'ang et Niao $\left(\frac{336}{}\right)$. A $\bullet{ }_{90}$ l'intérieur des quatre mers, tout le monde fut reconnaissant à l'empereur Choen de ses actions méritoires.

Alors $Y u$ mit en honneur la musique des neuf reprises $\left(\frac{337}{)}\right)$; il fit accourir les êtres étranges $\left(\frac{338}{)}\right)$; le phénix mâle et le phénix femelle vinrent en volant $(\underline{339})$.

Les vertus éclatantes dans l'empire commencèrent toutes au temps de l'empereur Choen $(\underline{340})$.

- ${ }_{91}$ A l'âge de vingt ans, Choen fut renommé pour sa piété filiale ; quand il eut trente ans, Yao le mit en charge ; quand il eut cinquante ans, il exerça par procuration le gouvernement qui appartient au Fils du ciel; quand il eut cinquante-huit ans, Yao mourut ; quand il eut soixante-un ans $(\underline{341})$, il remplaça Yao et prit la dignité impériale. Trente-neuf ans $(\underline{342})$ après avoir pris la dignité impériale, il alla dans le sud inspecter les fiefs ; il mourut dans la campagne de Ts'ang-ou et fut enterré sur (la montagne) Kieou-i $(\underline{343})$, au sud du Kiang ; c'est le lieu appelé la sépulture Ling ( $(\underline{344})$.

Quand Choen eut assumé la dignité impériale, il prit avec lui l'étendard de Fils du ciel et alla rendre hommage à son père Kou-seou; il fut plein de déférence et se montra très respectueux, observant la conduite qui convient à un fils. Il donna un fief à son frère cadet, Siang, et le nomma seigneur $(\underline{345})$. 
- ${ }_{92}$ Le fils de Choen, Chang-kiun, lui aussi (346), était indigne ; c'est pourquoi (Choen) présenta d'avance $Y u$ au Ciel $(\underline{347})$; dix-sept ans après, il mourut. Quand le deuil de trois ans fut terminé, $Y u$, lui aussi, se retira devant le fils de Choen, comme Choen s'était retiré devant le fils de Yao; les seigneurs se réunirent autour de lui et c'est après cela que $Y u$ prit la dignité impériale. Le fils de Yao, Tan-tchou, et le fils de Choen, Chang-kiun, eurent tous deux un domaine déterminé pour y accomplir les sacrifices à leurs ancêtres $(\underline{348})$; ils portaient leurs vêtements ; leurs rites et leur musique étaient conservés dans leur intégrité ; lorsqu'ils rendaient visite au Fils du ciel, c'était en qualité d'hôtes $(\underline{349})$; le Fils du ciel ne les traitait pas en $\bullet_{93}$ sujets, montrant ainsi qu'il ne se permettait pas d'agir de sa propre autorité $\left(\frac{350}{)}\right)$.

Depuis Hoang-ti jusqu'à Choen et $Y u$, tous (les empereurs) eurent le même nom de famille; mais ils se distinguèrent par les noms de leurs principautés, afin de mettre en lumière leur illustre vertu ( $\left.\frac{351}{}\right)$. Ainsi, Hoang-ti fut Yeou-hiong $\left(\frac{352}{2}\right)$; l'empereur Tchoan-hiu fut Kao-yang; l'empereur K'ou fut Kao-sin; l'empereur Yao fut T'ao-t'ang; l'empereur Choen fut Yеои-уи $(\underline{353})$; l'empereur $\mathrm{Yu}$ fut Hia-heou $(\underline{354}), \bullet_{94}$ mais il eut un autre nom de famille qui fut $\mathrm{Se}$; Sié fut Chang et eut pour nom de famille Tse; K'i fut Tcheou et eut pour nom de famille $K i\left(\frac{355}{3}\right)$.

- Le duc grand astrologue dit : Ceux qui ont étudié disent pour la plupart que les cinq empereurs sont la haute antiquité $\left(\frac{356}{3}\right)$. Or le Chang chou ne traite que de $Y a o$ et de ceux qui vinrent après lui ; d'autre part, les écrivains divers $(\underline{357})$ qui ont parlé de Hoang-ti font des récits qui ne sont pas exacts ; les maitres officiels $\left(\frac{358}{)}\right)$ répugnent à en parler. Ce qui nous vient de $K$ 'ong-tse, à savoir les «Questions de Tsai $Y u$ sur les vertus des cinq empereurs » et $\bullet_{95}$ la «Suite des familles des empereurs » $(\underline{359})$, certains lettrés ne l'enseignent point. - Pour moi, j’ai été à l'ouest jusqu'au Kong-t'ong $(\underline{360})$; au nord, j’ai passé le Tchouo-Lou; à l'est, je me suis avancé jusqu'à la mer ; au sud, j’ai navigué sur le Kiang et sur le Hoai $\left(\frac{361}{2}\right)$; lorsque je m'adressais aux no tables et aux vieillards, tous, pris chacun à part, me parlaient communément des localités où se trouvèrent Hoang-ti, Yao et Choen; leurs traditions et leurs notions étaient certes fort diverses; d'une manière générale celles qui ne s'écartent pas des anciens textes sont les plus proches de la vérité. J'ai examiné le Tch'oen ts'ieou et le Коио уи $(\underline{362})$; ils font voir clairement que « les Vertus des cinq empereurs » et la «Suite des familles des empereurs» sont (des textes) canoniques. En réfléchissant, à moins que l'examen auquel on se livre ne soit pas approfondi, on reconnaîtra que tout ce quils exposent n'est point vide de sens. Le Chou (king) est incomplet et a des lacunes ; mais ce qu'il omet peut se trouver parfois dans d'autres récits. Si un homme de forte instruction n'y pense pas profondément et si son intelligence ne comprend pas leurs idées $(\underline{363})$, il sera certes difficile que $\bullet_{96}$ ce soit raconté par des gens aux vues superficielles et aux connaissances bornées. J'ai mis l'ordre dans tout cela ; j'ai choisi ce qu'il y avait de plus exact dans ces dires et c'est ainsi que j'ai composé les Annales fonda mentales qui ouvrent mon livre. 


\section{CHAPITRE II}

\section{DEUXIÈMES ANNALES PRINCIPALES LES HIA}

- 97 , (comte de) Hia $\left(\frac{101}{)}\right.$, avait pour nom personnel Wen-ming $\left(\frac{102}{)}\right)$. Le père de $Y u$ s'appelait Koen $(\underline{103})$; le père de Koen $\bullet_{98}$ s'appelait l'empereur Tchoan-hiu $(\underline{104})$; le père de Tchoan-hiu s'appelait Tch'ang-i; le père de Tch'ang-i s'appelait Hoang-ti. $Y u$ était donc l'arrière-arrière-petit-fils de Hoang-ti et le petit-fils de l'empereur Tchoan-hiu. Ni l'arrière-grand-père de $Y u$, Tch'ang- $i$, ni son père, Koen, n'eurent la dignité impériale ; ils furent sujets du souverain.

C'était au temps de l'empereur Yao; [ $(\underline{105})$ les eaux énormes s'élevèrent jusqu'au ciel ; l'immense nappe entoura les montagnes et submergea les collines. A cause de cela, le peuple de la plaine fut dans l'affliction.] Yao demanda quelqu'un qui pût réprimer les eaux. La foule de ses officiers et les (chefs des) quatre montagnes [dirent tous :

- Koen en est capable.

Yao dit :

- Koen est un homme qui rejette mes ordres et il est funeste à ses collègues. C'est impossible.

Les (chefs des) quatre montagnes dirent :

- Parmi les autres, il n'y en a aucun qui soit plus sage que Koen. Nous désirons que l'em pereur le mette à l'essai.

Alors Yao écouta l'avis des (chefs des) quatre montagnes et se servit de Koen pour réprimer les eaux. Au bout de neuf ans les eaux ne s'étaient point arrêtées et les travaux (de Koen) n'eurent aucun succès.]

- 99 Alors l'empereur Yao chercha un autre homme et trouva Choen. Choeit fut élevé aux emplois ; il exerça par procuration le gouvernement de Fils du ciel ; il inspecta les fiefs; sur son passage il reconnut que les travaux que Koen avait faits pour réprimer les eaux n'étaient pas dignes de louange ; c'est pourquoi [ $(\underline{106})$ il exila Koen sur la montagne $\mathrm{Yu}$ ] pour qu’il y mourût. Tout l'empire approuva la condamnation prononcée par Choen. Puis Choen promut $Y u$, fils de Koen, et le chargea de continuer la tâche de Koen.

Yao mourut. L'empereur [ $(\underline{107})$ Choen interrogea les chefs des quatre montagnes, disant :

- Y a-t il quelqu'un qui soit capable de mener à bien et d'illustrer les entreprises de Yao ? je le mettrai en charge. 
Tous dirent :

- Le comte $Y u$ est intendant des travaux publics; il peut mener à bien et illustrer l'œuvre glorieuse de Yao.

Choen dit :

- Ah ! c'est bien.

Il donna donc cet ordre à $Y u$ :

- Vous réglerez les eaux et les terres; ne songez qu'à faire tous vos efforts.

$Y u$ salua et se prosterna, voulant se retirer devant Sié, le prince Tsi ou Kaoyao. Choen lui dit :

— Allez veiller à vos occupations.]

- $Y u$ était un homme [ $\left({ }^{108}\right)$ actif, serviable, capable et diligent; sa vertu n'évitait pas la peine ; sa bonté le rendait digne d'affection ; sa parole était digne de foi. Sa voix était l'étalon des sons ; son corps était l'étalon des me sures de longueur $(\underline{109})$; les mesures de poids dérivaient de lui. Très infatigable et très majestueux, il s'occupait de l'ensemble et des détails.]

- ${ }_{100}$ Alors $Y u$, avec $I(\underline{110})$ et le prince $T s i(111)$, s'acquitta du mandat de l'empereur ; il donna des ordres aux seigneurs et aux cent familles ; il mit sur pied des multitudes d'hommes à qui [ $(\underline{112})$ il confia $(\underline{113})$ les terres ; il parcourut les montagnes et fit des marques sur les arbres (114). Il détermina les hautes montagnes et les grands fleuves.]

- Yu était affligé de ce que, avant lui, son père Koen, pour n'avoir pas réussi dans sa tâche, avait reçu la mort. Il accabla donc de fatigues son corps ; sa pensée fut dévorée par les soucis. Il resta hors de chez lui treize $\bullet_{101}$ années $\left(\frac{115}{1}\right)$; quand il passait devant la porte de sa demeure il n'osait pas y entrer. Il restreignait ses vêtements et sa nourriture, mais il montrait une extrême piété pour les génies et les dieux; il n'avait qu'une humble demeure, mais il faisait les plus grandes dépenses pour des fossés et des canaux. Pour aller sur la terre ferme, il se servait d'un char ; pour aller sur l'eau, il se servait d'un bateau ; pour aller sur la boue, il se servait d'une sorte de van ; pour aller sur les montagnes, il se servait de crampons $(\underline{116})$. [ $(\underline{117}) \bullet$ A gauche il y avait des limites régulières; à droite $(\underline{118})$ il y avait des règles certaines. Il tint compte des quatre saisons. Pour ouvrir les neuf provinces, il rendit les neuf chemins praticables, il endigua les neuf marais, il nivela les neuf montagnes.] [ ( $\left.{ }^{119}\right)$ Il commanda à $I$ de donner au peuple du riz] pour qu'il pût le planter dans des lieux bas et humides ; [il chargea le prince Tsi de donner au peuple la nourriture qu'il lui était difficile de trouver; ceux qui avaient peu de nourriture rétablirent l'accord en échangeant avec les autres les objets qu'ils avaient $\bullet_{102}$ en trop ;] ainsi l'égalité fut établie parmi les seigneurs.

Alors $Y u$ fit une tournée pour examiner ce qu'il était convenable que la terre produisît, afin d'en déterminer le tribut ; il examina aussi quels étaient 
les avantages qu'offra ient les montagnes et les cours d'eau. La tournée de $Y u$ commença à la province de $K i\left(\frac{120}{)}\right)$.

$\bullet_{103}\left[(\underline{121}) \bullet\right.$ Province de $K i(\underline{122}):$ quand il eut travaillé à (la montagne) $\bullet_{104}$ Hou-k'eou, - il mit l'ordre sur les monts Leang et $K^{\prime} i(\underline{123})$. - Ayant fait des réparations à T'ai-yuen, - il arriva à • ${ }_{105}$ Yo-yang $(\underline{124})$. — A T'an-hoai, il eut le plus grand $\bullet_{106}$ mérite $(\underline{125})$; - il arriva jusqu'aux (rivières) Heng et Tchang $\left(\frac{126}{)}\right)$. - $\bullet_{107}$ La terre y est blanche et friable; les redevances y sont en somme au premier rang $\left(\frac{127}{)}\right)$; les champs y sont au cinquième $\bullet{ }_{108}$ rang. (Les rivières) Tch'ang ( $(28)$ et Wei suivirent un cours régulier; - Ta-lou $\left(\frac{129}{)}\right)$ fut mis en culture. - Les barbares Niao $(\underline{130})$ (apportent) des vêtements de fourrure ; ils longent de près à leur droite le Kié-che et entrent dans la mer.

- ${ }_{109}$ Le Tsi et le Ho délimitent la province de Yen $(\underline{131})$. Les neuf (branches du) Ho prirent un cours régulier $(\underline{132}) ;-\bullet_{110}$ Lei-hia devint un lac $(\underline{133}) ;-$ (les rivières) Yong et $T$ siu s'y réunirent $(\underline{134})$; - la terre propre aux mûriers fut peuplée de vers à soie. - Alors le peuple put descendre des collines pour demeurer dans la plaine $(\underline{135})$. La terre y est noire et forme des mottes; les herbes y sont luxuriantes et les arbres élevés; les champs y sont au sixième rang; les $\bullet{ }_{111}$ redevances furent exactement (au même rang que la province); celle-ci fut mise en culture la treizième année et alors celles-là (furent exigées) comme (pour les autres provinces) $(\underline{136})$. Le tribut (de cette province) consiste en laque et en soie $(\underline{137})$; ses mannes $(\underline{138})$ contiennent des tissus ornés ( $(\underline{139})$. En naviguant sur le $T s i$ et le $T$ ' $a$, on pénètre dans le $H o(\underline{140})$.

- ${ }_{112}$ La mer et (la montagne) Tai $(\underline{141})$ délimitent la province de Ts’ing ( $\underline{142}$ ). (Le territoire de) $Y u-i(\underline{143})$ fut rapidement $\bullet_{113}$ aménagé ; - le Wei et le Tse suivirent leur cours régulier $\left(\frac{144}{}\right)$. - La terre y est blanche et forme des mottes ; le long de la mer il y a de vastes étendues salées ;] les champs y sont couverts de sel $\left(\frac{145}{}\right)$. [Les champs y sont au troisième rang; les redevances $\mathrm{y}$ sont au quatrième rang. Le tribut (de cette province) consiste en sel, en toile fine, en produits de la mer, mais il est variable $(\underline{146})$; les vallées de la montagne Tai fournissent de la soie, du chanvre, du plomb, des pins et des pierres singulières. Les barbares Lai $(\underline{147}) \cdot \bullet_{114}$ sont pasteurs. Les mannes (de cette province) $(\underline{148})$ contiennent la soie (que donnent les vers nourris avec) le mûrier des montagnes $(\underline{149})$. En naviguant sur (la rivière) Wen $(\underline{150})$, on pénètre dans (la rivière) Tsi.

La mer, (la montagne) Tai et (la rivière) Hoai délimitent la province de Siu $(\underline{151})$. (Les rivières) Hoai et $I$ furent $\bullet_{115}$ dirigées $(\underline{152})$ dans leurs lits ; Mong et $Y u$ furent ensemencés $(\underline{153})$; - (le lac) Ta-yé $(\underline{154})$ fut enfermé dans des limites $\bullet_{116}$ fixes ; - Tong-yuen put être une plaine cultivée $(\underline{155})$. - La terre y est rouge, argileuse et forme des mottes; les herbes et les arbres s'y multiplient de plus en plus. Les champs y sont au second rang ; les redevances $\mathrm{y}$ sont au cinquième rang. Le tribut consiste en terres des cinq couleurs $\left(\frac{156}{)}\right)$, en faisans des vallées de la montagne $Y u(\underline{157})$, en $\bullet{ }_{117}$ Paulownias solitaires du sud de la montagne $I(\underline{158})$, en pierres sonores qui se trouvent posées sur les 
bords de la rivière $S e(\underline{159})$. $\bullet 118$ Les barbares du Hoai $(\underline{160})$ (apportent) des perles prises dans les huîtres et des poissons. Les mannes (de cette province) contiennent des soieries foncées, des soieries fines $(\underline{161})$ et des soieries blanches. En naviguant sur (les rivières) Hoai et $S e$, on pénètre dans le Ho $(\underline{162})$.

(La rivière) Hoai et la mer délimitent la province de Yang $(\underline{163})$. - (Le lac) P'ong-li fut enfermé dans des limites $\bullet_{119}$ restreintes $(\underline{164})$; - les oiseaux migrateurs s'y établirent. — Les trois Kiang entrèrent dans la mer $(\underline{165}) ;$ - le lac de Tchen parvint à être calmé $(\underline{166})$. - Les fins bambous se multiplièrent ; les herbes y furent minces et longues; les arbres y furent élevés. Le sol y est épais et boueux. Les champs sont au neuvième rang; les redevances sont au septième rang et parfois au rang supérieur. Le tribut consiste en métaux des trois qualités, en pierres des $\bullet_{120}$ espèces yao et koen, en fins bambous $(\underline{167})$, en dents, en cuir, en plumes et en queues $\left(\frac{168}{)}\right)$. Les barbares des îles $(\underline{169})$ (apportent) des vêtements faits avec des matières végétales. Les mannes (de cette province) sont pleines de tissus fabriqués avec des soies de couleurs variées $(\underline{170})$; ses paquets renferment des mandarines et des pamplemousses, mais c'est un tribut qu'ils n'apportent que quand ils en sont requis $\left(\frac{171}{)}\right)$. En suivant le Kiang et la mer, on arrive dans les rivières Hoai et Se $(\underline{172})$.

- ${ }_{121}$ (La montagne) King et le sud de (la montagne) Heng délimitent la province de King $\left(\frac{173}{)}\right)$. - L Kiang et le Han $\left(\frac{174}{)}\right.$ se rendirent à la mer comme les seigneurs vont aux audiences impériales du printemps et de l'été $(\underline{175})$. - Les neuf Kiang furent exactement ce qu'ils devaient être $\left(\frac{176}{}\right)$. - ${ }_{122}$ Le T'o et le Tch'en eurent un cours régulier $(\underline{177})$. — La terre de Yun-mong fut mise en culture et bien réglée $\left(\frac{178}{}\right)$. — $\bullet{ }_{123}$ Le sol y est épais et boueux. Les champs y sont au huitième rang; les redevances y sont au troisième rang. Le tribut consiste en plumes, en queues, en dents, en cuir, en métaux des trois qualités, en arbres tch'oen, kan, koai et po $\left({ }^{179}\right)$, en pierres meulières grossières et fines, en pierres servant à faire des pointes de flèches et en cinabre. Quant aux bambous des espèces kiun et lou $(\underline{180})$, et à l'arbre hou, les trois royaumes $(\underline{181})$ en envoient les spécimens les plus renommés comme tribut. Ils enveloppent, après les avoir liées en faisceaux, les herbes $\bullet_{124} t$ ' 'ing-mao $\left(\frac{182}{}\right)$. Leurs mannes sont remplies d'étoffes bleu foncé et rouges et de rangées de perles qui ne sont pas rondes. La contrée des neuf Kiang $(\underline{183})$ apporte, en présent extraordinaire, la grande tortue $(\underline{184})$. En naviguant sur le Kiang, le T'o ou le Tch'en, puis sur le Han (185), et en traversant le pays jusqu'au $L o$, on arrive à la partie méridionale du $\mathrm{Ho}$.

(La montagne) King ( $\left(\frac{186}{)}\right.$, et le $H o$ délimitent la province de $Y u$. — Le I, le Lo, le Tch'en et le Kien $(\underline{187})$ — se rendirent $\bullet_{125}$ dans le Ho. — Les eaux débordées du (lac) Yong ( $\left(\frac{188}{)}\right)$, furent enfermées dans des limites fixes ; - il $(Y u)$ conduisit (les eaux du) lac Ko jusqu'au lac Ming-tou (19). Le sol y est friable ; dans les parties basses, il forme des mottes et il est pauvre. - Les champs sont au quatrième rang; les redevances sont en moyenne au second rang. - Le tribut consiste en laque, en soie $(\underline{190})$, en toile fine, en gros 
chanvre; les mannes sont remplies de tissus en soie $(\underline{191})$ et $\bullet{ }_{126}$ de bourre de soie. (Cette province) apporte en tribut, lorsqu'elle en est requise, des pierres qui servent à polir les pierres sonores. - En naviguant sur le Lo, on arrive dans le $H o$.

Le sud (de la montagne) Hoa $(\underline{192})$ et la rivière $\mathrm{Hei}(\underline{193}) \bullet{ }_{127}$ délimitent la province de Leang. Min et Pouo furent mis en culture $\left(\frac{194}{)}\right) .-\bullet$ (Les rivières) T'o et Tch'en $(\underline{195})$ eurent un cours ${ }_{128}$ régulier. - A Ts'ai et à Mong (196), il $(Y u)$ célébra par des sacrifices le rétablissement de l'ordre. - A Ho-i $\left(\frac{197}{)}\right.$, il put exécuter des travaux. - Le sol y est vert et noir $(\underline{198})$. Les champs sont au septième rang; les redevances sont au huitième rang et tantôt au rang supérieur, tantôt au rang $\bullet_{129}$ inférieur $\left(\frac{199}{}\right)$. Le tribut consiste en pierres précieuses $(\underline{200})$, en fer, en argent $(\underline{201})$, en acier, en pierres destinées à faire des pointes de flèches et en pierres musicales, en peaux d'ours communs et d'ours rayés, de renards et de chats sauvages et en tissus faits avec leurs poils. (Partant du) Si-k'ing (202), ils viennent en suivant le cours de la rivière $\bullet_{130}$ Hoan : ils naviguent sur la rivière Ts'ien; ils font un portage jusqu'à la rivière Mien, pénètrent dans la rivière Wei et traversent le $\mathrm{Ho}$.

La rivière $\mathrm{Hei}(\underline{203})$ et le $\mathrm{Ho}$ occidental $(\underline{204})$ délimitent la province de Yong $(\underline{205})$. — La rivière $J o(\underline{206})$ se dirigea vers l'ouest ; — $\bullet_{131}$ le King fut amené à se réunir au Wei $(\underline{207})$. — Le Ts'i et le Tsiu firent de même (마) $)$ - Ce fut là aussi que la rivière $\bullet_{132}$ Fong vint se jeter $(\underline{209})$. - - Sur (les montagnes) King et $\mathrm{K}$ i, il $(\mathrm{Yu})$ fit des sacrifices $(\underline{210})$. - (Il fit de même sur les montagnes) Tchong-nan, Toen-ou — et jusqu'à (la montagne) $\bullet{ }_{133}$ Niao-chou ( $(111)$. - Il exécuta des travaux dans les plaines $(\underline{212})$ et les marécages — et jusqu’à Tou-yé $(\underline{213})$. - Le territoire de San-wei fut réglé ; — un ordre général fut établi chez ${ }_{134}$ les San-miao (214). — Le sol y est jaune et friable. Les champs $\mathrm{y}$ sont au premier rang; les redevances y sont au sixième rang. Le tribut consiste en pierres précieuses des espèces kieou, lin et lang-kan ( $\underline{215})$. Ils (les gens de cette province) naviguent depuis le Tsi-che (216) jusqu'à Long-men qui est sur le $H o$ occidental (217). D'autres les retrouvent au confluent de la rivière Wei $(\underline{218})$. Les ${ }_{135}$ Koen-loen qui ont des tissus faits de peaux, - les Si-tche, les $K^{\prime} i u$-seou — et les Jong de l'ouest furent soumis à la règle.

- Il $(Y u)$ parcourut les neuf montagnes $(\underline{219})$ :

(La première chaîne comprend) le $K^{\prime} i e n$, puis le $K^{\prime} i ; \bullet_{136}$ elle s'étend jusqu'à la montagne King $\left({ }^{220}\right)$. (La seconde chaîne comprend) de l'autre côté du Ho le Hou-k'eou, le Lei-cheou et s'étend jusqu'au T'ai-yo (221). (La troisième chaîne comprend) le Ti-tchou, le Si-tch'eng et s'étend jusqu'au Wang-ou $\left(\frac{222}{}\right)$. (La quatrième chaîne comprend) $\bullet_{137}$ le T'ai-hang, le Tch'ang-chan, s'étend jusqu'au Kié-che et entre dans la mer $(\underline{223})$. (La cinquième chaîne comprend) le Si-k'ing, le Tchou-yu, le Niao-chou et s'étend jusqu'au T'ai-hoa $(\underline{224})$. (La sixième chaîne comprend) le Hiong-eul, le • ${ }_{138}$ W'ai-fang, le T'ong-pe et s'étend jusqu' au P'ei-wei (225). (La • ${ }_{139}$ septième chaîne) passe $(\underline{226})$ au Pouo-tchong $(\underline{227})$ et s'étend jus qu'au King-chan. (La 
huitième chaîne comprend) le Nei-fang et s'étend jusqu'au Ta pié ( $\underline{228}$ ). (La neuvième chaîne $\bullet_{140}$ comprend) le sud de la montagne Min, s'étend jusqu'au Heng-chan, traverse les neuf Kiang et s'étend jusqu'au plateau de Fou-tsien (229).

Il $(Y u)$ parcourut les neuf cours d'eau $(\underline{230})$.

- ${ }_{141}$ La rivière Jo passe par (la montagne) Ho-li; le surplus de ses eaux entre dans les Sables mouvants $(\underline{231})$. - $(\mathrm{Yu})$ parcourut la rivière $\mathrm{Hei}$; elle passe par San-wei et entre dans la mer du Sud $(\underline{232})$. - ( $\mathrm{Yu}$ ) parcourut le Ho ; du Tsi-che, il va jusqu'à Long-men; au sud, il arrive au nord du Hoa ; à l'est il arrive au (mont) Ti-tchou; encore plus à l'est, il arrive au gué de Mong; à l'est, il dépa sse son confluent avec (la rivière) $L o$ et arrive à Ta-p'ei ; au nord, il dépasse la rivière Kiang et arrive au Ta-lou; au nord, il se divise en neuf $\mathrm{Ho}$; ceux-ci se réunissent pour former le $\mathrm{Ni}$-ho qui se jette dans la mer (233). — A partir du $\bullet{ }_{142}$ Pouo-tchong, ( $\mathrm{Yu}$ ) parcourut (la rivière) Yang ; elle coule à l'est et devient le Han; plus à l'est, (ce cours d'eau) de vient la rivière de Ts'ang-lang; il dépasse les trois Che et entre dans le (territoire de) Ta-pié ; au sud, il entre dans le Kiang. A l'est, le marais de Hoei devient le P'ong-li. A l'est, il devient le Kiang septentrional et se jette dans la mer (234). - A partir de la montagne Min, ( $Y u)$ parcourut $\bullet_{143}$ le Kiang; à l'est, il envoie une branche distincte qui est le $T^{\prime} O$; plus à l'est, il arrive au $L i$; il dépasse les neuf Kiang et arrive au Tong-ling ; plus à l'est, il tend vers le nord et se réunit au Hoei ; plus à l'est, il devient le Kiang central et se jette dans la mer $(\underline{235})$. $(Y u) \bullet{ }_{144}$ parcourut la rivière Yen; à l'est, elle devient le $T$ si qui entre dans le $H o$, puis en ressort pour former le Yong; à l'est, (ce cours d'eau) sort au nord du T'ao-k'ieou ; plus à l'est, il arrive au (marais de) Ko ; plus au nord-est, il se réunit à (la rivière) Wen; plus au nord, il entre à l'est dans la mer $(\underline{236}) .-\bullet_{145}$ (Yu) parcourut le Hoai ; il part du (mont) T'ong pe ; à l'est, il se réunit aux (rivières) $\mathrm{Se}$ et $I$; à l'est, il entre dans la mer $(\underline{237})$. - $(Y u)$ parcourut le Wei ; il part du (mont) Niao-chou-t'ong-hiue; à l'est, il se réunit au Fong; plus au nord-est, il arrive à (la rivière) King ; à l'est, il dé passe le Ts'i et le Tsiu et entre dans le Ho $(\underline{238})$. - - (Yu) parcourut le Lo; il vient du (mont) Hiong-eul $(\underline{239})$; au nord-est, il se réunit au Kien et au Tch'en ; plus à l'est, il se réunit à (la rivière) $I$; au nord-est, il entre dans le fleuve.

Alors les neuf provinces furent réglées d'une manière uniforme : dans les quatre directions, les terrains bas furent habités ; sur les neuf montagnes on entailla les arbres $(\underline{240})$ et on fit le sacrifice $l u$; les neuf cours d'eau furent nettoyés jusqu'à leurs sources ; les neuf lacs furent endigués ; dans (l’intérieur des) quatre mers tout fut uni $\bullet_{146}$ et harmonieux $(\underline{241})$; les six domaines (de la nature) $(\underline{242})$ furent dans un ordre parfait. Les diverses terres furent déterminées à leur valeur relative et, pour payer leurs contributions, eurent soin d'apporter la redevance de leurs productions ; pour toutes, la redevance fut fixée suivant celle des trois catégories $(\underline{243})$ dans laquelle elles étaient rangées. 
Dans le royaume du Milieu (244) (l'empereur) conféra des terres et des noms de clan; on se plut $(\underline{245})$ avec respect à prendre sa vertu pour guide : qu'on ne s'écarte point, (dit -il), de ma ligne de conduite.]

Il établit pour le royaume du Fils du ciel et pour ceux qui lui sont extérieurs la règle suivante $(\underline{246})$ : [Cinq cents $l i \bullet_{147}$ constituent le domaine impérial : dans les cent premiers $l i$, on apporte en redevance la céréale tout entière ; dans la seconde centaine de $l i$ on apporte les épis ; dans la troisième centaine de $l i$, on apporte le chaume, mais on est sujet à des corvées $(\underline{247})$; dans la quatrième centaine de $l i$, le grain n'est pas décortiqué ; dans la cinquième centaine de $l i$, il est décortiqué $(\underline{248})$. - Sur un espace de cinq ${ }^{\bullet}{ }_{148}$ cents $l i$ en dehors du domaine impérial, c'est le domaine des seigneurs : dans les cent premiers $l i$, on apporte des présents $(\underline{249})$; dans la seconde centaine de $l i$, sont ceux qui ont une charge publique $(\underline{250})$; dans les trois autres centaines de $l i$, sont les seigneurs. - Sur un espace de cinq cents $l i$ en dehors du domaine des seigneurs, c'est le domaine de la paix : dans les trois premières centaines de $l i$, on impose la règle par une instruction douce ; dans les deux autres centaines de $l i$, on déploie les garnisons militaires $(\underline{251})$. - Sur un espace de cinq cents $l i$ en dehors du domaine de la paix, c'est le domaine de la contrainte : dans les trois premières centaines de $l i$ sont les barbares $I$; dans les deux autres centaines de $l i$ sont les bannis. - Sur un espace de cinq cents li en dehors du domaine de la contrainte, c'est le domaine inculte ; dans les trois premières centaines de $l i$ sont les $\bullet{ }_{149}$ barbares Man $(\underline{252})$; dans les deux autres centaines de $l i$ sont les peuples errants $(\underline{253})$.

A l'est, ( $Y u)$ s'avança jusqu'à la mer ; à l'ouest, il alla jusqu'aux sables mouvants ; au nord et au sud, dans les lieux qu'éclaire le soleil, sa renommée fut un enseignement $(\underline{254})$; il pénétra $(\underline{255})$ jusqu'aux quatre mers.

Alors l'empereur conféra à $Y u$ un insigne en jade noir afin d’informer le monde que son ouvre était bien ac complie $(\underline{256})$.] A la suite de cela, le monde fut gouverné en grande paix.

- ${ }_{150} \mathrm{KaO}$-yao exerça les fonctions de chef chargé de rendre la justice dans le peuple. L'empereur Choen tint une audience; Yu, Po-i et Kao-yao discoururent entre eux en présence de l'empereur ; Kao-yao exposa ses idées en ces termes :

[ $(\underline{257})$ - Si (le souverain) reste fidèle à sa direction et à sa vertu, les conseils qu'on lui donnera seront sages, l'assistance qu'on lui prêtera sera harmonieuse.

$Y u$ dit :

— Sans doute ; mais qu'entendez -vous par là ?

Kao-yao dit :

— Oh ! s’il veille à la bonne conduite de sa personne, ses pensées seront profondes; il fera observer la sincérité et les rangs aux neuf degrés de parenté ; tous les sages seront les ailes sur lesquelles il 
s'élèvera ; ce qui est près sera digne d'approbation, ce qui est loin sera sous sa main $(\underline{258})$.

• ${ }_{151} Y u$ loua ce discours en saluant et dit :

- C'est vrai.

Kao-yao dit :

- Oh ! l'essentiel est qu'il se connaisse en hommes, 1 'essentiel est qu'il donne le calme au peuple.

Yu dit :

- Hé ! quỉl en soit absolument ainsi, c'est ce que l'empereur lui même a trouvé difficile $(\underline{259})$. Quand (le souverain) se connaît en hommes, alors il est prudent et sait nommer aux charges les hommes (qu'il faut); quand il sait donner le calme au peuple, alors il est bon et le peuple aux cheveux noirs l'aime. Quand, il sait être bon, quand il sait être prudent, comment serait-il inquiété par Hoan-teou, comment serait-il troublé $(\underline{260})$ par (San) miao, comment serait-il effrayé par l'homme trompeur aux paroles artificieuses et à l'extérieur agréa ble $(\underline{261})$ ?

Kao-yao dit :

- Oui. Hé ! si, d'une part il y a $\bullet{ }_{152}$ dans la conduite (de l'homme) neuf vertus, d'autre part $(\underline{262})$ quand on parle de ses vertus, on s'exprime en disant quill se livre à telle ou telle action : il est indulgent, mais énergique ; il est doux, mais ferme ; il est hardi, mais respectueux; il est autoritaire, mais circonspect; il est soumis, mais résolu; il est inflexible, mais affable; il est indifférent aux détails, mais attentif ; il est fort, mais sincère ; il est puissant, mais juste. Celui qui resplendit de ces vertus et qui les possède perpétuellement, c'est l'homme excellent. Celui qui, journellement manifeste trois de ces vertus, celui-là, matin et soir, est attentif $(\underline{263})$ et intelligent et il sera mis à la tête d'une maison $(\underline{264})$; celui qui, chaque jour, pratique $\bullet_{153}$ strictement et avec ardeur six de ces vertus, celui-là est un serviteur fidèle et sera mis à la tête d'un royaume. Si (le souverain) réunit et recueille de tels hommes pour administrer $(\underline{265})$, (ceux qui possèdent) les neuf vertus seront tous à son service; les hommes qui en valent mille $(\underline{266})$ et les hommes qui en valent cent rempliront les fonctions publiques; les cent officiers seront respectueux et diligents; ils n'enseigneront point les mauvaises pratiques ni les conseils artificieux; si ce ne sont pas de tels hommes qui occupent les charges qui leur reviennent, c'est ce qu'on appelle troubler l'ordre céleste $(\underline{267})$. Le Ciel punit le crime : les cinq châtiments ont leurs cinq applications! Mes paroles peuvent-elles être mises à exécution dans la pratique? 
$Y u$ dit :

— Vos paroles peuvent au plus haut point être mises à exécution avec succès.

Kao-yao dit :

— Pour moi, je n'en sais encore rien ; mais j’aide à marcher dans le droit chemin $(\underline{268})$.]

•• ${ }_{154}\left[\left(\frac{269}{}\right)\right.$ L'empereur Choen dit à Yu :

- A votre tour, parlez bien.

$Y u$ salua et dit :

— Hé ! que dirai-je ? Je n'ai pensé qu’à m’appliquer sans cesse chaque jour.

Kao-yao arrêta $Y u$ par cette question :

— Qu'entendez -vous par vous appliquer sans cesse ?

$Y u$ dit :

— Les eaux débordées s'élevaient jusqu'au ciel ; l'immense nappe entourait les montagnes et submergeait les collines ; tout le peuple de la plaine était accablé par les eaux ; pour aller sur la terre ferme, je montai en char; pour aller sur l'eau, je montai en bateau ; pour aller sur la boue, je montai sur un van; pour aller sur les montagnes, je montai sur des crampons $(\underline{270})$; je parcourus les montagnes et fis des entailles aux arbres (271). Avec $I$, je donnai à la multitude du riz et de la nourriture fraîche $(\underline{272})$. En ouvrant le cours des neuf fleuves, je les conduisis aux quatre mers; j'approfondis les canaux d'un pied et les canaux de seize pieds ( $\underline{273}$ ) et je les conduisis aux fleuves. $\bullet_{155}$ Avec $T s i\left(\frac{274}{}\right)$, je donnai à la multitude la nourriture qu'elle avait de la peine à se procurer $(275)$; ceux qui avaient peu de nourriture échangèrent les objets qu'ils avaient en trop contre ce qui leur manquait. J'ai déplacé les résidences de tout le peuple et les ai fixées; les dix mille États ont été bien gouvernés.

Kao-yao dit :

— Oui, cela certes est beau.

$Y u$ dit :

- Ah ! ô empereur, portez toute votre attlention sur la place que vous occupez; vous obtiendrez le calme en étant parvenu au but ; vos aides seront vertueux; l'empire répondra universellement à votre pensée pure; par là, il sera mis en lumière que vous avez reçu le mandat de l'Empereur d'en haut; le Ciel renouvellera son mandat en usant de faveur envers vous $(\underline{276})$. 
L'em pereur dit :

- Ah! mes ministres! mes ministres! mes ministres, soyez mes jambes et mes bras, mes oreilles $\bullet_{156}$ et mes yeux; si je désire secourir mon peuple, c'est à vous de l'aider $(277)$; si je désire contempler les images faites par les anciens hommes, à savoir le soleil, la lune et les étoiles dont les couleurs sont représentées par la peinture ou brodées sur les vêtements, c'est à vous de les bien distinguer; si je désire entendre les six tubes sonores, les cinq notes et les huit instruments de musique et observer les qualités et les défauts du gouvernement en répandant et en recueillant les paroles composées sur les cinq notes, c'est à vous d'écouter (278). Si je m'écarte $\bullet{ }_{157}$ du bien, c'est à vous de me corriger et de me résister; ne me flattez pas en face pour me critiquer par derrière. Soyez sur vos gardes, vous mes ministres qui m'assis tez des quatre côtés $(\underline{279})$. Quel que soit le nombre des sujets calomniateurs et pervers, si la vertu du souverain se répand avec sincérité, tous seront purs $(\underline{280})$.

Yu dit :

- C'est vrai ; si l'empereur n'agit pas ainsi et s'il emploie indifféremment les bons et les mauvais, alors il n'y aura plus de réussite.

L'empereur dit (281) :

- Ne favorisez $\bullet_{158}$ pas l'arrogance de Tan-tchou, il ne se plaisait qu'à la paresse et aux amusements ; quand il n'y avait plus d'eau, il voulait aller en bateau $(\underline{282})$; il se livrait à une débauche incestueuse dans sa propre famille; par cette conduite il a mis fin à sa lignée ; je ne pouvais pas favoriser cela.

$Y u$ dit :

- Aux jours sin et jen ( $\underline{283})$ je me mariai à (une fille de la famille) T'ou-chan (284) ; aux jours koei et kia, elle enfanta $K^{\prime} i(\underline{285})$. Je ne le traitai pas comme mon $\bullet_{159}$ fils ; c'est de cette manière que je pus accomplir mes grands travaux sur les eaux et sur les terres ; j'aidai à établir les cinq domaines et j'allai jusqu'à cinq mille $l i(\underline{286})$; dans les provinces il y eut douze maîtres $(\underline{287})$; au dehors, j'allai jusqu'aux quatre mers $(288)$; sur tous les hommes j'établis les cinq (classes de) chefs $\left(2 \frac{289}{)}\right.$. Chacun de ceux qui se conduisaient bien vit son mérite reconnu; les Miao ayant été récalcitrants furent donc sans mérite $(\underline{290})$. O empereur, pensez à cela !

L'empereur dit :

- Marcher dans la même voie vertueuse que moi, c'est votre mé rite qui le fera avec ordre $(\underline{291})$. 
Alors Kao-yao fut plein de respect pour la vertu de $Y u$; il ordonna aux gens du peuple de prendre tous $Y u$ pour règle ; ceux qui n'obéissaient pas à ses paroles, ils les poursuivit par les châtiments.

• ${ }_{160}$ La vertu de Choen fut fort éclatante. Alors K'oei fit de la musique ; l'aïeul et le père décédés vinrent $(\underline{292})$; tous les princes se firent des concessions mutuelles; les oiseaux voltigèrent et les animaux qui marchent dansèrent; au son des neuf airs de la musique siao chao $(\underline{293})$, le phénix mâle et le phénix femelle vinrent avec grâce, les cent animaux dansèrent à l'envi, les cent fonctionnaires furent fidèles et harmonieux. L'empereur profita de cela pour faire un chant ; il dit :

- Celui qui a été élevé par le mandat du Ciel doit être attentif à toutes les occasions, attentif aux moindres affaires.

Puis il chanta, disant (294) :

- Lorsque les jambes et les bras travaillent avec plaisir,

La tête en haut se dresse ;

Les cent fonctions sont remplies avec éclat.

Kao-yao baissa la tête à hauteur de ses mains et se $\cdot{ }_{161}$ prosterna la face contre terre, puis éleva la voix, disant :

- Songez-y ! La direction que vous donnez est ce qui fait fleurir toutes choses ; prenez garde à vos lois ; soyez vigilant.

Alors à son tour il fit un chant et dit :

- Lorsque la tête en haut est intelligente,

Les jambes et les bras sont excellents,

Toutes choses sont prospères.

Il chanta encore ceci :

- Quand la tête en haut n'a pas de vastes pensées,

Les jambes et les bras sont paresseux ;

Toutes choses vont à leur ruine.

L'empereur salua et dit :

— Oui. Allez et soyez vigilants. $(\underline{295})]$

Alors l'empire prit pour règle les mesures et les nombres, les notes et la musique tels que $Y u$ les avait clairement déterminés. $(Y u)$ présida aux dieux des montagnes et des cours d'eau $\left(\frac{296}{)}\right)$.

[ ( $\underline{297})$ L'empereur Choen présenta $Y u$ au Ciel] pour quil fût $\bullet{ }_{162}$ son successeur. [Dix-sept ans après, l'empereur Choen mourut. Quand le deuil de trois ans fut terminé, $Y u$ refusa le pouvoir et se retira devant Chang-kiun, fils de Choen, à Yang-tch'eng (298); Les seigneurs de l'empire quittèrent tous Chang-kiun et vinrent rendre hommage à $Y u$. C'est pourquoi donc $Y u$ prit la dignité de Fils du ciel ; tourné vers le sud il donna audience à l'empire. Le 
titre qui lui vient de son royaume fut le souverain de $\mathrm{Hia}(\underline{299})$; son nom de famille fut $S e$.

Quand l'empereur $Y u$ eut pris le pouvoir, il promut Kao-yao et le présenta (au Ciel) ; il voulait lui remettre le gouvernement, mais Kao-yao mourut. Il donna aux descendants $(\underline{300})$ de Kao-yao des fiefs à Yng et à Leou; l'un d'eux résida à $H i u$.

\# Puis le souverain promut $I$ et lui confia le gouvernement ; dix ans après, l'empereur $Y u$ alla dans l'est par courir les fiefs ; arrivé au (mont) Koei-ki $(\underline{301})$, il mourut. Il $\bullet_{163}$ avait remis l'empire à $I(\underline{302})$. [ $(\underline{303})$ Quand le deuil de trois ans fut terminé, $I$ céda le pouvoir à $K ’$, fils de $Y u$; il se retira est s'établit au sud de la montagne $K i\left(\frac{304}{)}\right)$.] $K^{\prime} i$, fils de $Y u$, était sage ; les sentiments de l'empire lui étaient attachés ; aussi, quand $Y u$ mourut, quoiqu'il eût remis l'empire à $I, I$ n'ayant aidé $Y u$ que peu de temps, n'avait point encore plu à l'ernpire ; c'est pourquoi les seigneurs quittèrent tous $I$ et vinrent rendre hommage à $K i$ en disant :

- Notre prince, c'est le fils de l'empereur $Y u(\underline{305})$.

Alors $K i$ prit donc la dignité de Fils du ciel; ce fut l'empereur $K^{\prime} i$, souverain de Hia $(\underline{306})$.

L'empereur $K^{\prime} i$, souverain de $H i a$, était le fils de $Y u$; sa mère était une fille de la tribu T'ou-chan $(\underline{307})$.

- Le prince de $\operatorname{Hou}\left(\frac{308}{2}\right)$ ne se soumit pas ; $K^{\prime} \boldsymbol{\imath}$ le punit ; il $\bullet_{164}$ livra une grande bataille à $\operatorname{Kan}\left(\frac{309}{}\right)$. Avant d'engager le combat, il fit la harangue de Kan ; [ $(\underline{310})$ il appela les six hauts dignitaires $(\underline{311})$ pour leur exposer sa pensée ; $\mathrm{K} i \mathrm{dit}$ :

- Ohé ! hommes des six armées $(\underline{312})$, j’ai une harangue à vous adresser. Le prince de Hou méprise avec hauteur les cinq éléments; il néglige et abandonne les trois principes régulateurs $(\underline{313})$. C'est pourquoi le Ciel supprime et interrompt son mandat; maintenant je ne fais qu'exécuter avec respect le châtiment céleste. Si ceux de gauche ne font pas leur devoir à gauche, si ceux de droite ne font pas leur devoir à droite $\left(\frac{314}{4}\right)$, ce sera que vous ne $\bullet{ }_{165}$ respectez pas mes ordres ; si vous, cochers, ne dirigez pas bien vos chevaux, ce sera que vous ne $\bullet{ }_{165}$ respectez pas mes ordres ;

«Ceux qui observeront mes ordres, je les récompenserai devant l'ancêtre ;

«Ceux qui n'observeront pas mes ordres, je les mettrai a mort devant le dieu de la terre $(\underline{315})$;

« Je vous ferai certes périr avec vos enfants $(\underline{316})$.

- ${ }_{166}$ Alors il écrasa le prince de Hou. Tout l'empire rendit hommage au souverain de Hia. L'empereur Ki mourut. 
Son fils, l'empereur T'ai-k'ang prit le pouvoir. L'empereur [ ( $\left(\frac{317}{3}\right) T$ 'ai k'ang perdit son royaume; ses cinq frères l'attendirent au confluent de la rivière $L o$ et firent les chants des cinq fils ( $(\underline{318})$.] T'ai-k'ang mourut.

Son frère cadet, Tchong-k'ang, prit le pouvoir; ce fut l'empereur Tchong-k'ang. Au temps de l'empereur Tchong-k'ang, [Hi et $\mathrm{Ho}(\underline{319})$ se plongèrent dans les orgies et les débauches; ils négligèrent les saisons et mirent le trouble dans les jours; (le prince de) $Y n$ alla les châtier. On fit le Châtiment de $Y n\left(\frac{320}{)}\right.$.] Tchong-k'ang mourut.

Son fils, l'empereur Siang, prit le pouvoir; il mourut. - Son fils, l'empereur Chao-k'ang, prit le pouvoir ; ${ }_{167}$ il mourut $\left(\frac{321}{2}\right)$. - Son fils, l'empereur Tchou, prit le pouvoir; il mourut. — Son fils, l'ernpereur Hoei, prit le pouvoir ; il mourut. - Son fils, l'empereur Wang (322), prit le pouvoir ; il mourut. - Son fils, l'empereur Sié, prit le pouvoir ; il mourut. — Son fils, l'empereur Pou-Kiang, prit le pouvoir; il mourut. - Son frère cadet, l'empereur Kiong, prit le pouvoir ; il mourut. — Son fils, l'empereur Kin, prit le pouvoir ; il mourut. — On donna le pouvoir à K'ong-kia, fils de l'empereur Pou-Kiang; ce fut l'em pereur K'ong-kia.

$\stackrel{-}{ }{ }_{168}$ Quand l'empereur K'ong-kia eut pris le pouvoir, il aima s'occuper des choses qui concernent les esprits et les dieux; il vécut dans la débauche et le désordre. La vertu de la dynastie Hia se pervertit; les seigneurs l'abandonnèrent. - Le Ciel fit descendre deux dragons, une femelle et un mâle $(\underline{323})$; K'ong-kia ne pouvait les nourrir, car il n'avait pas Celui qui entretient les dragons $(\underline{324})$; or, après que (la famille de) T'ao-t'ang $\left(\frac{325}{2}\right)$ fut tombée en déchéance, un de ses descendants, Lieou-lei, apprit à apprivoiser les dragons, auprès de Celui qui entretient les dragons ; c'est pourquoi il entra au service de K'ong kia; K'ong-kia lui conféra le nom de famille de Celui qui dirige les dragons $(\underline{326})$; (Lieou-lei) reçut la succession de Che-wei $(\underline{327})$; le dragon femelle étant mort, il le fit manger $\bullet_{169}$ au souverain de Hia $\left(\frac{328}{)}\right.$; le souverain de Hia envoya chercher (ce dragon); (Lieou-lei) eut peur et se transporta ailleurs $(\underline{329})$.

K'ong-kia mourut. - Son fils, l'empereur Kao, prit le pouvoir ; il mourut. - Son fils, l'empereur $F a$, prit le pouvoir ; il mourut. — Son fils, l'empereur Li-koei ( $(330)$, prit le pouvoir ; ce fut Kié.

- Au temps de l'empereur Kié, les seigneurs, qui avaient commencé à faire défection dès l'époque de Kong-kia, se révoltèrent en nombre de plus en plus grand. Kié, (souverain de) Hia, ne se souciait pas de la vertu, mais il terrorisait et faisait souffrir les cent familles; les cent familles ne le supportèrent pas. Alors (l'empereur) manda • ${ }_{170}$ T'ang et l'emprisonna à Hia-T'ai $(\underline{331})$; dans la suite, il le relâcha. T'ang pratiqua la vertu ; tous les seigneurs se réfugièrent auprès de lui; il se mit donc à la tête des soldats pour punir Kié, (de la dynastie) Hia. Kié s'enfuit à Ming-t’iao $(\underline{332})$; il fut donc exilé et mourut. Kié dit à ses gens : 
- Je regrette de n'avoir pas fait périr sur-le-champ T'ang à Hia-T'ai, car voici ce que j'ai amené.

Alors T'ang prit la dignité de Fils du ciel ; à la place du (souverain) Hia, il donna audience à l'empire. Il conféra un fief aux descendants des Hia qui, sous la dynastie Tcheou, reçurent le fief de $K^{\prime} i(\underline{333})$.

Le duc grand astrologue dit: $Y u$ avait pour nom de famille $\mathrm{Se}$; ses descendants se distinguèrent par leurs fiefs et prirent pour nom de famille les noms de leurs $\bullet_{171}$ royaumes; ainsi il y eut les familles de Hia-heou, de Hou, de Nan, de Tchen-siun, de T'ong-tch'eng, de Pao, de Fei, de K'i, de Tseng, de Sin, de Ming et de Tchen-ko ( $\left.{ }^{334}\right)$. — - Kong-tse prit pour règle les saisons des $H i a$ et les érudits en grand nombre nous ont transmis le petit calendrier des Hia $\left({ }^{335}\right)$. - C'est à partir de l'époque de Yu (Choen) et des Hia que le système des tributs et des redevances fut organisé. - On a dit : $Y u$ réunit les seigneurs au sud du Kiang pour faire le compte de leurs mérites, mais il mourut et fut enterré là ; le titre conféré (à ce lieu) fut Koei-ki, car Koei-ki signifie réunir et faire le compte $(\underline{336})$. 


\section{CHAPITRE III}

\section{TROISIÈMES ANNALES PRINCIPALES LES YN}

- ${ }_{173}$ La mère de Sié $(\underline{101})$, (ancêtre des) Yn, s'appelait Kien-ti ; c'était une fille de la famille princière de Song $(\underline{102})$; elle était l'épouse en second de l'empereur Kou; elle et deux autres personnes allèrent se baigner ; elles virent un oiseau de couleur sombre $(\underline{103})$ qui laissa tomber un oaf $; \cdot{ }_{174}$ Kien-ti le recueillit et l'avala ; c'est à la suite de cela qu'elle devint enceinte, puis enfanta Sié.

Quand Sié fut devenu grand, il aida $Y u$ à maitriser les eaux et y acquit de la gloire $(\underline{104})$.

L'empereur Choen donna alors à Sié l'ordre suivant $(\underline{105})$ :

[ $(\underline{106})$ - Les cent familles n'entretiennent pas des relations amicales ; les cinq ordres (de devoirs) ne sont pas observés ; vous, soyez directeur des multitudes et répandez avec soin les cinq enseignements ; les cinq enseignements (ont leur principe) dans la douceur. »]

Il lui conféra la possession du pays de Chang $\left(\frac{107}{)}\right.$; il lui donna le nom de famille Tse. Sié fleurit aux temps de $\bullet_{175}$ T'ang (Yao), de Yu (Choen) et du grand $Y u\left(\frac{108}{)}\right.$. Sa gloire et ses travaux se manifestèrent dans les cent familles et c'est pourquoi les cent familles furent en paix. Sié mourut.

- Son fils, Tchao-ming, prit le pouvoir ; il mourut. Son fils, Siang-t'ou ( $\left.\frac{109}{}\right)$, prit le pouvoir ; il mourut. Son fils, Tch'ang -jo, prit le pouvoir ; il mourut. Son fils, Ts'ao-yu (110), prit le pouvoir ; il mourut. Son fils, Ming, prit le pouvoir ; il mourut (111). Son fils, Tchen (112), prit le pouvoir; il mourut. Son fils, Wei $(\underline{113})$, prit le pouvoir; il mourut. Son fils, Pao-ting, prit le pouvoir ; il mourut. Son fils, Pao-i, prit le pouvoir ; il mourut. Son fils, Pao-ping, prit le - ${ }_{176}$ pouvoir ; il mourut. Son fils, Tchou-jen, prit le pouvoir ; il mourut. Son fils, Tchou-koei, prit le pouvoir ; il mourut. Son fils, Tien-i, prit le pouvoir ; ce fut T'ang (114) le victorieux.

Au temps de T'ang le victorieux, [ $(\underline{115})$ il y avait eu, depuis Sié jusqu'à T'ang, huit transferts (de capitale) (116). T'ang s'établit d'abord à Po et adopta la résidence de l'ancien roi. Il fit l'» Annoncement à l'empereur $(\underline{117})$. »

- ${ }_{177}$ Tang réduisit les seigneurs. Le comte de $K o(\underline{118})$ ne faisait pas les sacrifices ; ce fut par sa punition que commença T'ang. ]

T'ang dit: 
- Voici mes paroles : Les hommes regardent dans l'eau pour voir leur visage ; on regarde le peuple pour savoir si le gouvernement est bon ou non.

I Yn dit :

- Cela est sage ! si cette parole peut être écoutée, alors la bonne conduite sera près d'être at teinte. Celui qui règne sur l'État traite le peuple comme son fils; le principe de tout ce qui se fait d'excellent se trouve dans le roi et ses officiers. Faites tous vos ef forts! faites tous vos efforts !

T'ang dit :

- Ceux de vous qui ne sauront pas respecter mon ordre, je les punirai avec sévérité et les ferai périr; aucun d'e ux ne sera pardonné.

Il fit le «Châtiment (infligé par) T’ang (119). »

- ${ }_{178}$ \# I Yn avait pour nom personnel Ngo-heng $(\underline{120})$. Ngo-heng désirait entrer en rapports avec T'ang ; mais, n'en trou vant pas le moyen, il se mit au service de la suivante, fille de la famille princière de $\operatorname{Sin}(\underline{121})$ et mit sa confiance dans les trépieds et les tables de cuisine $(\underline{122})$; il discourut devant T'ang sur les goûts savoureux et en arriva à parler du gouvernement royal. Une autre tradition dit: I Yn était un simple particulier; T'ang envoya des gens le chercher en lui offrant des présents; ils s'en retou rnèrent cinq fois $(\underline{123})$; mais enfin il se résolut à venir ; c'est $\bullet{ }_{179}$ en accompagnant T'ang qu'il discourut sur le Roi sim ple et sur les neuf Maîtres (르).

T'ang l'éleva en charge pour que l'État fût bien dirigé.

• ${ }_{180}$ [ ( $(25)$ I Yn quitta T'ang pour aller à (la cour de) Hia. Le souverain Hia le remplit d'indignation et il revint à Po. Il entra par la porte du Nord et rencontra Jou Kieou et Jou Fang. Il fit le Jou Kieou et le Jou Fang (126).]

T'ang étant sorti, vit dans la plaine un filet qu'on étendait des quatre côtés avec une invocation en ces termes: "Que des quatre lieux du monde tous entrent dans mon filet. »-T'ang dit :

- Oh ! on les prendrait jusqu'au dernier !

Alors il enleva trois faces du filet et mit une prière en ces termes :

- Si vous voulez aller à gauche, allez à gauche, si vous voulez aller à droite, allez à droite ; que ceux qui en ont assez de la vie entrent dans mon filet.

Les seigneurs apprirent ce trait et dirent :

— La vertu de T'ang est extrême ; elle s'étend jusqu'aux oiseaux et aux quadrupèdes $(\underline{127})$. 
\# En ce temps, Kié, de la dynastie Hia, était cruel ; son gouvernement était pervers et barbare ; d'autre part, parmi les seigneurs, Koen-ou était un fauteur de troubles. T'ang leva alors des soldats et se mit à la tête des seigneurs. I Yn suivait T'ang. T'ang prit lui-même en main la hache d'armes pour réduire Koen-ou $(\underline{128})$ et ensuite pour réduire Kié.

$\bullet{ }_{181}$ T'ang dit : [ $(\underline{129})$

- $(\underline{130})$ Approchez, vous, multitude du peuple. Venez. Écoutez tous mes paroles. Ce n'est pas moi, petit enfant, qui ose entreprendre de susciter une rebellion. Le souverain Hia est fort coupable. J'ai entendu en effet votre multitude dire : «Hia est coupable. » Or, je crains l'Empereur d'en haut et je n'ose pas ne pas corriger (Hia). Maintenant Hia est fort coupable et le ciel ordonne de le mettre à mort. Maintenant parmi vous, la multitude, il en est qui disent : «Notre prince $(\underline{131})$ n'a pas pitié de nous, la multitude; il interrompt nos travaux de la moisson et son gouvernement est nuisible $\left(\frac{132}{}\right)$. » Il en est aussi qui disent : " Quels ne sont pas $\bullet{ }_{182}$ ses crimes ! Le roi de la dynastie Hia est le chef de ceux qui arrêtent les efforts de la multitude ; il est le chef de ceux qui dépouillent le royaume de $\mathrm{Hia}(\underline{133})$; le peuple en est de plus en plus las et ne lui est pas attaché. Il (Hia) a dit :

$$
\begin{aligned}
& \text { «Ce soleil, le jour où ilm ourra, } \\
& \text { M oiet vous périrons tous (134). }
\end{aligned}
$$

« ${ }_{183}$ La conduite de Hia étant telle, je me suis résolu à marcher contre lui.

«J'espère que vous vous unirez à moi, l'homme unique $(\underline{135})$, pour accomplir le châtiment céleste ;

«Alors je vous récompenserai $(\underline{136})$ grandement; gardez-vous de ne pas me croire; je ne suis pas un mangeur de paroles (137). Si vous n'obéissez pas à ce que je dis dans cette harangue,

«Je vous ferai périr avec vos enfants,

« Il n'y aura aucun pardon $(\underline{138})$. ]

• ${ }_{184}$ Par ces paroles, il donna ses ordres à ses soldats ; il fit la harangue de T'ang.

Alors Tang dit :

— Je suis très guerrier; mon surnom sera : le roi guerrier $(\underline{139})$.

Kié fut battu sur la colline de Song $(\underline{140})$; il s'enfuit à Ming-t'iao $(\underline{141})$.

[ ( $\left.{ }^{142}\right)$ Les soldats de Hia furent entièrement défaits. T'ang envahit aussitôt San-tsong $(\underline{143})$ et prit les joyaux et les pierres précieuses qui s'y trouvaient. I-po et Tchong-po firent «Le Joyau perpétuel. » 
Quand T'ang eut vaincu Hia, il voulut changer son dieu de la terre, mais ne put y parvenir ; il fit «Le dieu de la terre des Hia (144). ]

• ${ }_{185}$ I Yn annonça (le nouveau règne) ; alors les seigneurs se soumirent. - T'ang prit donc la dignité de Fils du ciel et pacifia l'intérieur des mers.

[ $(\underline{145})$ T'ang revint et arriva à T'ai-kiuen $(\underline{146})$. Tchong Lei fit sa «Proclamation » $(\underline{147})$.

Quand il (T'ang) eut enlevé à Hia la souveraineté, il revint à Po et fit la «Proclamation de T'ang $\left({ }^{148}\right)$. »] C'était $•{ }_{186}$ le troisième mois ; le roi vint luimême dans la banlieue orientale; il s'adressa aux seigneurs et à tous les chefs, disant :

- Gardez-vous de ne pas vous donner de la peine pour le peuple ; appliquez-vous de toutes vos forces à votre tâche ; (autrement), je vous punirais avec sévérité et je vous ferais périr; ne murmurez pas contre moi.

Il dit :

- Autrefois $Y u$ et Kao-yao peinèrent longtemps loin de chez eux ; ils méritèrent bien du peuple et le peuple alors fut en paix. A l'est, fut le Kiang; au nord, fut le Tsi; à l'ouest, fut le $H o$; au sud, fut le Hoai $(\underline{149})$; ces quatre fleuves ayant leur cours bien réglé, la foule du peuple put s'établir dans ses demeures. Le prince Tsi $(\underline{150})$ enseigna l'art de semer, de cultiver et de faire multiplier les cent céréales. Ces trois sages $(\underline{151})$ méritèrent bien du peuple et c'est pourquoi leurs $\bullet_{187}$ descendants $(\underline{152})$ eurent le pouvoir. Autrefois Tch'e-yeou avec ses hauts dignitaires suscita une rebellion parmi les cent familles ; mais l'Empereur $(\underline{153})$ ne le soutint pas et le mit en accusation. Ainsi les anciens rois nous disent: «Gardez-vous de ne pas faire tous vos efforts.

Il (T'ang) dit :

- Si vous n'agissez pas d'une manière raisonnable, je ne vous laisserai point dans vos royaumes. Ne murmurez pas contre moi !

Par ces paroles il donna ses ordres aux seigneurs.

[ $(\underline{154}) I Y n$ fit le «Tous $(\underline{155})$ ont une même vertu. »

Kao-chan fit l'» Exposé de la manière dont il faut établir (le peuple). »

T'ang alors changea le mois initial $(\underline{156})$ et le premier jour; il modifia la couleur des vêtements ; il mit en honneur le blanc. Il tint ses audiences à midi.

T'ang mourut (157).

L'héritier présomptif T'ai-ting mourut avant d'avoir pu prendre le pouvoir. Alors on nomma Wai-ping, frère cadet de T'ai-ting; ce fut l'empereur Wai-ping. 
L'empereur Wai ping, après deux années $\left(\frac{158}{)}\right)$ de règne, ${ }_{188}$ mourut. On nomma Tchong-jen, frère cadet de Wai-ping ; ce fut l'empereur Tchong-jen.

L'empereur Tchong-jen, après quatre années de règne, mourut.

I Yn nomma alors T'ai-kia, fils de T'ai-lin. T'ai-kia était le petit-fils légitimement $(\underline{159})$ aîné de T'ang le victorieux. Ce fut l'empereur T'ai-kia.

[ $\left(\frac{160}{)}\right.$ La première année de l'empereur T'ai-kia, I Yn fit les «Instructions de $I »$; il fit la «Déclaration au sujet du gouvernement»; il fit le «Prince décédé » $(\underline{161})$.]

L'empereur T'ai-kia, après trois années de règne $\left(\frac{162}{)}\right)$, se montra inintelligent et cruel; il ne suivait pas les principes de T'ang; il avait une conduite perverse; alors $\bullet_{189} Y n$ le relégua dans le palais de T'ong $(\underline{163})$. La troisième année, I Yn exerça la régence et gouverna le royaume ; il donna ainsi audience aux seigneurs. L'empereur T'ai-kia resta dans le palais de T'ong pendant trois années ; il se repentit de ses fautes et blâma sa propre conduite ; il revint au bien. Alors $I Y n$ alla chercher l'empereur T'ai-kia et lui remit le gouvernement. L'empereur T'ai-kia pratiqua la vertu ; les seigneurs firent tous retour à la dynastie $Y n$; les cent familles jouirent ainsi du calme. I Yn le loua et fit alors les «Instructions de T'ai-kia » $(\underline{164})$, en trois sections.

On décerna à l'empereur T'ai-kia le titre de T'ai-tsong $(\underline{165})$. T'ai-tsong mourut. Son fils, Ou-ting (166), prit le pouvoir.

Au temps de l'empereur Ou-ting, I Yn mourut ; [ $(\underline{167})$ quand on eut enterré I Yn à Po, Kao-chan mit sous forme d'instructions ce qu'avait accompli I Yn et fit le «Ou-ting ».]

Ou-ting mourut; son frère cadet, T'ai-keng, prit le pouvoir; ce fut l'empereur T'ai-keng. L'empereur T'ai-keng mourut; son fils, l'empereur Siao-kia, prit le ${ }_{190}$ pouvoir. L'empereur Siao-kia mourut ; son frère cadet, Yong-ki, prit le pouvoir; ce fut l'empereur Yong-ki. La conduite des Yn se pervertit ; parmi les seigneurs, il y en eut qui ne vinrent pas.

L'empereur Yong-ki mourut. Son frère cadet, T'ai-meou, prit le pouvoir. Ce fut l'empereur T'ai-meou (168).

- Quand l'empereur T'ai-meou eut pris le pouvoir, I Tche $(\underline{169})$ fut son conseiller. A $P o$, deux mûriers surnaturels $(\underline{170})$ poussèrent ensemble dans le palais et, en une soirée, devinrent si gros qu'on les embrassait à peine à deux mains. L'empereur T'ai-meou eut peur ; il interrogea I Tche. I Tche lui dit :

- Votre sujet a entendu dire : Un prodige n'est pas plus fort que la vertu. Le gouvernement de Votre Majesté a sans doute quelque défaut ; que Votre Majesté corrige sa conduite.

T'ai-meou suivit ${ }_{191}$ ce conseil ; les mûriers surnaturels se desséchèrent alors, périrent et disparurent. [ (ㅁ1) I Tche en parla au devin Hien] (172) ; le devin Hien gouvernait avec succès la maison royale ; [il fit le «Gouvernement de Hien »;] il fit le «T'ai meou (며). » L'empereur T'ai-meou parla de I Tche 
dans le temple ancestral et déclara qu'il n'était plus un sujet $(\underline{174})$; I Tche déclina (cet honneur); il fit « l'Ordre donné à Yuen (175). »

La dynastie $Y n$ fut de nouveau florissante ; les sei,gneurs lui firent retour. C'est pourquoi ( T'ai-meou) reçut le titre de Tchong-tsong.

Tchong-tsong mourut. Son fils, l'empereur Tchong-ting, prit le pouvoir. L'empereur Tchong-ting transféra sa résidence à Ngao $(\underline{176})$.

[ ( 177$)$ Ho-tan-kia demeura à Siang.]

• ${ }_{192}$ Tsou- $i$ transféra sa résidence à Keng $(\underline{178})$.

L'empereur Tchong-ting mourut. Son frère cadet, Wai-jen, prit le pouvoir ; ce fut l'empereur Wai-jen.

Le livre sur Tchong-ting nous fait défaut et n'est pas à notre disposition $(\underline{179})$.

L'empereur Wai-jen mourut ; son cadet, Ho-tan-kia, prit le pouvoir ; ce fut l'empereur Ho-tan-kia. Au temps de Ho-tan-kia, les Yn se pervertirent de nouveau.

Ho-tan-kia mourut. Son fils, l'empereur Tsou- $i$, prit le pouvoir. Quand Tsou-i eut pris le pouvoir, les Yn prospérèrent de nouveau. Le devin Hien ( $\underline{180}$ ) remplit une charge.

Tsou-i mourut. Son fils, l'empereur Tsou-sin, prit le pouvoir.

• ${ }_{193}$ L'empereur Tsou-sin mourut. Son frère cadet, Ou-kia, prit le pouvoir ; ce fut l'empereur Ou-kia.

L'empereur Ou-kia mourut. On donna le pouvoir à Tsou-ting, fils de Tsou-sin, qui était le frère aîné de Ou-kia. Ce fut l'empereur Tsou-ting.

Tsou-ting mourut. On nomma Nan-keng, fils du frère cadet (181) Ou-kia. Ce fut l'empereur Nan-keng.

L'empereur Nan-keng mourut; on nomma Yang-kia, fils de l'empereur Tsou-ting. Ce fut l'empereur Yang-kia. Au temps de l'empereur Yang-kia, les $Y n$ se pervertirent. A partir de Tchong-ting, on avait laissé tomber en désuétude le droit d'aînesse légitime et on avait préféré nommer des personnes prises parmi les frères cadets ou les fils, de quelque naissance qu'ils fussent $(182)$; les frères cadets et les fils se disputaient parfois pour s'enlever les uns aux autres le pouvoir; ces troubles durèrent pendant neuf générations $(\underline{183})$; alors les seigneurs ne vinrent plus rendre hommage à la cour.

L'empereur Yang-kia mourut. Son frère cadet, P'an-keng, prit le pouvoir ; ce fut l'empereur P'an-keng.

Au temps de l'empereu r Pan-keng, les $Y n$ avaient déjà placé leur résidence au nord du fleuve $\left(\frac{184}{)}\right.$; P'an-keng ${ }_{194}$ passa au sud du fleuve et s'établit de nouveau dans l'an cienne résidence de T'ang le victorieux. Il y avait eu ainsi 
cinq émigrations $(\underline{185})$ sans qu'on pût avoir un établis sement fixe. Le peuple des $Y n$ gémit, et tous, s'excitant les uns les autres, murmurèrent, ne voulant pas changer de place. P'an-keng alors adressa une admonition aux seigneurs et aux grands dignitaires en ces termes :

- Autrefois l'illustre prince T'ang le victorieux et vos ancêtres s'unirent pour pacifier le monde ; la bonne direction put ainsi être suivie. Rester immobile et ne faire aucun effort, est-ce le moyen de rendre la vertu triomphante $(\underline{186})$ ?

Il passa donc au sud du fleuve et s'établit à Po. Il gouverna comme T'ang ; c'est pourquoi, par la suite, les cent familles jouirent du calme ; la conduite des $Y n$ fut de nouveau florissante ; les seigneurs vinrent rendre hommage à la cour parce qu'il avait mis en pratique les vertus de T'ang le victorieux.

L'empereur P'an-keng mourut. Son frère cadet, Siao-sin, prit le pouvoir. Ce fut l'empereur Siao-sin. Quand l'empereur Siao-sin eut pris le pouvoir, les $Y n$ se pervertirent de nouveau. Les cent familles pensèrent avec regret à P'an-keng et c'est alors qu'on fit le « Pan keng » en trois sections.

• ${ }_{195}$ L'empereur Siao-sin mourut. Son frère cadet, Siao-i, prit le pouvoir. Ce fut l'empereur Siao-i.

\# L'empereur Siao-i mourut. Son fils, l'empereur Ou-ting, prit le pouvoir. Quand l'empereur Ou-ting eut revêtu cette dignité, il pensa à faire de nouveau prospérer les $Y n$; mais il n'avait pas encore trouvé celui qui était capable de l'aider. Pendant trois années il ne parla pas; toutes les affaires du gouvernement étaient décidées par le premier ministre; il en profita pour observer les mours du royaume. Ou-ting rêva pendant la nuit qu'il avait trouvé un sage ; son nom était Yue ; il compara avec la figure qu'il avait vue en songe la foule de ses ministres et ses cent officiers ; ce n'était aucun d'eux ; alors donc il chargea les cent artisans d'en faire le des sein $(\underline{187})$ et de le rechercher dans la campagne; on trouva Yue dans les parages difficiles de Fou. En ce temps Yue était parmi les malfaiteurs qui élevaient des terrassements dans les parages difficiles de Fou $(\underline{188})$. Il fut admis en présence de Ou-ting. Ou-ting dit :

- C'est lui.

Quand il l'eut ainsi trouvé, il s'entretint avec lui et re connut que c'était en effet un sage. Il le promut à la dignité de conseiller. Le royaume des $Y n$ fut fort bien gouverné. (Ou-ting) lui donna donc pour nom de famille le nom des parages difficiles de Fou et on l'appela Fou Yue.

- ${ }_{196}$ L'empereur Ou-ting fit le sacrifice à T'ang le victorieux. Le lendemain, [ $\left(\frac{189}{)}\right)$ un faisan vint en volant se poser sur l'anse du trépied et cria.] Ou-ting fut effrayé. Tsou-ki $(\underline{190})$ lui dit :

- Que le roi ne sinquiète pas ; commencez par réformer votre gouvernement.

Tsou-ki [ (191) donna donc ses instructions au roi, disant : 
- Quand le Ciel considère ceux qui vivent en bas, il se règle sur leur justice et leur envoie des années qui sont ou longues ou courtes ; ce n'est pas le Ciel qui donne une mort prématurée aux hommes et qui interrompt leur destinée en son milieu, mais, parmi les hommes il en est qui ne se conforment pas à la vertu et qui ne reconnaissent pas leurs fautes; le Ciel leur donne donc une destinée par laquelle il corrige leur conduite et ils disent alors : «Comment ferons-nous (192) ? » Ah! les rois ont pour charge héréditaire d'être attentifs pour le peuple et il n'e st aucun d'eux qui ne soit le continuateur du Ciel $(\underline{193})$; les sacrifices étant réguliers ne doivent pas être exagérés] jusqu'à faire abandonner la droite voie $\left(\frac{194}{)}\right.$.

Ou-ting $\bullet{ }_{197}$ réforma son gouvernement et pratiqua la vertu ; tout l'empire fut heureux ; les $Y n$ prospérèrent derechef.

L'empereur Ou-ting mourut; son fils, l'empereur Tsou-keng, prit le pouvoir. Tsou-ki loua Ou-ting d'avoir trouvé une occasion d'être vertueux dans l'apparition merveilleuse du faisan. On lui éleva un temple ancestral en lui décernant le nom de Kao-tsong (195). On fit alors le «Jour du sacrifice supplémentaire de Kao-tsong » et les «Instructions ( $\underline{196}$ ) (de Kao-tsong). »

L'empereur Tsou-keng mourut ; son frère cadet, Tsou-kia, prit le pouvoir ; ce fut l'empereur Kia. L'empereur Kia se livra à la débauche et aux désordres ; les $Y n$ se pervertirent derechef.

L'empereur Kia mourut; son fils, l'empereur Lin-sin, prit le pouvoir. L'empereur Lin-sin mourut ; son frère cadet, Keng-ting, prit le pouvoir ; ce fut l'empereur Keng-ting. L'empereur Keng-ting mourut ; son fils, l'empereur • 198 $O u-i$, prit le pouvoir. Les $Y n$ abandonnèrent de nouveau $P_{o}$ et passèrent au nord du fleuve $\left(\frac{197}{}\right)$.

\# L'empereur $O u$ - $i$ agissait d'une manière déraisonnable ; il fit une image de forme humaine et l'appela l'Es prit du Ciel ; il joua avec elle (aux tablettes) et ordonna à un homme de ranger (les tablettes) pour elle ; l'Esprit du Ciel ayant perdu, il l'injuria et l'insulta. Il fit un sac en peau et le remplit de sang ; il le suspendit en l'air et tira sur lui des flèches, disant qu'il tirait sur le Ciel $\left(\frac{198}{)}\right)$. - Ou-i étant allé chasser dans la région comprise entre le fleuve et la rivière $W e i(199)$, il y eut un coup de tonnerre terrible et $\mathrm{Ou}-i$ mourut foudroyé.

Son fils, l'empereur T'ai-ting, prit le pouvoir. L'empe reur T'ai-ting mourut. Son fils, l'empereur I, prit le pouvoir. Quand l'empereur $I$ eut pris le pouvoir, les $Y n$ se pervertirent encore davantage.

Le fils aîné de l'empereur $I$ s'appelait $K^{\prime} i$, vicomte de $W e i$; comme la mère de $K^{\prime} i$ avait un rang secondaire, il $\bullet_{199}$ ne put succéder à son père. Le plus jeune fils était $\operatorname{Sin}$; la mère de Sin était l’impératrice en titre ; c'est pourquoi il fut l'héritier $(\underline{200})$. 
L'empereur I mourut; son fils, Sin, prit le pouvoir ; ce fut l'empereur Sin ; l'empire lui donna le surnom de Tcheou. L'empereur Tcheou se distinguait par des qualités supérieures pour le mal; il entendait et voyait avec beaucoup d'acuité ; sa force était surhumaine ; avec la main il terrassait des animaux furieux. Son savoir lui permettait de contredire les remontrances ; son habileté à parler lui permettait de colorer ses mauvaises actions. Il intimidait ses officiers par ses capacités ; il s'éleva haut dans l'empire par sa renommée ; de la sorte il fit que tous étaient sous sa dépendance. Il aimait le vin, la débauche et les réjouissances; il s'adonnait aux femmes ; sa favorite était $T a-k i(\underline{201})$; les paroles de $T a-k i$ étaient des ordres obéis. Alors il ordonna à maitre Kiuen $(\underline{202})$ de ${ }_{200}$ faire de nouvelles harmonies lascives, des danses du Peili $(\underline{203})$ et des airs de musique flatteurs. Il exigea des redevances et des taxes considérables pour accumuler de la monnaie à la Terrasse du Cerf $(\underline{204})$, pour faire regorger de grain le (grenier de) Kiu-kiao $(\underline{205})$. Il rassemblait en nombre toujours plus grand des chiens, des chevaux et des objets rares; il en remplissait ses palais et ses demeures. Il étendait sans cesse les parcs et les terrasses de Cha-kïeou (206): il réunit une quantité de bêtes sauvages et d'oiseaux ailés qu’il plaça là. Il négligea les es prits des morts et les esprits célestes. Il organisa de grands divertissements à Cha-k'ieou : il fit un étang de vin ; il suspendit des quartiers de viande de façon à en former une forêt; il envoya des hommes et des femmes nus se poursuivre dans ces lieux ; il donna des orgies qui duraient toute la nuit. Les cent familles murmuraient et attendaient la délivrance; parmi les seigneurs, il y en $\bullet_{201}$ eut qui se révoltèrent. Alors Tcheou rendit plus terrible les supplices et les châtiments ; il y eut la torture de la poutre de métal placée sur le feu $(\underline{207})$.

Les ducs du palais (208) étaient le Chef de l'ouest, Tch'ang (므), le marquis de Kieou $(\underline{210})$ et le marquis de $N g o(\underline{211})$. Le marquis de Kieou avait une fille qui était belle ; il la fit entrer dans (le sérail de) Tcheou; la fille du marquis de Kieou ne se plaisait pas à la débauche ; Tcheou, irrité, la tua, puis il hacha en morceaux le marquis de Kieou. Le marquis de Ngo le blâma avec force et le jugea avec indignation ; il coupa aussi en pièces le marquis de Ngo. Tch'ang, chef de l'ouest, l'apprit et en gémit secrètement ;

- 202 Hou, marquis de Tch'ong (212), sut ce fait et le dénonça à Tcheou; Tcheou emprisonna le Chef de l'ouest à Yeou-li (1ㅡ) : Les officiers du Chef de l'ouest, Hong Yao et ses collègues, recherchèrent une belle femme, des objets rares et des chevaux excellents et les offrirent à Tcheou. Tcheou pardonna alors au Chef de l'ouest. Le Chef de l'ouest, étant sorti (de prison), of frit le territoire situé à l'ouest de la rivière $L o(\underline{214})$, en demandant qu'on supprimât le supplice de la poutre de métal placée sur le feu ; Tcheou y consentit. Il lui donna un arc, des flèches, une hachette et une hache d'arm es et le chargea spécialement $(\underline{215})$ de ${ }_{203}$ réduire et de combattre (les rebelles) en lui conférant le titre de Chef de l'ouest (16).

\# Puis (Tcheou) se servit de Fei Tchong pour gouverner. Fei Tchong était un flatteur habile et était intéressé ; le peuple des $Y n$ ne lui était pas attaché. Tcheou se servit en outre de Ngo-lai (217). Ngo-lai s'entendait fort bien à 
perdre les gens et à les calomnier ; c'est pourquoi les seig neurs s'éloignèrent de plus en plus.

Le Chef de l'ouest revint chez lui ; il pratiqua alors secrètement la vertu et fit le bien; les seigneurs se détachèrent en grand nombre de Tcheou et firent retour au Chef de l'ouest. Le Chef de l'ouest grandit et par suite Tcheou perdit graduellement son autorité et son importance. Le fils du roi $(\underline{218}), P i-k a n$, lui fit des remontrances; il ne les écouta pas. Chang Yong était un sage que les cent familles aimaient ; Tcheou le dégrada.

Il arriva que le Chef de l'ouest combattit le royaume de $K i(\underline{219})$ et le détruisit. Un ministre de Tcheou, Tsou I, ${ }_{204}$ l'apprit et augura mal (du Chef de l'ouest, prince) $(\underline{220})$ de Tcheou : saisi de crainte, [ (221) il se hâta d'en informer Tcheou, disant :

- Le Ciel met donc fin au mandat de nos souverains, les Yn. Si nous nous en rapportons aux hommes et à la grande tortue $(\underline{222})$, nous n'osons rien prévoir d'heureux. ${ }_{205} \mathrm{Ce}$ n'est pas que les anciens rois ne nous aident pas, nous leurs descendants ; mais c'est que Votre Majesté est débauchée et cruelle $(\underline{223})$, et que, par sa conduite, elle cause elle-même sa fin ; c'est pourquoi le Ciel nous a rejetés et nous ne pouvons plus jouir de la nourriture. Vous ne tenez pas compte de la nature que le Ciel vous a donnée ; vous ne suivez pas les lois directrices $(\underline{224})$. Maintenant, dans tout notre peuple, il n'est personne qui ne désire votre ruine et ne dise : «Pourquoi le Ciel ne «fait-il pas descendre sur lui sa colère ? pourquoi quelqu'un, investi du grand mandat, ne vient-il pas $(\underline{225})$ ? » Maintenant, ô roi, que ferez-vous ?

Tcheou dit :

— La destinée de ma vie ne dépend-elle pas du Ciel ?

Tsou I se retira en disant :]

— Il est impossible d'adresser des répri mandes à Tcheou.

Après la mort du Chef de l'ouest, le roi $\mathrm{Ou}$, (prince de) Tcheou, dirigea une expédition armée du côté de l'est ; il parvint au gué de Mong $(\underline{226})$; les seigneurs se révoltèrent contre les $Y n$; il y en eut huit cents qui se réunirent au (roi $\mathrm{Ou}$, prince de) Tcheou; les seigneurs disaient tous :

- On peut punir Tcheou.

Le roi $\mathrm{Ou}$ dit :

— Vous ne connaissez point encore le décret du Ciel.

Alors il revint.

Tcheou s'enfonça de plus en plus dans la débauche et $\bullet{ }_{206}$ le désordre et ne s'arrêta pas. Le vicomte de Wei $(\underline{227})$, le reprit plusieurs fois sans être écouté ; 
il projeta alors avec le grand précepteur et le second précepteur $(\underline{228})$ de s'en fuir aussitôt. \# Pi-kan dit :

- L'homme qui est un sujet ne saurait se dispenser de lutter jusqu'à la mort.

Il adressa donc de fortes remontrances à Tcheou. Tcheou se mit en colère et dit :

— J'ai appris que le cour d'un sage avait sept ouvertures.

Il coupa Pi-kan en deux pour regarder son cour. Le vicomte de $K i(\underline{229})$ eut peur ; il feignit alors la folie et se livra à des occupations serviles ; Tcheou le jeta en prison. Le grand précepteur et le second précepteur des $Y n$ prirent leurs ustensiles des sacrifices et leurs instruments de musique et s'enfuirent auprès du (roi $\mathrm{Ou}$, prince de) Tcheou.

Alors le roi $\mathrm{Ou}$, (prince de) Tcheou, se mit aussitôt à la tête des seigneurs pour attaquer Tcheou. Tcheou de son côté envoya des soldats pour le repousser dans la $\bullet_{207}$ Campagne de Mou $(\underline{230})$. Au jour kia tse, les soldats de Tcheou furent battus; Tcheou s'enfuit et rentra (dans la ville) ; il monta sur la Terrasse du Cerf $(\underline{231})$; il revêtit ses habits ornés de joyaux précieux, se précipita dans le feu et mourut. Le roi $\mathrm{Ou}$, (prince de) Tcheou, coupa alors la tête de Tcheou et la suspendit à l'étendard blanc ; il tua Ta-ki. [ ( $(232)$ Il délivra le vicomte de $K i$ de prison ; il éleva un tertre sur la sépulture de Pi-kan; il honora la porte du village de Chang Yong] (233). Il conféra une terre au fils de Tcheou, Ou-keng Lou-fou (234) pour qu'il perpétuât les sacri fices des $Y n$ et lui ordonna de remettre en pratique le gouvernement de P'an-keng $(\underline{235})$; le peuple des $Y n$ en fut très heureux.

Alors le roi $O u$, (prince de) Tcheou, fut Fils du ciel. Ses descendants renoncèrent au titre d'empereur et prirent le titre de rois. On conféra au descendant des $Y n$ la dignité de seigneur; il dépendit des Tcheou.

A la mort du roi $\mathrm{Ou}$ (de la dynastie) Tcheou, Ou-keng de concert avec Koan-chou et Ts'ai-chou $(\underline{236})$, fomenta une $\bullet_{208}$ révolte. Le roi Tch'eng ordonna au duc de Tcheou de le tuer; puis il nomma le vicomte de Wei dans le territoire de Song $(\underline{237})$ pour qu'il continuât la descendance des $Y n$.

- Le duc grand astrologue dit : «C'est avec les odes sacrificatoires que j'ai mis en ordre les événements qui concernent Sié (238). A partir de T'ang le victorieux, j'ai com pilé le Chou (king) et le Che (king). - Sié avait pour nom de famille $T s e$; ses descendants reçurent divers apanages et prirent pour nom de famille le nom de leurs royaumes; il y eut la famille $Y n$, la famille Lai, la famille Song, la famille Kong-t'ong, la famille Tche, la famnille Pe-yn, la famille Mou-i $(\underline{239})$. - Kong-tse a dit: «Le char impérial des Yn était excellent et la couleur qu'ils mirent en honneur fut le blanc $(\underline{240})$. » 


\section{CHAPITRE IV}

\section{QUATRIÈMES ANNALES PRINCIPALES LES TCHEOU}

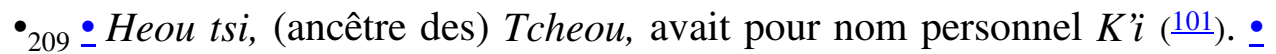
Sa mère était une femme de la famille princière de T'ai $(\underline{102})$, et s'appelait Kiang-yuen. Kiang-yuen était la première des épouses de l'empereur K'ou. ${ }_{210}$ Kiang-yuen sortit dans la campagne; elle vit les empreintes des pas d'un géant ; son cour s'en réjouit et elle y prit plaisir ; elle voulut marcher sur ces traces; quand elle marcha sur ces traces, son corps eut un frémissement comme celui d'une femme qui conçoit. Elle resta chez elle pendant toute la durée de la gestation, puis elle enfanta un fils. Estimant que c'était un malheur, elle exposa l'enfant dans une ruelle étroite ; mais les chevaux et les boufs qui passaient l'évitaient tous et ne le fou laient pas aux pieds. Elle l'emporta et le mit au milieu de la forêt, mais justement plusieurs hommes se trouvaient dans la forêt de la montagne. Elle transporta son enfant ailleurs et l'exposa sur la glace au milieu d'un canal ; mais des oiseaux vinrent en volant pour le protéger et le soutenir avec leurs ailes. Kiang-yuen vit là un prodige ; elle recueillit donc son enfant, le nourrit et l'éleva. - Comme elle avait voulu d'abord l'aban donner, il reçut le nom de $K^{\prime} i(\underline{103})$

- Quand $K^{\prime} i$ était encore enfant, il avait une fermeté de caractère comparable à celle d'un géant. Quand il allait çà et là pour jouer, il aimait à semer et planter du chanvre et des haricots; le chanvre et les haricots prospéraient. - Devenu homme fait, il se plut encore au labourage; il connaissait ce qui convient à la terre ; les céréales qui convenaient étaient semées et donnaient des récoltes. Tout le peuple le prenait pour modèle.

L'empereur Yao apprit cela et éleva $K^{\prime} \boldsymbol{i}$ à la dignité d’intendant de l'agriculture. L'empire y trouva son avan tage et $\left(K^{\prime} i\right)$ fut couvert de gloire.

\section{[ ( $(\underline{104})$ L'empereur Choen dit :}

- O $K i$, le peuple aux cheveux noirs était auparavant affamé. Vous, Prince Millet $\bullet_{211}$ (Heou-tsi), @- semez et transplantez les cent céréales $(\underline{105})$. »]

- Il donna en fief à $K^{\prime} i$ le pays de $T^{\prime} a i(\underline{106})$; le surnom de $K^{\prime} i$ fut Heou-tsi; il avait en outre un nom de clan qui était $K i\left(\frac{107}{}\right)$. Il fleurit à l'époque de T'ao-t'ang, de $Y u$ et de $\mathrm{Hia}(\underline{108})$. Sous tous ces princes, il eut une éminente vertu.

Heou-tsi mourut. Son fils $(\underline{109})$, Pou-tchou, prit le pouvoir. Vers la fin de la vie de Pou-tchou, le roi (de la dynastie) Hia gouverna mal (1ㅡ). Il supprima 
(l'intendant du) millet et $\bullet_{212}$ ne s'en occupa pas $(\underline{111})$. Pou-tchou perdit donc sa charge et s'enfuit dans le pays des (barbares) Jong et Ti. Pou-tchou (112) mourut.

Son fils, Кiu, lui succéda. Kiu mourut.

Son fils, le duc Lieou, lui succéda. Quoique le duc Lieou fût dans le pays des Jong et des $T i$, il remit en honneur les occupations auxquelles s'était livré Heou-tsi. Il s'appliqua à labourer et à semer. Il fit ce qui était favorable à la terre. Depuis les rivières $T s ' i$ et $T \operatorname{siu}(\underline{113}) \bullet_{213}$ jusqu'au delà de la rivière $W e i$, il prit les plantes qui pouvaient lui servir. Ceux qui voyageaient s'enrichirent ; ceux qui restaient chez eux eurent des troupeaux et des réserves de grain. Le peuple eut confiance dans son zèle; les cent familles l'aimèrent. Plusieurs personnes émigrèrent pour venir se mettre sous sa protection. C'est alors que commença la prospérité de la conduite des Tcheou. C'est pourquoi les poètes chantaient et se réjouissaient en pensant à sa vertu (114). Le duc Lieou mourut.

Son fils, K'ing-kié, lui succéda. Il eut sa capitale à Pin (115). K'in-kié mourut. Son fils, Hoang-p'ou, lui succéda; Hoang-p'ou mourut. Son fils, Tch'a-fou, lui succéda; Tch'a-fou mourut. Son fils, Hoei-yu, lui succéda; Hoei-yu mourut. Son fils, le duc Fei, lui succéda ; le duc Fei mourut. Son fils, Kao-yu, lui succéda; Kao-yu mourut. Son fils, Ya-yu, lui succéda ; Ya-yu mourut. Son fils, le duc Chou-tsou-lei $(\underline{116})$, lui succéda ; le duc Chou-tsou-Lei mourut.

Son fils, l'Ancien duc Tan-fou, lui succéda. L'Ancien duc Tan-font remit en honneur les occupations de $\bullet_{214}$ Heou-tsi et du duc Lieou. Il eut une abondance de vertus et pratiqua la justice. Les habitants du pays l'honoraient tous. Les Hiun-yu (117), les Jong et les Ti l'attaquèrent; ils désiraient s'emparer de se s richesses et de ses biens. Il les leur livra. Ils l'attaquèrent derechef, car ils voulaient prendre sa terre et son peuple. Tout le peuple était indigné et voulait combattre. L'Ancien duc dit (118) :

- Lorsqu'un peuple se n omme un chef, c'est afin de tirer de lui quelque avantage. Maintenant si les Jong et les Ti m'attaquent, c'est pour avoir ma terre et mon peuple. Que le peuple dépende de moi ou qu'il dépende d'eux, quelle différence cela fait -il ? Le peuple veut combattre à cause de moi. Mais tuer les pères et les fils des hommes sur lesquels on règne, c'est ce que je ne puis souf frir.

Il prit donc avec lui sa famille et quitta $\operatorname{Pin}(\underline{119})$; il traversa les rivières $T s$ ' $i$ et Tsiu $(\underline{120})$, franchit la montagne Leang $(\underline{121})$ et s'arrêta au pied de la montagne $K \dot{i}$. Les $\bullet_{215}$ habitants de Pin partirent en masse, soutenant les vieillards et aidant les faibles; tous vinrent de nouveau se mettre sous la protection de l'Ancien duc, au pied de la montagne $K^{\prime} \boldsymbol{i}$. Puis d'autres pays voisins, entendant parler de la bonté de l'Ancien duc, vinrent aussi en grand nombre auprès de lui.

Alors l'Ancien duc renonça aux mours des Jong et des Ti; car il construisit et éleva un rempart et une enceinte, des maisons et des salles; la 
ville fut alors un lieu distinct $(\underline{122})$. Il institua les cinq fonctionnaires $(\underline{123})$ qui eurent des attributions. - Tout le peuple le chantait, était joyeux à cause de lui et célébrait ses vertus.

L'Ancien duc avait un fils aîné qui s'appelait $T$ 'ai-po et un second fils qui s'appelait Yu-tchong. T'ai-Kiang enfanta le plus jeune fils, Ki-li; Ki-li prit pour femme T'ai-jen. (T'ai-Kiang et T'ai-jen $(\underline{124})$ ) furent toutes deux des épouses parfaites. A la naissance de Tch'ang $(\underline{125})$, il y eut $\bullet_{216}$ un saint miracle $(\underline{126})$. L'Ancien duc dit :

- Ce qui, chez mes descendants, doit être glorieux, c'est chez Tch'ang que cela se trouve! Les fils aînés, T'ai po et $Y u$-tchong, sachant que l'Ancien duc désirait donner le pouvoir à $\mathrm{Ki}$-li, afin qu'il fût transmis à Tch'ang, se retirèrent tous deux chez les Man (du pays) de King $\left(\frac{127}{)}\right)$. Ils se tatouèrent et coupèrent leurs cheveux $(\underline{128})$ et cédèrent ainsi la place à $K i$-li.

A la mort de l'Ancien duc, Ki-li prit le pouvoir; ce fut le duc $K i$. Le duc $K i$ continua à observer les maximes de conduite que lui avait laissées l'Ancien duc ; il s'ap pliqua avec fermeté à pratiquer la justice. Les seigneurs lui furent soumis. Le duc $K i$ mourut.

- ${ }_{217}$ Son fils, Tch'ang, prit le pouvoir. Ce fut le Chef de l'ouest. Le Ch ef de l'ouest s'appela le roi Wen. Il se livra aux occupations de Heou-tsi et du duc Lieou; il observa les principes de l'Ancien duc et du duc $K i$; il s'appliqua avec fermeté à être bon. Il honorait les vieillards ; il chérissait les enfants ; il était respectueux et humble à l'égard des sages. Pendant le jour il ne se donnait pas le loisir de manger, afin de s'occuper des hommes de valeur ; aussi les hommes de valeur venaient-ils en grand nombre auprès de lui. Po-i et Chou-ts' $i$, qui étaient dans le pays de Kou-tchou (129), apprirent que le Chef de l'ouest, dans sa bonté, entretenait les vieillards ; ils vinrent donc auprès de lui. Plusieurs grands, T'ai Tien, Hong Yao, San I-cheng, Yu-tse (130), Sin-kia, vinrent tous auprès de lui.

- Hou, marquis de Tch'ong (131), parla mal du Chef de l'ouest $\bullet_{218}$ à Tcheou, (souverain de la dynastie) Yn, disant :

- Le Chef de l'ouest a perfection sur perfection, vertu sur vertu. Les seigneurs inclinent vers lui. Cela ne sera pas à l'avantage de l'empereur.

L'empereur Tcheou emprisonna alors le Chef de l'ouest à Yeou-Li (132).

Hong Yao et ceux qui étaient avec lui en furent fort attristés ; ils firent alors venir une belle femme de la famille princière de $\operatorname{Sin}(\underline{133})$, un cheval tacheté du pays de $L i$-jong $(\underline{134})$, neuf quadriges de la tribu qui occupait le pays de Hiong $\left(\frac{135}{}\right)$ et d'autres objets très merveilleux, Ils les offrirent à Tcheou par l'entremise de Fei Tchong qui était un favori à la cour des Yn. Tcheou, très joyeux, dit : 
«Parmi ces présents il en est un qui, à lui seul, aurait suffi à faire relâcher le Chef de l'ouest $(\underline{136})$. A combien plus forte raison lorsqu'ils sont en si grand nombre !

\# Il pardonna donc au Chef de l'ouest et lui fit cadeau d'un arc, de flèches, d'une hachette et d'une hache d'armes. Il chargea le Chef de l'ouest d'aller réduire les rebelles et dit :

- C'est Hou, marquis de Tch'ong $(\underline{137})$, qui avait calomnié le Chef de l'ouest.

- ${ }_{219}$ Puis le Chef de l'ouest offrit à Tcheou le pays situé à l'ouest de la rivière $L o\left(\frac{138}{3}\right)$, en le priant de renoncer au supplice de la poutre de métal placée sur le feu. Tcheou y consentit.

Le Chef de l'ouest fit le bien en secret. Les seigneurs venaient tous à lui pour quil tranchât leurs querelles et leur donnât la paix.

En ce temps les habitants de $Y u$ et ceux de Joei $(\underline{139})$ avaient un différend qu'ils ne pouvaient vider. Ils se rendirent donc auprès (du prince) de Tcheou ; quand ils entrèrent sur son territoire, (ils virent que) les laboureurs ne se contestaient jamais les limites de leurs champs, que le peuple tout entier était habitué à témoigner de la déférence aux vieillards. Les habitants de $Y u$ et ceux de Joei n'avaient pas encore vu le Chef de l'ouest qu'ils étaient déjà tout confus et se disaient les uns aux autres :

- Ce qui fait l'objet de notre dispute serait tenu pour chose déshonorante par les hommes du pays de Tcheou; pourquoi aller plus avant? nous ne recueillerions que de la honte.

Ils s'en retournèrent aussitôt et se séparèrent pleins de condescendance les uns pour les autres. Les seigneurs, en apprenant ce fait, dirent :

- ${ }_{220}$ Le Chef de l'ouest est certainement un prince qui a reçu le mandat (divin).

L'année suivante, le Chef de l'ouest battit les K’iuen Jong (140). L'année suivante, il battit (les gens de) Mi-siu (ㄴ14). L'année suivante, il fut vainqueur du pays de $K^{\prime} i(\underline{142})$. Tsou-i, qui était un sujet des $Y n$, ayant appris ces choses, eut des craintes et en informa l'empereur Tcheou. Tcheou dit :

- N'ai-je pas le mandat céleste ? Comment cela pourrait-il arriver $(\underline{143})$ ?

L'année suivante, (le Chef de l'ouest) triompha de Yu (ㄴ4).

- 221 L'année suivante, il fut vainqueur de Hou, marquis de Tch'ong et construisit la ville de Fong (145). Il émigra du pied de la montagne $K{ }^{\prime} i$ et vint transférer sa capitale à Fong. L'année suivante, le Chef de l'ouest mourut.

L'héritier présomptif, $\mathrm{Fa}$, prit le pouvoir. Ce fut le roi $\mathrm{Ou}$.

Le Chef de l'ouest dut régner cinquante ans ; lorsqu'il fut emprisonné à Yeou-li, il passe $(\underline{146})$ pour avoir multiplié les huit trigrammes des 
Changements et en avoir fait les soixante-quatre hexagrammes. Les poètes célébrèrent le Chef de l'ouest. L'année où il reçut le mandat et où il se proclama roi dut être celle où il trancha le différend qui existait entre les pays de $Y u$ et de Joei $\left(\frac{147}{(4)}\right)$ Sept ans $(\underline{148})$ plus $\bullet_{222}$ tard, il mourut. Son titre posthume $\left(\frac{149}{14}\right)$ fut : le roi Wen. - Il changea les règles et les mesures et détermina le premier jour du premier mois. Il conféra, par une vénération rétrospective, à l'ancien duc le titre d'Auguste roi $(\underline{150})$; et au duc $K i$ le titre de Roi $K i$. L'heureux présage de la royauté dut $(\underline{151})$ apparaître dès le temps de l'Auguste roi.

Lorsque le roi $O u$ prit le pouvoir, T'ai-kong-wang $(\underline{152})$ fut $\bullet_{223}$ nommé précepteur et le duc de Tcheou, Tan $(\underline{153})$, fut nommé assistant; leurs collègues, les ducs de Chaoi $(\underline{154})$ et de $P i(\underline{155})$, furent les précepteurs royaux de gauche et de droite du roi. (Le roi $\mathrm{Ou}$ ) mit en honneur les principes de conduite que lui avait laissés le roi Wen.

La neuvième année $(\underline{156})$, le roi $O u$ offrit un sacrifice en ${ }_{224}$ haut à $P i(\underline{157})$.

Il passa, dans l'est, une revue de ses soldats et arriva au gué de Mong ( $(158)$. Il avait fait en bois une tablette du roi Wen et la transportait dans un char au milieu de l'armée $(\underline{159})$; le roi $O u$ s'appelait lui-même « l'héritier présomptif, $F a\left(\frac{160}{)}\right) \gg$; il disait qu’il obéissait au roi Wen en dirigeant les hostilités et qu'il n'osait pas agir de sa propre autorité. Il parla en ces termes au Se-ma, au Se-t'ou, au Se-k'ong $(\underline{161}) \bullet_{225}$ et à tous les officiers :

- Soyez respectueux, vigilants et de bonne foi ! je suis ignorant mais, par mes ancêtres, j'ai de la force ; moi, sujet et petit enfant $\left(\frac{162}{)}\right.$, je suis le dépositaire de la gloire de mes ancêtres. J'épuiserai ma force $(\underline{163})$ pour récompenser et punir afin de conserver cette gloire.

Il mit donc son armée en mouvement. Le grand précepteur $(\underline{164})$ donna ses ordres en ces termes $(\underline{165})$ :

- ${ }_{226}$ Rassemblez vos multitudes ; réunissez vos barques et vos rames ; ceux qui arriveront en retard seront décapités !

Le roi $O u$ traversa la rivière ; au milieu du passage, un poisson blanc sauta hors de l'eau et vint tomber dans la barque du roi $\left(\frac{166}{6}\right)$. Le roi $\mathrm{Ou}$ se baissa et le ramassa pour l'offrir en sacrifice. Lorsqu'il eut passé la rivière, une flamme vint de haut en bas, contrairement à ce qui se passe d'habitude ; arrivée sur la demeure du roi, elle se transforma en un corbeau de couleur rouge dont la voix était douce $(\underline{167})$.

En ce temps, huit cents seigneurs se réunirent au gué de Mong, quoiqu'on ne leur eût point donné rendez-vous. Ces seigneurs disaient tous :

- C'est le moment de punir Tcheou.

Le roi $O u$ leur dit : 
- Vous ne connaissez pas encore la volonté du Ciel ; le moment n'est pas encore arrivé.

Il ramena donc ses soldats et s'en retourna.

Deux ans plus tard $(\underline{168})$ on apprit que Tcheou se livrait à ${ }_{227}$ des orgies et à des cruautés de plus en plus grandes : il avait tué le fils de roi Pi-kan; il avait emprisonné le vicomte de $K i$. Le grand précepteur, $T s ' e$, et le second précepteur, Kiang, prirent leurs instruments de musique et s'enfuirent auprès de (Ou, prince de) Tcheou. Alors le roi $\mathrm{Ou}$ fit une proclamation à tous les seigneurs en ces termes : « $Y n$ a accumulé crime sur crime. Il m'est impossible, si je ne le punis pas définitivement, d'obéir au roi Wen. »

Il se mit donc à la tête de ses chars de guerre qui comptaient trois cents quadriges, de trois mille guerriers ardents comme des tigres et de quarantecinq mille soldats armés de cuirasses pour aller dans l'est punir Tcheou.

La onzième année, au douzième mois, au jour ou ou $(\underline{169})$, les soldats franchirent tous le gué de Mong. L'assemblée entière des seigneurs disait :

- Courage ! courage $(\underline{170})$ ! N'ayons aucune mollesse !

Le roi $O u$ fit alors la grande harangue $(\underline{171})$ et s'a dressa à la foule en ces termes :

- Voici, le roi (de la dynastie) Yn, Tcheou, obéit aux paroles de - 228 sa femme $(\underline{172})$; il s'est séparé lui -même du Ciel ; il a ruiné et corrompu les trois principes $(\underline{173})$. Il s'est aliéné ses on cles et ses frères $\left(\frac{174}{}\right)$. Il a interrompu et rejeté la musique de ses ancêtres pour la remplacer par des chants de débauche ; il a changé et altéré les sons justes pour plaire à sa femme. C'est po urquoi maintenant moi, $F a$, je me borne à exécuter avec respect le châtiment céleste. Faites tous vos efforts, ô hommes vaillants ! C'est une tentative qu'on ne peut répéter ni deux, ni trois fois $(\underline{175})$.

La deuxième lune $\left(\frac{176}{)}\right),\left[\left(\frac{177}{)}\right)\right.$ au jour kia tse, à l'aube, le roi $O u$ arriva le matin dans la plaine de Mou (178) qui était dans le voisinage de Chang $(\underline{179})$; alors il fit une harangue. Le roi $\bullet_{229} \mathrm{Ou}$, s'appuyant de la main gauche sur la grande hache jaune et de la main droite brandissant le fanion blanc afin de donner un signal $(\underline{180})$, s'écria :

— Vous êtes venus bien loin, ô hommes de la terre d'Occident !

Le roi $O u$ dit :

- O vous, mes chefs illustres qui possédez des royaumes $(\underline{181})$, directeurs de lintérieur, de la guerre et des travaux publics $(\underline{182})$, grands dignitaires $(\underline{183})$, officiers des gardes $(\underline{184})$, capitaines de mille soldats et capitaines de cent soldats, et vous, hommes des pays de Yong, de Chou, de Kiang, de ${ }_{230}$ Meou, de Wei, de Lou, de P'ong et de Pou $\left(\frac{185}{)}\right.$, haussez vos piques, réunissez vos boucliers, dressez vos lances, j'ai à vous parler ! 
Le roi dit :

- Les anciens avaient ce proverbe : La poule ne chante pas le matin ; si la poule chante le matin, c'est la ruine de la maison $(\underline{186})$. Maintenant, le $\bullet_{231}$ souverain de la dynastie $Y n$, Tcheou $(\underline{187})$, ne prête plus d'atten tion qu'aux paroles de sa femme. Il a lui-même rejeté les sacrifices disposés $\left(\frac{188}{)}\right)$ en l'honneur de ses ancêtres et ne répond pas $(\underline{189})$ (aux bienfaits de ces derniers); dans sa stupidité, il a repoussé les princes de sa famille ; il a négligé ses oncles et ses frères $(\underline{190})$ et ne les a pas nommés à des fonctions. Ceux-là seulement qui viennent des quatre bouts (du monde) chargés de crimes et fugitifs $(\underline{191})$, ce sont ceux-là qu'il honore, ce sont ce ux-là qu'il élève, ce sont ceux -là en qui il se confie, ce sont ceux-là quill emploie ; de la sorte, ils exercent leurs cruautés sur les cent familles; ainsi, ils se conduisent en ennemis et en traîtres $(\underline{192})$ dans le royaume de Chang. Maintenant moi, $F a$, je ne fais qu'exécuter avec respect le châtiment céleste. Pour ce qui est de l'affaire d'aujourd'hui, ne faites que six pas ou sept pas (à la fois), puis arrêtez-vous pour reprendre vos rangs. Hommes braves, faites tous vos efforts! Ne dépassez pas quatre coups, cinq coups, six $\bullet_{232}$ coups ou sept coups $(\underline{193})$, puis arrêtez-vous pour reprendre vos rangs. Faites tous vos efforts, hommes braves ! Prenez un air terrible $(\underline{194})$ ! soyez comme des tigres et comme des ours rayés, corme des loups et comme des dragons $\left(\frac{195}{)}\right)$. Avancez dans la banlieue de Chang $(\underline{196})$; n'empêchez pas que (les soldats de Tcheou) puissent fuir $\left(\frac{197}{)}\right.$, afin qu'ils deviennent les serviteurs de notre terre d'Occident. Faites tous vos efforts, hommes braves ! D'ailleurs, si vous ne faites pas tous vos efforts, vous attirerez sur vous la mort. »] Ainsi se termina la harangue.

- ${ }_{233}$ Les soldats des seigneurs qui s'étaient réunis comp taient quatre mille chars de guerre ; [ils se rangèrent en bataille dans la campagne de Mou (198).] L'empereur Tcheou, ayant appris la venue du roi $\mathrm{Ou}$, envoya de son côté sept cent mille soldats pour les opposer au roi $\mathrm{Ou}$. [• Le roi $\mathrm{Ou}$ ordonna au grand précepteur $(199)$ de prendre avec lui cent guerriers pour provoquer les troupes $(\underline{200})$; avec ses grands bataillons $(\underline{201})$, il se précipita sur les soldats de l'em pereur Tcheou ;] quoique les soldats de Tcheou fussent en grand nombre, aucun d'eux n'avait le désir de $\bullet{ }_{234}$ combattre ; mais ils souhaitaient que le roi $O u$ entrât promptement (dans le pays). Les soldats de Tcheou tournèrent tous leurs armes en arrière pour combattre $(\underline{202})$ et ainsi ils livrèrent passage au roi $\mathrm{Ou}$. Le roi $\mathrm{Ou}$ s'élança sur eux ; les soldats de Tcheou furent tous mis en déroute et firent défection à Tcheou. [Tcheou s'enfuit et s'en revint dans (sa ville); il monta sur la Terrasse du Cerf $(\underline{203})$; il se couvrit et se para de ses perles et de ses jades, puis il se brûla dans le feu et mourut. Le roi $O u$ saisit le grand étendard blanc afin de donner un signal aux seigneurs; les seigneurs vinrent tous se prosterner devant le roi $O u$ et celui-ci alors les salua.] Les seigneurs suivirent tous le roi $\mathrm{Ou}$ et ils arrivèrent dans le royaume de Chang. [Le peuple tout entier du royaume de Chang les attendait hors de la ville; alors le roi $O u$ envoya la foule de ses officiers parler au peuple de Chang en ces termes :

«Le Ciel suprême a fait descendre la prospérité. 
Les gens de Chang se prosternèrent par deux fois et touchèrent du front la terre. Le roi $O u$ répondit à son tour par une prosternation $(\underline{204})$.

Puis il pénétra dans le lieu où Tcheou était mort. Le roi $O u$ tira en personne de l'arc sur lui (le cadavre de Tcheou); il lança trois flèches; ensuite il descendit de $\bullet_{235}$ son char; avec son poignard $(\underline{205})$, il le frappa; avec la grande hache jaune il coupa la tête de Tcheou; il la suspendit au grand étendard blanc. Puis il alla auprès des deux femmes favorites de Tcheou $(\underline{206})$; toutes deux s'étaient tuées en s'étranglant ; le roi $O u$ tira encore trois flèches, les frappa de son épée et les décapita avec la grande hache noire ; il suspendit leurs têtes au petit étendard blanc. Quand le roi $O u$ eut fini, il sortit et regagna l'armée.

Le lendemain, il fit déblayer la route et réparer l'(au tel du) dieu de la terre ainsi que le palais de Tcheou (de la dynastie) Chang. Lorsque le moment fut venu, cent hommes portaient les étendards han (207) pour faire faire place devant lui. Le frère cadet du roi $O u$, le fils puîné Tchen-to $(\underline{208})$ présentait avec ordre le char de cérémonie ; le duc de Tcheou, Tan, avait en main la grande hache ; le duc de $P i(\underline{209})$ avait en main la petite hache ; ils se tenaient ainsi aux côtés du roi. San I-cheng, T'ai Tien et Hong Yao (1ㅡ) tenaient tous des épées ; ils faisaient ainsi une garde au roi $O u$. Puis ils entrèrent et se tinrent debout - ${ }_{236}$ au sud (de l'autel) du dieu de la terre. Tous ceux des grands bataillons, à droite et à gauche, le suivaient. Mao Tcheng le puîné offrait l'eau pure (211) ; Kang le puîné, (prince de) Wei (1ㅡ), avait l'enveloppe de toile et la natte ; le

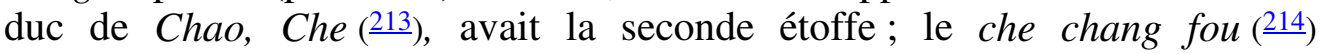
conduisait la victime; Yn I tira les sorts et prononça la prière $(\underline{215})$ en ces termes :

- Le dernier descendant des Yn, Tcheou, le plus jeune de tous, détruisait et perdait la brillante vertu des anciens rois ; il méprisait et négligeait les dieux du ciel et les dieux du sol ; il ne faisait pas les sacrifices; dans sa stupidité, il était cruel pour le peuple du royaume de Chang. Que cela soit clairement et manifestement entendu par le Souverain céleste, Empereur d'en haut (216).]

- 237 Alors le roi $O u$ se prosterna deux fois et baissa la tête jusqu’à terre. (Le prieur) dit $(\underline{217})$ :

- Il faut changer le grand mandat, dégrader les $Y n$ et recevoir le glorieux mandat du Ciel.

[Le roi $O u$ se prosterna derechef deux fois et baissa la tête jusqu'à terre, puis sortit.

Il donna en fief à Lou-fou ( $(18)$, fils de Tcheou (de la dynastie) Chang, ce qui restait du peuple des $Y n$. Le roi $O u$, considérant que (le peuple des) $Y n$ venait à l'instant d'être calmé et n'était pas encore réuni, chargea donc ses frères cadets le puîné Sien, prince de Koan, et le puîné Tou, prince de Ts'ai ( $\underline{219}$ ), d'aider Lou-fou à gouverner (le peuple des) Yn. 
Quand ce fut fini, il ordonna au duc de Chao de délivrer le vicomte de $K i$ de prison; il ordonna au duc de $P i$ de délivrer ceux du peuple qui étaient emprisonnés ; il honora la porte du village de Chang Yong $(\underline{220})$; il ordonna à Nan-kong Коио (221) de répandre les richesses de la Terrasse du Cerf (르) et de distribuer le grain de $\bullet_{238}$ Kiu-kiao $(\underline{223})$, afin de secourir les gens $(\underline{224})$ pauvres et misérables; il ordonna à Nan-kong Kouo et au clerc $I(\underline{225})$ d'exposer les neuf trépieds et les joyaux protecteurs $(\underline{226})$; il ordonna à Hong Yao d'élever un tertre sur la tombe de Pi-kan; il ordonna au prieur ancestral de faire les offrandes aux morts dans le camp. (227)] Puis il licencia ses troupes et revint dans l'ouest; il parcourut les fiefs. Pour rappeler les événements de son expédition, on fit la « Réussite de la guerre » $(\underline{228})$.

(Le roi $\mathrm{Ou}$ ) conféra des fiefs aux seigneurs - il distribua en présent les vases ancestraux $(\underline{229})$; on fit le «Partage des ustensiles et des objets que possédaient les $Y n$. $(\underline{230}) »$

Le roi $O u$ eut une pensée rétrospective pour les anciens rois sages ; il éleva donc le descendant de Chen-nong en lui donnant un fief à Tsiao (231) ; (il conféra) au $\bullet_{239}$ descendant de Hoang-ti le fief de Tchou (232), au descendant de l'empereur Yao le fief de $K i(\underline{233})$, au descendant de l'empereur Choen le fief de Tch'en (234), au descendant de $Y u$ le Grand le fief de $K^{\prime} i(\underline{235})$. Puis il donna des fiefs aux ministres qui avaient fait des actions d'éclat et à ceux qui avaient donné des avis ; or, le précepteur, le vénérable Chang $(\underline{236})$, fut le premier à recevoir un fief ; (le roi $\mathrm{Ou}$ ) donna Yng-k’ieou en fief au vénérable Chang et (ce pays) s'appela $T s^{\prime} i(\underline{237})$; il donna $K^{\prime} i u-f e o u$ en fief à son frère cadet, le duc de Tcheou, Tan, et (ce pays) s'appela Lou $(\underline{238})$; il donna en fief au duc de Chao, Che, (le pays de) Yen $(\underline{239})$; il donna en fief $\bullet_{240}$ à son frère cadet, le puîné Sien, (le pays de) Koan $(\underline{240})$ et à son frère cadet, le puîné Tou, (le pays de) $T$ s'ai $(\underline{241})$. Les autres reçurent des fiefs chacun à son tour.

[ $(\underline{242})$ Le roi $O u(\underline{243})$ convoqua les chefs (appelés) les neuf pasteurs $(\underline{244})$; il monta sur la colline de $\operatorname{Pin}(\underline{245})$ afin de regarder $\bullet_{241}$ de loin le pays $(\underline{246})$ de Chang. Le roi $O u$ étant arrivé à Tcheou $(\underline{247})$, de toute la nuit ne se couchait pas. Le duc de Tcheou, Tan, tint donc ce langage au roi :

- Pourquoi ne vous couchez-vous pas ?

Le roi dit :

— Je vous l'expliquerai : il est de fait que le Cïel n'agréait pas les offrandes des Yn; depuis le moment où moi, $F a$, je n'étais pas encore né $(\underline{248})$, jusqu'à aujourd'hui, pendant ces soixant e années, des cerfs de grande taille ont apparu dans la banlieue, des vols d'oies sauvages remplissaient la campagne $(\underline{249})$; le Ciel n'avait pas pour agréables les $Y n$ et maintenant j'ai réussi. Mais, quand le Ciel a établi les $Y n$, il a élevé (en même temps) trois cent soixante hommes renommés ; c'est pourquoi les $Y n$ n'avaient pas un grand éclat, mais n’étaient pas non plus chassés et $\bullet_{242}$ détruits $(\underline{250})$. Jusqu'à maintenant je n'ai point encore (251) été assuré de la protection du Ciel ; comment aurais-je le loisir de me coucher? 
Le roi dit :

- M'assurer la protection céleste, m’appuyer sur la résidence céleste $(\underline{252})$, rechercher partout les hommes méchants pour les punir comme (j'ai puni) le roi (de le dynastie) Yn, Cheou ( $\underline{253})$, voilà ce à quoi jour et nuit je m'appliquerai, (maintenant que je suis) venu dans ma terre d'Occident. Je dois briller dans mes actions et ma vertu doit resplendir de tous côtés $(\underline{254})$. - Depuis le tournant de la rivière $L o$ jusqu'au ${ }_{243}$ tournant de la rivière $I(\underline{255})$, c'est une résidence commode et sans lieux difficiles; c'était la résidence des Hia (256). Au sud, j’ai considéré au loin (le pays de) San-t'ou (ㄷ7) ; au nord, j'ai considéré au loin les pays à la fron tière des montagnes $(\underline{258})$; j'ai observé et regardé le pays où se trouve le Fleuve; je constate donc que les rivières $L o$ et $I$ ne sont pas éloignées de la résidence céleste $(\underline{259})](\underline{260})$.

Il traça le plan de la demeure des Tcheou à la ville de $L o(\underline{261})$ et ensuite il s'en alla.

Il mit ses chevaux en liberté au sud de la montagne Hoa; il fit paître ses boufs sur la colline de Tao-lin $(\underline{262})$. Il ${ }_{244}$ renversa ses boucliers et ses lances ; il arrêta $(\underline{263})$ ses soldats et licencia ses troupes, montrant (ainsi) à l'empire qu'il ne s'en servirait plus $(\underline{264})$.

Deux ans après que le roi $O u$ eut terminé sa victoire sur les $Y n$, il demanda au vicomte de $K i$ quelles étaient les causes pour lesquelles les $Y n$ s'étaient perdus. Le vicomte de $K i$ n'était pas disposé à parler des vices des $Y n\left(\frac{265}{)}\right.$; il discourut sur la conservation et sur la ruine et sur ce qui est avantageux à un royaume ; le roi $\mathrm{Ou}$ de son côté fut honteux (de sa question) et c'est pourquoi il l'interrogea sur la voie que suit le Ciel $(\underline{266})$.

Le roi $O u$ tomba malade; l'empire n'était pas encore réuni (sous sa domination); tous les hauts dignitaires eurent peur; avec respect ils consultèrent les sorts ; alors le duc de Tcheou se purifia pour écarter le mal ; il s'offrit en victime et souhaita d'être substitué au roi $\mathrm{Ou}$. Le roi $\mathrm{Ou}$ guérit $(\underline{267})$.

Plus tard, il mourut. L'héritier présomptif, Song, prit $\bullet_{245}$ le pouvoir à sa place ; ce fut le roi Tch'eng. Le roi Tch'eng était jeune et les Tcheou venaient seulement de s'assurer l'empire ; le duc de Tcheou, craignant une révolte des seigneurs, prit donc en main la régence et gouverna l'État. Ses frères cadets, parmi lesquels le puîné prince de Koan et le puîné prince de Ts'ai $(\underline{268})$, mirent le duc de Tcheou en suspicion $(\underline{269})$; ils s'unirent à Ou-keng pour faire un soulèvement et se révolter contre les Tcheou. Le duc de Tcheou reçut avec respect les ordres du roi Tch'eng ; il réprima et mit à mort Ou-keng et le puîné prince de Koan ; il exila le puîné prince de T'sai ; il mit le vicomte de Wei, $K^{\prime} a i(\underline{270})$, à la place du descendant des $Y n$ et sa capitale fut à Song (271) ; il réunit ce qui restait $\bullet_{246}$ encore du peuple des $Y n$ et le donna en apanage au frère cadet du roi $\mathrm{Ou}$, Fong, qui fut appelé le puîné (prince de) K'ang (et seigneur de) Wei (그). 
Le puiné prince de T'ang ( $\underline{273})$ (et ancêtre des ducs de) Tsin trouva une céréale de bon augure $(\underline{274})$; il l'offrit au roi Tch'eng. Celui-ci la remit au duc de Tcheou au lieu où se trouvait l'armée ; le duc de Tcheou reçut l'épi dans la terre orientale : il exposa ( $(\underline{275})$ l'ordre donné par le Fils du ciel.

Auparavant, quand (le prince de) Koan et (le prince de) Ts'ai s'étaient révoltés contre les Tcheou, le duc de Tcheou les punit et en trois ans il acheva la pacification; c'est ainsi que furent composés d'abord la « Grande • 247 proclamation », ensuite la «Charge donnée au vicomte de Wei», ensuite l'« Épi offert», ensuite l'« Épi de bon augure », ensuite la « Proclamation à K'ang », ensuite la "Proclamation au sujet du vin», ensuite le « Bois de catalpa (276) ». Ces choses se trouvent dans le chapitre sur le duc de Tcheou (277).

Quand le duc de Tcheou eut exercé le gouvernement pendant sept années, le roi Tch'eng se trouva grand et le duc de Tcheou rendit le gouvernement au roi Tch'eng ; il se tourna vers le nord $(\underline{278})$ et se mit à la place des sujets.

- Le roi Tch'eng, se trouvant à Fong $(\underline{279})$, chargea le duc de Chao de reprendre la construction de la ville de $L o$ pour se conformer à la pensée du roi $\mathrm{Ou}(\underline{280})$; le duc de Tcheou consulta de nouveau les sorts et réitéra son examen ; en définitive il bâtit (la ville) et y plaça les neuf trépieds ; il dit :

- Ce lieu est le centre de l'empire ; pour y apporter le tribut des quatre côtés, les $l i$ de la route sont uniformes $(\underline{281})$.

On composa la «Proclamation de Chao » et la «Proclamation relative à $L o$ ». Le roi Tch'eng ${ }_{248}$ transporta alors (là) le reste du peuple des $Y n(\underline{282})$; le duc de Tcheou annonça les ordres du roi ; il fit les «Officiers nombreux » et le « Contre les excès ».

[ (283) Le duc de Chao fut le Protecteur et le duc de Tcheou fut le Précepteur.

A l'est, (le roi) punit les barbares de la rivière Hoai $(\underline{284})$; il détruisit (le pays de) Yen et transporta son prince à Pouo-kou (285).

Le roi Tch'eng revint de Yen (286) et se trouvant au Tcheou ancestral (287) il fit les « Nombreuses régions ».

Quand il eut dégradé les $Y n$ en leur enlevant leur mandat et quand il eut attaqué à l'improviste les barbares de la rivière Hoai, il revint à Fong et fit les » Fonctionnaires des Tcheou. »]

- ${ }_{249}$ Les rites et la musique fleurirent et furent corrects ; les mesures et les règles furent alors changées. Le peuple vécut donc dans l'harmonie et la concorde; le son des odes s'éleva.

[ ( $(288)$ Quand le roi Tch'eng eut puni les barbares de l'est, les Si-tchen ( $\left.{ }^{289}\right)$ vinrent le féliciter ; le roi récompensa le comte de $Y n g(\underline{290})$; on fit l'» Ordre de récompenser les Si-tchen».

Quand le roi Tch'eng fut sur le point de mourir,] il craignit que l'héritier présomptif, Tchao, ne fût pas capable de remplir sa charge ; [il ordonna donc 
au duc de Chao et au duc de $P i$ de prendre la direction des seigneurs et d'aider] l'héritier présomptif ; puis il lui donna le pouvoir. Quand le roi Tch'eng fut mort, les deux ducs prirent la direction des seigneurs; ils menèrent l'héritier présomptif Tchao rendre visite au temple des rois ses ancêtres et lui exposèrent en détail les difficultés qu'avaient eues les rois Wen et $\mathrm{Ou}$ à faire leur métier de roi ; (ils lui montrèrent que) l'essentiel était d'être modéré, de n'avoir pas beaucoup de désirs ; avec sincérité et bonne foi (ils lui donnèrent) les instructions dernières (du roi Tch'eng); ainsi fut composé l'» Ordre prononcé au moment de mourir » (이).

L'héritier présomptif, Tchao, prit alors le pouvoir ce fut le roi K'ang. Quand le roi K'ang fut sur le trône, il fit une proclamation à tous les seigneurs et leur $\bullet_{250}$ exposa quelle avait été l'auvre des rois Wen et $\mathrm{Ou}$ afin qu'on la continuât; il fit la «Proclamation de K'ang ». C'est pourquoi, au temps des rois Tch'eng et $K$ 'ang, l'em pire jouit du calme et les dispositions (292) relatives aux châtiments pendant plus de quarante années n'eurent pas à être mises en vigueur.

Le roi K'ang donna un ordre par écrit pour que le duc de $P i$ répartît les résidences et administrât le pays-frontière de Tch'eng-tcheou $(\underline{293})$. Il fit l'» Ordre donné à $\mathrm{Pi}$ » .

- Le roi K'ang mourut ; son fils $H i a$, (qui fut le) roi T'chao, prit le pouvoir. Au temps du roi Tchao, la conduite royale devint faible et défectueuse; le roi Tchao alla au sud parcourir les fiefs ; il ne revint pas et mourut sur les bords du Kiang $(\underline{294})$; ses soldats ne revinrent pas l'annoncer et gardèrent le silence à ce sujet.

On donna le pouvoir à Man, fils du roi Tchao ; ce fut le roi Mou. Quand le roi $M o u$ monta sur le trône, il avait déjà cinquante ans. La conduite royale s'était pervertie et affaiblie ; - le roi $M o u$, affligé de ce qu'on manquait à la conduite des rois Wen et $\mathrm{Ou}$, ordonna à Po-kiong de réitérer les règles et d'être le grand conducteur du $\bullet_{251}$ gouvernement de l'État $(\underline{295})$. Ainsi fut composé l'« Ordre donné à Kiong ». Le calme se rétablit.

[ ( $\left.{ }^{296}\right)$ Le roi Mou voulut châtier les K'iuen Jong (297). Meou-fou, duc de Tchai ( $\left.{ }^{298}\right)$, le blâma, disant :

- Il ne faut pas agir $\bullet_{252}$ ainsi. Les rois vos prédécesseurs rendaient éclatante leur vertu et ne faisaient point parade de leurs soldats. Aussi les rassemblements de soldats n'étaient-ils mis en mouvement qu'au moment voulu ; mais, lorsqu'ils étaient mis en mouvement, ils inspiraient la terreur tandis que lorsqu'on en fait parade, ils ne sont qu'un amu sement; or un amusement n'est pas redoutable. C'est pourquoi l'ode composée par le duc Wen $(\underline{299})$, de Tcheou, dit :

O h ! rassemblez les boucliers et les lances;

o h !m ettez dans leurs étuis les arcs et les flèches.

Je recherche la belle vertu. 
Pour déployer cette grandeur $\left(\frac{300}{)}\right)$,

En vérité, moi le roi, je la préserverai(이) (c'est-à-dire la

vertu).

« ${ }_{253}$ Les rois vos prédécesseurs donnaient tous leurs soins au peuple; ils faisaient prospérer et rectifiaient sa vertu et ils amélioraient sa nature ; ils augmentaient l'usage des richesses $(\underline{302})$ et rendaient profitable l'utilité des instruments ; ils lui montraient où était son avantage et où était son désavantage. Par la paix ( $\underline{303}$ ) ils l'amélioraient et lui ${ }_{254}$ apprenaient à s'occuper de ce qui lui était profitable, à éviter ce qui lui était nuisible, à chérir la vertu et à craindre ce qui est majestueux. ils savaient donc protéger les hommes de façon à (assurer) l'augmentation et l'agrandissement $\left(\frac{304}{)}\right) \cdot$ Autrefois nos anciens rois remplirent la charge héréditaire de surintendant des céréales $(\underline{305})$, et servirent en cette qualité Yu (Choen) et les Hia. Puis les Hia se pervertirent; ils méprisèrent les céréales et ne s'en occupèrent plus. C'est pourquoi notre ancien roi Pou-tchou $(\underline{306})$ perdit sa charge et s'alla réfugier chez les Jong et les $T i$; mais il n'osa point négliger ses travaux et, suivant l'ordre des saisons, il exerça ses talents; il continua à mettre en honneur ce qui lui avait été légué ; il observa ces instructions et ces règles; matin et soir il s'y conformait avec respect; il les pratiquait avec sincérité et constance ; il les suivait avec fidélité et confiance. Les générations qui lui succédèrent furent aussi vertueuses et ne furent pas indignes de leurs ancêtres. Lorsque arrivèrent le roi Wen et le roi $O u$, ils brillèrent du même éclat que leurs ancêtres et eurent en outre l'affabilité et la cordialité. Ils honorèrent les dieux et protégèrent le peuple ; il n'y eut personne qui ne fût satisfait et joyeux. Le souverain de la dynastie Chang, ${ }_{255}$ l'empereur $\operatorname{Sin}(\underline{307})$, était fort mauvais pour le peuple ; la foule du peuple ne pouvait le souffrir et mettait toutes ses joies et ses espérances dans le roi $\mathrm{Ou}$. C'est pour quoi il amena ses soldats dans (la plaine de) Mou, (dans le pays des) Chang. Ainsi le roi votre prédécesseur ne prenait pas intérêt à la guerre ; il avait seulement pitié des aspirations secrètes du peuple et arracha le fléau (dont il souffrait).

« D'ailleurs, d'après les règlements des anciens rois, ceux qui sont dans le territoire (du Fils du ciel) sont les vassaux du domaine royal; ceux qui sont en dehors du royaume sont les vassaux seigneuriaux; depuis les seigneurs jusqu'aux protecteurs, ce sont les vassaux qui viennent comme hôtes; les $I$ et les Man sont les vassaux par contrainte; les Jong et les $T i$ sont les vassaux des terres incultes $\left(\frac{308}{}\right)$. Les vassaux du domaine royal ${ }_{256}$ (contribuent aux) sacrifices tsi; les vassaux seigneuriaux (contribuent aux) sacrifices se; les vassaux qui viennent en hôtes (contribuent aux) sacrifices hiang; les vassaux par contrainte (contribuent aux) 
sacrifices kong; les vassaux des pays incultes (contribuent aux sacrifices qui se font à l'avènement du) roi.

«Les sacrifices $t s i$ se font chaque jour; les sacrifices se se font chaque mois; les sacrifices hiang se font à chaque saison; les sacrifices kong se font chaque année ; (c'est lorsque le deuil était) fini (qu'on faisait le sacri fice de l'avènement du) roi. Telle était la règle qu'observaient les anciens rois dans les sacrifices $(\underline{309})$. Lorsque les $\bullet_{257}$ vassaux ne (contribuaient) pas aux sacrifices $t s i$, (le roi) améliorait ses pensées ; lorsque les vassaux ne (contribuaient) pas aux sacrifices se, il améliorait ses paroles, lorsque les vassaux ne (contribuaient) pas aux sacrifices hiang, il améliorait ses écrits ; lorsque les vassaux ne (contribuaient) pas aux sacrifices kong, il améliorait sa renommée; lorsque les vassaux ne (contribuaient) pas (au sacrifice de l'avènement du) roi, il améliorait sa vertu $(\underline{310})$. $\mathrm{Si}$, lorsque cette gradation avait été observée, des vassaux ne venaient point encore, (le roi) recourait aux punitions. Il châtiait donc ceux qui ne (contribuaient) pas aux sacrifices $t s i$; il réprimait ceux qui ne (contribuaient) pas aux sacrifices se; il corrigeait ceux qui ne (contribuaient) pas aux sacrifices hiang; il faisait des reproches à ceux qui ne (contribuaient) pas aux sacrifices kong; il avertissait ceux qui ne (contribuaient) pas au sacrifice (fait à l'avènement du) roi. Il avait donc, pour châtier par les punitions, des supplices; pour réprimer $\bullet_{258}$ par l'attaque, des armes de guerre ; pour corriger avec vigueur, des préparatifs ; pour faire des reproches avec autorité, des injonctions; pour avertir avec douceur, des explications. Lorsqu'il avait publié ses ordres et exposé ses explications (ㄴ1ㄱ), s'il y avait (des vassaux) qui ne ve naient pas, il améliorait derechef sa vertu, mais n'en voyait pas son peuple souffrir dans des contrées éloignées. De cette manière il n'était personne qui ne lui obéît au près, personne qui ne lui fût soumis au loin. Maintenant, depuis la mort de Ta-pi et de Po-che $(\underline{312})$, les K'iuen Jong sont toujours, suivant leur devoir, venus aux sacrifices (faits aux avènements de) rois. Le Fils du ciel dit : «Certainement je les corrigerai parce quils ne viennent pas aux sacrifices hiang $(\underline{313})$ ! » Bien plus, il fait parade de ses soldats. N'est-ce pas là rejeter les instructions des anciens rois $(\underline{314})$ ? Or je crains que Votre Majesté n'en retire du dommage. J'ai appris que Chou-toen, (chef des) K'iuen Jong ( $\underline{315}$ ), pratiquait les vertus de ses ancêtres et $\bullet_{259}$ qu'il défendait l'intégrité (de son territoire avec obstination et fermeté. Il est capable de nous résister. »

Le roi partit aussitôt pour corriger (les Kiuen Jong); à son retour, il rapporta quatre loups blancs et quatre cerfs blancs. A partir de ce moment, les vassaux des pays incultes ne vinrent plus à la cour $(\underline{316})$.] (1ㅡㄹ 
Parmi les seigneurs, il y en avait qui ne maintenaient pas la concorde. Le marquis de Fou parla avec le roi et ainsi fut composée la «Réforme des peines et des supplices $\gg(\underline{318})$.

[ $(\underline{319})$ Le roi dit :

- Hé, venez, vous qui gouvernez les hommes $\bullet_{260}$ et les terres $(\underline{320})$ ! Je vous dirai comment on rend les châtiments bienfaisants $(\underline{321})$. Si maintenant (vous voulez) maintenir l'ordre dans les cent familles, qui choisir avec soin $\bullet_{261}$ sinon les hommes capables ? à quoi faire attention sinon aux châtiments convenables ? à quoi s'arrêter sinon à ce qui est profitable ? Lorsque les deux parties sont venues entièrement prêtes (devant le tribunal), les juges décident d'après les cinq témoignages $(\underline{322})$; lorsque les cinq témoignages assurent la culpabilité $(\underline{323})$ et sont évidents, ${ }_{262}$ (les juges) règlent le cas au moyen des cinq châtiments. Si les cinq châtiments ne sont pas véritablement (mérités $(\underline{324})$ ), ils règlent le cas au moyen des cinq amendes. Si les cinq amendes ne conviennent pas, ils règlent le cas en le faisant rentrer dans les cinq erreurs $(\underline{325})$. Il est mal d'invoquer les cinq erreurs soit parce que la cause implique des fonctionnaires, soit parce que la cause implique des femmes $(\underline{326})$; recherchez en toute sincérité quelle est la faute et ne la faites rentrer dans les erreurs qu'à juste titre $\left(\frac{327}{}\right)$. Lorsqu'il est douteux que les cinq châtiments (soient mérités), il faut en faire grâce ; lorsqu'il est dou teux que les cinq amendes (soient méritées), il faut en faire grâce. Que l'exame n du cas soit décisif! Même quand plusieurs points sont certains et évidents, cependant il faut que le juge instructeur fasse son examen ; lorsque (le juge) est convaincu sans que la certitude soit établie $(\underline{328})$, il a toujours à craindre la rigueur du Ciel. $\bullet_{263}$ Lorsqu'il est douteux que la peine de la marque (soit méritée) et qu'on en fait grâce, l'amende sera de cent choa $(\underline{329})$; recherchez en toute sincérité quelle est la faute - Lorsqu'il est douteux que la peine de l'ablation du nez soit méritée et qu'on en fait grâce, l'amende sera du double ou du quintuple $(\underline{330})$; recherchez en toute sincérité quelle est $\bullet_{264}$ la faute. Lorsqu'il est douteux que la peine de l'ablati on des rotules $(\underline{331})$, soit méritée et qu'on en fait grâce, l'amende sera du double moins un tiers $(\underline{332})$; recherchez en toute sincérité quelle est la faute. Lorsqu'il est douteux que la peine de la castration $(\underline{33})$ soit méritée et qu'on en fait grâce, l'amende sera de cinq cents choa $(\underline{344})$; recherchez en toute sincérité quelle est la faute. Lorsqu'il est douteux que la peine capitale soit mérité e et qu'on en fait grâce, l'amende sera de mille choa; recherchez en toute sincérité quelle est la faute. — Les gens dont le crime mérite la marque sont dans la proportion de mille ; ceux dont le crime mérite l'ablation du nez sont dans la proportion de mille ; ceux dont le crime mérite l'ablation des rotules sont dans Ia proportion de cinq 
cents; ceux dont le crime mérite la castration sont dans la proportion de trois cents; ceux dont le crime mérite la peine capitale sont dans la $\bullet_{265}$ proportion de deux cents, le nombre total de ceux qui se rendent passibles des cinq châtiments étant ainsi de trois mille $(\underline{335})$.]

Le nom (de cette réglementation) fut : le Code criminel de Fou ( $\left.\frac{336}{}\right)$.

Le roi $M o u$ fut au pouvoir cinquante-cinq années ( $(\underline{37})$, puis mourut.

Son fils, I-hou, qui fut le roi Kong, prit le pouvoir.

[ $(\underline{338}) \bullet$ Le roi Kong alla se promener sur les bords de la rivière King $(\underline{339})$. Le duc $K$ 'ang, de $M i(\underline{340})$, l'accompagnait. ${ }_{266}$ Trois femmes l'avaient épousé contrairement aux rites $(\underline{341})$. Sa mère lui dit :

- Il vous faut remettre ces femmes au roi. En effet, trois animaux forment un troupeau ; trois personnes forment une assemblée ; trois femmes forment un luxe $(\underline{342})$. Lorsque le roi va chasser, il ne s'empare ${ }_{267}$ pas d'un troupeau $\left(\frac{343}{3}\right)$; lorsqu'un duc agit, il ne soumet pas (sa décision) à une assemblée $(\underline{344})$; lorsque le roi prend des concubines $(\underline{345})$, il ne choisit pas trois femmes du même clan $(\underline{346})$. Or le luxe est une chose magnifique ; cette assemblée, qui constitue une chose magnifique, vous est revenue $(\underline{347})$; comment auriez-vous qualité pour en être digne ? Si le roi même n'en est pas digne, à combien plus forte raison ne l'êtes -vous pas, vous, petit avorton. Si vous, petit avorton, vivez avec faste, vous finirez par périr.

Le duc K'ang ne donna pas (les femmes au roi); un an plus tard le roi Kong détruisit l'État de $M i$.]

- ${ }_{268}$ Le roi Kong mourut.

Son fils Kien, qui fut le roi $I$, prit le pouvoir $\left(\frac{348}{)}\right)$. Au temps du roi $I$, la maison royale déclina rapidement; les poètes firent des satires $(\underline{349})$. Le roi $I$ mourut.

$P i$-fang, frère cadet du roi Kong, prit le pouvoir. Ce fut le roi Hiao. Le roi Hiao mourut.

Les seigneurs reportèrent alors leur choix sur Sié, ,qui était le fils aîné du roi $I$; ce fut le roi $I\left(\frac{350}{}\right)$. Le roi $I$ mourut.

Son fils $\mathrm{Hou}$, qui fut le roi $\mathrm{Li}$, prit le pouvoir. Après trente ans de règne, le roi $L i$ devint avide de richesses et éleva en dignité le duc I, de Yng (ㅎ1).

[ ( $\left(\frac{352}{)}\right)$ Le grand dignitaire Leang-fou, (comte de) Joei $(\underline{353})$, blâma le roi $L i$ en lui disant $(\underline{354})$ :

— - La maison royale court à sa $\bullet_{269}$ perte. En effet, le duc de Yng aime accaparer les richesses et il ne sait pas quelles graves difficultés (s'ensui vront). L'utilité est ce que produisent tous les 
êtres, (qui eux-mêmes) sont soutenus par le ciel et par la terre. Si l'on vient à l'accaparer, c'est une cause de maux nom breux. Les cent espèces d'êtres qui dépendent du ciel et de la terre, tous (les hommes) $(\underline{355})$ veulent les prendre ; comment pourrait-on les accaparer? ceux qu'on irrite rait seraient fort nombreux et comment ne préparerait-on pas ainsi de graves difficultés ? • C'est pourquoi j'aver tis Votre Altesse, car comment pourrait-elle mener longtemps cette conduite ? Celui qui règne sur les hommes doit diriger l'emploi de ce qui est utile et le répartir en haut et en bas de façon à ce que parmi les dieux, les hommes et tous les êtres il n'y en ait aucun qui n'at teigne à sa perfection. Il y fait une attention de tous les jours et craint d'exciter contre lui l'animosité. C'est pourquoi une ode chantée aux sacrifices dit $(\underline{356})$ :

O parfait H eou-tsi $(\underline{357})$ !

Vous avez été digne d'être placé à côté du Ciel( $\left.\frac{358}{2}\right) ; \bullet 270$

Vous avez donné à manger à la foule de notre peuple;

C'est uniquem ent l'effet de votre perfection.

Et dans le Ta ya, il est dit :

Il répandit ses bienfaits de m anière à soutenir les T cheou $\left(\frac{359}{)}\right)$.

«N'est-ce pas la preuve que, s’ils n'avaient pas réparti les avantages, ils (les anciens princes) auraient craint les difficultés ? C'est grâce à ces principes qu'ils ont pu main tenir la (maison) des Tcheou jusqu'à aujourd'hui. Mainte nant Votre Altesse étudie les moyens d'acca parer ce qui est utile ; comment le peut-elle faire ? Un homme du commun, sil s'approprie un objet utile, est déclaré un voleur. Si quelqu'un est roi et qu'il agisse ainsi, il verra peu de sujets lui rester soumis $\left(\frac{360}{2}\right)$. Si le duc de Yng est écouté, les Tcheou sont perdus.]

Le roi $L i$ n'écouta pas ces conseils, mais en définitive, il fit du duc de Yng un haut dignitaire et l'employa dans les affaires. Le roi eut une conduite cruelle et hautaine. ${ }^{271}$ [ $\left(\frac{361}{)}\right)$ Les gens du royaume le blâmèrent $(\underline{362})$. Le duc de Chao $(\underline{363})$ a reprit (le roi) en lui disant :

- Le peuple ne peut supporter son sort $(\underline{364})$.

Le roi se mit en colère et chargea un $\bullet_{272}$ devin $(\underline{365})$ du pays de Wei de découvrir ceux qui le blâmeraient ; ceux qu'il dénonçait étaient aussitôt mis à mort; les critiques furent rares, mais les seigneurs ne vinrent plus à la cour rendre leur hommage. La trente-quatrième année, le roi redoubla de sévérité ; les gens du royaume n'osaient plus parler ; ils se jetaient seulement un regard en passant leur chemin. Le roi $L i$ s'en réjouit et dit au duc de Chao :

- J'ai supprimé toute critique, car on n'ose plus parler.

Le duc de Chao répondit: 
- Vous avez fait un barrage. Mais retenir les bouches du peuple est plus difficile que de retenir les eaux. Lorsque les eaux sont arrêtées, elles débordent et les personnes qui en sont victimes sont en grand nombre. Il en est de même pour le peuple. C'est pourquoi, comme ceux qui s'occupent des eaux leur pratiquent des issues et les laissent s'écouler, ceux qui s'occupent du peuple le libè rent et le laissent parler. Aussi, le Fils du ciel, lorsqu'il gouverne, engage-t-il les fonctionnaires, depuis les ducs du palais $(\underline{366})$ et les hauts fonctionnaires jusqu'aux divers officiers $(\underline{367})$, à lui présenter les poésies, ceux qui n'ont pas d'yeux à lui présenter les pièce s de musique $(\underline{368}), \bullet_{273}$ les annalistes à lui présenter les livres $(\underline{369})$; les maîtres de la musique donnaient les avertissements ; ceux dont les yeux sont privés de pupilles récitaient $(\underline{370})$; ceux dont les yeux ne voient point, quoique ayant des pupilles, chantaient $(\underline{371})$; les cent fonctionnaires $(\underline{372})$ exprimaient leurs critiques. Les gens du commun peuple faisaient transmettre $(\underline{373})$ leurs paroles (au souverain) ; les officiers qui approchaient (le souverain) rectifiaient tous (les abus) ; ses parents réparaient ses fautes et le surveillaient ; ceux qui étaient privés d'yeux et les annal istes l'instrui saient et l'informaient; les hommes de soixante et de cinquante ans le perfectionnaient $\left(\frac{374}{3}\right)$. Alors le roi $\bullet_{274}$ lui-même délibérait. C'est ainsi que dans la conduite des affaires il n'y avait pas d'injustice. Le peuple a des bouches comme la terre a des montagnes et des fleuves d'où viennent les choses dont on se sert, comme elle a des lieux hauts et des lieux bas, des plaines et des marais où se produisent ce dont on shabille et ce dont on se nourrit. Les bouches manifestent les paroles; c'est en elles que se trouve (l'indication de) ce qui est excel lent et de ce qui est funeste ; (grâce à elles), on pratiquera ce qui est excellent et on préviendra ce qui est funeste; c'est ce qu'on entend en les comparant à ce qui produit les choses dont on se sert, ce dont on s'habille et ce dont on se nourrit $\left(\frac{375}{)}\right)$. Quand le peuple a des soucis dans son cour et qu'il les expose par sa bouche, (on peut alors) perfectionner et accomplir (ce qu'il réclame $(\underline{376})$ ). Si on lui ferme la bouche, comment cela pourrait-il durer longtemps $(\underline{377})$ ?

Le roi n'écouta pas ces conseils. Alors personne dans le royaume n'osa parler. Trois ans plus tard,] des gens se liguèrent pour faire une révolte et attaquèrent à l’improviste le roi $L i$. Le roi $\mathrm{Li}$ sortit du royaume) et se réfugia à Tche $\left(\frac{378}{}\right)$.

- ${ }_{275}$ L'héritier présomptif du roi $L i$, Tsing $(\underline{379})$, se cacha dans la maison du duc de Chao. [ $(\underline{380})$ Les gens du pays, l'ayant appris, vinrent cerner la maison. Le duc de Chao leur dit :

- Autrefois j'ai adressé souvent des remontrances au roi, mais le roi n’y a point cédé, ce qui a amen é les difficultés présentes. Si maintenant vous tuez l'héritier présomptif, le roi pensera que je me 
venge et que je suis haineux et irrité. Or celui qui sert un prince, même quand il a été mis en danger, ne doit pas se venger ni être haineux ; même quand il a été affligé, il ne doit pas être irrité. A combien plus forte raison en est-il ainsi quand on sert un roi.

Le duc de Chao substitua donc son propre fils] à l'héritier présomptif et celui-ci put en définitive échapper (au péril).

Les deux conseillers, le duc de Chao et le duc de Tcheou exercèrent le gouvernement. Le nom (de leur régence) fut Kong-ho ( $\underline{381})$.

La quatorzième année Kong-ho (828 av. J.-C.), le roi Li mourut à Tche. L'héritier présomptif, Tsing, avait grandi ${ }_{276}$ dans la maison du duc de Chao ; les deux conseillers le nommèrent alors roi d'un commun accord. Ce fut le roi Siuen. Lorsque le roi Siuen fut au pouvoir, les deux conseillers l'aidèrent et perfectionnèrent son gouvernement; il prit pour règle les principes laissés par les rois Wen, $O u$, Tch'eng et $K^{\prime}$ 'ang. Les seigneurs recommencèrent à respecter les Tcheou.

La douzième année (816 av. J.-C.), le duc Ou, de Lou, vint rendre hommage à la cour $(\underline{382})$.

[ $(\underline{383})$ Le roi Siuen ne pratiqua pas la cérémonie du labourage dans le domaine de mille meou ( $\left(\frac{384}{)}\right)$. Le duc Wen, de Kouo ( $\left(\frac{385}{)}\right)$, l'en blâma, disant :

- Vous ne devez pas agir $\bullet_{277}$ ainsi $\left(\frac{386}{)}\right)$.

Le roi ne l'écouta pas. La trente-neuvième année (789 av. J.-C.), une bataille fut livrée à $T$ s'ien-meou $(\underline{387})$ et les soldats du roi furent complètement défaits par les Jong des tribus Kiang.]

[ $(\underline{388})$ Comme le roi Siuen avait perdu des troupes dans les royaumes du sud $(\underline{389})$, il (voulut) faire le recensement du peuple à T'ai-yuen $\left(\frac{390}{)}\right)$. Tchong Chan-fou (이) l'en blâma, en disant :

— On ne doit pas faire le dénombrement du ${ }_{278}$ peuple( $\left(\frac{392}{2}\right)$.]

Le roi Siuen n'écouta pas ce conseil et fit en définitive le dénombrement du peuple.

Après quarante-six ans de règne (782 av. J.-C.), le roi Siuen mourut $(\underline{393})$.

Son fils, Kong-nié, qui fut, le roi Yeou, prit le pouvoir.

[ $(\underline{394})$ La deuxième année (780 av. J.-C.) du règne du roi Yeou, les trois cours d'eau de la province occidentale $(\underline{395})$ furent soulevés $(\underline{396})$. Po-yang-fou (으) dit :

- - Les Tcheou vont $\bullet_{279}$ périr. (Il importe en effet que) les influences du ciel et de la terre ne perdent pas leur ordre ; si elles y manquent, c'est que le peuple est troublé $\left(\frac{398}{)}\right)$. Lorsque le principe Yang est caché et qu'il ne peut sortir et lorsque le principe $Y n$ l'opprime et qu'il ne peut s'élever $(\underline{399})$, alors il y a un tremblement de terre. Or maintenant les trois cours d'eau ont été réellement 
soulevés; c'est que le Yang a perdu sa place et que le $Y n$ pèse sur lui $(\underline{400})$. Lorsque le Yang a perdu son rang et se trouve (sous) le $Y n$, les sources alors sont fermées ; lorsque les sources sont fermées, le royaume est certainement perdu. Lorsque l'eau et la terre sont dans un état propice, le peuple trouve ce qui lui est nécessaire. Lorsque la terre $(\underline{401})$ n'est pas dans une condition propice, le peuple est privé des choses dont il se sert. Comment espérerait-on éviter la ${ }_{280}$ ruine ? Autrefois le $I$ et le $L o(\underline{402})$ se desséchèrent, et la dynastie des Hia périt. Le Ho se dessécha et la dynastie des Chang $(\underline{403})$ périt. Maintenant la vertu des Tcheou est comme était celle de ces deux dynasties à leur déclin. Les sources de ses rivières sont aussi fermées ; ces sources étant fermées, les rivières se dessèchent. Or un royaume a pour fondement ses montagnes et ses cours d'eau ; lorsque les montagnes s'écroulent et que les cours d'eau se dessèchent, c'es $t$ un présage de la ruine de l'État. Comme les cours d'eau se sont desséchés, les montagues s'écrouleront. Quant à la ruine du royaume, elle arrivera dans un délai de dix ans, car c'est là le cycle des nombres $(\underline{404})$. L'abandon du Ciel se manifeste dans un délai qui ne dépasse pas ce cycle.

En cette année donc, les trois cours d'eau se dessé chèrent et la montagne $K ’ i(\underline{405})$ s'écroula.]

La troisième année de son règne (779 av. J.-C.), le roi Yeou devint fort épris de Pao-se $(\underline{406})$. Pao-se enfanta un fils, Po-fou, et le roi Yeou voulut dégrader l'héritier ${ }_{281}$ présomptif. La mère de l'héritier présomptif était fille du marquis de Chen $\left(\frac{407}{)}\right.$, et était reine. Mais plus tard, lorsque le roi Yeou eut Pao-se et l'aima, il voulut dégrader la reine Chen, renvoyer en même temps l'héritier présomptif I-kieou et nommer Pao-se reine et $\mathrm{Po}$-fou héritier présomptif. Le grand astrologue des Tcheou, Po-yang $(\underline{408})$, ayant lu les mémoires des annalistes $(\underline{409})$, dit :

— Les Tcheou sont perdus.

[ $(\underline{410}) \div-$ Autrefois, lorsque les souverains de la dynastie Hia s'étaient pervertis, il y eut deux dragons divins $(\underline{411})$ qui s'arrêtèrent dans le palais de l'empereur (de la dynastie) Hia, et dirent :

- Nous sommes deux princes $(\underline{412})$ du pays de Pao.

L'empereur (de la dynastie) Hia tira les sorts pour savoir s'il devait les tuer, ou les renvoyer, ou les garder; aucune réponse ne fut favorable. Il tira alors les sorts pour savoir sil devait demander aux dragons de ${ }_{282}$ l'écume (de leur bouche $(\underline{413})$ ) et la conserver ; (la réponse) fut favorable. Alors on étendit une pièce d'étoffe devant les dragons et on leur présenta une prière écrite. Ils se retirèrent et leur écume resta ; elle fut placée dans un coffret qu'on mit à part $\left(\frac{414}{}\right)$. Lorsque les Hia disparurent, on transmit cet objet aux $Y n$; lorsque les $Y n$ disparurent, on transmit derechef cet objet aux Tcheou. - Pendant ces trois dynasties successives il ne se trouva personne qui osât l'ouvrir. Mais à la 
fin du règne du roi $L i\left(\frac{415}{4}\right)$, on l'ou vrit et on regarda. L'écume coula dans le palais et on ne put l'enlever; le roi $L i$ fit venir ses femmes nues pour prononcer des imprécations $(\underline{416})$ contre elle. L'écume se transforma en un lézard (177) noir et sous cette forme elle entra dans le sérail. Dans le sérail, une petite fille, qui était à l'âge où on perd ses dents de lait $(\underline{418})$, la trouva. Lorsqu'elle arriva à l'âge où les jeunes filles mettent $\bullet_{283}$ une épingle à leurs cheveux $(\underline{419})$, elle se trouva enceinte $\left({ }^{420}\right)$. Sans avoir eu de mari, elle enfanta ; saisie de crainte, elle abandonna son enfant $(\underline{421})$. Au temps du roi Siuen, une petite fille chanta, disant :

- Celui qui a un arc fait avec du bois de mûrier sauvage et un carquois fait de roseaux, celui-là certainement perdra le royaume des Tcheou.

Le roi Siuen vint à entendre ces paroles et, comme il y avait un homme et sa femme qui vendaient de tels objets, il envoya des gens pour les arrêter et les mettre à mort. Ils s'enfuirent et dans leur marche ils aperçurent gisant sur le chemin l'enfant qui avait été abandonné par la jeune femme du sérail. Ils l'entendirent crier pendant la nuit; ils en eurent pitié et le recueillirent. L'homme et la femme continuèrent à s'éloigner et se réfugièrent dans le pays de Pao. Les gens du pays de Pao, ayant commis une faute, demandèrent à racheter leur faute en remettant au roi la fille qui avait été abandonnée par la jeune femme ;] c'est ainsi que la fille abandonnée vint du pays de Pao et c'est pourquoi on l'appela $\mathrm{Pao}-\mathrm{Se}(\underline{422})$. C'était alors la troisième année du roi Yeou. Le roi se rendit dans le sérail, y vit (Pao-se) et l'aima. Elle enfanta un fils, Po-fou. En définitive la reine Chen et l'héritier présomptif furent dégradés ; $\mathrm{Pao}$-se fut faite reine et $\bullet_{284} \mathrm{Po}$-fou héritier présomptif. Le grand astrologue Po-yang dit :

— Le malheur est consommé ; il n'y a plus moyen d'y échapper.

- Pao-se ne riait pas volontiers. Le roi Yeou désirait la faire rire ; il eut recours à mille moyens, mais elle ne riait point. Le roi Yeou avait établi un bûcher qu'on pouvait allumer le jour, un bûcher qu'on pouvait allumer la nuit $(\underline{423})$ et un grand tambour. (Comme si) les ennemis étaient arrivés, il alluma le bûcher destiné au jour et les seigneurs accoururent; lorsqu'ils arrivèrent, il n'y avait point d'ennemis. Pao-se rit alors aux éclats. Le roi Yeou en fut aise et plusieurs fois il alluma le bûcher destiné au jour ; mais dans la suite on n'y crut pas et les sei gneurs de leur côté cessèrent les uns après les autres de venir $(\underline{424})$.

Le roi Yeou nomma haut dignitaire Che-fou, prince de Kouo $(\underline{425})$ et lui confia le gouvernement; tous les habitants du royaume s'en indignèrent. Che-fou était habile à tenir des discours trompeurs; il savait flatter et il était âpre au gain. Le roi l'employa ; en outre il dégrada la reine Chen et renvoya l'héritier présomptif. Le marquis $\bullet_{285}$ de Chen $(\underline{426})$, irrité, s'allia au pays de Tseng (427), aux barbares occidentaux et aux Kiuen Jong et attaqua le roi Yeou. Le roi Yeou alluma le bûcher destiné au jour, afin d'appeler les soldats ; les soldats ne vinrent pas. (Les ennemis) tuèrent donc le roi Yeou au pied de la 
montagne $\mathrm{Li}(\underline{428})$, emmenèrent prisonnière Pao-se, s'emparèrent de toutes les richesses des Tcheou, puis se retirèrent.

Alors les seigneurs s'entendirent avec le marquis de Chen pour donner le pouvoir à l'ex-héritier présomptif du roi Yeou, I-kieou, qui fut le roi P'ing, afin qu'il fût chargé des sacrifices des Tcheou $(\underline{429})$. Le roi $P$ 'ing, ayant pris le pouvoir, transféra (sa capitale) du côté de l'est, à la ville de $L o(\underline{430})$, pour se soustraire aux incursions des Jong. Au temps du roi P'ing, la maison des Tcheou déclina et s'affaiblit ; les seigneurs usaient de leur force pour opprimer les faibles. Ts'i, Tch'ou, Ts'in et $T \sin (\underline{431}) \cdot{ }_{286}$ commencèrent à grandir ; le pouvoir fut exercé par celui qui avait l'hégémonie dans sa région $(\underline{432})$. — La quarante-neuvième année (722 av. J.-C.), le duc Yn, de Lou, prit le pouvoir $(\underline{433})$. - Après cinquante et un ans de règne (720 av. J.-C.), le roi P'ing mourut.

L'héritier présomptif, Sié-fou, étant mort prématurément, on mit sur le trône son fils, Lin. Ce fut le roi Hoan. Le roi Hoan était (donc) petit-fils du roi P’ing.

La troisième année (717 av. J.-C.) du roi Hoan, le duc Tchoang, de Tcheng, vint à la cour. Le roi Hoan ne le traita pas avec les rites qui lui étaient dus $(\underline{434})$. - La cinquième année (715 av. J.-C.), (le duc de) Tcheng, irrité $\left({ }^{435}\right)$, fit un échange avec Lou et acquit ainsi le pays de Hiu-tien. Hiu-tien était le lieu dont se servait le Fils du ciel $\bullet_{287}$ pour faire le sacrifice au T'ai-chan $\left({ }^{436}\right)$. — La huitième année (712 av. J.-C.), les gens de Lou assassinèrent le duc Yn et nommèrent le duc Hoan. - La treizième • ${ }_{288}$ année (707 av. J.-C.), (le roi) attaqua Tcheng ; (un homme de) Tcheng blessa d'une flèche le roi Hoan ( 437$)$; celui-ci se retira et opéra sa retraite. - La vingt-troisième année (697 av. J.-C.), le roi Hoan mourut.

Son fils, T'ouo, qui fut le roi Tchoang, prit le pouvoir. La quatrième année (693 av. J.-C.) du roi Tchoang, le duc de Tcheou, Hei-kien (438), projeta de tuer le roi Tchoang et de donner le pouvoir au fils de roi, $K^{\prime} O(\underline{439})$. Sin po en avertit le roi ; celui-ci mit à mort le duc de Tcheou; le fils de roi, $K^{\prime} o$, s'enfuit (dans le pays de) Yen $(\underline{440})$. — La quinzième année (682 av. J.-C.), le roi Tchoang mourut.

Son fils, Hou-ts $i$, qui fut le roi $H i(\underline{441})$, prit le pouvoir. - La troisième année (679 av. J.-C.) du roi $H i$, le duc Hoan, de $T s ' i$, pour la première fois eut l'hégémonie $(\underline{442})$. - La cinquième année (677 av. J.-C.), le roi Hi mourut.

Son fils, Lang, qui fut le roi Hoei, prit le pouvoir. - $\bullet_{289} \mathrm{La}$ deuxième année (675 av. J.-C.) du roi Hoei (arrivèrent les faits suivants) $(\underline{443})$ : autrefois, le roi Tchoang avait fort aimé sa concubine Yao; celle-ci enfanta un fils, T'oei, qui jouit de la faveur royale). Lorsque le roi Hoei prit le pouvoir, il (le roi) s'empara du jardin d'un de ses principaux officiers $(\stackrel{444}{)}$ pour en faire un parc ; c'est pourquoi cinq grands officiers, parmi lesquels était Pien Po, soulevèrent des troubles; ils projetèrent d'appeler les sol dats de Yen et de Wei; ils attaquèrent le roi Hoei ; le roi Hoei s'enfuit à Wen $(\underline{445})$; ensuite il s'établit 
à $L i(446)$, ville du pays de Tcheng. On nomma roi T'oei, frère cadet $\left(\frac{447}{)}\right)$ du roi $H i$; on fit de la musique et on dansa toutes les danses ; ${ }_{290}$ les princes de Tcheng et de Kouo $\left({ }^{448}\right)$ en furent irrités $\left({ }^{449}\right)$. — La quatrième année (673 av. J.-C. les princes de Tcheng et de Kouo attaquèrent et tuèrent le roi T'oei ; ils réintégrèrent le roi Hoei (dans ses États).

La dixième année (667 av. J.-C.) du roi Hoei, celui-ci conféra au duc Hoan, de $T s ` i$ l'hégémonie $(\underline{450})$. — La vingt-cinquième année (652 av. J.-C.), le roi Hoei mourut $(\underline{451})$.

Son fils, Tcheng, qui fut le roi Siang, prit le pouvoir. La mère du roi Siang était morte de bonne heure; sa seconde mère s'appelait la reine (femme du roi) Hoei $\left({ }^{452}\right)$. La reine (femme du roi) Hoei enfanta Chou-tai $(\underline{453})$ qui fut en faveur auprès du roi Hoei; le roi Siang le craignait. — La troisième année (649 av. J.-C.), Chou-tai s'allia aux Jong et aux Ti et projeta d'attaquer le roi Siang. Celui-ci voulut mettre à mort Chou-tai et Chou-tai s'enfuit (dans le pays de) Ts $i$. Le duc Hoan, de Ts $i$, [ ( $\left.{ }^{454}\right)$ envoya $\bullet_{291}$ Koan Tchong $\left({ }^{455}\right)$ pour faire la paix entre les Jong et les Tcheou; il envoya Si P'ong pour faire la paix entre les Jong et les Tsin (456). Le roi honora Koan Tchong avec les rites qui sont dus à un haut dignitaire de premier rang. Koan Tchong s'y refusa, disant :

- Votre sujet est un fonctionnaire infime, Voici Kouo et $\mathrm{Kao}\left({ }^{457}\right)$ qui sont deux surveillants nommés par le Fils du ciel. Si, aux époques fixées, au printemps et en automne, ils viennent pour recevoir les ordres du roi, avec quels rites les traiterez-vous? Moi qui suis doublement sujet $\left(\frac{458}{)}\right.$, je me permets de refuser.

Le roi dit :

- $(\mathrm{O}$ envoyé de $)$ mon beau-père $\left(\frac{459}{)}\right)$; je loue votre mérite. $\mathrm{Ne}$ résistez pas à mon ordre.

En définitive, Koan Tchong accepta les rites qui sont dus à un haut dignitaire de second rang, puis il s'en re tourna].

La neuvième année (643 av. J.-C.), le duc Hoan, de Ts’i, mourut.

La douzième année (640 av. J.-C.), Chou-tai revint à (la cour des) Tcheou ( $(\underline{460})$.

La treizième année (639 av. J. -C.), (le prince de) Tcheng $\bullet_{292}$ attaqua (le prince de) Hoa $(\underline{461})$. Le roi envoya Yeou Suen et Po Fou $(\underline{462})$ pour intercéder en faveur de Hoa; les gens de Tcheng emprisonnèrent ces (messagers); le duc Wen, de Tchen, [ ( $\underline{463})$ était irrité de ce que le roi Hoei, lors de sa rentrée (dans sa capitale), n'avait pas donné un vase tsio $(\underline{464})$ au duc $L i$; il était irrité aussi de ce que le roi Siang s'était mis du parti de Wei et de Hoa] (ㄴ5) ; c'est pourquoi il emprisonna $\mathrm{Po} F o u$. [Le roi en fut irrité et se proposa de se servir des Ti pour attaquer Tcheng. Fou Tchen l'en reprit, disant] :

- En toute occasion, depuis que notre maison des Tcheou s'e st transportée dans l'est, (les princes de) Tsin et de Tcheng ont été nos 
appuis ; • 293 lorsque le prince T'oei s'est révolté, c'est grâce à Tcheng que l'ordre a été rétabli. Maintenant, pour une petite animosité, vous le rejetez ( $(\underline{466})$.

[ ( $(467)$ Le roi n'écouta pas (ces con seils).

- La quinzième année (637 av. J.-C.), le roi fit descendre les soldats des Ti pour attaquer Tcheng. Le roi, par estime pour les services que lui avaient rendus les $T i$, voulut prendre la fille (de leur prince) pour en faire la reine (sa femme). Fou Tchen le reprit, disant] :

- (Les rois) P'ing, Hoan, Tchoang et Hoei ont tous profité de la peine que Tcheng a prise pour eux; que Votre Majesté rejette ses parents et s'apparente aux $T i$, c'est ce qu'on ne peut approuver $(\underline{468})$.

[Le roi n'écouta pas (ces conseils).

La seizième année (636 av. J.-C.), le roi dégrada la reine $T i(\underline{469})$. Les $T i$ vinrent faire du carnage et tuèrent T'an Po $\left(\underline{470}^{4}\right)$. Fou Tchen dit :

- J'ai souvent fait des remontrances qui n'ont point été suivies. Dans ces circonstances, si je ne $\bullet_{294}$ sors pas (pour combattre), le roi estimera que j'agis par haine.

Alors avec tous les siens il alla périr (en combattant contre) eux (les Ti) $(\underline{471})$.

Autrefois, la reine (femme de l'empereur) Hoei avait voulu donner le pouvoir au prince Tai et c'est ainsi qu'avec so n parti, (Tai) fit des ouvertures aux $T i\left({ }^{472}\right)$. Les $T i$ pénétrèrent donc dans (la capitale des) $T c h e o u$; le roi Siang sortit et s'enfuit (dans le pays de) Tcheng]. (Le prince de) Tcheng l'installa à $\operatorname{Fan}\left(\frac{473}{3}\right)$. Le prince Tai assuma le pouvoir et se proclama roi ; il prit la reine $T i$ qui avait été dégradée par le roi Siang et s'établit avec elle à Wen ( $(774)$.

La dix-septième année (635 av. J.-C.), le roi Siang implora le secours (du prince de $T \sin$. Le duc Wen de Tsin réinstalla le roi et tua Chou-tai. Le roi Siang donna alors au duc Wen, de Tsin, une tablette de jade, un fourreau d'arc, un arc et des flèches et le nomma hégémon $(\underline{475}) ; \cdot{ }_{295}$ il donna le territoire du Ho-nei $\left({ }^{476}\right)$ à Tsin.

La vingtième année (632 av. J.-C.), le duc Wen, de Tsin, manda le roi Siang. Le roi Siang vint le trouver à Ho-yang et à Tsien-t'ou ( $(\underline{47})$. Les seigneurs (lui) rendirent tous homrnage. Le livre ( $\underline{478}$ ) dissimule (ces faits) en disant « Le roi (nommé) par le Ciel (passa l'inspection des) fiefs à Ho-yang. »

La vingt-quatrième année (628 av. J.-C.), le duc Wen, de Tsin mourut.

La trente et unième année (621 av. J.-C.), le duc Mou, de Ts in, mourut.

La trente-deuxième année $\left(\frac{479}{)}\right)(620$ av. J.-C.), le roi Siang $\bullet 296$ mourut. Son fils, Jen-tch'en, qui fut le roi King, prit le pouvoir. 
La sixième année (613 av. J.-C.), le roi K’ing mourut. Son fils, Pan, qui fut le roi K'oang, prit le pouvoir.

La sixième année (607 av. J.-C.), le roi K'oang mourut. Son frère cadet, $\mathrm{Yu}$, prit le pouvoir; ce fut le roi Ting.

La première année (606 av. J.-C.) du roi Ting, le roi Tchoang, de Tch'ou, attaqua les Jong de Lou-hoen ( $(480)$; puis il arriva au bord de (la rivière) Lo ; il envoya des gens poser des questions au sujet des neuf trépieds (ㅎ1); le roi envoya Wang-suen Man (ㄴ2) lui répondre; celui-ci trouva un moyen pour éviter (de s'expliquer). Les soldats de Tch'ou alors se retirèrent.

- ${ }_{297}$ La dixième année (597 av. J.-C.), le roi Tchoang, de Tch'ou, assiégea (la capitale du pays de) Tcheng. Le comte de Tcheng se rendit, mais ensuite recouvra (son territoire) $(\underline{483})$.

La seizième année (591 av. J.-C.), le roi Tchoang, de Tch'ou, mourut.

La vingt et unième année (586 av. J.-C.), le roi Ting mourut. Son fils $I$, qui fut le roi Kien, prit le pouvoir.

La treizième année (573 av. J.-C.) du roi Kien, (les gens de) Tsin tuèrent leur prince, le duc $L i$; ils allèrent chercher le fils (du duc), Tcheou, à (la capitale des) Tcheou ; ils lui donnèrent le pouvoir ; ce fut le duc Tao.

La quatorzième année (572 av. J.-C.), le roi Kien mourut. Son fils, Sie-sin, qui fut le roi Ling, prit le pouvoir.

La vingt-quatrième année (548 av. J.-C.) du roi Ling, Ts'oei Tchou, du

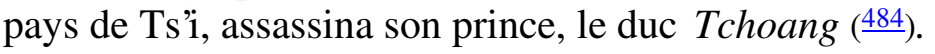

La vingt-septième année (545 av : J.-C.), le roi Ling mourut. Son fils, Koei, qui fut le roi King, prit le pouvoir.

La dix-huitième année (527 av. J.-C.) du roi King, le fils aîné de la reine, qui était sage, mourut prématurément $(\underline{485})$.

La vingtième année (525 av. J.-C.), le roi King, qui avait $\bullet_{298}$ en affection son fils, Tchao ( $(\underline{486})$, aurait voulu lui donner le pouvoir. Il arriva que (le roi) mourut $(\underline{487})$. Le parti du prince Kai $(\underline{488})$ disputa le pouvoir à (Tchao) ; les gens du royaume mirent sur le trône le fils aîné, Mong $(\underline{489})$, et le nommèrent roi ; le prince Tchao attaqua et tua Mong ; Mong fut appelé le roi Tao $(\underline{490})$. Les gens de $T \sin$ attaquèrent le prince $T c h a o$ et mirent sur le trône Kai : ce fut le roi King.

La première année (519 av. J.-C.) du roi King, les gens de Tsin (voulurent) faire entrer le roi King (dans la capitale); le prince Tchao s'arrogea le pouvoir ; le roi King ne put entrer et résida à Tsé (ㅂ1).

La quatrième année (516 av. J.-C.), Tsin, à la tête des seigneurs, réintégra le roi King dans (la capitale des) Tcheou; le prince Tchao devint un sujet. Les seigneurs construisirent un rempart à (la capitale des) Tcheou (92). 
La seizième année (504 av. J.-C.), les partisans du prince Tchao suscitèrent de nouveau une révolte ; le roi King s'enfuit (dans le pays de) Tsin.

La dix-septième année (503 av. J.-C.), le duc Ting, de Tsin, fit aussitôt rentrer le roi King dans (la capitale des) Tcheou.

• 299 La trente-neuvième année (481 av. J.-C..), T’ien Tch'ang, du pays de Ts'i, tua son prince, le duc Kien.

La quarante et unième année (479 av. J.-C.), (l'État de) Tch'ou anéantit (l'État de) Tch'en. Kong-tse mourut ( $(993)$.

La quarante-deuxième année $(\underline{494})$ (478 av. J.-C.), le roi King mourut. Son fils Jen, qui fut le roi Yuen, prit le pouvoir ( $(995)$.

- 300 La huitième année (469 av. J.-C.), le roi Yuen mourut. Son fils, Kié, qui fut le roi Ting, prit le pouvoir.

La seizième année (453 av. J.-C.) du roi Ting, les trois $T \sin$ tuèrent Tche-po $\left({ }^{496}\right)$ et se partagèrent ses terres.

La vingt-huitième année (441 av. J.-C.), le roi Ting mourut. Son fils aîné, K’iu-tsi, prit le pouvoir: ce fut le roi Ngai. Le Ngai avait pris le pouvoir depuis trois mois, lorsque son frère cadet, Chou, l'attaqua soudain, le tua et s'arrogea le pouvoir ; ce fut le roi $S e$. Le roi $S e$ avait pris le pouvoir depuis cinq mois quand son frère plus jeune, Wei, l'attaqua, le tua et s'arrogea le pouvoir ; ce fut le roi K'ao. Ces trois rois étaient tous fils du roi Ting.

La quinzième année (426 av. J.-C.), le roi K’ao mourut. Son fils, $O u$, qui fut le roi Wei-lié, prit le pouvoir.

Le roi K'ao avait donné Ho-nan en fief à son frère cadet, qui fut le duc Hoan, afin qu'il héritât des charges et dignités du duc de Tcheou; à la mort du duc Hoan, son fils, le duc Wei, prit le pouvoir à sa place ; à la mort du $\bullet_{301}$ duc Wei, son fils, le duc Hoei, prit le pouvoir à sa place ; il donna alors Kong en fief à son fils cadet pour qu'il fût chargé du roi ; son titre fut le duc Hoei des Tcheou orientaux $(\underline{497})$.

La vingt-troisième année (403 av. J.-C.) du roi Wei-lié, les neuf trépieds furent frappés de la foudre. (Le roi) ordonna que Han, Wei et Tchao devinssent des seigneurs $(\underline{498})$.

La vingt-quatrième année (402 av. J.-C.), il mourut. Son fils, Kiao, qui fut le roi Ngan, prit le pouvoir. Cette année-là, des brigands tuèrent le roi Cheng, de Tch'ou .

- ${ }_{302}$ Après vingt-six ans de règne, le roi Ngan mourut (376 av. J.-C.). Son fils, $H i$, qui fut le roi Lié, prit le pouvoir.

La deuxième année (374 av. J.-C.) du roi Lié, Tan, grand astrologue des Tcheou, rendit visite au duc Hien, de Ts'in, et lui dit :

- Autrefois les Tcheou ont été en bonne harmonie avec le royaume de $T$ s'in, puis ils s'en sont séparés ; après cinq cents ans 
de séparation, ils se réuniront de nouveau ; après dix-sept ans de réunion, celui qui sera roi par la force apparaîtra $\left({ }^{499}\right)$.

- ${ }_{303}$ La dixième année $(\underline{500})$, le roi Lié mourut : Son frère cadet ; Pien, prit le pouvoir ; ce fut le roi Hien.

- ${ }_{304}$ La cinquième année (364 av. J.-C.) du duc Hien, celui-ci complimenta le duc Hien, de Ts'in. Le duc Hien se proclama hégémon.

La neuvième année (360 av. J.-C.), (le roi) envoya au duc Hiao, de Ts'in, de la viande des sacrifices offerts aux rois Wen et $\mathrm{Ou}$.

La vingt-cinquième année (344 av. J.-C.), Ts'in rassembla les seigneurs à (la capitale des) Tcheou.

La vingt-sixième année (343 av. J.-C.), (le roi) Tcheou offrit l'hégémonie au duc Hiao, de Ts'in.

La trente-troisième année (336 av. J.-C.), il complimenta le roi Hoei, de Ts'in.

La trente-cinquième année (334 av. J.-C.), il envoya au roi Hoei, de Ts'in, de la viande des sacrifices offerts aux rois Wen et $\mathrm{Ou}$.

La quarante-quatrième année (325 av. J.-C.), le roi Hoei, de Ts'in, se proclama roi. A la suite de cela, tous les seigneurs devinrent rois.

La quarante-huitième année (321 av. J.-C.), le roi Hien mourut. Son fils, Ting, qui fut le roi Chen-tsing, prit le pouvoir.

- ${ }_{305}$ La sixième année (315 -av. J.-C.), il mourut. Son fils Yen, qui fut le roi Nan ( $(\underline{501})$, prit le pouvoir.

Au temps du roi Nan, les Tcheou orientaux et les Tcheou occidentaux se partagèrent le gouvernement. Le roi Nan transféra sa résidence chez les Tcheou occidentaux ( $(\underline{502})$.

[ ( $\underline{503})$ L’héritier présomptif, Kong, du duc Ou, des Tcheou occidentaux, mourut. (Le duc) avait cinq fils nés de femmes secondaires et n'avait pas décidé $(\underline{504})$ lequel il nommerait (héritier présomptif). Le généralissime $(\underline{505})$ Tsien dit au roi de Tch'ou $(\underline{506})$ :

- Le mieux est de donner une terre à Kieou, fils du duc, et d'en profiter pour demander qu'il soit l'héritier présomptif.

Tso Tch'eng dit :

- Il ne faut pas agir ainsi; si Tcheou ne vous écoute pas, votre sagesse sera alors à bout de ressources et un éloignement se produira dans nos rapports avec Tcheou. Le mieux est de demander au prince Tcheou qui il veut nommer.

A mots couverts, (le duc $O u$ ) parla à Tsien $(\underline{507}) ; \bullet_{306}$ Tsien lui proposa d’inviter (le roi de) Tch'ou à lui donner une terre en guise de félicitations] ; (le duc) nomma en effet son fils Kieou héritier présomptif. 
La huitième année (307 av. J.-C.), Ts ïn attaqua I-yang $\left(\frac{508}{)}\right)$ Tch'ou vint à son secours, puis croyant que Tcheou embrassait le parti de $T$ s'in, il se prépara à l'attaquer. Sou Tai $(\underline{509})$ parla en faveur de Tcheou au roi de Tch'ou et lui dit :

- Pourquoi (amener) une calamité en pensant que Tcheou agit en faveur de Ts'in ( $\underline{510})$ ? Ceux qui disent que Tcheou est plus en faveur de $T$ s'in que de $T$ ch'ou désirent faire que Tcheou s'unisse à $T s$ 'in, et c'est pourquoi ils disent Tcheou-Ts'in ( $(\underline{511})$. Si Tcheou sait qu'il ne peut rompre (votre dessein), il s'unira certainement à $T s$ 'in, c'est là le moyen subtil (qu'ont imaginé) ceux qui désirent que Ts'in s'empare de Tcheou. Ceux qui font des plans pour Votre Majesté (lui diront): Si Tcheou s'allie à Ts'in, profitez-en pour l'approuver ; s'il ne s'allie pas à $T s^{\prime}$ in , dites encore que c'est fort bien; de ${ }_{307}$ cette manière vous le détacherez de Ts'in : Tcheou, s'étant séparé de $T s$ 'in, s'unira certainement à $Y n g(\underline{512})$.

[ ( $(\underline{513}) T s$ 'in (voulait) emprunter le chemin qui se trouvait entre les deux Tcheou, dans l'intention d'attaquer Han $\left(\frac{514}{2}\right)$. Tcheou eut peur que, sil le prêtait, il eût tout à craindre de Han, que, s'il ne le prêtait pas, il eût tout à craindre de Ts’in. Le clerc Yen dit au prince de Tcheou $(\underline{515})$ :

- Pourquoi n'ordonnez -vous pas à des gens d'aller parler à Chou, duc de Han, en ces termes: Si Ts'in ose couper Tcheou par le milieu pour attaquer Han, c'est qu'il a con fiance dans les Tcheou orientaux ; pourquoi Votre Altesse ne donne-t-elle pas une terre à Tcheou et ne livre-t-elle pas des otages qu'elle enverra à Tch'ou ? (Si vous agissez ainsi,) Ts'in certainement soupçonnera Tch'ou et ne se fiera pas à Tcheou et ainsi Han ne sera pas attaqué. - Vous ferez dire d'autre part à Ts in : C'est forcé par la contrainte que Han donne une terre à Tcheou, car il se propose de rendre ainsi Tcheou suspect aux yeux de Ts'in; Tcheou n'ose pas ne pas recevoir (ce présent). — Ts'in n'aura certainement aucune raison pour ordonner à Tcheou de ne pas l'accepter ; ainsi vous aurez reçu une terre de Han et vous aurez obéi à $T$ s'in. ]

- 308 [ $\left(\frac{516}{)}\right) T$ s'in manda le prince des Tcheou occidentaux; le prince des Tcheou occidentaux redoutait ce voyage ; c'est pourquoi il envoya des gens dire au roi de $\operatorname{Han}(\underline{517})$ :

- Si Ts'in mande le prince des Tcheou occidentaux, c'est qu'il compte en profiter pour envoyer (une armée) attaquer votre ville de Nan-yang. Pourquoi Votre Majesté ne fait-elle pas sortir des soldats devant Nan-yang ( $(18)$ ? Le prince de Tcheou en profiterait pour s'en faire une excuse auprès de $T$ s'in, et si le prince de Tcheou n'entre pas dans (le pays de) Ts'in, Ts'in n'osera certainement pas franchir le Fleuve pour attaquer Nan-yang.]

[( $(519)$ Les Tcheou orientaux se trouvant en lutte avec les Tcheou ocidentaux, Han (voulut) venir au secours des Tcheou occidentaux. Quelqu'un parla en faveur des Tcheou orientaux au roi de Han, disant : 
— Les Tcheou occidentaux sont l'ancien royaume des Fils du ciel ; ils possèdent beaucoup d'objets renommés et de joyaux précieux. Si Votre Majesté tient ses armes en repos et ne met pas ses soldats en campagne, elle pourra ainsi s'attirer la reconnaissance des Tcheou orientaux et d'autre part les joyaux des Tcheou occidentaux pourront certainement être tous obtenus $(\underline{520})$.]

- ${ }_{309}$ Le roi Nan parla à Tch'eng-kiun $\left(\frac{521}{)}\right)$.

Tch'ou assiégeait (la ville de) Yong-che $(\underline{522})$. [ $(\underline{523})$ Han exigea des Tcheou orientaux des cuirasses et du grain. Le prince des Tcheou orientaux, saisi de peur, manda Sou Tai ( $(\underline{524})$ et lui exposa (l'affaire). ( Sou) Tai lui dit :

- Pourquoi Votre Altesse s'afflige -t-elle de cela ? Votre sujet se charge de faire que Han ne demande à Tcheou ni cuirasses, ni grains ; bien plus, je puis obtenir (la ville de) Kao-tou $(\underline{525})$ pour Votre Altesse.

Le prince Tcheou répliqua :

- Si vous en êtes en effet capable, je vous prierai de commander à tout le royaume.

(Sou) Tai fut admis auprès du conseiller d'État de Han et lui dit :

- Tch'ou a commencé à assiéger (la ville de) Yong-che au troisième mois ; maintenant c'est le cinquième mois et il n'a pu la prendre; c'est (une marque de) la faiblesse de Tch'ou. Si maintenant, ô conseiller d'État, vous exigez de Tcheou des cuirasses et du grain, ce sera déclarer votre faiblesse à Tch'ou.

Le conseiller d'État $(\underline{526})$ de Han dit :

— C'est fort bien ; l'envoyé suspendra (르) son départ.

(Sou) Tai dit :

— Pourquoi ne donnez-vous à Tcheou (la ville de) Kao-tou?

Le conseiller d'État de Han se mit fort en colère et dit :

- Je n'exige de Tcheou ni cuirasses ni grain, et c'est déjà beaucoup. Pourquoi donc donnerais-je à Tcheou (la ville de) Kaotou?

(Sou) Tai répliqua :

- Si vous donnez à Tcheou (la ville de) Kao-tou, ce sera cause que Tcheou se décidera ( $(\underline{52})$ et prendra le parti de Han. Lorsque Ts'in l'ap prendra, il sera fort en colère et s’irritera contre Tcheou $\left(\frac{529}{2}\right)$; c'est pourquoi il n'aura plus de relations avec les envoyés des Tcheou; au prix (de la ville) peu importante de Kaotou vous obtiendrez Tcheou tout entier; pourquoi ne pas la donner ? 
Le conseiller d'É tat dit :

- C'est bien.

Il donna donc à Tcheou (la ville de) Kao-tou .]

La trente-quatrième année (281 av. J.-C.), [ ( $(\underline{30})$ Sou Li ( $(\underline{531})$ parla au prince de Tcheou en ces termes. ; "Ts'in a écrasé ${ }_{311}$ Han et Wei; il a battu Che $O u(\underline{532})$; au nord, il s'est emparé de Lin et de Li-che ( $\underline{533})$, (villes du pays de) $T c h a o$; celui qui a fait tout cela $(\underline{534})$, c'est $P o K^{\prime} i(\underline{535})$; en effet (ce général) sait fort bien se servir des soldats, et en outre il est prédestiné par le Ciel. Maintenant il (se propose de) sortir de nouveau de la frontière $(\underline{536})$ à la tête de ses soldats pour attaquer Leang ( $(\underline{537})$. Lorsque Leang aura été écrasé, Tcheou sera en danger. Pourquoi Votre Altesse n'envoie -t-elle pas des gens dire à $P o$ $K ’ i$ : Dans le pays de Tch'ou vivait un certain Yang Yeou-ki ( $\left.\frac{538}{6}\right)$ qui était excellent archer; en tirant à cent pas sur une feuille de mûrier, il tira cent coups et l'atteignit c ent fois. Les assistants, qui étaient au nombre de plusieurs milliers, disaient tous : C'est admirablement tiré. Un homme vint cependant se placer ${ }_{312}$ à côté de (Yang Yeou-ka et dit :

— C'est bien, mais je puis vous apprendre à tirer.

Yang Yeou-ki en colère lâcha son arc, saisit son épée et dit :

— Étranger, prétendez-vous être capable de m’enseigner à tirer ?

L'étranger lui répondit :

- Ce n'est pas que je sois capable de vous enseigner à tendre le bras gauche et à replier le bras droit. Mais, lorsqu'à une distance de cent pas d'une feuille de mûrier vous avez tiré cent fois et que vou s l'avez touchée cent fois, si vous ne vous arrêtez pas sa tisfait, petit à petit votre ardeur se ralentira, vos forces faibliront, votre arc se tordra, vos flèches se courberont, et un seul coup où vous ne réussirez pas détruira l'effet de vos cent coups (précédents). Or (푸) maintenant vous avez écrasé Han et Wei; vous avez battu Che Ou; au nord, vous vous êtes emparé de Lin et de Li-che, (villes de) Tchao ; vous avez acquis une grande gloire ; cependant vous allez derechef sortir de la frontière à la tête de vos soldats pour traverser les deux Tcheou, tourner le dos à Han et attaquer Leang. Si une seule de vos entreprises ne réussit pas, toute votre gloire passée sera perdue. Il vaut mieux pour vous prétexter une maladie et ne pas vous mettre en campagne. »]

La quarante-deuxième année (273 av. J.-C.), [ $(\underline{540})$ Ts'in viola la convention relative à Hoa-yang ( $\left.{ }^{541}\right)$. Ma Fan parla au prince de Tcheou en ces termes :

- Je vous prie d'ordonner $\bullet_{313}$ à Leang $(\underline{542})$, de construire un rempart pour Tcheou.

Puis il dit au roi de Leang : 
- Le roi de Tcheou est malade $(\underline{543})$; s’il meurt, moi Fan, je mourrai certainement. Permettez-moi, je vous prie de remettre de ma propre autorité les neuf trépieds à Votre Majesté ; que Votre Majesté reçoive les neuf trépieds et avise à un plan en faveur de Fan.

Le roi de Leang dit :

- C'est fort bien parlé.

Aussitôt il lui donna des soldats en leur disant de tenir garnison à Tcheou. Alors (Ma Fan) dit à Ts'in :

— Leang ne veut point tenir garnison à Tcheou ( $(\underline{54})$; mais il se propose de l'attaquer; que le roi essaie de faire sortir ses soldats à la frontière pour l'observer.

Ts'in fit en effet sortir ses soldats. (Ma Fan) revint alors dire au roi de Leang : «Le roi de Tcheou est fort malade ; moi, (Ma) Fan, je demande à vous envoyer les trépieds plus tard, dès que l'occasion le permettra. Maintenant que Votre Majesté a envoyé des soldats à Tcheou, les seigneurs vous soupçonnent tous; lorsque, ensuite vous voudrez agir, ils ne vous croiront plus. Le mieux est d'ordon ner à vos soldats de construire un rempart pour ${ }_{314}$ Tcheou afin de cacher votre entreprise $(\underline{545})$.

Le roi de Leang dit :

- C'est fort bien parlé.

Aussitôt il chargea (ses soldats) de construire un mur pour Tcheou.]

La quarante-cinquième année (270 av. J.-C.), [ $(\underline{546})$ le prince de Tcheou vint (dans le pays de) Ts'in. Un étranger dit à Tcheou Siu $(\underline{547})$ :

- Ce que vous avez de mieux à faire, c'est de flatter la piété filiale du roi de $T$ s'in, et, pour cela, de donner en présent Yng $(\underline{548})$ à la reine-douairière $\left(\frac{549}{)}\right.$ comme son domaine propre, Le roi de $T s^{\prime}$ 'in s'en réjouira cer tainement. Vous aurez ainsi des rapports $(\underline{550})$ avec Ts'in. ${ }_{315} \mathrm{Si}$ ces rapports sont bons, le prince de Tcheou vous en saura gré ; si ces rapports sont mauvais, vous serez un homme qui aura encouragé l'annexion de Tcheou à $T s^{\prime} i n$ et vous serez certainement considéré comme criminel.]

[ ( $\underline{551}) T$ s’in (voulut) attaquer Tcheou. Tcheou Siu parla au roi de Ts'in en ces termes :

- Si je puis donner un conseil au roi, c'est de ne pas attaquer Tcheou; si vous attaquez Tcheou, en vérité vous n'y aurez pas de profit $(\underline{552})$. Votre renommée sera abhorrée de l'empire, et l'empire, détestant $T$ s 'in à cause de sa renommée, s'alliera certai nement à l'est avec $T s$ 'i. Vos armes se seront abaissées (en entrant en conflit) avec Tcheou et vous aurez fait s'al lier l'empire avec Ts’i. 
Alors $T$ 'sin n'aura plus la royauté. L’empire désire abaisser $T$ s'in et c'est pourquoi on engage Votre Majesté à attaquer Tcheou. Si $T s$ ’in est abaissé aux yeux de l'empire, ses ordres ne seront plus obéis.]

La cinquante-huitième année (257 av. J.-C.), [ ( $(\underline{533})$ les trois $T \sin (\underline{554})$ résistèrent à $T s^{\prime}$ 'in. Tcheou ordonna à son conseiller d'État de se rendre à $T s$ 'in. Comme $T$ s'in le traita avec mépris, celui-ci revint de sa mission. Un étranger parla $\bullet_{316}$ au conseiller d'État en ces termes :

- Si Ts’in vous a méprisé ou honoré, c'est ce que je ne puis savoir. Mais Ts’in désire connaître les dispositions des trois royaumes ; le mieux est donc que vous alliez promptement voir le roi de $T s$ 'in et que vous lui disiez: Je prie Votre Majesté d'écouter les changements qui se produisent dans l'est $(\underline{555})$. - Le roi de $T s^{\prime}$ in vous estimera certainement; en vous estimant, Ts'in estimera Tcheou et Tcheou par là se sera gagné Ts'in. Quant à l'estime de $T s ’$, il y a certainement Tcheou Siu $(\underline{556})$ grâce à qui $T s$ 'i nous est acquis. Ainsi Tcheou ne perdra point ses bonnes relations avec les royaumes puissants.] Ts'in aura confiance en Tcheou et enverra ses soldats attaquer les trois $\mathrm{T} \sin (\underline{557})$.

La cinquante-neuvième année (256 av. J.-C.), Ts’in prit (au pays de) Han le village de Fou-chou ( $(558)$, (près de) Yang tch'eng. • Les Tcheou occidentaux eurent peur; ils $\bullet_{317}$ rompirent avec $T$ s in et firent une ligue du nord au sud $\left(\frac{559}{}\right)$ avec les seigneurs. Ils se mirent à la tête de soldats d'é lite et sortirent par I-k'iue $(\underline{560})$ il pour attaquer $T s^{\prime} i n$ et faire quil ne pût avoir de communications avec Yang-tch'eng. Le roi Tchao, de Ts'in, se mit en colère et envoya le général Kieou attaquer les Tcheou occidentaux. Le prince des Tcheou occidentaux ( $\underline{561}$ ) s'enfuit dans (le pays de) $T$ s in ; il se prosterna et se reconnut coupable; il offrit toutes ses villes qui étaient au nombre de trente-six et comptaient trente mille habitants. Ts'in accepta ce qu'il offrait. Il renvoya ce prince à Tcheou. Le prince de Tcheou et le roi Nan moururent. Le peuple des Tcheou s'enfuit alors à l'est ; Ts'in s'empara des neuf trépieds et des ustensiles précieux ; puis il transféra le duc des Tcheou occidentaux ( $\left.\frac{562}{2}\right)$ à Tan-hou. Sept années plus tard, le roi $\bullet_{318}$ Tchoang-siang, de $T$ s'in, anéantit les Tcheou orientaux et les Tcheou occidentaux; les Tcheou orientaux et les Tcheou occidentaux furent tous deux annexés à $T s$ 'in et dès lors les sacrifices des Tcheou cessèrerit.

Le duc grand astrologue dit: Les érudits prétendent tous que lorsque (le roi $\mathrm{Ou}$ de) Tcheou battit Tcheou, (de la dynastie $\mathrm{Yn}$ ), il résidait à la ville de Lo $(\underline{563})$; en rassemblant les faits réels, on voit qu'il n'en est pas ainsi. Le roi $O u$ traça le plan (de cette ville) $(\underline{564})$; le roi Tch'eng envoya le duc de Chao consulter les sorts sur cette résidence et y plaça les neuf trépieds $\left(\frac{565}{}\right)$; cependant les Tcheou eurent encore leur capitale à Fong et à Hao $(\underline{566})$. Puis, lorsque les K'iuen-jong battirent le roi Yeou, alors les Tcheou transférèrent leur capitale dans l'est, à la ville de $L o(\underline{567})$. Au sujet de ce qu'on rapporte que 
le duc de Tcheou fut enterré au lieu qui est de nos jours $P i(\underline{568})$, (je dirai que) $P i$ est au milieu des poiriers, au sud-est de Hao. - Après que les Ts'in eurent anéanti les Tcheou et quand les Han régnaient déjà depuis plus de quatre-vingt-dix années, le Fils du ciel $(\underline{569})$, voulant aller faire le ${ }_{319}$ sacrifice fong sur le T'ai-chan, inspecta les fiefs à l'est ; arrivé à Ho-nan $(\underline{570})$, il s'informa des descendants des Tcheou et donna à leur descendant, Kia, une terre de trente $l i$ avec le titre de «prince Tcheou de Tse-nan» (ㄱ1 $)$; il le mit sur le même pied que les seigneurs indépendants pour qu'il pût s'acquitter des sacrifices à ses ancêtres. 


\begin{abstract}
$\begin{array}{lllll}\mathrm{N} & \mathrm{O} & \mathrm{T} & \mathrm{E} & \mathrm{S}\end{array}$
Mémoires Historiques : Chapitres : $\underline{\mathrm{I}} \cdot-\underline{\mathrm{II}}-\underline{\mathrm{III}}-\underline{\mathrm{IV}}$

Les $n^{\circ}$ de note sont précédés $d u n^{\circ}$ de chapitre. Les renvois à des notes du même chapitre ne mentionnent pas le $n^{\circ}$ du chapitre, à la différence des renvois à des notes d'autres chapitres.
\end{abstract}

\title{
SE-MA TCHENG. LES TROIS SOUVERAINS
}

00. (101) Sur Se-ma Tcheng, sur les raisons qui lui firent écrire les Annales principales des trois souverains et sur ce quil entend par les trois souverains, cf. le cinquième chapitre de notre Introduction.

L'opus cule de Se-ma Tcheng ainsi que le premier chapitre des Mémoires historiques de Se-ma Ts'ien ont été traduits en anglais par M. H. J. Allen (Journal of the Royal Asiatic Society, avril 1894, p. 269-295).

00. (102) T'ai-hao signifie «le grand éclat»: de même que T'ai-hao ouvre la série des trois souverains, ainsi Chao-hao, c'est-à-dire «l'éclat secon daire », est en tête de la liste des cinq empereurs dans tous les systèmes chronologiques qui, comme le chapitre Lu li tche, du Ts'ien Han chou, admettent huit règnes (les trois souverains, plus les cinq empereurs) avant la première dynastie. - Se-ma Ts'ien, qui n'admet que les cinq règnes des cinq empereurs, ne reconnaît pas la légitimité de Chao-hao, quoiqu'il en parle incidemment dans divers passages.

- P'ao- $h i$ signifie «élever des animaux pour la cuisine » et ce nom est souvent remplacé par celui de Fou-hi qui signifie «soumettre des animaux domestiques ». La raison d'être de ces noms sera donnée plus loin par Se-ma Tcheng.

00. (103) Se-ma Tcheng dit: C'est le Koиo yи qui nous apprend que le nom de clan de Fou-hi était Fong.

Nous devons justifier, par quelques considérations la traduction «nom de clan » que nous adoptons pour rendre le mot [a] : Les termes [a] et [b] sont employés comme équivalents par Se-ma Ts'ien ; ainsi il nous dit en parlant de Ts’in Che-hoang que son nom de clan était le nom de famille Tchao. La confusion faite par Se-ma Ts'ien est devenue d'un usage général et tous les noms de famille [b] sont appelés aujourdhui noms de clans [a]. Cependant les anciens textes ne sont intelligibles que si ou rétablit la distinction entre ces deux termes. Kou Yen-ou, dans son Je tche lou (chap. XXIII. Sur cet ouvrage, voyez Wylie, Notes..., p. 130), a traité cette question d'une manière très intéressante ; nous nous sommes servis de son livre pour rédiger la note suivante :

Les noms de clan [a] étaient réservés autrefois aux princes et aux nobles; les gens de la plèbe n'avaient qu'un nom personnel. Le nom de clan n'était pas souvent mentionné : on désignait les princes régnants par le nom de leur royaume ; ainsi le prince qui avait pour nom personnel Chen et qui régnait sur l'État de Lou s'appelait Lou Chen ; quant aux patriciens qui avaient, de par leur naissance, accès aux fonctions publiques, ils se distinguaient entre eux par des noms de famille [b], mais on énonçait rarement leur nom de clan [a]. Les noms de clans étaient fort peu nombreux; on n'en compte que vingt-deux dans le Tch'oen-ts'ieou. Au contraire, les noms de famille augmentaient sans cesse en nombre ; plusieurs d'entre eux sont d'anciens noms de fonctions ; c'était parfois le nom de la charge exercée par le premier ancêtre qui était devenu celui de toute la famille; tel est le nom de Se-ma ; d'autres exprimaient la relation de parenté qui avait existé entre le premier ancêtre et le prince 
régnant : tels sont les noms de [], proprement fils du duc, petit-fils du duc. Ainsi les noms de famille allaient en se multipliant à mesure que les branches des anciens clans se constituaient en familles nouvelles.

Quand on nommait un homme, on ne l'appelait pas par son nom de clan mais par son nom de famille. Quand on nommait une femme, au contraire, on indiquait toujours son nom de clan; en effet, l'importance principale du nom de clan venait de la règle d'exogamie qui interdisait les mariages entre membres d'un même clan ; par exemple, lorsque le duc Tchao, de Lou épousa une femme du pays d'Ou, il commit une action condamnée par les rites, car les deux familles qui avaient fondé les États de Lou et $O u$ avaient le même nom de clan, $K i$. Les anciens noms de clan paraissent nous reporter à une époque reculée où la descendance par la mère était le principe constituant de la famille. Les noms de famille, au contraire, sont fondés sur la prédominance de l'élément paternel et, dans la substi tution graduelle du nom de famille au nom de clan, il nous semble qu'on peut entrevoir la trace de toute une évolution sociologique.

00. (104) Le caractère Soei désigne une sorte de vilebrequin au moyen duquel on produisait le feu. Soei-jen est regardé comme l'in venteur de l'art de cuire les aliments. On verra plus loin qu'il succéda aux trois dynasties divines appelées les Souverains du ciel, les Souverains de la terre et les Souverains de l'homme ; c'est à cette légende que fait allusion Se-ma Tcheng quand il dit que Fou-hi continua le ciel.

00. (105) Hoang-fou Mi : Ti wang che ki.

00. (106) Hoa-siu est, d'après d'autres auteurs, le nom de la localité où habitait la mère de Fou-hi; ce lieu se trouvait dans la sous-préfecture actuelle de Lan-t'ien, préfecture de Srngan, province de Chàn-si.

00. (107) Les légendes relatives aux conceptions miraculeuses sont très peu variées en Chine : marcher dans les empreintes de pas gigantesques, avaler un neuf qui tombe du haut des airs ou apercevoir un météore dans le ciel, telles sont presque inévitablement les causes qui déterminent les grossesses surnaturelles d'où doivent sortir les héros mythologiques.

00. (108) Le marais de Lei joue un grand rôle dans l'ancienne his toire de la Chine ; nous le retrouverons mentionné à propos de Choen; il était situé dans la préfecture actuelle de P'ou-tcheou, province de Chôn-si.

00. (109) Tch'eng-ki correspond à la sous-préfecture de Ts'in-ngan, préfecture secondaire de Ts'in, province de Kan-sou.

00. (110) Voyez la représentation figurée de Fou-hi dans les bas-reliefs du Chan-tong (La sculpture sur pierre en Chine au temps des deux dynasties Han, planche III).

00. (111) I king, chap. XV, p. $4 \mathrm{v}^{\circ}$, trad. Legge, p. 382.

00. (112) L'appendice du I king, dont Se-ma Tcheng fait ici usage, contient des vestiges d'anciens vers quil est d'ailleurs assez difficile de rétablir sous leur forme primitive. Toan $Y u$-ts'ai (H.T.K. K., chap. DCLX, p. $15 \mathrm{r}^{\circ}$ ) dit que les mots [] et [] qui terminent les deux phrases que nous venons de traduire, riment ensemble et sont au p'ing-cheng de la $17^{\mathrm{e}}$ catégorie. Mais les mots [] (12 $2^{\mathrm{e}}$ catégorie) et [] (13 ${ }^{\mathrm{e}}$ catégorie) qui terminent les premières parties de ces deux phrases, ne riment pas ensemble, en sorte qu'on ne voit pas bien de quel nombre de syllabes les vers étaient constitués.

00. (113) Les huit trigrammes sont les huit combinaisons qu'on peut faire avec une ligne droite continue et une ligne droite brisée en les groupant trois par trois. La ligne droite continue étant le symbole du principe yang et la ligne droite brisée étant le symbole du principe yn, ces huit trigrammes sont supposés représenter en raccourci les combinaisons des deux principes qui constituent l'univers. Le roi Wen, de la dynastie Tcheou, passe pour avoir développé ce système cosmogonique en faisant des combinaisons, non plus de trois, mais de six lignes et en 
traçant ainsi un tableau de soixante-quatre hexagrammes ; cependant ce perfectionnement est souvent attribué à d'autres person nages.

00. (114) Cf. I king, trad. Legge, p. 385. [css : trad. Philastre p. 1224] — D'après ce texte, les Chinois paraissent avoir préludé à l'invention de l'écriture par une sorte de notation analogue à celle des anciens Péruviens qui employaient des cordes nouées appelées quipos pour exprimer leurs pensées.

00. (115) Dans le $\underline{I l i}$, au chapitre I, qui traite de la prise du bonnet viril par les officiers, on voit que le don des deux peaux de bêtes faisait partie de la cérémonie par laquelle tout fonctionnaire devait consacrer son arrivée à l'âge viril. On lit en effet :

«Le maître de la maison répond à la politesse de son hôte en lui offrant un rouleau de soie et deux peaux de bêtes.

00. (116) I king, chap. XV, p. 5 r .

00. (117) Cf. note 102 .

00. (118) Le Tso tchoan, à la $17^{\mathrm{e}}$ année du duc Tchao, donne des renseignements assez étendus sur les noms des officiers sous le règne des premiers souverains de la Chine.

«En automne, dit-il, le vicomte T'an vint à la cour ; pendant un banquet que le duc lui donnait, Tchao-tse lui demanda pourquoi Chao-hao avait donné à ses officiers des noms d'oiseaux. T'an-tse répondit :

— J'en sais la raison, car Chao-hao était mon ancêtre. Autrefois Hoang-ti réglait tout, grâce aux nuages; c'est pourquoi il institua des officiers-nuages et les Nuages étaient leurs noms. Yen-ti réglait tout grâce au feu; c'est pourquoi il institua des officiers-flammes et les Flammes étaient leurs noms. Kong-kong réglait tout grâce à l'eau ; c'est pourquoi il institua des officiers -eaux et les Eaux étaient leurs noms. T'ai-hao réglait tout grâce au dragon; c'est pourquoi il institua des officiers-dragons et les Dragons étaient leurs noms. Lorsque mon premier ancêtre, Chao-hao, arriva au pouvoir, un phénix apparut ; c'est pourquoi il régla tout grâce aux oiseaux ; il institua des officiers-oiseaux et les Oiseaux furent leurs noms. L'officier appelé le Phénix présidait au calendrier ; l'Hirondelle était l'officier des équinoxes ; la Pie-Grièche était l'officier des solstices ; l'Oise au-Bleu était l'officier du début (des saisons) ; l'Oiseau -Rouge était l'officier de la fin (des saisons). — L'Épervier était l'officier du peuple ; l'Aigle de mer était l'officier de la guerre ; le Ming-kieou était l'officier des travaux publics ; le Choang-kieou était l'officier de la justice ; le Milan était l'officier des affaires. Ces cinq directeurs dirigeaient le peuple, — Les cinq Faisans présidaient aux cinq arts; ils étaient ceux qui communiquaient l'usage avantageux des instruments, ceux qui réglaient les dimensions et les mesures, ceux qui maintenaient la justice dans le peuple. - Les neuf Hou présidaient aux neuf occupations de l'agriculture et gardaient le peuple de la mauvaise conduite. - A partir de l'empereur Tchoan Hiu, les souverains ne furent plus capables de régler tout par des principes reculés, mais ils réglèrent tout par des principes immédiats ; ils instituèrent des officiers du peuple et les nommèrent d'après les occupations du peuple. Ils étaient donc incapables de faire comme dans l'antiquité.

00. (119) La leçon « trente-cinq cordes » est celle de l'édition de Kien-long ; l'édition de 1596 donne la leçon « vingt-cinq cordes ».

00. (120) I king, chapitre XVII. M. Legge (I king, trad., p. 425), traduit ici le mot par Dieu ; le passage, dans son entier, semble en effet être symbolique; mais ce n'est pas de Dieu qu'il s'agit, c'est du soleil. Quant à l'idée que Se-ma Tcheng a en vue quand il fait cette citation, elle est assez claire : le trigramme Tchen est celui qui correspond à l'orient ; or, l'orient est, 
dans la théorie des cinq éléments, le symbole du bois par la vertu duquel régna Fou-hi; le texte du I king, en établissant que l'empereur apparaît d'abord à l'orient, $\mathrm{j}$ ustifie donc le système de Se-ma Tcheng qui fait de Fou-hi le premier des souverains.

00. (121) Le Livre des Ordonnances mensuelles est le quatrième livre du Li ki.

00. (122) Tch'en est aujourd'hui Tch'en-tcheou-fou, province de Ho-nan. Cette localité est située sur les bords de la rivière $T s^{\prime} a i$, affluent de la rivière Hoai ; c'est de la rivière $T s^{\prime} a i$ que sortit, suivant certaines fables, la tortue sur la carapace de laquelle Fou-hi découvrit les huit trigrammes.

00. (123) Se-ma Tcheng tire ce renseignement de la légende rapportée par Koan Tchong au sujet de soixante-douze souverains qui accomplirent les cérémonies fong et chan (cf. ma première traduction du Traité de Se-ma Ts'ien sur les sacrifices fong et chan, p. 13).

00. (124) Le T'ai-chan est une montagne située auprès de T'ai-ngan-tcheou, province de Chan-tong.

00. (125) On appelle période Tch'oen-ts'ieou celle dont l'histoire est ra contée dans les Annales qui portent ce nom et qui sont attribuées à Confucius. Cette période s'étend de 722 à 481 avant J.-C.

00. (126) Il est important, à cause de la grave question de la légitimité des intermariages, de savoir à quels clans appartenaient les nombreux États féodaux de la période Tch'oen-tsieou ; on voit dans ce passage quels étaient ceux qui se rattachaient au clan Fong. On trouvera plusieurs renseignements relatifs aux autres clans dans Kou Yen-ou, Je tche lou, chapitre XXIII, p. 1.

- Voici les indications que donne le Tch'oen ts'ieou ti li k'ao che de Kiang Yong (H. T. K. $K$., ch. CCLII-CCLV), au sujet de l'emplacement de ces principautés :

* Jen, préfecture secondaire de Tsi-ning, province de Chan-tong ;

* Sou, à $20 l i$ à l'est de la préfecture secondaire de Tong-p̈ing, préfecture de Tai-ngan, même province ;

* Siu-kiu, au sud-est de cette même préfecture secondaire de Tong-p'ing ;

* Tchoan-yu, à 80 li au nord-ouest de la sous-préfecture de Fei, préfecture de I-tcheou, province de Chan-tong.

00. (127) W. F. Mayers a écrit un intéressant article sur les légendes relatives à Niu-koa (Notes and queries on China and Japan, July 1868, p. 99-101). Il cite les passages de Lié-tse qui parlent de ce personnage mythologique et rappelle que ces fables se retrouvent plus développées dans Hoai-nan-tse (mort en 122 av. J.-C.). Il montre que, d'après les critiques chinois modernes, le caractère qui entre dans la composition du nom de Niu-koa, ne saurait être une preuve que ce personnage ait été une femme.

00. (128) Le Li ki, au chapitre Ming t'ang wei, parle du cheng et en attribue aussi l'invention à Niu-koa. On peut voir le dessin de cet instrument de musique dans Legge, Sacred Books of the East, vol. XXVIII, p. 37 [css : Couvreur]. Le Cheng se composait d'une calebasse au milieu de laquelle étaient fixés verticalement dix-neuf ou treize tuyaux appelés hoang ; un autre tube latéral servait d'embouchure au musicien qui produisait les sons en aspirant l'air et en bouchant avec les doigts tels ou tels des trous pratiqués sur les tuyaux verticaux. Voyez sur ce sujet une étude de M. Warrington Eastlake (The Chinese reed organ, dans China Review, vol. XI, p. 33-41).

00. (129) Les bas-reliefs de l'époque des Han, qu'on a découverts dans le Chan-tong, représentent $\mathrm{Fou}$-hi et Niu-koa entrelaçant leurs queues de serpent et formant un groupe indivisible. D'après la théorie que supposent ces bas-reliefs, Niu-koa et Fou-hi réunis ne forment qu'un seul des trois souverains ; en effet, comme le dit Se-ma Tchéng lui-même, à la 
fin de ce paragraphe, Niu-koa ne trouve pas place dans le cycle quinaire, c'est-à-dire dans la succession des cinq éléments, car Niu-koa, comme Fou-hi, régna par la vertu du bois. Il est vrai qu'au paragraphe suivant, Se-ma Tcheng cite une autre théorie d'a près laquelle un cycle entier se serait écoulé entre Fou-hi et Niu-koa en sorte que, tout en ayant régné par la vertu du même élément, le bois, Fou-hi et Niu-koa n'en formeraient pas moins deux souverains distincts.

00. (130) On trouve, chez les auteurs qui n'ont pas admis Hoang-ti au nombre des trois souverains, trois opinions différentes : les uns, comme Tsiao Tcheou (232-297 ap. J.-C.), disent que les trois souverains sont Fou-hi, Soei-jen (ef. note 1 de la p. 5) et Chen-nong; d'autres comme Song Kiun (Ier siècle ap. J.-C.), admettent que les trois souverains sont Fou-hi, Tchou-yong (voy. plus loin) et Chen-nong ; c'est cette théorie qui a été adoptée par l'auteur des bas -reliefs d'Ou Leang, dans le Chan-tong ; enfin la troisième hypothèse est celle que propose Se-ma Tcheng à la suite de Tcheng Hiuen (127-200 ap. J.-C.) et de Hoang-fou Mi (214-282 ap. J.-C.) : les trois souverains seraient Fou-hi, Niu-koa et Chen-nong.

00. (131) Lie-tse et Hoai-nan-tse parlent tous deux de Kong-kong, mais ils le font combattre avec Tchoan-hiu, petit-fils de Hoang-ti; comme cependant Kong-kong était de plusieurs générations antérieur à Hoang-ti, il faut admettre que cc ne fut pas lui, mais ses descendants qui combattirent avec Tchoan-hiu. En remplaçant Tchoan-hiu par Tchou-yong, Se-ma Tcheng peut faire une transposition heureuse dans l'ordre des deux phrases suivantes ; Lie-tse en effet dit que Niu-koa raffermit le ciel et la terre, puis il parle, comme d'un tout autre sujet, du combat de Kong-kong contre Tchoan-hiu; Se-ma Tchéng au contraire place le raffermissement de la terre et du ciel par Niu-koa après l'ébranlement causé par Kong-kong.

00. (132) Dans la théorie de Se-ma Tcheng, à l'élément bois doit succéder l'élément feu ; Kong-kong qui s'appuyait sur la vertu de l'eau n'était donc pas à sa place dans le cycle des cinq éléments ; il doit ainsi être considéré comme illégitime. (Cf. Ts ien Han chou, Kiao se tche, dernière page).

00. (133) Tchou-yong est donné dans les Ordonnances mensuelles du Li ki comme présidant au premier mois de l'été. D’après le commentaire du Li ki appelé «Interprétation correcte », Tchou-yong serait le fils de l'empereur Tchoan-hiu et présiderait au feu. Tchou-yong est appelé aussi l'empereur rouge, parce que le rouge est la couleur qui correspond au feu.

00. (134) Lie-tse, chap. T'ang wen. Hoai nan-tse, chap. T'ien wen hiun.

00. (135) Le commentateur de Lie-tse dit que la montagne Pou-tcheou est la montagne du coin nord-ouest de la terre.

00. (136) Lie-tse, chap. T'ang wen.

00. (137) D'après le commentateur de Lie-tse, la pierre de cinq couleurs serait un symbole représentant les cinq éléments primordiaux; c'est par la fusion harmonieuse de ces cinq éléments que Niu-koa rétablit l'ordre. M. Mayers émet l'hypothèse que la pierre de cinq couleurs est le charbon dont Niu-koa aurait été le premier à découvrir les utiles qualités ; mais cette supposition est plus ingénieuse que plausible.

00. (138) La province de $K i$ est une des neuf provinces qu'on voit décrites dans le tribut de $Y u$; elle comprenait le Chân-si actuel et une partie du Tche-li.

00. (139) Chen-nong signifie «le laboureur divin»; en effet, comme on le lira plus bas, ce souverain passe pour avoir institué l'agriculture. On l'appelle aussi Yen-ti, «l'e mpereur-fumée », parce qu’il régnait par la vertu du feu.

00. (140) Le T'ong kien kang mou et le T'ong kien tsi lan écrivent Ngan-teng.

00. (141) Il ressort du contexte que cette fille de la famille Koa n'est autre que Niu-teng. 
- Se-ma Tcheng dit quill se fonde sur le Kouo yu pour établir que la mère de Yen-ti était une fille de la famille Koa; mais, si nous nous reportons au Коио уи (chap. X, p. 10 v $^{\circ}$ ), nous y lisons ceci :

«Autrefois, Chao-tien prit une femme dans la famille Kiao; cette femme enfanta Hoang-ti et Yen-ti.

Ce texte présente deux différences avec le récit de Se-ma Tcheng :

* la première porte sur le nom de famille de la femme: elle ne s'explique qu'en admettant que Se-ma Tcheng avait sous les yeux un texte du Коио уи autre que ceux qui ont cours actuellement ;

* la seconde consiste en ceci que le Kouo yu semble faire de Hoang-ti et de Yen-ti deux frères nés d'une même mère, tandis que, selon Se-ma Tcheng, Yen-ti aurait été fort antérieur à Hoang-ti; Se-ma Tcheng résout la difficulté en disant que le texte du Коио уи ne doit pas être pris au pied de la lettre et quil signifie simplement que Hoang-ti et Yen-ti furent tous deux des descendants d'une même femme, quoique à des générations différentes.

— Le Ti wang che ki de Hoang-fou Mi (cité dans Mém. hist., chap. I, p. 3 r $^{\circ}$ ) doit que la mère de Yen-ti s'appelait Jen-se et qu'elle était de la famille Kiao.

00. (142) La rivière Kiang s'appelle aujourd'hui la rivière $K^{\prime} i$; elle coule dans la sous-préfecture de Ki-chan, préfecture de Fong-siang, province de Chàn-si. Ce petit cours d'eau est un affluent indirect de la rivière Wei, qui se jette dans le Hoang-ho (Chou king tchou che, chap. XVIII, p. 6).

00. (143) Cf. note 118 .

00. (144) I king, chap. XV, p. $5 \mathrm{v}^{\circ}$, trad. Legge, p. 383.

00. (145) Ce sacrifice est ici désigné par le terme tcha, mot qui se trouve employé dans le $L i k i$, au début du chapitre Li yun.

00. (146) Le rouge est la couleur qui correspond à l'élément feu : on ne voit pas bien quel est le sens caché de cette phrase; $M$. Allen traduit: «On se servit de lanières rouges pour enguirlander les plantes et les arbres. » Mais je n'ai jamais vu le mot [] avoir le sens d'enguir lander.

00. (147) I king, chap. XV, p. 5 v , trad. Legge, p. 383.

00. (148) Cf. Legge, Sacred Books of the East, vol. XVI, p. 383.

00. (149) Ce passage est assez surprenant, car linvention des soixante -quatre hexagrammes est généralement attribuée au roi Wen, de la dynastie Tcheou.

00. (150) Cf. note 122 .

00. (151) K'iu-feou est une sous-préfecture de la province de Chan-tong, préfecture de Yen-tcheou.

00. (152) Tch'ang -cha est aujourd'hui la capitale du Hou-nan. Le T'ong kien tsi lan (chap. I, p. $4 \mathrm{r}^{\circ}$ ) dit que Chen-nong fut enterré à Tch'a-ling, préfecture de Tch'ang-cha, province de Hou-nan. Mais une légende locale place la tombe de Chen-nong dans la sous-préfecture de Ling, préfecture de Heng-chan, province de Hou-nan (Koang yu ki, chap. XV, p. $17 \mathrm{v}^{\circ}$ ).

00. (153) La montagne Lié ou $L i$ est au nord de la préfecture secondaire de Soei, préfecture de Té-ngan, province de Hou-pe (T'ong kien tsi lan, chap. I, p. 3 r $^{\circ}$ ).

00. (154) Tso K’ieou-ming, auteur supposé du Kouo yu. On lit dans cet ouvrage : 
«Le fils de Chen-nong eut pour nom personnel Tchou ; il présida à l'agriculture, c'est pourquoi il eut pour nom personnel Nong.

Le T'ong kien tsi lan (chap. I, p. $4 \mathrm{v}^{\circ}$ ) fait allusion à cette légende, quand il dit :

«Yen-ti eut un autre fils qui s'appelait Tchou; il aida l'empereur en répandant et semant les cinq céréales. Les générations suivantes lui sacrifièrent comme au dieu des moissons.

00. (155) Li ki, chap. Tsi fa :

«C'est ainsi que Li-chan eut l'empire ; son fils s'appela Nong.

Cf. Legge, Sacred Books of the East, vol. XXVIII, p. 208.

00. (156) Ces chiffres sont ceux du Ti mang che ki de Hoang-fou Mi (Yuen kien lei han, chap. $\mathrm{XL}$, p. $\left.4 \mathrm{v}^{\circ}\right)$. - Le T'ong kien hang mou et le T'ong kien tsi lan donnent la liste de ces huit empereurs descendants de Chen-nong : ce sont Lin-k'oe i, Tch'eng, Ming, I, Lai, Li et Yuwang.

00. (157) Hien-yuen est un surnom de Hoang-ti. Voyez Mémoires historiques, chap. I, au début.

00. (158) Nous avons ici l'énumération des principautés féodales qui, à l'époque Tch'oen-ts'ieou, faisaient remonter leurs généalogies jusquà Chen-nong; leurs princes avaient le même nom de clan et ne pouvaient donc prendre femmes les uns chez les autres (cf. note 126).

Voici d'après le Tch'oen-ts-ieou ti li k'ao che de Kiang Yong (H. T. K. K., ch. CCLII-CCLV) les identifications géographiques de la plupart de ces localités :

* Tcheou : sous-préfecture de Ngan-k'ieou, préfecture de Ts'ing-tcheou, province de Chan-tong ;

* Hiu se trouva d'abord dans la préfecture secon daire indépendante de Hiu, province de Ho-nan, mais par la suite se déplaça souvent ;

* Ts'i: sous-préfecture de Lin-tche, préfecture de Ts'ing-tcheou, province de Chan-tong ;

* Ki: sous-préfecture de Cheou-koang, préfecture de Ts'ing tcheou, province de Chan-tong ;

* Hiang est identifié avec deux places différentes dans le Chan-tong, l'une à 100 li au sud-ouest de I-tcheou, l'autre à $70 \mathrm{li}$ au sud de Lu-tcheou;

* les deux principautés de Chen et de $L u$ étaient limitrophes et occupaient le territoire de la sous-préfecture de Nan-yang, préfecture de Nan-yang, province de Ho-nan.

- Je n'ai pas trouvé l’identification des pays de Kan, Hi, Lou et $I$.

* Quant à la principauté de $F o u$, elle semble avoir un étroit rapport avec celle de $L u$, car on sait que le chapitre du Chou king intitulé les Châtiments de $L u$ était autrefois appelé les Châtiments de Fou.

00. (159) Les princes de Fou et de Chen rattachaient leur généalogie à des chefs des quatre montagnes (cf. Che king, ode 5 de la décade de T'ang ; Legge, Chinese Classics, t. V, p. 535). De même, on nous apprend que, l'ancêtre des princes de $T s^{\prime} i$ était un des chefs des quatre montagnes quand il aida $Y u$ à triompher des eaux débordées (H.T.K. K., ch. CCLV, p. $\left.5 \mathrm{r}^{\circ}\right)$.

00. (160) Dans l'ode du Che king précitée, on voit que les princes de Fou et de Chen furent les principaux appuis du roi Siuen (827-782 av. J.-C.). 
00. (161) L'expression implique l'id ée d'un détachement, d'une autonomie qui n'appartenait pas à tous les seigneurs. En effet, si l'on jette un regard sur la carte de Chine à l'époque Tch'oen-ts'ieou, on voit, que, des nombreux princes descendants de Chen-nong, ceux de Ts'i et de Hiu seuls avaient des royaumes.

00. (162) Le duc Hoan de Ts'i (qui, d'après le deuxième tableau chronologique de Se-ma Tsien, régna de 685 à 643 av. J.-C.), fut le premier des cinq hégémons qui, de 685 à 591 avant J.-C., exercèrent tour à tour une influence prédominante dans l'empire féo dal gouverné nominalement par les Tcheou. Les quatre autres hégémons furent le duc Wen de Tsin, le duc Mou de Ts'in, le duc Siang de Song et le roi Tchoang de Tch'ou.

00. (163) C'est -à-dire Chen-nong.

00. (164) Cette seconde théorie parait être plus ancienne que la première ; en effet, quoique Se-ma Ts'ien ne la rapporte pas, un passage des Mémoires historiques (ch. VI, p. $10 \mathrm{v}^{\circ}$ ) nous prouve qu'elle avait cours dès le temps de $T$ s'in Che-hoang-ti; au moment où ce prince délibéra sur le titre quill prendrait, ses ministres lui dirent :

«Autrefois il y eut le souverain du ciel, le souverain de la terre et le souverain majestueux ; le souverain majestueux fut le plus élevé.

- Il est difficile de savoir à quelle époque on substitua le souverain de l'homme au souverain majestueux.

00. (165) D'après une légende, un dragon -cheval sortit du Hoang-ho sous les yeux de Fou-hi; il portait sur son dos un tableau sur lequel étaient tracés les huit trigrammes. Il existait autrefois un livre intitulé «le Tableau du Fleuve», en neuf chapitres (appendice au Tch'oen-ts'ieou, cité par le Dictionnaire de K'ang-hi, au mot t'ou). L'appendice au Tableau doit avoir été un complément de ce livre.

- Le mot wei désigne la trame d'un tissu comme le mot king en désigne la chaîne. Les wei sont ainsi le complément des king ou livres canoniques. On distingue les wei en sept classes suivant le livre canonique auquel ils se rattachent: ce sont les wei du I king, ceux du Chou king, ceux du Che king, ceux des Rituels, ceux de la musique, ceux du Hiao king et ceux du Tch'oen ts'ieou. On trouvera les titres des plus importants d'entre eux dans le Che t'ong t'ong che, chap. I, p. $4 \mathrm{r}^{\circ}$.

00. (166) Le T'ong kien hang mou, et, d'une manière générale, toutes les histoires de date récente comptent 13 souverains du ciel et non 12. Cette variante est très importante ; en effet, si l'on suppose 13 souverains du ciel ayant régné chacun 18,000 années, le total de leurs années sera $18,000 \times 13=234,000$. D'autre part les souverains de la terre sont au nombre de 11 qui ont régné chacun 18,000 années ; le total est pour eux de 18,000 x 11 =198,000 années. Si nous additionnons les règnes des souverains de la terre à ceux des souverains du ciel, nous obtenons un total de $234,000+198,000=432,000$ années.

Ce nombre est exactement celui qui représente la durée des dix dynasties babyloniennes antérieures au déluge, d'après Bérose ; c'est aussi celui qui exprime la longueur de la période Kali-youga en Inde (Fergusson, Chinese Chronology and Cycles, p. 139 ; T. P, Crawford, The ancient dynasties of Berosus and China compared with those of Genesis, Chinese Recorder, $\mathrm{t}$. XI, p. 411-429 ; t. XII, p. 77-86 et 193-201). Ce rapprochement est intéressant ; à supposer qu'il ne soit pas fortuit et que le chiffre de 12 souverains donné par Se-ma Tcheng soit une erreur, il prouvera simplement ceci : c'est qu'au V IIIe siècle de notre ère, à la suite de ses fréquentes relations avec les pays d'Occident et l'Inde, la Chine connut quelques-unes de leurs fables et modela son histoire légendaire d'après la leur.

00. (167) La constellation Ché-t’i est formée de deux astérismes composés l'un des étoiles ç, ô, õ, du Bouvier, l'autre des étoiles î, đ, aede la même constellation. Sur le rôle joué par la constellation Ché-t’i dans les anciens calculs du calendrier, cf. Le calendrier des Yn dans le Journal asiatique de novembre-décembre 1890, p. 463-510. 
00. (168) La montagne Hiong-eul, «oreilles d'ours », est située dans la sous-préfecture de Lou-che, préfecture secondaire de Chàn, province de Ho-nan ; c'est de la montagne Hiong-eul que sort la rivière $I$, qui se jette dans la rivière $L o$, affluent du Hoang-ho.

- Quant à la montagne Long-men, «porte du dragon », elle est située entre les rivières $I$ et $L o$, non loin de leur confluent.

Il ne peut être question ici de la montagne de même nom qui se trouve sur la rive droite du Hoang-ho, dans la province de Chàn-si.

00. (169) Proprement : neuf têtes. Le commentateur fait remarquer que le mot «tête » joue ici le rôle d'un classificateur ; c'est ainsi qu'on dit tant et tant de têtes, de bétail. Il ne faut donc pas entendre, comme l'a fait M. Edkins (Chinese Recorder, t. XV, p. 337, note), que le souverain de l'homme était une espèce de monstre à neuf têtes, mais bien qu'il y eut neuf souverains de l'homme.

00. (170) Mot à mot : montant sur des chars de nuages, attelant six ailes.

00. (171) Kou-k'eou était le nom d'une gorge de montagnes qui se trouvait dans la sous-préfecture établie par les Han sous le nom de Yun-yang (ap. commentaire du Livre des Han postérieurs, cité par le Fei wen yun fou à l'expression Kou-k'eou ). Cette sous-préfecture correspond à la sous-préfecture actuelle de Choen-hoa, préfecture secondaire de Pin, province de Chàn-si.

00. (172) Les neuf provinces sont énumérées et décrites dans le Tribut de $Y u$ (voyez plus loin : Annales principales des $\mathrm{Hia}$ ).

00. (173) C'étaien t, dit le commentaire, cinq frères qui, montés sur des dragons, s'élevaient à leur gré dans les airs.

00. (174) Cf. note 104.

00. (175) Ta-t'ing est la leçon de l'édition de 1596. L'édition de Kien-long écrit Fou-t'ing .

00. (176) Hoen-toen désigne proprement le chaos.

00. (177) On sait que le Livre des Vers ou Che king, existait en trois recensions principales, celle du pays de $L o u$, celle du pays de $T s$ 'i et celle du pays de Han. C'est à cette dernière que Se-ma Tcheng emprunte son renseignement.

00. (178) Le mont Leang-fou est une petite hauteur au pied du Tai-chan. Cf. note 2 de la p. 9.

00. (179) Tchong-ni est le surnom de Confucius.

00. (180) Cf. note 124 .

00. (181) I-ou est le nom personnel de Koan-tse. Cette citation se retrouve plus complète dans le traité sur les sacrifices fong et chan de Se-ma Ts'ien; elle est extraite du $50^{\mathrm{e}}$ article des œures de Koan-tse.

00. (182) C'est-à-dire comment ils faisaient les sacrifices fong et chan qui étaient la déclaration de la prise de possession du pouvoir.

00. (183) Une citation semblable à celle qui va suivre se trouve dans le T'ong kien kang mou qui l'attribue au livré intitulé Yuen ming pao; or le Yuen ming pao est indiqué par le Che t'ong t'ong che (chap. I, p. $4 \mathrm{r}^{\circ}$ ) comme étant un des appendices ou wei (cf. note 165) du Tch'oen ts'ieou. C'est donc, selon toute vraisemblance, à ce livre que Se-ma Tcheng se référait.

00. (184) La séparation du ciel d'avec la terre, c'est -à-dire le commencement du monde.

00. (185) Le lin (cf. Mayers, Chin. Reader's Manual, $\mathrm{n}^{\circ}$ 389) est un animal fabuleux dont l'apparition est regardée comme un présage surna turel ; un lin fut pris du temps de Confucius, 


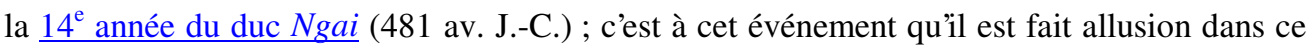
passage.

00. (186) Le T’ong kien kang mou écrit 2,267,000 années.

00. (187) Ce membre de phrase ne se retrouve pas dans la citation que fait le T'ong kien kang mou ; .... Dans le sens que nous donnons à ce texte [qui ne laisse pas d'être obscur], chaque génération aurait une durée moyenne d'en viron quarante-six ans et demi.

00. (188) La période des neuf têtes est celle des neuf souverains de l'homme mentionnés plus haut dans une autre tradition. De même la période des cinq dragons est commune aux deux systèmes chronologiques. M. Herb. J. Allen a cherché à dégager le sens de ces noms dans un article de la China Review (vol. XIV, p. 21-28) intitulé Pan-kou; mais son étude ne nous paraît pas conduite avec une méthode assez rigoureuse pour que nous puissions en admettre les résultats.

00. (189) Nous lisons dans le T'ong kien kang mou que la neuvième période ou période Chan-t'ong finit à Yen-ti et que la dixième période ou période Lieou-ki commence à Hoang-ti.

\section{CHAPITRE PREMIER. LES CINQ EMPEREURS}

01. (101) Les cinq empereurs correspondant aux cinq éléments sont, dans le système de Se-ma Ts'ien : Hoang-ti (terre); Tchoan-hiu (bois); K'ou (métal); Yao (feu); Choen (eau).

01. (102) Ta Tai li : Chap. VII, Ou ti.

01. (103) Hoang-ti signifie l'empereur jaune ; le jaune est en effet la couleur qui correspond à l'élément terre. - On verra plus loin dans ce même chapitre que Hoang-ti est appelé quelquefois l'empereur Hong et quelquefois Yeou Hiong-che.

01. (104) Chao-tien est donné par Se-ma Tcheng comme étant aussi le père de Yen-ti Chen-nong. Si l'on s'en tient au texte du Kоио уи cité dans la note 00.141, Chen-nong et Hoang-ti seraient donc frères. Mais, d'après Se-ma Tcheng, Chen-nong et Hoang-ti sont distants l'un de l'autre de cinq cents années environ ; il faut donc admettre que Chao-tien n'est pas le nom d'un homme, mais celui d'un État dont les princes engendrèrent à des époques très différentes Chen-nong puis Hoang-ti; Se-ma Tcheng confirme son dire en citant une phrase des Annales principales des Ts'in (Mém. hist., ch. V, p. $1 \mathrm{v}^{\circ}$ ) d'après la quelle un ancêtre des $T s^{\prime}$ 'in aurait épousé une fille de Chao-tien; comme cet ancêtre des $T s^{\prime}$ in vivait longtemps après Hoang-ti, le Chao-tien dont il est ici question ne peut donc être que le nom d'un État. - En réalité l'hypothèse de Se-ma Tcheng n'est qu'un expédient subtil pour concilier les incohérences des anciennes légendes.

01. (105) Se-ma Ts'ien dit que le nom de clan de Hoang-ti était Kong-suen; mais nous avons fait remarquer que cet auteur méconnaît l'antique distinction des noms de clan et des noms de famille (cf. note 00.103). Kong-suen n'est pas un nom de clan, mais un nom de famille ; le nom de clan de Hoang-ti était, d'après Hoang-fou Mi, Ki.

01. (106) Le T'ong kien kang mou (ts'ien pien, chap. a, p. $10 \mathrm{r}^{\circ}$ ) dit :

«Une concubine du prince du royaume de Chao-tien, nommée Fou pao, fut émue en voyant la lueur d'un éclair entourer la Gra nde Ourse et conçut; elle enfanta l'empereur sur la colline de Hien-yuen; c'est pourquoi son nom personnel fut Hien-yuen.

— D'après le T'ong hien tsi lan (ch. I, p. 5 r ${ }^{\circ}$ ), Hien-yuen se trouvait dans la sous-préfecture actuelle de Sin-tcheng, préfecture de K'ai-fong, province de Ho-nan: D'après le Choei king tchou che (chap. XVII, p. $10 \mathrm{v}^{\circ}$ ), Hien yuen était le nom d'une gorge de montagne dans la préfecture secondaire de $T$ s in , province de Kan-sou. - Une autre interprétation que rapporte 
le Lu li tche, du Ts'ien Han chou (chap. XXI b, p. 15 r $^{\circ}$ ) considère Hien-yuen comme un surnom qui fut donné à Hoang-ti parce qu'il inventa les vêtements longs (yuen) et le chapeau en forme de char (hien). — Cf. le P. L. Gaillard, Croix et swastika, p. 264-268.

01. (107) On appelle [], proprement : faible, tendre, l'enfant qui n'a pas encore soixante -dix jours.

01. (108) Lorsque l'homme prend à vingt ans le bonnet viril, on l'appelle homme fait.

01. (109) Chen-nong ou Yen-ti est le dernier des trois souverains d'après Se-ma Tcheng. Voyez plus haut, p. $\bullet 12$ et suiv.

01. (110) Ce passage donne à entendre que Se-ma Ts'ien, d'accord avec le Koиo yи (cf. n. 00.141), considère Chen-nong et Hoang-ti comme contemporains. Chen-nong, frère de Hien-yuen, était empereur; ses parents et ses enfants qui étaient des seigneurs n'obéissaient pas à ses ordres; Hien-yuen se chargea de les ramener au devoir. Plus tard cependant, Chen-nong fut injuste envers les seigneurs; alors Hien-yuen le combattit, lui enleva le pouvoir et devint lui-même empereur sous le nom de Hoang-ti.

01. (111) Dans les Rites de Tai l'aîné, au chapitre de l'Emploi des soldats ( Ta Tai li, section 75), on lit que «Tch'e-yeou fut un ambitieux sorti du peuple. »Ce texte a une certaine autorité aux yeux des critiques chinois parce que le chapitre d'où il est extrait fut, dit-on, écrit par Confucius pour répondre aux questions du duc Ngai de Lou. Cependant, d'après le texte de Se-ma Ts'ien, il semble que Tch'e-yeou n'était pas un homme vulgaire, mais un seigneur. - Tchang Cheou-kié, citant un livre intitulé Long yu ho t'ou, dit :

«Quand Hoang-ti était régent de l'empire, il y avait quatre-vingt un frères appelés Tch'e-yeou; ils avaient tous des corps de bêtes et des voix humaines, des têtes de cuivre et des fronts de fer ; ils mangeaient du sable ; ils fabriquèrent les cinq sortes d'armes de guerre, des glaives, des lances et de grandes arbalètes ; ils terrorisaient le monde ; ils massacraient et tuaient sans raison. Les dix mille familles donnèrent avec respect à Hoang-ti le mandat de remplir la tâche du Fils du ciel. Hoang-ti ne parvint pas à réprimer Tch'e-yeou par la bonté et la justice ; alors il leva les yeux au ciel et soupira. Le ciel envoya une femme sombre qui descendit et vint donner à Hoang-ti un écrit scellé sur la guerre ; il subjugua Tch'e-yeou. Dans la suite, l'empire fut de nouveau troublé ; Hoang-ti dessina alors l'image de Tch'e-yeou pour effrayer l'empire ; tous dirent que Tch'e-yeou n'était pas mort et que dans les huit directions tout allait être détruit.

On voit dans cette légende que le premier écrit sur l'art de la guerre passe pour avoir été communiqué d'une m anière surnaturelle à Hoang-ti.

01. (112) Ta Tai li : Chap. VII, Ou ti té.

01. (113) Les cinq influences sont celles des cinq éléments primordiaux.

01. (114) D’après Tcheng Hiuen les cinq semences sont celles des cinq céréales, à savoir : le millet glutineux (Panicum miliaceum), le millet commun (Panicum miliaceum, autre variété), une sorte de haricot (Soja hispida), le blé et l'orge, le riz (cf. Breischneider, Botanicon sinicum, $\left.\mathrm{n}^{\circ} 335\right)$.

01. (115) Ce passage rappelle les beaux vers où Lucrèce nous représente les anciens cherchant à employer dans les combats des animaux furieux (De natura rerum, chant V, vers 1307 et suiv.)

Tentarunt etiam tauros in moenere belli,

Expertique sues saevos sunt mittere in hostes;

Et validos Parthi prae se misere leones

Cum ductoribus armatis saevisque magistris,

Qui moderarier hos possent vinclisque tenere... 
Le fonctionnaire qui, à la cour des anciens souverains chinois, avait la charge de ces animaux de combat, s'appelait le fou pou-che, c'est-à-dire celui qui soumet ceux qui ne sont pas soumis. Il est mentionné dans le Tcheou li chap. XXVIII et XXX, trad. Biot, t. II, p. 147 et 209). - Il n'y a pas lieu de pren dre en considération l'explication trop ingénieuse de Tchang Cheou-kié d'après qui ces noms de bêtes féroces étaient les appellations que Hoang-ti donnait à ses soldats pour effrayer l'ennemi (cf. aujourd'hui encore les soldats appelés tigres).

01. (116) Les Rites de Tai l'aîné écrivent « l'empereur rouge » au lieu de Yen-ti. Ce souverain régnait en effet par la vertu du feu, élément auquel correspond la couleur rouge.

01. (117) Pan-k'iuen, c'est-à-dire la source de la montagne Pan, se trouvait à peu de distance (1 li suivant les uns, 5 li suivant les autres) de Tchouo-lou qui fut la capitale de Hoang-ti. Tchouo-lou était situé au sud de la préfecture secondaire de Pao-ngan, préfecture de Siuen-hoa, province de Tche-li. Pao-ngan se trouve en dehors de la première grande muraille au bord d'un des cours d'eau dont la réunion constitue le Yong-ting-ho.

— La bataille que Hoang-ti livra dans la plaine de Pan-k'iuen était célèbre avant le temps de Se-ma Ts'ien car il y est fait allusion dans le Tso tchoan (cité dans le T'ong kien tsi lan, chap. I, p. $5 \mathrm{r}^{\circ}$ ) ; ainsi, quoique le Chou king et le Che king ne fassent pas mention de Hoang-ti, les légendes relatives à ce souverain sont anciennes.

01. (118) Voyez la note précédente.

01. (119) La montagne Hoan était située dans la sous-préfecture actuelle de Lin-kiu, préfecture de Ts'ing-tcheou, province de Chan-tong. D'après la géographie Kouo ti tche, elle s'appelait aussi la montagne Tan, et donnait naissance à la rivière Tan.

01. (120) Le Tai-tsong est la cime orientale du T'ai-chan, dans la préfecture secondaire de T'ai-ngan, province de Chan-tong.

01. (121) Il existe deux montagnes appelées K'ong-t'ong dans la province de Kan-sou; l'une est située à l'est de cette provinee, dans la préfecture de P'ing-Leang; l'autre est située beaucoup plus à l'ouest, dans la préfecture secondaire de Sou non loin de la célèbre passe appelée Kia-yu-koan. Toutes deux passent pour avoir reçu la visite de Hoang-ti. Parmi les légendes taoïstes qui se sont accumulées autour du nom de Hoang-ti, il en est une d'après laquelle ce souverain aurait reçu du sage Koang-tch'eng-tse les enseignements taö̈stes sur la montagne K'ong-t'ong : on lira le récit de l'entrevue de Hoang-ti et de Koang-tch'eng-tse dans quelques belles pages de Tchoang-tse (chap. XI ; cf. trad. Legge, Sacred Books of the East, t. XXXIX, p. 297-300 ; [trad. Wieger, Les pères ... Tch11C]).

01. (122). Le mont Ki-t'eou, dont le nom signifie tête de coq, parait être une des cimes du massif appelé K'ong-t'ong ; c'est du mont Ki-t'eou que sort la rivière King mentionnée dans le Tribut de $Y u$ (voyez plus loin Annales fondamentales des Hia).

01. (123) Le Kiang est le Yang-tse-Kiang.

- Plusieurs montagnes en Chine portent le nom de Hiong ou Hiong-eul (proprement: oreilles d'ours). D'après les indications que nous donne le Kouo ti tche, celle dont il est ici question devrait se trouver à l'est de la préfecture secondaire de Chang, province de Chàn-si. Mais le contexte semble cependant indiquer que cette montagne devait se trouver beaucoup plus dans le sud.

- Quant à la montagne Siang, elle était dans la sous-préfecture actuelle de Pa-ling, préfecture de Yo-tcheou, province de Hou-nan; une devait donc être située sur la rive orientale du lac Tong-t'ing.

01. (124) Les Hiun-yu étaient les nomades qui habitaient les plaines de la Mongolie actuelle. D'après Se-ma Tcheng, on les appelait, au temps de Yao et de Choen, les Jong des montagnes ou les Hiun-yu; au temps des Hia, les Choen-wei (au début du CXe chapitre des Mémoires historiques, Choen-wei est donné par Se-ma Ts'ien comme le premier ancêtre des Hiong-nou) ; au temps des Yn, leur pays était désigné sous le nom de Koei-fang ; au temps des Tcheou, on les appelait les Hien-yun; au temps des Han, les Hiong-nou. 
- Ces nomades étaient sans doute connus des Chinois sous le nom de celle de leurs tribus qui avait la suprématie et lorsque cette suprématie passait d'une tribu à une autre, le nom par lequel on les désignait tous changeait aussi.

01. (125) La montagne Fou était située dans le voisinage immédiat de Tchouo-lou (cf. n. 117).

— La vérification des insignes consistait à réclamer à tous les vassaux la tablette qui leur conférait l'investiture et à constater que cette tablette se raccordait exactement avec une autre dont elle n'était qu'un morceau détaché. On verra plus loin que l'empereur $Y u$ passe pour avoir pris une mesure analogue à l'égard des seigneurs.

- S’il faut en croire un passage du T'ong ming ki de Kouo Hien (auteur du $1^{\text {er }}$ siècle de notre ère ; son opuscule est réimprimé dans le Han wei ts'ong chou, mais je n'ai pas pu y trouver le texte que cite ici Se-ma Tcheng), on devrait donner à cette phrase un tout autre sens : la montagne Fou serait une montagne merveilleuse située dans la mer orientale ; elle émettait une vapeur qui changeait de couleur suivant le souverain qui était appelé à régner ; elle était rouge pour Yao qui régnait par la vertu du feu ; elle était jaune pour Hoang-ti. La phrase de Se-ma Ts'ien signifierait donc que Hoang-ti se rendit sur la montagne Fou afin de vérifier que la vapeur magique était bien de la couleur çorrespondant à l'élément terre.

01. (126) Cf. n. 117. Tchouo-lou est ici le nom d'une mo ntagne.

01. (127) Cette phrase semble témoigner d'un ancien État nomade.

01. (128) Cf. n. 00.118.

01. (129) L'achillée est la plante dont les tiges servent à la divination. Il est assez difficile de voir quelle relation il y avait entre le trépied et l'achillée qui sont toujours mentionnés simultanément dans les légendes de Hoang-ti. Sur les travaux attribués à Hoang-ti relativement au calendrier, voyez dans le Traité sur les cérémonies fong et chan, les discours tenus par Kong-suen King à l'empereur $O u$ (cf. ma première trad. de ce traité, p. 66). — Une tradition rapportée par le Che pen dit :

«Hoang-ti, ayant reçu l'achillée magique, ordonna à Ta-nao de faire le cycle sexagénaire, et à Jong-tch'eng à de dresser le calendrier.

01. (130) Les noms de Fong-heou et de Li-mou ont donné lieu à une légende que Hoang-fou $M i$ rapporte dans son $T i$ wang che ki : Hoang-ti aurait vu en rêve un grand vent qui balayait toute la poussière, puis un homme qui tenait un arc énorme et gardait des brebis ; il en conclut que le ciel lui désignait ainsi les noms de ceux qu'il devait prendre pour conseillers ; en effet vent se dit fong - et poussière se dit keou; en retranchant de ce dernier caractère la clef qui se trouve à gauche, on obtient exactement le nom de Fong-heou; d'autre part, l'arc énorme suggère l'idée de force, $l i$, et le fait de garder les moutons suggère l’idée de berger, mou; on obtient ainsi le nom de Li-mou. Hoang-ti n'eut pas de cesse qu'il n'eût trouvé deux hommes répondant à ces noms.

- Nous ne savons rien sur Tch'ang-sien; quant à Ta-hong, le Traité sur les cérémonies fong et chan nous apprend que c'était le surnom d'un certain Koei-yu-kiu (cf. ma première trad. de ce traité, p. 68).

S’il fallait indiquer l'origine de ces légendes, nous ferions volontiers l'hypothèse qu'elles ont dû naître du désir d'expliquer les titres de certains ouvrages d'une haute antiquité que la croyance populaire rattachait au cycle littéraire de Hoang-ti. Ainsi, dans le XXXe chapitre du livre des Han antérieurs, nous voyons cités les treize chapitres du Fong heou, les quinze chapitres du Li mou, les trois chapitres du Koei yu kiu. Le sens de ces titres étant perdu, on imagina d'y voir des noms propres et, pour rendre compte du rapport qui existait entre ces livres et Hoang-ti, on crut que ces noms propres désignaient des officiers de ce souverain.

01. (131) Ta Tai li : Chap. VII, Ou ti té. 
01. (132) La terre et le ciel, l'obscur et le clair, la mort et la vie, le trouble et le calme sont des séries de termes antithétiques qui dérivent de la grande opposition primitive des principes yn et yang.

01. (133) Le mot tch'en désigne les syzygies de conjonction. Les syzygies de conjonction ont une grande importance dans le calendrier chinois, car elles sont prises comme point de départ dans le calcul des lunaisons. Le premier jour de la lunaison est le jour de la syzygie de conjonction.

01. (134) Il indiqua les lieux où il fallait construire des digues et ceux où il fallait laisser s'échapper l'eau des fleuves ; il détermina les endroits qu'on devait défricher par le feu et ceux où on devait s'en abstenir. Tel est le sens que Tchang Cheou-kié voit dans la phrase : «Il régla l'usage de l'eau et du feu. »

01. (135) Ce présage fut l'apparition d'un dragon de couleur jaune ; nous avons vu que le nom de Hoang-ti signifie l'empereur jaune.

01. (136) Le Kouo yu (chap. X, p. 10 r $^{\circ}$ ) dit aussi :

«Hoang-ti eut vingt-cinq fils qui fondèrent des familles; ceux qui eurent des noms de clans furent au nombre de quatorze répartis entre douze clans qui sont ceux de Ki, Yeou, K’i, Ki, T'eng, Tchen, Jen, Siun, Li, Ki, Tsiuen, I .

Mais il est assez malaisé d'établir, d'après le Коио уи, quels sont les quatre fils qui n'ont que deux noms de clans; en effet le Коио уи dit d'une part que Ts'ing-yang (celui qui fut empereur sous le nom de Chao-hao) et I-kou eurent tous deux pour nom de clan $\mathrm{Ki}$, et d'autre part il dit que ce même Ts'ing-yang et Ts'ang-lin eurent tous deux pour nom de clan Ki. Ces deux assertions sont contradictoires. Se-ma Tcheng suppose que dans la seconde il faut remplacer Ts'ing-yang par Hiuen-hiao (le grand-père de l'empereur K'ou), et dire que Hiuen-hiao et Ts'ang-lin eurent tous deux pour nom de famille $K i$. Il est vrai que l'explication de Se-ma Tcheng n'est admiss ible que si l'on accepte, comme lui, la théorie de Hoang-fou Mi suivant laquelle Hiuen-hiao et Ts'ing-yang sont deux personnages différents ; d'après Se-ma Ts'ien, ces deux noms s'appliquent à un seul et même homme, comme on va le lire quelques lignes plus bas.

01. (137) Ta Tai li : Chap. VII, Ti hi.

01. (138) Cf. n. 106.

01. (139) Tchang Cheou-kié : Si-ling est le nom d'un royaume.

01. (140) Lei-tsou passe pour avoir enseigné au peuple l'art d'élever les vers à soie. On remarquera que Se-ma Ts'ien omet les légendes qui rapportent l'invention de tous les arts à l'époque de Hoang-ti.

01. (141) D'après Se-ma Tcheng, Hoang-ti, pour imiter les quatre étoiles appelées les Concubines impériales, prit quatre femmes. Hoang-fou Mi donne leurs noms :

* la première était originaire de Si-ling et s'appelait Lei-tsou ; elle enfanta Tch'ang -i ;

* la seconde était originaire de Fang-lei et s'appelait Niu-kié; elle enfanta Ts'ing -yang ;

* la troisième était originaire de T'ong-yu et enfanta I-kou qui s'appelle aussi Ts'ang-lin ;

* la quatrième était Mo-mou.

Cette tradition diffère de celle qui est adoptée par Se-ma Ts ien, puisque celui-ci nous dit que Lei-tsou enfanta Tch'ang-i et Ts'ing-yang. Elle diffère aussi de celle du Коио yи suivant lequel I-kou et Ts'ang-lin sont deux personnages différents, et de celle de Pan Kou qui, dans le chapitre Kou kin jen piao du livre des Han antérieurs, dit que T'ong -yu enfanta I-kou et que Mo-mou enfanta Ts'ang-lin. 
01. (142) On verra plus loin que Tch'ang-i fut le père de l'empereur Tchoan-hiu et que Ts'ing-yang fut le grand-père de l'empereur K'ou. - D'après Hoang-fou Mi, Ts'ing-yang exerça lui-même le pouvoir souverain et fut appelé l'empereur Chao-hao (cf. n. 00.102). Mais Se-ma Ts'ien ne parle pas de cet empereur dans le premier chapitre de son histoire, quoiqu'il en rappelle le nom dans divers autres endroits (cf. Traité sur les sacrifices fong et chan).

01. (143) Se-ma Tcheng, se fondant sur un passage du Choei king, pense que la rivière Kiang n'est autre que la rivière Lou-Kiang, cours d'eau qui se trouve dans la province de Se-tch'oan.

D’après Tchang Cheou-kié, la rivière Kiang arrosait l'ancien État de Kiang qui était situé dans la préfecture secondaire de $Y u$, province de Ho-nan.

01. (144) Le Choei king tchou che (ch. XXXVI, p. $4 \mathrm{r}^{\circ}$ ) rapporte la même légende. D’après la description que le Choei king donne de la rivière Jo, ce cours d'eau aurait passé par la préfecture de Ning-yuen, province de Se-tch'oan ; or la rivière qui arrose cette ville se réunit plus au sud, dans le territoire de la préfecture secondaire de Hoei-li, au Yang-tse ; mais on sait que les géographes chinois regardent la rivière Min, comme étant le cours principal du Yangtse ; c'est ce qui explique pourquoi le Choei king considère comme faisant aussi partie de la rivière $J o$ toute la section du fleuve appelé encore Yang-tse par les géographes européens, entre la préfecture secondaire de Hoei-li et la préfecture de Siu-tcheou.

- Tch'ang-i, fils de Hoang-ti, est tenu pour le premier ancêtre des princes de Chou.

01. (145) Dans d'autres textes, cette femme est appelée Niu-tch'ou.

01. (146) Hoang-fou Mi dit que Hoang-ti mourut à l'âge de cent onze ans, après avoir régné cent ans. C'est aussi la durée que les chronologies vulgaires assignent au règne de Hoang-ti. D'après les indications que donne la géographie Kouo ti tche, la tombe de Hoang-ti serait située dans la sous-préfecture actuelle de Tchen-ning, préfecture de K’ing-yang, province de Kan-sou.

- Tchen-ning se trouve sur un petit affluent de gauche de la rivière Wei. — D'après un autre texte, la montagne Kiao serait située plus au nord-est, dans la sous-préfecture de Ngan-ting, préfecture de Yen-ngan, province de Chàn-si.

01. (147) Ta Tai li : Chap. VII, Ou ti té.

01. (148) La traduction que nous donnons de cette phrase est conforme au commentaire de $\mathrm{Se}$ ma Tcheng.

- D’après Tchang Cheou-kié, l'ex pression koei chen désignerait, non les âmes des morts, mais les dieux des montagnes et des cours d'eau.

01. (149) Tchang Cheou-kié : c'est l'arrondissement de Yeou. — L'arrondissement qui portait ce nom à l'époque des T'ang se trouvait au sud-est de Péking.

01. (150) Le Kiao-tche correspond au Tonkin actuel.

- Le nom de Kiao-tche est écrit parfois [] ; avec cette dernière orthographe, il signifie «doigts du pied croisés ». D'après un auteur annamite cité par M. des Michels ( Du sens des mots " Giao-chi » dans le Recueil de textes et de trad. pub. par l'École des langues orientales en 1889, p. 293-297),

« le gros doigt du pied chez les Giao-chi était largement écarté. Lorsqu'ils se tenaient debout en rapprochant leurs deux pieds l'un contre l'autre, les deux orteils se croisaient.

Cette fable est répétée à satiété par les commentateurs chinois. Mais M. des Michels fait remarquer avec raison que les Annamites ne présentent point cette particularité physiologique; il revient donc à la première orthographe et explique Kiao-tche comme signifiant «le point où les zones frontières des deux pays se joignent ». Cependant on pourra objecter que, si le sens de Kiao-tche est si simple, il est bien surprenant que les Chinois eux-mêmes ne l'aient pas aperçu et qu'ils aient eu recours, pour exp liquer cette expression, à 
la légende des orteils écartés. C'est pourquoi certains auteurs ont pensé que Kiao-tche n'avait aucun sens et n'était qu'une transcription phonétique d'un nom indigène dont on pourrait peut-être retrouver la trace dans la Cattigara de Ptolémée et dans le nom de Kesho qui désignait récemment encore Hanoï (Richthofen, China, t. I, p. 510, n. 2).

- Pour ma part, considérant que le Kiao-tche est appelé Nan-kiao = le Kiao du sud, dans le Chou king, je serais disposé à voir dans le mot kiao seul une transcription phonétique et à prendre le mot tche dans son sens ordinaire de "pays au pied d'une montagne »; ainsi le Tonkin serait appelé soit le Kiao du sud, soit le pays de Kiao qui est au pied des montagnes.

- On remarquera que les limites de l'empire de Tchoan-hiu sont portées beaucoup plus au sud que celles de l'empire de Hoang-ti (cf. p. 29 et 30); il est évident d'ailleurs que la légende ne repose ici sur aucun fondement réel.

01. (151) Le Leou-cha ou «sables mouvants » est le nom que prend le désert de Gobi en dehors de la passe appelée Kia-yu-koan.

01. (152) Le Hai wai king (partie du Chan hai king), cité par P'ei Yn, dit :

«Dans la mer orientale on trouve une montagne qui s'appelle Tou-souo. Sur cette montagne est un grand pêcher (l'arbre P'an-mou dont il est ici parlé) qui a trois mille $l i$ de circonférence. Au nord-est est une porte qui s'appelle la porte des génies ; c'est là que se rassemblent les dix mille gén ies. L'empereur du ciel en a confié la garde aux hommes divins ; l'un de ceux -ci s'appelle Yu-tié; ils passent en revue et gouvernent les dix mille génies. Si un génie fait du mal aux hommes, ils l'enchaînent avec des liens de roseau, ti rent sur lui avec des arcs faits en bois de pêcher et le jettent en pâture au tigre.

- Yu-tié a pour compagnon T'ou-yu. Ces deux personnages sont considérés aujourd'hui comme les divinités protectrices des portes (cf. China Review, vol. IX, p. 20 ; de Groot, Les fêtes annuelles à Emoui, trad. française, p. 597 et suiv.).

01. (153) Le Che pen appelle ce personnage K'iong-che ; dans le système chronologique de Se-ma Ts'ien, ce fut l'ancêtre de l'empereur Choen.

01. (154) Hoang-fou Mi dit que Tchoan-hiu mourut à l'âge de quatre-vingt-dix-huit ans, après avoir régné soixante-dix-huit années. - On montre la tombe de Tchoan-hiu au nord-est de la sous-préfecture de Hoa, préfecture de Wei-hoei, province de Ho-nan (T'ong kien tsi lan, ch. I, p. $\left.12 \mathrm{r}^{\circ}\right)$.

01. (155) D'après Tchang Yen, Kao-yang et Kao-sin sont les noms des localités où fleurirent les empereurs Tchoan-hiu et K'ou. - La ville de Kao-yang était située dans la sous-préfecture de $K^{\prime} i$, préfecture de K'ai-fong, province de Ho-nan; le village de Kao-sin se trouve dans la sous-préfecture de Chang-kieou, préfecture de Koei té, province de Ho-nan (T'ong kien tsi lan, ch. I, p. $11 \mathrm{r}^{\circ}$ et $12 \mathrm{r}^{\circ}$ ).

— D'après Hoang-fou Mi, le nom personnel de l'empereur K'ou était Ts'iun.

01. (156) Hoang-fou $M i:$ Il établit sa capitale à Po.

- Cette ville passe aussi pour avoir été la capitale de T'ang, fondateur de la dynastie des $Y n$; c'est aujourd'hui la ville de Yen-che, préfecture de Ho-nan, province de Ho-nan.

01. (157) Le mot «neveu» ne rend pas exactement l'expression chinoise. Kao-sin était, à parler exactement, le fils du cousin germain de Tchoan-hiu.

01. (158) Ta Tai li : Chap. VII, Ou ti té.

01. (159) C'est-à-dire quill établit un calendrier pour prévoir l'apparition et la disparition du soleil et de la lune. 
01. (160) Tchang Cheou-kié : les esprits du ciel s'appellent chen: les esprits des hommes s'appellent koei. - Les puissances surnaturelles que vénérait l'empereur K'ou étaient donc les dieux célestes et les génies ou âmes des morts.

01. (161) Ta Tai li : Chap. VII, Ou ti té.

01. (162) Le Che pen (Ti hi pien, ch. IV dans l'édition du Tchang che ts'ong chou, p. $7 \mathrm{v}^{\circ}$ ) dit :

«L'empereur K'ou tira les sorts au sujet des fils de ses quatre femmes et reconnut qu'ils seraient tous empereurs. Sa première fe mme était une fille de la famille des princes de T'ai et s'appelait Kiang-yuen elle enfanta Heou-tsi (c'est l'ancêtre de la dynastie Tcheou). Sa seconde femme était une fille de la famille des princes de Song et s'appelait Kien-ti; elle enfanta Sié c'est l'ancêtre de la dynastie Chang). Sa troisième femme était une fille de la famille Tch'en-fong et s'appelait K'ing -tou; elle enfanta l'empereur Yao. Sa quatrième femme était une fille de la famille Tsiu-tse et s'appelait Tch'ang - $i$ : elle enfanta Tche.

01. (163) Tchang Cheou-kié : Le nom de Fang-hiun signifie : (celui qui sait) imiter la gloire (de ses ancêtres). - La plupart des commentateurs admettent que ce fut le nom personnel de Yao.

01. (164) L'empereur Tche n'a trouvé place dans aucun système chro nologique ; on voit que Se-ma Ts'ien le mentionne mais sans le compter au nombre des cinq empereurs; il en est de même du T'ong kien kan mou et du T'ong kien tsi lan qui lui attribuent neuf ans de règne, mais ne le font pas rentrer dans leur liste de souverains ; enfin le Tchou chou ki nien identifie Tche avec Chao-hao et le place immédiatement après Hoang-t $i$; mais ces Annales n'assignent aucune durée au règne de ce souverain et par conséquent leur série de cinq empereurs reste identique au fond à celle de Se-ma Ts'ien .

01. (165) Le Hoang lan dit que la tombe de l'empereur K'ou se trouvait au sud de Toen-k'ieou ; Toen-k'ieou était au sud-ouest de la sous-préfecture de Ts'ing-fong, préfecture de Ta-ming, province de Tche-li. — Le Hoang lan est le titre d'un livre qui traitait des sépultures des souverains ; il fut composé au temps de la dynastie Wei (220-264) par Wang Siang et Mieou Si (Che t'ong t'ong che, chap. V, p. $4 \mathrm{v}^{\circ}$ ).

01. (166) Yao est un titre posthume qui signifie : soutenir le bien et répandre la sainteté. — On trouve souvent aussi Yao désigné par les noms de T’ang ou de T'ao Tang; Hoang-fou l'explique en disant que, sous le règne de l'empereur Tche, Yao fut nommé seigneur du pays de T'ang; il avait été auparavant seigneur du pays de T'ao. T'ao correspond à la sous-préfecture actuelle de Ting-t'ao, préfecture de Ts'ao-tcheou, province de Chan-tong. T'ang est aujourd'hui la sous-préfecture de même nom, préfecture de Pao-ting, province de Tche-li.

— Le nom de clan de Yao était Ki. Mais, grâce à la confusion qui s'est établie entre les noms de clan et les noms de famille (cf. n. 00.103), certains auteurs, tels que Hoang-fou Mi, disent que le nom de clan de $Y a o$ fut le nom de famille $I-k$ i. $I$ est expliqué comme le nom du lieu où la mère de Yao l'enfanta ; c'est aujourd'hui la sous -préfecture de I-yang, préfecture de Joutcheou, province de Ho-nan.

01. (167) Ta Tai li : Chap. VII, Ou ti té.

01. (168) De près il était comme le soleil qui réchauffe tout de son ardeur bienfaisante; de loin il était comme les nuées qui couvrent le ciel et répandent une pluie fertilisante.

01. (169) Le mot [] désigne, dans l'acception où il est pris ici, une sorte de bonnet qui fut en usage jusque sous la dynastie des Hia.

01. (170) Chou king : Yao tien.

01. (171) Le mot [] est remplacé dans le texte du Chou king par le mot [] et la phrase doit être alors traduite : il savait mettre en lumière les hommes capables et vertueux. 
01. (172) Les neuf degrés de parenté comprennent tous les parents par agnation depuis le trisaïeul jusqu'à l'arrière -arrière-petit-fils. Une autre interprétation veut introduire dans les neuf degrés des parentés collatérales et des parentés par les femmes ; mais la première opinion est la plus généralement adoptée.

01. (173) Le mot [] employé ici par Se-ma Ts'ien dans le Chou king; mais ces deux caractères sont tous deux pris par abus pour représenter un ancien caractère inusité dont le sens est [] = distinguer, séparer (Chang chou heou ngan, dans H. T. K. K., chap. CCCCIV, p. 4 v).

01. (174) C'est sur l'autorité de K'ong Ngan-kouo que nous traduisons [] comme signifiant les cent fonctionnaires.

01. (175) Nous signalons ici (à partir des mots «par l'amour qu'il eut... » jusqu'aux mots « éclairés et intelligents ») un fragment en vers dans le texte du Yao tien. Les deux premiers vers ont pour rimes [] et [] qui, dans la théorie de Toan Yu-ts'ai, sont au jou cheng de la troisième catégorie (H.T.K.K., ch. DCLX, p. $4 \mathrm{v}^{\circ}$ ) ; les deux derniers vers ont pour rimes [] et [] qui sont au p'ing cheng de la onzième catégorie (loc. cit., p. $11 \mathrm{r}^{\circ}$ ). - Les deux phrases qui suivent dans le texte du Chou king forment aussi deux vers qui ont pour rimes [] et [] au p’ing cheng de la huitième catégorie; mais elles ont été modifiées dans le texte de Se ma Ts'ien.

01. (176) Dans ce passage et les suivants, il va être question de six personnages : deux d'entre eux sont $\mathrm{Hi}$ et $\mathrm{Ho}$; les quatre autres sont deux frères cadets de $\mathrm{Hi}$ et deux frères cadets de $\mathrm{Ho}$. Ces quatre derniers sont préposés aux quatre saisons, comme il ressort du texte même du Chou king. Quant aux deux premiers, ils avaient à s'occu per, s’il faut en croire Tcheng Hiuen, l'un du ciel, l'autre de la terre, c'est -à-dire l'un du principe yang et l'autre du principe $y n$, dont dépendent les quatre saisons ; une légende rapportait que l'empereur Kou avait préposé un certain Tchong au ciel et un certain Li à la terre; 'Tcheng Hiuen en conclut que Hi et $\mathrm{Ho}$ étaient les descendants de Tchong et de $\mathrm{Li}$.

01. (177) Les $Y u$ - $i$ (=barbares $Y u$ ), ou la localité appelée $Y u$-i, devaient se trouver à l'extrémité de la presquîle de Chan-tong. Le second des $H i$ présidait ainsi au côté de l'est et au printemps. Nous n'avons aucune raison d'adopter l'opinion qui placerait $Y u-i$ dans le Leao-tong ou en Corée, car une telle position, suivant la judicieuse remarque de Wang Koang-lou, n'aurait pas été l'est, mais le nord -est.

01. (178) Proprement : les occupations de l'est.

01. (179) Le jour moyen du printemps est celui qui est également éloigné du jour le plus court de l'hiver et du jour le plus long de l'été ; c'est donc l'équinoxe du printemps.

01. (180) Le mot niao = oiseaux, désigne proprement une partie du firmament. Le ciel était divisé en quatre régions que symbolisaient quatre animaux : à l'est correspondait le dragon ; à l'ouest, le tigre ; au nord, la tortue et au sud l'oiseau ( K. T. K. K., chap. CCCCIV, p. 10 r $^{\circ}$ ). Sept des vingt-huit constellations zodiacales étaient comprises dans chacune de ces régions ; d'après K'ong Ngan-kouo, le milieu du printemps était marqué par le fait que les sept constellations du côté sud étaient visibles vers le soir. Cependant dans deux des paragraphes suivants, c'est une constellation et non un groupe de cons tellations dont la culmination sert à marquer les grandes époques de l'année ; on a donc cherché à déterminer quelle était la constellation particulière qui indiquait l'équinoxe du printemps ; voyez sur ce sujet Legge, Chinese Classics, t. III, p. 19.

01. (181) Le peuple sort des maisons où il s'était tenu renfermé dur ant l'hiver et il se répand dans les champs pour les labourer.

01. (182) Les animaux viennent d'avoir des petits et sont occupés à les nourrir. Le Chou king écrit, au lieu du mot wei=petit que nous trouvons dans Se-ma Ts'ien, le mot wei=queue ; si on adopte la leçon du Chou-king, il faut la considérer comme étant une image très grossière et traduire wei par «copuler ». C'est l’interprétation de M. Legge. Mais la leçon des Mémoires 
historiques ne demande pas qu'on force ainsi le sens d'un mot et paraît préférable ; elle est adoptée par la plupart des critiques chinois (H.T.K. K., chap. CCCXC, p. $\left.13 \mathrm{v}^{\circ}\right)$.

01. (183) K'ong Ngan-kouo explique nan kiao comme le lieu où l'été et le printemps se touchent (kiao) ; mais le sud symbolise l'été seul et non le rapport de l'été et du printemps ; d'ailleurs les trois autres points cardinaux sont désignés par des noms de lieu ; c'est pourquoi Se-ma Tcheng considère nan kiao comme un nom de lieu et fait de kiao une abréviation de Kiao-tche. Nous avons dit plus haut (n. 150) que l'empire de Tchoan-hiu passait pour s'être étendu jusqu'au Kiao-tche, c'est-à-dire jusqu'au Tonkin actuel. — Le troisième des $H i$ réside dans le sud et préside à l'été. Tcheng K'ang tch'eng fait observer avec raison qu'après les mots nan kiao devaient se trouver les trois mots yue ming tou. Ce membre de phrase est nécessaire en effet pour rétablir le parallélisme qui est manifeste dans tout ce passage.

* Le second des $H i$ demeure à l'est, dans le lieu appelée vallée du Soleil levant ;

* Le second des Ho demeure à l'ouest, dans le lieu appelé vallée de l'Obscurité ;

* Le troisième des Ho demeure au nord, dans le lieu appelé la Sombre Résidence ;

Il faut donc une quatrième phrase ainsi conçue :

* Le troisième des $\mathrm{Hi}$ demeure au sud, dans le lieu appelé la Claire Résidence.

01. (184) Se-ma Tcheng montre que la leçon du Chou king préconisée par K'ong Ngankouo est obscure et embarrassée. - D'une manière générale, si l'on veut b ien se rapporter à ce que nous avons dit de la constitution du texte du Chou king dans notre introduction, on verra que nous n'avons aucune raison de préférer a priori le texte traditionnel du Chou king à celui que nous donne Se-ma Ts'ien, puisque Se-ma Ts'ien écrivit avant l'établissement de ce texte traditionnel.

01. (185) C'est en été que les semences plantées par les laboureurs attei gnent leur entier développement. A côté de cette interprétation, il faut citer l'opinion de Tcheng K'ang-tch'eng qui croit voir dans cette phrase l'indication qu'on observait l'extrême limite atteinte par l'ombre de la tige du cadran solaire ; mais rien n'autorise une théorie aussi alambiquée.

01. (186) Le jour le plus long est le solstice d'été. - Il n'y a pas à pro prement parler de constellation ho; le mot ho signifie feu, et comme l'élément feu correspond au sud et par suite à l'été, on appelle constellations feu celles qui culminent au moment du solstice d'été ; on donne plus spécialement ce nom, parmi les sept constellations qui occupent la région du ciel symbolisée par le dragon, aux deux constellations centrales qui sont [] et [].

01. (187) En été, le peuple se répand en toujours plus grand nombre dans les champs; même les enfants et les vieillards sortent des maisons.

01. (188) D'après Tcheng K'ang-tch'eng, le mot ne signifierait pas changer, mais aurait son sens propre de cuir, peau : les plumes et les poils se faisant rares, on voit la peau qui est dessous.

01. (189) L'équinoxe d'automne est indiqué par la nuit de longueur moyenne et l'équinoxe du printemps par le jour de longueur moyenne. Le printemps correspond en effet au principe yang que symbolise le jour, et l'automne correspond au principe $y n$ que symbolise la nuit.

01. (190) Hiи occupe la place du centre parmi les sept constellations de la région du ciel symbolisée par la tortue. On donne souvent le nom de [] ou guerrier sombre à cette région du ciel; en effet une légende rapportée par le Seou chen ki raconte que le roi des démons se changea en une tortue que vainquit l'empereur sombre, au temps de Tcheou, de la dynastie des $Y n$.

Le nom du vainqueur est resté attaché à la région céleste que symbolise en réalité la tortue, comme on peut le voir sur toutes les représentations graphiques.

01. (191) Proprement : ont des plumes et des poils et renouvellent leurs plumes et leurs poils. 
01. (192) La leçon [] = les êtres qui se cachent, se retrouve, nous dit Se-ma Tcheng, dans le grand commentaire de Fou Cheng; Se-ma Ts'ien nous donne donc ici le texte moderne du Chou king (cf. H. T. K. K., chap. CCCXC, p. $17 \mathrm{v}^{\circ}$ ). L'édition classique du Chou king présente la leçon []$=$ les changements de l'hiver.

01. (193) Le solstice d'hiver indique le milieu de l'hiver. A ce moment les sept constellations de la région du ciel symbolisée par le tigre sont visibles au firmament et c'est la constellation centrale, mao, qui culmine.

- Les indications que nous donne ce texte sur les diverses constellations qui culminaient au ciel aux équinoxes et aux solstices peuvent donner la tentation de chercher à le dater en tenant compte de la loi de précession des équinoxes; Medhurst et le Dr Legge croient pouvoir trouver par ce moyen une confirmation de la chronologie du T'ong kien kang mou qui place le règne de Yao de 2357 à 2255 avant J.-C. Mais M. S. M. Russell, professeur d'astronomie au T'ong-wen-koan à Péking, a repris la question dans un article intitulé : Discussion of astronomical records in ancient Chinese books (Journal of the Peking Oriental Society, vol. II, $\mathrm{n}^{\circ} 3$ ); il montre que les indications de ce texte sont trop vagues pour permettre des calculs précis, qu'elles coïn cident en partie avec celles fournies par le Hia siao tcheng qui passe pour postérieur, enfin que la vague approximation à laquelle on pourrait arriver avec de telles données nous reporterait à une date postérieure de quelques siècles à celle de la chronologie ordinaire. Selon M. Russell, les étoiles mentionnées dans ce texte sont les suivantes : • de l'Hydre pour l'équinoxe du printemps, • du Scorpion pour le solstice d'été, • du Verseau pour l'équinoxe d'automne et • du Taureau pour le solstice d'hiver ; d'après les commentateurs chinois, ces observations étaient faites à 6 heures du soir.

01. (194) Ma Jong donne ce sens qui est tout à fait conforme à la signification du mot employé par Se-ma Ts'ien. D’après Tcheng K'ang-tch'eng, la leçon du Chou king serait [] et signifierait l'intérieur d'une chambre.

01. (195) Les commentateurs ont accumulé autour de ce passage toute leur science astronomique. Il nous suffit de n'y voir que ce qui s'y trouve exprimé, à savoir que, dès l'époque très reculée à laquelle remonte ce texte, les Chinois avaient évalué la durée de l'année avec une assez grande approximation, puisqu'ils l'estimaient à 366 jours, en second lieu qu'ils avaient recours à l'artifice des mois intercalaires pour rétablir l'ac cord entre l'année solaire et le calendrier lunaire. - Le Chou king met ce paragraphe dans la bouche de Yao s'adressant à $H i$ et à $H o$; il nous semble que c'est une modification relativement récente et que Se-ma Ts'ien nous présente le texte dans son intégrité en le laissant sous sa forme abrupte. Il n'est pas difficile en effet de reconnaître dans tout ce qui précède un vieux calendrier analogue au Hia siao tcheng qui se trouve dans les Rites de Tai l'aîné ou au Yue ling du Li ki ou au Che hiun kié du Tcheou chou; ce vieux débris de l'antiquité a été incorporé dans la légende de $Y a o$, mais devait former à l'origine un tout indépendant.

01. (196) Le caractère [] employé par Se-ma Ts'ien est, d'après Kiang Cheng (H.T.K.K., chap. CCCXC, p. $18 \mathrm{v}^{\circ}$ ), la bonne leçon ; le caractère [] qui se trouve dans le Chou king n'y aurait été introduit que par l'édition de la période k'ai yuen (713-741).

01. (197) Le texte de Se-ma Ts'ien est ici une traduction en caractères faciles d'une phrase en termes obscurs du Chou king. Il en sera souvent de même dans ce qui suit.

01. (198) L'opinion générale des commentateurs est que Kong-kong est le nom d'une fonction qui était celle d'intendant des travaux publics ou de surveillant des eaux. Mais Kiang Cheng (H. T. K. K. chap. CCCXC, p. $21 \mathrm{r}^{\circ}$ ) est d'avis que le personnage ici désigné ne remplis sait pas cette charge, puisque précisément Yao refuse de la lui confier : on voit en effet par ce qui suit que l'empereur cherchait quelqu'un qui fût capable de lutter contre l'inondation. Peut -être un des ancêtres de Kong-kong avait-il été intendant des travaux publics et le nom de la fonction était-il devenu celui de la famille (cf. n. 00.103).

01. (199) M. Legge traduit l'expression [] comme ne désignant qu'un seul personnage, le chef des quatre montagnes ; cette interprétation ne s'appuie que sur l'autorité de Tchou Hi et les commentateurs antérieurs admettent que les chefs des quatre montagnes sont plusieurs 
personnes ; cette opinion paraît beaucoup plus plausible, puisque, lorsque Yao s'est adressé aux chefs des quatre montagnes, on lit la phrase : Tous dirent. En outre, un texte du Коио уu (Tcheou yu, chap. III, p. $8 \mathrm{r}^{\circ}$ ) dit formellement, que les chefs des quatre montagnes étaient au nombre de quatre; il rappelle les récompenses données à $Y u$ et aux chefs des quatre montagnes qui l'avaient aidé dans ses travaux, puis il ajoute : ce roi (c'est-à-dire $Y u$ ) et ces quatre chefs... (c'est -à-dire les chefs des quatre montagnes). — Enfin on verra plus loin que les chefs des quatre montagnes sont dans une étroite relation avec les quatre portes de la capitale ou les quatre côtés de l'empire et paraissent être les surveillants des quatre points cardinaux. - Il ne faut pas enlever à ces vieilles légendes leur symétrie mathématique sous le prétexte de leur donner plus de vraisemblance.

Mais, ce premier point établi, il est assez difficile de savoir qui étaient ces chefs des quatre montagnes. D’après Tcheng K'ang-tch'eng, ces chefs étaient les intendants des quatre saisons ; c'étaient à l'origine, comme on l'a vu plus haut, le second et le troisième des $H i$, le second et le troisième des Ho. A la mort de ces personnages, les chefs des quatre montagnes furent au nombre de huit et s'appelèrent les pa po; quatre d'entre eux auraient précisément été ceux des ministres de Yao dont nous venons de voir les noms, Hoan-teou, Kong-kong, Fang-ts'i auxquels il faut ajouter Koen dont il sera question plus loin. Mais toute cette théorie n'est guère solide.

01. (200) Koen fut le père de l'empereur $Y u$, fondateur de la dynastie des Hia.

01. (201) Cette interprétation est celle de K'ong Ngan-kouo, mais le mot [] ne laisse pas que d'être obscur.

01. (202) A la fin de chaque période de trois ans, on examinait quelle avait été la conduite des fonctionnaires, et après trois de ces examens triennaux, c'est-à-dire au bout de neuf ans, on procédait aux promotions et aux révocations; c'est ce qui explique pourquoi Koen fut renvoyé au bout de neuf ans.

01. (203) Le mot [] pourrait signifier les ordres impériaux; mais d'après Tcheng K'ang-tch'eng, il s'agit ici d'un ordre céleste, de ce fameux décret d'en haut qui co nfère à un homme le droit de régner sur les autres.

01. (204) D'après les rites, l'homme doit être marié à trente ans et la femme à vingt ; l'homme qui dépassera trente ans sans s'être marié est appelé du nom particulier de koan; tel était le cas de Choen.

01. (205) Ce texte montre combien sont artificielles les généalogies de Se-ma Ts'ien qui font descendre de Hoang-ti tous les anciens souverains de la Chine. D'après le système de Se-ma Ts'ien (cf. Mém. hist., chap. XIII), Choen serait l'arrière-arrière-petit-fils du cousin germain de Yao. Au contraire, la légende telle que nous la trouvons ici veut qu'il ait été un homme du peuple. Ajoutons que si le système de Se-ma Ts'ien était exact, le mariage de Choen avec les deux filles de Yao serait une infraction scandaleuse aux règles de la morale chinoise.

01. (206) Les commentateurs sont généralement d'accord pour dire que Choen est un titre posthume. Quant au nom de $Y u$, l'exp lication la plus plausible est celle qui en fait le nom du lieu qui vit naître Choen. Mais les opinions varient au sujet de l'emplacement de cette localité. D'après les indications du Kouo ti tche cité par Tchang Cheou-kié, la ville de Yu aurait été située dans la sous-préfecture de P’ing-lou, préfecture secondaire de Kié, province de $C h \bullet n-s i$. D’après Kou Yé-wang, il faudrait l’identifier avez la sous-préfecture de Chang-yu, préfecture de Chao-hing, province de Tche-Kiang. Le Hiao king dit que Choen naquit à Yao-k'iu c'est-à-dire dans le Chan-tong, au sud de la sous-préfecture de Se-choei. Le dernier de ces textes serait le plus conforme au passage de Mencius (trad. Legge, p. 192), où il est dit que Choen était un homme du pays des barbares orientaux ; mais c'est la première hypothèse, celle qui place le lieu de naissance de Choen dans le $C h \bullet n s i$, qui est la plus généralement adoptée. - Le nom de clan de Choen était Yao. Yao passe aussi pour avoir été le nom du lieu où naquit Choen; on l'identifie avec la sous-préfecture de Yong-tsi, préfecture de P'outcheou, province de $C h \bullet n$-si. 
01. (207) On verra plus loin que le père de Choen s'appelait Kou-seou. les deux caractères qui entrent dans la composition de ce nom signifient tous deux «aveugle ». K'ong Ngan-kouo explique qu'il ne s'agit que d'un aveuglement moral ; mais rien dans le texte ne justifie cette interprétation.

01. (208). Comm. Tcheng-i: Les deux filles de Yao s'appelaient, l'une Ngo-hoang et l'autre Niu-yng ; la première n'eut pas de fils ; la seconde enfanta Chang-kiun.

01. (209) Le Koei est une petite rivière du $C h \bullet n$-si qui traverse la localité appelée aujourd'hui encore le village de $Y u$ (Choen), Yu-hiang, préfecture de P'ou-tcheou, et va se jeter dans le Hoang-ho. D'après K'ong Ngan-kouo, le mot Joei signifierait une petite crique et il faudrait traduire que Choen demeurait auprès d'une crique de la rivière Koei. D'autres commentateurs disent que ce mot désigne le confluent de deux rivières ou encore la rive nord d'une rivière. Selon d'autres aute urs enfin, Joei serait le nom d'un petit cours d'eau. affluent de la rivière Koei ; cette dernière interprétation est celle du T'ong hien tsi lan (ch. I, p. $15 \mathrm{r}^{\circ}$ ).

01. (210) Le sens que nous donnons à cette phrase ne s'accorde pas avec le texte du Chou king, mais on verra quelques pages plus loin que Se-ma Ts'ien l'entendait bien ainsi.

01. (211) Ici se termine, à quelques variantes près, la Règle de Yao, le premier chapitre du Chou king; on peut y distinguer trois sections: dans la première, on traite du bon gouvernement de Yao; dans la seconde, on montre comment il sut établir le calendrier et connaître les saisons; dans la troisième enfin, on met en lumière les principes au moyen desquels il choisissait les hommes à qui il voulait confier le gouvernement.

Le texte de Se-ma Ts'ien ne distingue pas le Choen tien du Yao tien; c'est artificiellement que le Chou king traditionnel a divisé ces deux chapitres (cf. mon Introduction, IIIe partie). En effet, tous les auteurs antérieurs au IIIe siècle de notre ère, lorsqu'ils citent des passages de ce qui est aujourd'hui appelé le Choen tien, les rapportent au Yao tien; les exemples qu'on en peut donner sont très nombreux; le plus célèbre se trouve dans Mencius (trad. de Legge, Chinese Classics, t. II, p. 229). Wang Sou (vers 256 ap. J.-C.) est le premier commentateur où l'on voie ces deux chapitres distingués ; plus tard, pour donner plus d'unité au pseudo Choen tien, on y ajouta un début de vingt-huit caractères qui ne se trouve naturellement pas dans $S e$ ma Ts'ien; on attribue cette interpolation à un certain Lieou Hiuen qui vivait sous la dynastie des Soei (581-618 ap. J.-C.) (cf. Ting Yen-kien, dans le Siu hoang Tsing king kié, chap. DCCCXLIV, p. $23 \mathrm{r}^{\circ}$ ). Ce que nous lisons dans Se-ma Ts'ien est donc le Yao tien en texte moderne, sans interpolation ni division artificielle ; aussi les critiques modernes qui ont tenté de reconstituer le Chou king ont-ils tous suivi le grand historien et écrivent-ils le pseudo Choen tien à la suite du Yao tien dont il n'est en réalité qu'une partie. (cf. Wang Ming-cheng, dans le Hoang Ts'ing king kié, chap. CCCCIV, p. $29 \mathrm{r}^{\circ}$ et Kiang Cheng, dans le même recueil, chap. CCCXC, p. $26 \mathrm{r}^{\circ}$ ).

M. Legge est d'avis que le Choen tien, tel que nous l'avons aujourd'hui, se compose de deux parties, l'une qui faisait partie du Yao tien, l'autre qui est un fragment du véritable Choen tien et il dit: "On ne peut trouver aucune citation où un paragraphe de cette seconde partie soit rapportée au Yao tien. » Cette affirmation est contredite par les faits : le Luen heng de Wang Tch'ong (Ier siècle ap. J.-C.) cite la dernière phrase du pseudo Choen tien comme appartenant au Yao tien; on trouvera d'autres citations analogues dans le DCCCXLIVe chapitre du Siu hoang Ts'ing king kié, p. $22 \mathrm{v}^{\circ}$. C'est donc le pseudo Choen tien tout entier, et non pas seulement une partie de ce chapitre, qui faisait corps primitivement avec le Yao tien.

01. (212) Chou king : Choen tien. [et Legge [css : édition/rechercher : '2.']]

01. (213) L'expression òu tièn « les cinq règles » ne se trouve que dans ce texte du Chou king : les commentateurs veulent y voir les cinq vertus qui règlent les relations de mari et femme, père et fils, souverain et sujets, frère aîné et frère cadet, ami et ami.

01. (214) D'après le texte du Chou king, il faudrait traduire : fut investi des cent surveillances, c'est -à-dire qu'il eut la surveillance générale des cent fonctionnaires. 
01. (215) Les quatre portes sont les portes de la capitale où Choen allait recevoir les seigneurs qui venaient des quatre points cardinaux. Certains commentateurs ont voulu y voir les quatre portes du Ming t'ang ou salle de la distinction où le Fils du ciel recevait les seigneurs en les distinguant suivant leurs rangs. Dans cette phrase, le mot $p \bullet n$ est l'équivalent du mot qui signifie « recevoir un hôte », tandis que, dans la phrase suivante, il a son sens propre « être un hôte ».

\section{1. (216) Chou king : Choen tien.}

01. (217) Au lieu de [], le Chou king écrit [] ; ce mot a le même sens, car le commentaire de Kou-Leang l'explique en disant : C'est une forêt au pied d'une montagne. On voit les libertés que Se-ma Ts'ien prend avec le texte du Chou king, substituant des gloses aux termes obscurs.

01. (218) Le texte de Se-ma Ts'ien est ici beaucoup plus clair que celui du Chou king et ne laisse aucun doute sur le sens de la phrase ; dans le Chou king, la concision est telle que le pseudo K'ong Ngan-kouo a pu en donner l'int erprétation suivante : «Le vent violent, le tonnerre et la pluie ne troublèrent pas », c'est-à-dire que, grâce au bon gouvernement de Choen, tout les phénomènes naturels se passèrent avec ordre. Mais le sens indiqué par Se-ma Ts'ien est le plus simple et le plus évident,

01. (219) Dès le premier examen triennal (cf. p. 51, n. 3), Choen est jugé digne d'exercer par procuration le gouvernement.

01. (220) C'est-à-dire que, ne se sentant pas capable de supporter le fardeau de l'État, Choen ne fut pas heureux d'entendre la proposition de Yao.

Le texte antique, adopté par le Chou king traditionnel, écrit [] il ne succéda pas, il ne voulut pas succéder. - Ce qui suit montre d'ailleurs que Choen ne persista pas dans son refus.

01. (221) Dans cette phrase, ajoutée au texte du Chou king, Se-ma Ts'ien nous donne son avis sur le sens très controversé de l'expression Wen-tsou. Wen-tsou — l'aïeul parfait, semble bien en tous cas être un ancêtre de Yao et c'est ainsi que le culte des ancêtres est la plus ancienne manifestation religieuse de l'esprit chinois.

- La glose de Se-ma Ts'ien implique une théorie quinaire que la doctrine des cinq éléments avait mise en vogue à son époque, mais qui paraît bien postérieure à l'âge du Yao tien. En effet, si Wen-tsou est l'aïeul à la cinquième génération, il faut de nécessité qu'à côté de son temple se soient trouvés les quatre temples du trisaïeul, du bisaïeul, de l'aïeul et du père (cf. Wang Koang-lou, dans H. T. K. K., ch. CCCCIV, p. $32 \mathrm{r}^{\circ}$ ). Mais le trisaïeul de Yao est Hoang-ti qui passe pour le premier des souverains; l'aïeul à la cin quième génération ne peut donc être que le ciel qui seul régna avant Hoang-ti ; c'est le ciel qui serait l'a ncêtre accompli, suivant Ma Yong. Nous ne craindrions pas, pour notre part, d'accepter cette interpréta tion qui montre bien comment le culte des ancêtres, fondement premier de la religion chinoise, se rattache par des gradations insensibles à l'adoration des forces naturelles. Le ciel est imposant par son immensité, mais si on le vénère, c'est parce qu'il est regardé comme le pre mier ancêtre, et cela non pas au figuré, mais au sens propre, car il est lui-même un souverain mort ou peut-être la réunion de toutes les âmes des souverains morts.

Le commentateur Tchang Cheou-kié explique d'une manière diffé rente le terme Wen-tsou dans lequel il veut voir non pas le nom d'un per sonnage, mais celui d'un temple. Quoique sa note se fonde sur la théorie des cinq empereurs d'en haut qui ne date guère que de l'époque des Han et ne saurait expliquer les anciennes conceptions théologiques chinoises, elle mérite d'être citée à cause des renseignements curieux qu'elle nous donne sur les cinq empereurs :

«L'ouvrage inti tulé : Chang chou ti ming yen dit : Les empereurs continuent le ciel : on leur élève des palais pour vénérer les diverses formes que prend le ciel. Les cinq palais au temps de Yao et de Choen étaient appelés les cinq palais; sous les Hia on les appelait les maisons des générations; sous les Yn, on les appelait les habitations diverses; sous les Tcheou, on les appelait la salle de la distinction.Tous ces édifices étaient les lieux où on sacrifiait aux cinq empereurs. 
Pour ce qui est du terme Wen-tsou, le nom du palais de l'empereur rouge, Piao-nou, est Wen-tsou ; l'essence du feu est l'éclat et la clarté ; c'est l'ancêtre de ce qui est parfait et manifeste; c'est pourquoi on appelle (ce palais) Wen-tsou, l'aïeul parfait ; sous les Tcheou, le nom en fut Ming-t'ang (salle de la distinction).

Pour ce qui est de Chen-teou le nom du palais de l'empereur jaune, Han-tch'eou-nieou, est Chen-teou; teou signifie «présider»; l'essence de la terre est pure et calme : elle préside aux quatre autres éléments, c'es t pourquoi on appelle (ce palais) Chen teou (le président saint); sous les Tcheou on l'appelait T'ai che (grande maison).

Pour ce qui est de Hien-ki, le nom du palais de l'empereur blanc, Tchao-kiu, est Hien-ki; $k i$ signifie régler; l'essence du métal coupe et tranche toutes choses ; c'est pourquoi on appelle (ce palais) Hien-ki (la règle manifeste); sous les Tcheou, on l'appelait Tsong-tchang.

Pour ce qui est de Hiuen-kiu, le nom du palais de l'empereur noir, Koang-ki, est Hiuen-kiu; kiu signifie règle ; l'essence de l'eau est sombre et obscure, elle peut peser le léger et le lourd; c'est pourquoi on appelle (ce palais) Hiuen kiu (la règle sombre); sous les Tcheou on l'appelait Hiuen-t'ang (la salle sombre).

Pour ce qui est de Ling-fou, le nom du palais de l'empereur vert, Ling-wei-yang, est Ling-fou ; sous les Tcheou on l'appelait Ts'ing-yang (principe yang vert). »

- Le sens des noms attribués ici aux cinq empereurs est fort obscur; Chalmers (prolég. au Chou king de Legge, p. 97) croit que ce sont des mots d'origine étrangère transcrits en chinois. Il ne semble pas cependant que tel soit le cas pour tous ces noms sans exception; ainsi l'empereur rouge qui préside au feu s'appelle Piao-nou et ces deux mots signifient: « flamme qui s'élève, s'é lancer».

01. (222) Ce paragraphe est une addition de Se-ma Ts'ien qui explique pourquoi Yao résigna le pouvoir entre les mains de Choen.

01. (223) Chou king : Choen tien. [et Legge [css : édition/rechercher : '3.']]

01. (224) Nous traduisons cette phrase en lui donnant le sens que devait lui attribuer Se-ma Ts'ien lui-même. Dans son chapitre sur les Directeurs du ciel (Mém. hist., chap. XXVII, p. 1 $\left.\mathrm{v}^{\circ}\right)$, il nous dit en effet :

«Les sept étoiles de la Grande Ourse sont ce dont il est question dans la phrase : (il observa) le mécanisme de l'évolution et la balance de jade pour vérifier l'accord entre les sept gouvernements.

Dans ce système d'interprétation, la Grande Ourse est regardée comme le méca nisme qui préside à l'évolution universelle, elle est comme la balance qui maintient l'équilibre entre toutes choses ; on lui applique l'épi thète « de jade » à cause de sa couleur blanche. Les sept gouvernements sont alors, d'après l'explication de Tcheng K'ang-tch'eng, les sept domaines sur lesquels s'exerce l'action régulatrice de la Grande Ourse, à savoir : le printemps, l'été, l'automne, l'hiver, les mouve ments des astres, la configuration de la terre et la conduite des hommes.

- C'est cependant une interprétation entièrement différente qui a prévalu chez les commentateurs du Chou king traditionnel ; selon eux, les quatre caractères siuên kî $i \bullet$ hêng désignent un appareil astronomique au moyen duquel on observait les étoiles ; cet appareil, d'après les représentations graphiques qu'on en donne (cf. Couvreur, Dict. chinois -français, p. 316), se composait de plusieurs cercles concentriques représentant l'un l'horizon et les au tres les cours des différents astres; au centre se mouvait un tube qui jouait le rôle d'une lunette astronomique ; à l'aide de cet appareil Choen observa les sept Gouverneurs ; c'est-à-dire le soleil, la lune et les cinq planètes qui dirigent tous les autres corps célestes. 
- Quelle que soit l'interprétation qu'on adopte, la démarche que Choen passe pour avoir accomplie est faite dans le même but : Yao ayant résigné l'empire entre ses mains, il consulte les astres pour voir s'ils témoignent par la régularité de leur cours qu'ils ap prouvent ce changement. La réponse étant favorable, il accomplit tous les sacrifices qui lui concilieront la bonne volonté des dieux.

01. (225) Les commentateurs expliquent généralement le nom du sacrifice lei de la manière suivante: le sacrifice régulier fait à époque fixe en l'honneur de l'Empereur d'en haut. c'est-à-dire du ciel, était le sacrifice kiao ; mais, lorsqu'on avait quelque déclaration spéciale à adresser au ciel, comme ici, par exemple, l'annonce d'un changement de souverain, on accomplissait un sacrifice spécial qui était du même genre que le sacrifice kiao et c'est ce qui exprime le mot lei qui signifie genre, espèce.

Le roi $O u$, fondateur de la dynastie Tcheou, fit la même cérémonie quand il eut vaincu le dernier souverain de la dynastie Yn (cf. Chou king, chap. T'ai che, trad. Legge, Chinese Classics, III, p. 287). Dans le Tcheou li (au chap. XXV,.trad. Biot, t, I, p. 92), il est dit que le grand prieur fait le sacrifice lei à l'Empereur d'en haut. D'après ces textes, il semblerait donc que le sacrifice lei s'adressât au ciel.

— Mais d'autres textes viennent ébranler cette opinion :

* dans le Che king (décade du roi Wen, ode 7 ; trad. Legge, Chinese Classics, IV, p. 455), le roi Wen nous est représenté comme faisant le sacrifice lei alors qu'il n'est qu'un seigneur et que, n'ayant pas le titre de Fils du ciel, il n'est pas autorisé à sacrifier au ciel.

* Dans le Tcheou li (au chap. XIX, trad. Biot, t. I, p. 441) il est parlé des quatre sacrifices lei (Biot traduit assez inexactement : les quatre spécialités) et plus loin il est dit (trad. Biot, t. I, p. 453) que toutes les fois qu'il y a une grande calamité dans le ciel ou sur la terre, l'officier appelé siao tsong po offre le sacrifice lei aux dieux de la terre et des moissons et au temple ancestral.

Du rapprochement de ces passages il résulte que les sacrifices appelés lei ne s'adres saient pas uniquement au ciel, mais qu'on appelait de ce nom tout sacrifice extraordinaire du même genre qu'un sacrifice prescrit par les rites (cf. Siu hoang Ts'ing king kié, chap. VIII, p. 15 r $^{\circ} 16$ $\left.\mathrm{v}^{\circ}\right)$

- Nous rencontrons dans ce texte pour la première fois la fameuse expression Chang li qui a donné lieu à tant de controverses. Nous ne pouvons pas entamer à ce sujet une longue discussion dans une note :

* nous nous bornerons à faire remarquer que, la théorie des cinq Chang li étant intimement liée à celle des cinq éléments qui ne prit corps que vers le IVe siècle avant notre ère, il est très vraisemblable que, dans les plus anciens textes, le terme Chang li désigna une divinité unique.

* En second lieu, cette divinité est identifiée par la plupart des commentateurs avec l'étoile polaire ; nous ne voyons aucune raison (je parle des raisons scientifiques) de regarder cette identification comme une perversion tardive d'un monothéisme primi tif, et par conséquent nous l'adoptons comme l'expression de l'ancienne croyance religieuse des Chinois.

* Enfin nous croyons que les mots «Empereur d'en haut » sont ceux qui rendent le mieux le sens du terme Chang li, parce que c'est à leur image que les hommes conçoivent leurs dieux et que par conséquent le plus élevé en dignité parmi les êtres célestes doit être appelé l'Empereur d'en haut, tout comme ici -bas on appelle empereur celui à qui tous obéissent.

01. (226) Le sacrifice in est expliqué comme étant un sacrifice fait avec une intention pure.

- L'expression leou tsong = les six Vénérables, est l'une des plus obscures de tout le Chou king ; rien n’indique son véritable sens et chaque commentateur l’interprète à sa guise. 
* Fou Cheng voulait y voir le ciel, la terre et les quatre saisons.

* Un passage du Li ki (trad. Legge, t. Il, p. 203) a autorisé K'ong Ngan-kouo à dire que les six Vénérables étaient les saisons, le chaud et le froid, le soleil, la lune, les étoiles, les inondations et la sécheresse.

* Tcheng K'ang-tch'eng y reconnaît les cinq planètes, les douze mansions lunaires, l'étoile Se-tchong qui est la cinquième de la Grande Ourse, l'étoile Se-ming qui est la quatrième de la même constellation, le maître du vent qui est l'astérisme $K i$ et le maître de la pluie qui est l'astérisme $P i$.

01. (227) Le sacrifice aux montagnes illustres et aux grands fleuves se faisait de loin et c'est ce qu'indique le mot wang qui signifie « regarder de loin ».

01. (228) Le mot chênn désigne proprement les dieux du ciel et le mot [] les dieux de la terre. Quoique le premier seul soit employé ici, il désigne l'ensemble de tous les dieux soit du ciel soit de la terre, Rendre hommage à tous les dieux appartient en propre à l'empereur ; aucun autre homme n'a u n pouvoir religieux aussi étendu.

01. (229) On explique ce passage au moyen d'un texte des Rites des Tcheou où il est dit que les cinq degrés de noblesse (kong, heou, po, tse, nan) avaient chacun un insigne qui était comme la marque de leur investiture.

Les ducs, marquis et comtes avaient des sortes de rectangles en jade (celui des ducs s'appelait []; celui des marquis [], celui des comtes []; voyez des dessins de ces insignes dans Couvreur, Dict. chinois-francais, p. 433 [css : et Chou king, trad. Couvreur, notes 17 et 251]) ; les vicomtes et les barons avaient des anneaux (celui des vicomtes s'appelait [], parce qu'on y avait gravé l'image de céréales ; celui des barons s'appelait [] parce qu'on y voyait la représentation de joncs ; cf. Couvreur, ibid., p. 620).

- Au moment où le pouvoir changeait de mains, tous les insignes étaient rendus au nouveau souverain qui les conférait ensuite lui-même aux seigneurs. Il est manifeste d'ailleurs que tout ce cérémonial féodal date de l'époque des Tcheou et cette considération montre bien le caractère légendaire des récits relatifs à Choen.

01. (230) Dans ce texte, qui se retrouve le même au chapitre des Mémoires historiques intitulé Fong chan chou et au chapitre du livre des Han antérieurs appelé Kiao se tche, c'est aux chefs des quatre montagnes et aux pasteurs (c'est-à-dire à ceux qui dirigent le peuple, comme le berger conduit son troupeau) que Choen remet les insignes d'investiture. Dans le texte du Chou king, les chefs des quatre montagnes et les pasteurs n'interviennent que comme témoins et c'est aux nobles que sont donnés les i nsignes.

01. (231) L'expression siun cheou est expliquée par un texte de Mencius (Legge, Chinese Classics, t. II, p. 35) :

«Quand le Fils du ciel allait chez les seigneurs, cela s'appelait siun cheou : siun cheou signifie parcourir les lieux dont ils avaient reçu la garde.

- Le Tai-tsong n'est autre que le T'ai-chan, la célèbre montagne au nord de T'ai-ngantcheou, province de Chan-tong.

— D’après Ma Yong, on plaçait une victime sur le bûcher.

01. (232) Cf. note 227. L'ordre auquel il est fait allusion est le suivant, d'après Fou Cheng qui développe un passage des Ordonnances royales du $\mathrm{Li} \mathrm{ki}$ :

* on sacrifiait aux cinq pics (du centre et des quatre points cardinaux) avec les rites qui conviennent aux trois ducs ;

* aux quatre grands cours d'eau, avec les rites des seigneurs ;

* on sacrifait aux autres montagnes et rivières avec les rites des comtes, vicomtes et barons suivant leur importance. 
01. (233) Les tubes sont les douze tubes musicaux qui servent de principes à toutes les mesures; on en trouvera la théorie exposée en détail dans le XXVe chapitre des Mémoires historiques. Il est à remarquer que ce système compliqué et savant ne saurait remonter à une haute antiquité. D’une manière générale, le chapitre du Chou king qui traite de Choen rapporte à ce souverain toute une série d'institutions qui sont d'une date évidemment plus tardive et fait de son règne comme le raccourci de l'organisation politique de la dynastie Tcheou; nous y trouvons en effet les cinq ordres de noblesse, les mesures ayant pour principe les tubes musicaux, les rites politiques du Tcheou li, les cinq sortes de châtiments et les dispositions mitigées du code pénal, toutes choses que les commentateurs n'expliquent qu'en recourant aux textes de l'époque des Tcheou.

01. (234) D'après le Tcheou li, les cinq rites sont les suivants :

1. les rites de réjouissance par lesquels on rend hommage aux mânes et aux divinités célestes et terrestres des royaumes et principautés ;

2. les rites de tristesse par lesquels on s'afflige sur les malheurs des royaumes et principautés ;

3. les rites de l'hospitalité par lesquels on établit d'étroi tes relations entre les royaumes et principautés ;

4. les rites militaires, par lesquels on allie les royaumes et principautés ;

5. les rites de félicitation, par lesquels on apparente les dix mille tribus. Cf. Tcheou li, trad. Biot, t. I, p. 419 et suiv.

01. (235) Les cinq jades étaient les insignes conférés aux diverses classes de seigneurs. Cf. note 229 .

01. (236) Ces soies étaient ou rouge clair ou bleu foncé ou jaunes, suivant le rang des personnes qui les offraient.

01. (237) Les deux animaux vivants étaient l'agneau que présentaient les hauts dignitaires et l'oie sauvage que présentaient les grands officiers. L'animal mort était le faisan que présentaient les simples fonctionnaires.

01. (238) Les cinq instruments sont expliqués par Ma Yong comme étant les cinq insignes de jade que Choen confère de nouveau aux seigneurs. Mais il est assez singulier de voir ces insignes appelés des instruments et c'est pourquoi Ts'ai Tch'en (Chou king, chap. II, p. 15 v) suppose que l'ordre des phrases a été interverti : suivant lui, la phrase : « les cinq (insignes de jade), les trois pièces de soie, les deux animaux vivants et l'animal mort lui furent apportés en offrande » doit être placée immédiatement après la phrase : «Il donna audience aux chefs de la contrée orientale. » Le texte qui suit devrait alors être traduit de la manière que voici :

« Il mit l'accord dans les saisons et dans les mois et rectifia les jours ; il rendit uniformes les tubes musicaux et les mesures de longueur, de capacité et de poids ; il restaura les cinq rites ; il rendit uniformes les cinq sortes d'instruments (dont on se servait dans les cinq rites) ; quand ce fut fini, il s'en retourna.

01. (239) Le deuxième mois, c'est-à-dire au printemps, Choen va dans l'est ; le cinquième mois, c'est-à-dire en été, il va dans le sud; le huitième mois, c'est-à-dire en automne, il va dans l'ouest ; le onzième mois, c'est-à-dire en hiver, il va dans le nord. On reconnaît ici le parallélisme entre les saisons et les points cardinaux et cette constatation témoigne une fois de plus du caractère mythique des traditions qui concernent Choen.

01. (240) Le Chou king donne la leçon I-tsou, expression tout analogue à celle de Wen-tsou (cf. note 221) ; Choen se serait donc rendu au temple de «l'ancêtre instruit ». Le texte de Sema Ts'ien est beaucoup plus clair; en outre il est conforme à un passage des ordonnances royales du $L i$ ki qui décrit la tournée d’inspection que le Fils du ciel devait faire tous les cinq ans (cf. Li ki, trad. Legge, Sacred Books of the East, t. XXVII, p. 218). 
01. (241) Selon Ts'ai Tch'en, la première année le Fils du ciel parcourait tous les fiefs, la seconde année, il recevait à la cour les vassaux de l'est ; la troisième année, ceux du sud; la quatrième année, ceux de l'ouest ; la cinquième année, ceux du nord. Puis le cycle quinaire étant terminé, il recommençait (cf. note 239).

01. (242) Ce chiffre de douze provinces est embarrassant. En effet, la Chine ancienne ne comptait que neuf provinces, celles même qui sont mentionnées dans le tribut de $Y u$. Pour tourner la difficulté, les commentateurs ont imaginé de dire que, lorsque $Y u$ régla les eaux et les terres de l'empire, le règne de Yao était encore loin d'être fini et que c'est après l'accomplissement des travaux de $Y u$ que Choen, exerçant l'em pire par une délégation de Yao, distingua l'empire en douze provinces. C'est ainsi que le Tong kien tsi lan place les travaux de $Y u$ entre la $72^{\mathrm{e}}$ et la $80^{\mathrm{e}}$ année de $Y a o$ et rapporte la distinction des douze provinces à la $81^{\mathrm{e}}$ année. Quelle que soit la valeur de cette singulière explication, voici les noms des douze provinces: Ki, Yen, Ts'ing, Siu, King, Yang, Yu, Leang, Yong, Yeou, Ping et Yng. Les provinces de Ping et de Yeou avaient été formées avec des parties de la province de $K i$; la province de $Y n g$ avait été formée avec une partie de la province de Ts'ing.

01. (243) La phrase siáng ì tièn hîng a donné lieu aux interprétations les plus diverses. Le sens que nous avons adopté est celui de Ma Yong qui dit :

Le peuple au temps de Choen était si vertueux que personne n'était coupable ; c'est pourquoi les châtiments étaient représentés par des images, mais n'étaient pas appliqués en réalité.

Pour d'autres interprétations, cf. Legge [css : édition/rechercher : 'punish'], Chinese Classics, t. III, p. 38.

01. (244) Quoique les commentateurs chinois ne donnent ici aucune explication, il semble que le style narratif est interrompu et fait place à l'édic tion des peines qui est mise dans la bouche d'une personne déterminée, comme le prouve l'apostrophe de la fin : «Soyez sur vos gardes. » Je serais tenté de voir là un fragment d'un vieux code qui a été incor poré dans le Choen tien.

01. (245) Selon Ma Yong, les mots liôu ióu òu hîng constituent deux phrases et il faut traduire :

«On bannit ceux qui sont dignes d'une mitigation de peine ; il y a les cinq châtiments.

Il y avait trois catégories de criminels dignes d'une mitigation de pe ine : les enfants, les vieillards et les imbéciles. - Les cinq châtiments étaient la marque, l'ablation du nez, l'ablation des rotules ou des pieds, la castration et la mort. — D'après K'ong Ngan-kouo, les quatre mots précités ne font qu'une seule phrase et il faut traduire : le bannissement adoucit les cinq châtiments.

01. (246) D'après le commentaire de K'ong Yng-ta (Chou king, ch. II, p. 20 r ${ }^{\circ}$ ), le fouet et la verge auraient été les châtiments infligés par les magistrats et les instructeurs, et non pas aux magistrats et aux instructeurs, comme le dit M. Legge.

01. (247) Ts'ai Tch'en (Chou king, ch. II, p. $31 \mathrm{r}^{\circ}$ ) remarque que les fautes rachetables étaient les fautes légères, celles qui ne tombaient pas sous le coup des cinq châtiments. Le Choen tien n'impliquerait donc point le principe condamnable que toutes les fautes, quelque graves qu'elles soient, peuvent être rachetées à prix d'argent; ce principe est énoncé pour la première fois dans le Code pénal du roi Mou, de la dynastie Tcheou, les Châtiments de $L u$ (on trouve une partie du chapitre du Chou king intitulé «Les Châtiments de $L u$ » dans le IVe chapitre des Mémoires historiques).

01. (248) Ce qui suit est une interpolation introduite dans le texte du Chou king; par cette addition, Se-ma Ts'ien rappelle, au prix d'une répétition, de quelles fautes Hoan-teou, Kong-kong, Koen et San-miao s'étaient rendus coupables et il explique ainsi pourquoi ils méritèrent d'être bannis. On retrouvera plus loin, sous une autre forme, la légende des quatre grands criminels exilés aux quatre points cardinaux. 
01. (249) Par San-miao, il faut entendre le chef du peuple de San-miao, car les commentateurs sont unanimes à dire que San-miao est le nom d'un pays. Leur assertion s'appuie sur un passage du Tso tchoan ( $1^{\mathrm{e}}$ année du duc Tchao, trad. Legge, p. 577 ; [trad. Couvreur]) et sur un texte du Tchan kouo ts'é (chap. XIV) où un certain $\mathrm{Ou} \mathrm{Ki}$ dit que les limites du territoire de San-miao sont, à gauche, le lac Tong-t'ing (province de Hou-nan) et à droite le lac P'ong-li (ou lac Po-yang, dans la province de Kiang-si).

- La province de King dont il est question dans le texte de Se-ma Ts'ien, est une des neuf provinces de $Y u$; elle se trouvait au sud du Kiang ou Yang-tse-Kiang et comprenait le lac Tong-t'ing. - Elle était assez distante de la rivière appelée Hoai ; ce n'est donc pas de cette rivière qu'il est ici parlé ; selon Se-ma Tcheng, Hoai ou Hoei est un autre nom du lac P'ong-li ou Po yang.

01. (250) Chou king : Choen tien. Ta Tai li : Ou ti té. Mencius, liv. V, $2^{\mathrm{e}}$ partie, ch. III.

01. (251) Au lieu de Yeou-ling, le Chou king donne la leçon « lîle de Yeou ». D'après le Kouo ti tche, le lieu où fut banni Kong-kong se serait trouvé au nord-est de la sous-préfecture de $M i$ yun, préfecture de Choen tien (Péking).

01. (252) En exilant les quatre coupables au nord, au sud, à l'ouest et à l'est, Choen prétend faire un exemple destiné à engager au bien les $T i$, les Man ,les Jong et les $I$ c'est-à-dire les peuples barbares des quatre points cardinaux ; le Chou king n'en fait pas mention.

01. (253) La montagne Tch'ong se trouvait dans le territoire de la sous-préfecture actuelle de Yong-ting, préfecture secondaire de Li, province de Hou-nan.

01. (254) San-wei est le nom d'une montagne sur les bords de la rivière Tang, au sud de Toen-hoang, à l'ouest du Kan-sou.

01. (255) D'après le Kouo ti tche, la montagne $Y u$ était sur le territoire de la sous-préfecture de Lan-chan, préfecture secondaire de I, province de Chan-tong. D'après le T'ong kien tsi lan (ch. I, p. $17 \mathrm{r}^{\circ}$ ), elle se trouvait dans la sous-préfecture de Kan-yu, préfecture secondaire de Hai, province de Kiang-sou. Les deux localités sont très voisines.

01. (256) Le mot crime, condamnation, est écrit dans Se-ma Ts'ien []; c'est l'ancienne orthographe du mot; mais $T s^{\prime}$ in Che-hoang-ti trouva que ce caractère ressemblait trop au caractère hoang $=$ souverain, qui faisait partie de son titre et c'est pourquoi il ordonna qu'on l'é crivit à l'avenir [] (H.T.K.K., ch. CCCXC, p. 38 vº).

01. (257) Chou king : Choen tien. [et Legge [css : édition/rechercher : 'twenty']

01. (258) D'après ce texte et un autre que nous trouverons plus loin, il est clair que Se-ma Ts'ien compte quatre-vingt-dix-huit années $(70+28)$ depuis le moment où Yao prit le pouvoir jusqu'à sa mort. Si l'on s'en rapporte cependant au texte seul du Chou king, il faudra dire avec Ts'ai Tch'en (Chou king, ch. II, p. $23 \mathrm{v}^{\circ}$ ), que Yao régna d'abord soixante-dix-sept ans, qu'il mit ensuite Choen à l'essai pendant trois ans, enfin qu'il lui délégua son pouvoir pendant vingt-huit ans ; Yao aurait donc régné cent un ans.

01. (259) D'après Hoang-fou Mi, la mère de Tan-tchou était une fille de la tribu San-i, qui s'appelait Niu-hoang.

01. (260) Se-ma Tcheng dit: Lorsque le fils succède au père, c'est la mé thode ordinaire ; lorsqu'on cherche un sage pour lui céder le pouvoir, c'est la méthode qui tient compte des circonstances.

01. (261) Mencius, liv. V, $1^{\mathrm{e}}$ partie, ch. V.

01. (262) Le Nan-ho, ou Ho du sud, est, d'après P'ei Yn, la plus méridionale des neuf branches du Hoang-ho. On trouvera dans notre traduction du Tribut de Yu (Mém. hist., chap. II) une note sur les neuf branches du Ho. D'après Tchang Cheou-kié, l'expression Ho du sud signifie simplement que le Hoang-ho était au sud de la capitale de Yao, laquelle était située à 15 li au nord-est de la préfecture secondaire de Fou, province de Chan-tong. 
Tchang Cheou-kié remarque en outre qu'à 15 li au nord-ouest de la préfecture secondaire de $P^{\prime}$ ou, il y a les ruines de la ville appelée Yen tchou, ce qui signifie « l'obstacle fait à Tchou »; il explique ce nom en rappelant une légende qui se trouve dans des livres écrits sur bambou : Yao s'étant perverti, Choen l'aurait emprisonné, puis il aurait mis des obstacles et des barrières devant Tan-tchou pour l'empêcher de re voir son père.

01. (263) Le terme qui désigne la capitale est ici, proprement: le royaume du milieu. On voit que cette expression, qui signifie maintenant la Chine tout entière par opposition aux nations voisines, s'ap pliquait à l'origine à la résidence impériale.

01. (264) L'appellation Tch'ong-hoa est expliquée par K'ong Ngan-kouo comme signifiant «gloire renouvelée»; parce que Choen fit preuve des mêmes vertus que Yao. Une autre interprétation que nous trouvons, entre autres, dans Hoai-nan-tse et dans le commentaire des Annales écrites sur bambou (Legge, Chinese Classics, t. III, prolég., p. 114) veut que tch'ong hoa, signifiant.' » double éclat », fasse allusion au fait que Choen avait une double prunelle.

01. (265) Le caractère k'iao, nous dit Tchang Cheou-kié, se prononce ici sans aspiration.

01. (266) Dans cette généalogie ne figure pas un certain Mo qui est cité par le Tso tchoan $\left(8^{\mathrm{e}}\right.$ année du duc Tchao; cf. Legge, Chinese Classics, t. V, p. 62 ), comme un des ancêtres de Choen; aussi quelques critiques ont-ils mis en doute la valeur de la généalogie dressée par $S e$ ma Tsien.

01. (267) D'après Hoang-fou Mi, la mère de Yu s'appelait Ou-teng.

01. (268) La province de $K i$ est la plus septentrionale des neuf provinces de $Y u$ (cf. le $Y u$ kong) ; elle comprenait en gros les provinces de Chàn-si et de Tche-li; cependant, la petite portion du Chan-tong qui est au nord de Hoang-ho en faisait aussi partie ; ce texte ne nous permet donc pas de déterminer si le lieu de naissance de Choen était, aux yeux de Se-ma Ts ïen, dans le Chàn-si ou dans le Chan-tong (cf. note 206).

01. (269) On trouve un écho de cette légende dans Mencius (II, a. 8, trad. Legge, p. 82 ; [trad. Couvreur]) qui dit :

«Depuis le temps où Choen labourait, semait, façonnait des vases et pêchait, jusqu'au moment où il devint empereur, il ne manqua jamais de prendre exemple sur autrui.

L'identification de la montagne $L i$ est incertaine ; les uns la placent dans la préfecture actuelle de P'ou-tcheou, province de Chàn-si; d'autres, au sud-est de la préfecture secondaire de P'ou préfecture de Ts'ao-tcheou, province de Chan-tong, tout auprès de l'étang de Lei dont il est fait mention à la phrase suivante; d'autres la trouvent dans la sous-préfecture de Yu-yao, préfecture de Chao-hing, province de Tche-Kiang; d'au tres enfin y voient une montagne de la sous-préfecture de Hoai-lai, préfecture de Siuen-hoa, province de Tche-li. On remarque ici la même dispersion des légendes que dans le cas du lieu de naissance de Choen.

01. (270) Cheou-k'ieou est, d'après certaines légendes, le lieu de naissance de Hoang-ti. C'était une hauteur à l'est de la sous -préfecture de K’iu-feou, préfecture de Yen-tcheou, province de Chan-tong.

01. (271) L'e mplacement de Fou-hia n'est pas indiqué d'une manière exacte par les commentateurs. Tcheng Hiuen se borne à dire qu'il se trouvait sur le territoire du pays de Wei, lequel comprenait la pointe sud du Tche-li et les parties avoisinantes du Ho-nan et du Chantong. - Dans le livre de Mencius on lit (IV, b. 1, Legge, p. 192 ; [trad. Couvreur]) :

«Mong-tse dit: Choen naquit à Tchou-fong, il se transporta à Fou-hia; il mourut à Ming-t'iao.

01. (272) Ce texte confirme la traduction que nous avons donnée plus haut:

«Choen... dirigea et rendit humbles ces deux femmes, en sorte qu'elles observèrent les rites des épouses. 
Cf. note 210 .

01. (273) Cf. p.• 72 . Ces répétitions montrent à nu le procédé de composition de Se ma Ts'ien qui coud bout à bout des légendes diverses sans se préoccuper de mettre de l'unité dans son récit :

01. (274) Le mot que nous traduisons par «ville» est le mot []. C'est par allusion à cette légende que Choen est appelé dans Mencius (V, a. 2, Legge, p. 222 ; [trad. Couvreur]) le prince créateur de villes.

01. (275) Cf. Mencius (V, a. 1. Legge, p. 219 ; [trad. Couvreur]) :

«L'empereur fit que ses enfants, neuf fils et deux filles, les divers fonctionnaires, des bøufs et des moutons, des magasins et des greniers fussent mis au service de Choen...

01. (276) D'après Se-ma Tcheng les deux larges chapeaux jouèrent le rôle d'un parachute et empêchèrent Choen de se blesser quand il se précipita du haut du grenier. Le Lié niu tchoan dit que ce furent les deux filles de Yao qui enseignèrent à Choen l'art de voler comme un oi seau.

01. (277) Ce passage se trouve avec des variantes dans Mencius (V. a. 2, Legge, p. 222-223 ; [trad. Couvreur]) :

«Ses parents envoyèrent Choen réparer le grenier; ils enlevèrent l'échelle et Kou-seou incendia le grenier. Ils l'en voyèrent creuser un puits ; il sortit par côté et ils comblèrent le puits. Siang dit :

— Le stratagème de couvrir (de terre) le prince créateur de villes (cf. note 274), c'est moi qui en ai tout le mérite. Que les bœufs et les moutons soient à mon père et à ma mère ; que le magasin et le grenier soient à mon père et à ma mère. Que le bouclier et la lance soient miens; que le luth soit mien ; que l'arc soit mien ; que ses deux femmes prennent soin de mon lit.

Siang se rendit dans la demeure de Choen; Choen était sur sa couche et jouait du luth. Siang dit :

— Je me réjouissais en pensant à vous.

Il fut couvert de confusion.

— L'expression yu t'ao que nous traduisons par «se réjouir » ou «plein de joie » demande une explication. Dans le texte de Mencius, M. Legge lui donne le sens d' «éprouver de l'anxiété »; on la retrouve dans une phrase du chapitre du Chou king intitulé : Le Chant des cinq fils yu t'ao ... ; le contexte impose là la traduction : «Ils sont pleins de tristesse nos cours. » Il semblerait donc que le sens de l'expression yu t'ao fût celui de tristesse ou d'anxiété et non celui de joie.

Mais Yen Jo-kiu a fort bien démontré (cité par Wang Ming-cheng, H. T. K. K., chap. CCCCXXXIV b, p. $8 \mathrm{r}^{\circ}$ ) que ce sens ne saurait convenir aux deux caractères employés : le caractère t'ao a deux sens; le premier est celui de façonner un objet en terre ; le second, qui est indiqué par tous les dictionnaires et en particulier par le Koang yun (fin du Xe siècle ap. J.-C.) est celui de joie. Quant au caractère $y u$, il peut avoir le sens de tristesse mais il a aussi, d'après le Koang yun, celui de disposition ou sentiment de l'âme. L'expression yu t'ao est donc donnée par le Eul ya comme signifiant se livrer à la joie.

Dès lors, dans le texte de Mencius, Siang, se trouvant inopinément en présence de Choen qu'il croyait mort, explique sa venue en disant qu'il voulait avoir le plaisir de lui rendre visite ; c'est un mensonge par lequel il se tire d'embarras ; dans le texte de Se-ma Ts'ien, il paie d'audace et dit qu'il est heureux de re voir son frère ; en réalité il est pénétré de dépit. Les anciens critiques n'ont pas compris ce texte et ils ont admis que l'expression yu t'ao signifiait être triste ou anxieux, ce qui mène à une interprétation absurde, car Siang doit nécessairement 
feindre d'ignorer le danger auquel vient d'échapper Choen. Ainsi, soit par le sens des mots, soit par la suite des idées, nous devons, dans le texte de Mencius, traduire yu t'ao par «être joyeux ».

Mais ce sens répugne absolument à la phrase du Chant des cinq fils ; voici comment on écarte cette dernière objection : le Chant des cinq fils fait partie du pseudo-texte antique du Chou king et doit donc être considéré comme inauthentique ; les érudits qui le composèrent, ayant fait un contresens sur le texte de Mencius, empruntèrent à ce texte les caractères mêmes qu'ils comprenaient de travers pour donner à leur œure un faux air d'antiquité.

01. (278) Ce sens est celui qui est indiqué par Se-ma Tcheng. Le texte correspondant de Mencius comporte une tout autre interprétation (cf. Legge, Chinese Classics, t. II, p. 223).

01. (279) Cf. p. 55. Le Che ki loen wen met 1a ponctuation après po koan, ce qui confirme notre traduction.

01. (280) Tso tchoan, $18^{\mathrm{e}}$ année du duc Wen.

01. (281) Kao-yang est identifié par Se-ma Ts'ien avec Tchoan-hiu (cf. p.• 37 ). Dans ce texte, qui est tiré du Tso tchoan, il n'est pas cer tain que Kao-yang et Tchoan-hiu soient considérés comme un seul et même personnage ; en effet, Kao-yang est donné comme ayant eu huit fils excellents, tandis que plus loin Tchoan-hiu est cité comme le père d'un scélérat.

01. (282) Kao-sin est identifié par Se-ma Ts’ien avec l'empereur Kou (cf. p.• 39 ).

01. (283) Le Tcheng $i$ du Tch'oen ts'ieou dit: Le ciel est appelé le ciel impérial ; la terre est appelée la terre souveraine.

01. (284) Les cinq enseignements sont, comme la phrase suivante l'in dique clairement, ceux qui concernent les devoirs des pères, des mères, des frères aînés, des frères cadets et des enfants.

01. (285) L'empereur Hong « est identifié par les commentateurs avec Hoang-ti (cf. note 102).

01. (286) Les quatre scélérats dont il va être question sont identifiés par les commentateurs avec les quatre criminels dont il a été parlé plus haut (cf. n. 248). Hoen-toen, c'est-à-dire Chaos, ne serait autre que Hoan-teou; K'iong- $k$ 'i , c'est-à-dire le Vaurien-trompeur, ne serait autre que Kong-kong ; Tao-ou, c'est-à-dire le Soliveau, ne serait autre que Koen et T'ao-t'ié, c'est-à-dire le Glouton, ne serait autre que San-miao. Quoique ces rapprochements n'aient pas grande valeur en eux-mêmes, il est évident que nous avons affaire à deux formes différentes d'une seule et même légende.

01. (287) Chao-hao est l'empereur que la chronologie du T'ong kien kang mou place avant Tchoan-hiu et après Hoang-ti. Il ne trouve pas place dans la liste des cinq empereurs telle que la donnent les Mémoires historiques. Chao hao est considéré comme présidant à l'ouest (cf. ma première trad. du Traité sur les sacrifices fong et chan, p. 9), et comme le métal correspond à l'ouest dans la théorie des cinq éléments, on appelle souvent Chao-hao «le ciel-métal »

01. (288) Les deux caractères t'ao ou désignent, l'un une souche d'arbre, l'autre un arbre sans branches. Nous les traduisons par «soliveau », ce mot ayant acquis, grâce à La Fontaine, le sens d'une épithète assez désobligeante. - Il est assez curieux que ces deux mêmes mots t'ao $o u$ aient servi à désigner les Annales du pays de Tch'ou; on ne sait pas quelle en est la raison ; quoi qu'il en soit, voici le pas sage de Mencius (trad. Legge, p. 203) qui nous donne ce renseignement :

«Le Cheng (proprement: Chariot) de Tsin, le T'ao ou de Tch'ou et le Tch'oen ts 'ieou de Lou sont des ouvrages identiques.

01. (289) D’après Kia K'oei, Tsin-yun était un descendant de Chen-nong. 
01. (290) Quoiqu'il ne fût pas fils d'un empereur, on le mettait sur le même pied que les trois criminels fils d'empereurs.

01. (291) Les démons ne sont autres que les barbares ; on a vu, plus haut (cf. note 124), qu'au temps de la dynastie $Y n$, le pays des Hiong-nou était appelé Koei-fang, c'est-à-dire région des démons.

01. (292) Tout ce paragraphe est une répétition de ce qui a été dit plus haut.

01. (293) Yu était le fils de ce Koen qui fut banni comme l'un des quatre grands criminels ; il fut le fondateur de la dynastie des Hia (cf. Mém. hist., chap. II) ; avant d’être empereur il était comte du fief de Hia et c'est pourquoi on l'appelle quelques lignes plus bas le comte $Y u$.

D’après Kong Yng-ta (Chou king; ch. II p. $26 \mathrm{v}^{\circ}$ ), Yu aurait été comte du fief de Tch'ong aujourd'hui sous -préfecture de Hou, préfecture de Si-ngan, province de Chàn-si.

01. (294) Kao-yao (le second caractère doit se prononcer ici yao et non t'ao) est identifié avec l'un des huit fils capables de Tchoan-hiu (cf. p. ${ }_{77}$ ). On verra plus loin que $Y u$ voulait lui léguer l'empire, comme il l'avait lui -même reçu de Choen, mais que la mort prématurée de Kao-yao mit à néant ce projet.

01. (295) Sié est l'ancêtre de la dynastie Chang ou Yn (Mém. hist., chap. III).

01. (296) Heou-tsi, c'est-à-dire le prince Millet, est le titre donné dans le Choen tien à $K^{\prime} i$, ancêtre de la dynastie Tcheou, et ne semble se rapporter qu'à la charge de ministre de l'Agriculture qui lui fut confiée par Choen.

- Dans d'autres textes, Heou-tsi nous apparaît comme une divinité étroitement associée à celle de Heou-t'ou, le prince Terre ; le dieu des moissons et celui de la terre sont au nombre des divinités les plus anciennes de la Chine ; elles n'étaient que des hommes divinisés ; au temps des Hia le dieu de la terre était Keou-long, fils de Kong-kong, et le dieu des moissons était Tchou) (cf. note 00.154), fils de Tchoan-hiu; lorsque T'ang le Victorieux substitua sa dynastie à celle des Hia il voulut remplacer ces anciens dieux ; il ne put changer le dieu de la terre dont le culte était sans doute trop invétéré ; mais il mit $K{ }^{\prime} i$ (qui devait être l'ancêtre des Tcheou), à la place de Tchou (Ts'ien Han chou, chap. Kiao se tche, p. 2 r $^{\circ}$ ).

- Le fait que, dans le texte du Choen tien reproduit par Se-ma Ts'ien, le titre de Heou-tsi est donné à $K^{\prime} i$ prouve que ce texte est postérieur à l'époque où $K^{\prime} i$ fut substitué à $T c h o u$; nous avons eu déjà l'occasion de signaler d'autres faits qui tous con courent à prouver que la composition du Yao tien et du Choen tien ne peut remonter plus haut que la dynastie Tcheou (cf. n. 233).

01. (297) Po-i passe pour l'ancêtre des princes de $T s$ 'i.

01. (298) K'oei Long et Choei ne nous sont guère connus que par le texte du Choen tien que Se-ma Ts'ien va reproduire quelques lignes plus bas.

01. (299) Les commentateurs chinois identifient $I$ avec Po-i qui est l'ancêtre des $T$ s'in d'après Se-ma Ts'ien (Mém. hist., ch. V) ; mais le rapprochement ne paraît pas se justifier par des raisons bien solides. - P'ong -tsou nous est inconnu.

01. (미) Chou king: Choen tien. [et Legge [css : édition/rechercher : '5.'] ]

01. (01) Cf. note 221 .

01. (302) C'est-à-dire qu'il ouvrit les quatre portes de la capitale, pour que les hommes vinssent des quatre points cardinaux à la cour, et qu'il connût par eux ce qui se passait dans les quatre directions, comme s'il le voyait de ses yeux et l'entendait de ses oreilles. Ce passage semble bien confirmer l'opinion que les chefs des quatre montagnes étaient au nombre de quatre (cf. note 199).

01. (지) Les douze pasteurs (de peuples) sont les chefs des douze provinces (cf. note 242). 
01. (304) L'empereur n'est autre que Yao dont le bon gouvernement doit servir de règle aux douze chefs.

01. (305) Le nom de la charge d'intendant des travaux publics est ici se-k'ong: un peu plus bas, on verra que Choei est nommé à une charge identique qui est appelée kong-kong ; les commentateurs chinois se perdent dans de subtiles explications pour établir une différence entre ces deux charges ; ils disent que le se-k'ong n'exerçait ses fonctions qu'en vertu d'une délégation spéciale et temporaire, tandis que le kong-kong rentrait dans les cadres de l'administration régulière.

— En réalité, se-k'ong est le nom qui fut donné sous la dynastie Tcheou (cf. Tcheou-li, article du fonctionnaire de l'hiver) au fonctionnaire qui était appelé autrefois kong-kong; le fait que ces deux dénominations d'époques différentes se trouvent réunies dans un même texte du Chou king prouve simplement que ce texte date du moment où le titre de se-k'ong était en vigueur et où on se rappelait l'ancien titre de kong-kong sans savoir quil était au fond identique à celui de se-k'ong .

01. (306) D'après l'explication traditionnelle, les travaux de $Y u$ sont rapportés à l'époque du règne de $Y a o$ : la phrase serait donc au passé. La gloire que $Y u$ s'est acquise précédemme nt par ses travaux le fait élever par Choen à la première dignité de l'empire, celle de conseiller chargé d'aider l'empereur dans toutes les affaires.

- Mais Se-ma Ts'ien considère ce passage comme exprimant la nomination de $Y u$ aux fonctions de régulateur des eaux et des terres; comme on le verra plus loin, c'est à la suite de cette nomination que $Y u$ exécute ces travaux.

01. (307) Tsi n'est autre que Heou tsi (cf. note 296).

01. (308) $K ’ i$ est le nom propre du personnage qui avait mérité d'être ap pelé Heou-tsi, c'est-à-dire le prince Millet, à cause des services qu'il avait rendus à l'agriculture.

01. (309) Au commencement, c'est -à-dire autrefois, au moment où les eaux étaient débordées. Le mot employé par Se-ma Ts'ien est l'équivalent du caractère, qui était, d'après Siu Koang, la leçon du texte moderne du Chou king. Le pseudo-texte antique, qui nous est donné par le Chou king traditionnel, présente la leçon qui signifie « obstacle, détresse». — En suivant le texte du Chou king, M. Legge a traduit :

« Ki, le peuple aux cheveux noirs souffre (encore) la détresse de la famine ; il vous appartient, ô prince, ministre de l'Agri culture, de planter (pour lui) les diverses sortes de grains.

Le texte de Se-ma Ts'ien nous oblige à mettre la phrase au passé et à sous-entendre que Choen confirme $K^{\prime} i$ dans les fonctions qu'il a exercées avec tant de succès.

01. (310) La phrase chinoise est ainsi conçue [...]. Se-ma Tcheng dit qu'elle signifie : en vous conformant aux quatre saisons, vous avez planté les cent céréales, Mais Kiang Cheng $(H . T$. $K$. K., ch. CCCXC, p. $46 \mathrm{r}^{\circ}$ ) remarque que la position du mot che après le mot pouo rend ce sens inadmissible; il faut donc considérer comme équivalent de transplanter.

01. (311) Les cinq ordres sont les cinq sortes de devoirs que les cinq enseignements inculquent aux pères, aux mères, aux frères aînés, aux frères cadets, aux fils.

— On a vu plus haut (p.• 77 ) que Choen confia aux huit Excellents, descendants de Kao-sin, le soin de répandre les cinq enseignements ; on en conclut que Sié était l'un des huit Excellents.

01. (312) Le titre de se-t'ou paraît appartenir, comme celui de se-k'ong, à l'organisation administrative de l'époque des Tcheou.

01. (313) Nous avons suivi la glose de Tcheng Hinen qui dit que Hia signifie «illustre et grand». 
- On pourrait se demander cependant si le mot Hia ne désigne pas la Chine, parce que la dynastie Hia avait donné son nom au pays sur lequel elle régna; le mot Hia, dans ce texte, serait alors un anachronisme et en dénoncerait la composition tardive. Il va sans dire qu'aucun commentateur chinois n'est assez au dacieux pour soutenir une pareille hypothèse.

01. (314) Le sens de ces deux derniers mots est nettement indiqué par un passage du Tso tchoan (16 année du duc Tch'eng) où il est dit que ceux qui font des troubles au dehors sont appelés [], que ceux qui font des troubles au dedans sont appelés []. On cite parfois ce passage en intervertissant le sens de ces deux mots, mais c'est une erreur.

01. (315) Les commentateurs ont donné les explications les plus diverses de cette phrase, parce qu'ils ont cherché à concilier deux renseigne ments entièrement indépendants l'un de l'autre, à savoir, d'une part la liste des cinq châtiments qui a été indiquée plus haut (cf. note 245), d'autre part un texte du Коио уи qui énumère les trois places où sinfligeaient les châtiments. Kiang Cheng (H. T. K. K., ch. CCCXC, p. $47 \mathrm{v}^{\circ}$ ) a fort bien montré que les châtiments dont parle le Коио уи ne sont pas ceux de la liste précitée et que, d'autre part, le texte du Коио уи est bien celui qui peut jeter quelque lumière sur ce texte puisque dans le Koиo yu, comme ici, les criminels ne sont pas seulement ceux qui enfreignent les lois civiles, mais aussi les barbares, les ennemis de l'État. Voici l'explication qu'on peut tirer du Коио уи (Lou yи, p. 6) :

1. les armes offensives et défensives (c'est-à-dire les armées) punissent les plus grands criminels (c'est-à-dire les ennemis) ;

2. les deux sortes de haches d'armes punissent les crimes moins graves du même genre (on décapite ceux qui violent les commandements militaires).

Ces deux châtiments sont infligés en rase campagne ;

3. le couteau et la scie punissent les crimes moyens (c'est-à-dire les criminels qu'on décapite, qu'on coupe en morceaux ou à qui on enlève le nez);

4. le foret et l'instrument à marquer pu nissent les crimes moins graves du même genre (c'est-à-dire les criminels à qui on enlève les rotules ou qu'on marque au visage).

Ces deux sortes de châtiments sont infligés en présence du souverain, à la cour ;

5. le fouet et les verges punissent les crimes peu importants.

Ce châtiment est infligé sur la place publique.

Ainsi la rase campagne, la cour et la place publique sont les trois lieux où l'on subit les cinq châtiments.

01. (316) Le sens de cette phrase est que le lieu du bannissement peut être fixé à un éloignement plus ou moins grand de la capitale ; il y avait cinq éloignements fixés par la loi et répartis sur trois zones concentriques de plus en plus distantes de la capitale.

01. (317) Le juge qui prononce les peines doit savoir discerner la gravité des fautes.

01. (318) Le caractère doit être prononcé che + wei - choei (H. T. K. K., ch. CCCXC, p. $\left.49 \mathrm{r}^{\circ}\right)$.

01. (319) Le nom de cette fonction est ici kong-kong; cf. note 305.

01. (320) Le titre de cette fonction est tchen-yu; dans le Chou king, cette phrase est prononcée par Choen lui-même ; c'est pourquoi plusieurs commentateurs ont cru que le mot yu désignait à lui seul la fonction et que tchen était le pronom possessif de la première personne. Le texte de Se-ma Ts'ien semble prouver que tchen-yu sont deux mots inséparables qui représentent le nom de la charge ; c'e st d'ailleurs aussi l'interprétation que donne Tcheng Hiuen (H. T..K. K., ch. CCCXC, p. $50 \mathrm{r}^{\circ}$ ). Cependant un peu plus loin (p. 88, ligne 14), Se-ma Ts'ien, d'accord avec les autres commentateurs, désigne cette charge par le seul mot $y u$.

— Sur les travaux de défrichement qui sont attribués à $I$, cf. Mencius, III, a, 4, Legge, p. 126 ; [trad. Couvreur]. 
01. (21) Les noms Tchou, Hou, Hiong et $P$ 'i signifient littéralement le Sapin, le Tigre, l'Ours et l'Ours rayé, et donnent à la cour de Choen, comme le fait remarquer M. Legge, quelque ressemblance avec un conseil de chefs Peaux-Rouges. - Hou et Hiong sont mentionnés par le Tso tchoan au nombre des huit Excellents, fils de Kao-sin (cf. p.• 77 ).

01. (322) Les trois cérémonies rituelles sont le culte rendu aux dieux du ciel, aux ësprits de la terre et aux mânes des hommes.

01. (23) Le Chou king écrit simplement po = comte. Il fait donc de $I$ le nom de ce personnage. et de po son titre. Au contraire, Se-ma Ts'ien ne disjoint jamais les deux caractères po et $i$ et semble les considérer comme un nom propre unique (cf. p. 80, n. 1).

01. (324) Cette charge est celle du ta tsong po dans le Tcheou li. Le chapitre Po koan piao du livre des Han antérieurs nous apprend que l'usurpateur Wang Mang (9-23 ap. J.-C.) rétablit l'ancien titre de che tsong qui est donné dans ce texte.

01. ( $\underline{325)}$ Les fils de l'État, d'après Tcheng Hiuen; c'est-à-dire les fils de ceux qui prennent part au gouvernement de l'État, depuis le souverain jusqu'aux ta-fou.

01. (26) Tout ce paragraphe, dans le Choen tien, est mis dans la bouche de Choen; il faut le traduire alors par une série de définitions : «La poésie est l'expression de la pensée ; le chant prolonge cette expression..., etc. »

- Le chant prolonge les paroles en les modulant; de ces modulations on tire la gamme primitive de cinq notes : hong, chang, hio, tche, yu ;

- Les rapports mathématiques entre les cinq notes et les douze tubes sonores seront étudiés dans le XXVe chapitre des Mémoires historiques ;

Les huit instruments de musique sont les suivants d'après le Po hou t'ong ( $1^{\text {er }}$ chap., p. 26 r $^{\circ}$, section $\mathrm{Li}$ yo) :

* «l'instrument en terre s'appelle hiuen (sorte d'ocarina ; voyez le dessin qu'en donne Couvreur, Dict. chinois-français, p. 139);

* l’instrument en bambou s'appelle koan (flûte composée de deux tuyaux avec un seul bec ; cf. Couvreur, p. 427);

* l’instrument en peau s'appelle hou (tambour ; cf. Couvreur, p. 444);

* l’instru ment fait d'une calebasse s'appelle cheng (sorte de flûte composée de treize ou dix-neuf tuyaux placés sur une calebasse ; cf. p. 10, n. 1 et Couvreur, p. 18) ;

* l’instrument fait en fils de soie s’appelle hien (ce sont tous les instruments à cordes) ;

* l'instrument de pierre s'appelle k’ing (c'était une pierre sonore suspendue à un support ; cf. Couvreur, p. 383) ;

* l'instrument de métal s'appelle tchong (cloche);

* les instruments faits en bois s'appellent tchou et yu (c'étaient de petites caisses en bois sur lesquelles on frappait pour annoncer le commencement et la fin de la musique ; cf. Couvreur, p. 833 et 251).

C'est là ce qu'on appelle les huit instruments de musique. »

01. (27) Les cent animaux sont, d'après les comme ntateurs, les animaux féroces qui étaient commis à la garde du fonctionnaire appelé le fou pou che (cf. note 115).

- Le commentateur Sou Che (Chou king, ch. II, p. $34 \mathrm{v}^{\circ}$ ) remarque que cette phrase est assez singulière dans la bouche de $K^{\prime}$ oei ; tous les autres fonctionnaires nommés par Choen ont voulu céder leurs honneurs à de plus dignes; lui seul se vante de ses talents; Sou Che en conclut que ce passage devait à l'origine faire partie du chapitre I et Tsi du Chou king et a été incorporé dans le Choen tien par erreur. 
- A nos yeux, ce n'est pas seulement cette phrase, mais toute la théorie musicale qui précède, qui n'est guère à sa place.

01. (328) Choen redoute les malentendus que de faux rapports peuvent faire naître entre lui et son peuple; il charge Long de promulguer ses ordres sans les altérer et de le renseigner exactement pour que ces ordres soient appropriés aux circonstances.

01. (329) Ce texte est, à vrai dire, le seul qui pourrait justifier l'opinion que l'expression « les quatre montagnes » désigne un fonctionnaire unique; dans cette hypothèse en effet, les vingt-deux hommes sont le chef des quatre montagnes, les douze pasteurs et les neuf personnes dont nous avons lu la nomination à des charges diverses.

- Mais nous avons montré quelles raisons nous font préférer l'ancienne interpréta tion qui voit quatre fonctionnaires dans les chefs des quatre montagnes (cf. notes 199 et 302). Nous devons dès lors accepter le commentaire de Ma Yong, d'après qui, dans les neuf personnes promues par Choen, il y en a trois, Heou-tsi, Sié et Kao-yao, qui ne sont que confirmés dans des charges anciennes et ne doivent pas entrer en ligne de compte ; les vingt-deux hommes sont alors les six personnes restantes, plus les chefs des quatre montagnes et les douze pasteurs.

01. (3ㅜ) Nous suivons ici le sens indiqué par Tchang Cheou-kié. Le ciel dont il est question est le ciel physique ; on observe l'ordre établi par le ciel en se conformant aux saisons.

01. ( $\underline{331})$ Encore aujourd'hui la coutume de faire subir un examen triennal à tous les fonctionnaires est de règle. Tous les trois ans, le gouverneur de chaque province rédige un rapport sur ses subordonnés (cf. notes 202 et 219).

01. (332) On a vu plus haut que le peuple de San-miao avait été transporté par Choen du sud dans l'ouest ; Kiang Cheng explique que, les San-miao se montrant encore insubordonnés dans leur nouvelle résidence, on fut obligé d'user envers eux de nouveaux moyens de rigueur. - Tout ce qui précède avait trait à la nomination des fonctionnaires; on ne comprend guère ce que vient faire ici cette phrase isolée.

01. (333) La confusion entre la division de l'empire en douze provinces et la division en neuf provinces apparaît manifestement dans cette phrase (cf. note 242).

01. (334) Sur les travaux des $Y u$, voyez les Annales principales des Hia.

01. (335) Sur le domaine des terres incultes, qui était à 2,500 li de la capitale au nord, au sud, à l'est et à l'ouest et avait par consé quent 5000 li de côté, cf. le Tribut de $Y u$, ad fin [p. • $\left.{ }_{148}\right]$.

01. (336) Tout ce passage est fort altéré et les leçons des Rites de Tai l'aîné (chap. Ou ti té, p. $\left.3 \mathrm{v}^{\circ}\right)$ ne contribuent guère à l'éclaircir. Se-ma Tcheng propose de corriger le texte de la manière suivante $[. . .$.$] . Il faut alors traduire :$

«Au sud, il soumit Kiao-tche et Pei-hou; à l'ouest, les Jong de l'ouest, Si-tche, Kiu-seou, les Ti-k’iang ; au nord, les Jong des montagnes, Pei-fa et Si-tchen; à l'est, les barbares Tch'ang et Niao.

- Le Kiao-tche correspond au Tong-king actuel (cf. note 150); le Pei-hou, d'après un commentaire du Eul ya cité par le K'ang hi tse tien, est identique à la commanderie de Je-nan sous les Han, c'est-à-dire au Quang-nam actuel, dans l'empire d'Annam ; le Pei-hou est mentionné dans la sixième strophe de l'inscription que Ts'in Che-hoang-ti fit faire en l'an 219 avant J.-C. sur la terrasse Lang-ya (cf. Annales principales de Ts'in Che-hoang-ti).

— Les Jong de l'ouest sont les barbares qui habitaient le Kan-sou actuel ; le Si-tche est appelé Sien-tche et le Kiu-seou est appelé Kiu-yu dans les Rites de Tai l'aîné ; ces deux pays sont aussi mentionnés dans le Yu kong (province de Yong);

- les Ti-k’iang (ou, suivant quelques uns, les $T i$ et les K’iang) sont des barbares souvent assimilés aux Jong, mais qui paraissent avoir habité surtout le Se-tch'oan occidental et le Tibet. Le Pei-fa est cité par le livre des Han antérieurs comme un pays du nord; le Si-tchen a 
été identifié assez arbitrairement par Tcheng Hiuen avec les Sou-tchen, ou Jou-tche qui régnèrent en Chine sous le nom de dynastie Kin et sont regardés comme les ancêtres des Mandchous actuels.

- Les barbares Tch'ang nous sont inconnus; dans le nom des barbares niao, certains commentateurs proposent de corriger Niao en tao ; il faut alors traduire les barbares des îles ; ces îles seraient soit l'archipel Japonais, soit l'archipel des îles de la Sonde.

Je rapporte tout ce paragraphe à Choen parce qu'il lui est formellement attribué dans les Rites de Tai l'aîné.

01. (337) La musique de $Y u$ comprenait neuf chants successifs, chantés chacun sur un ton différent.

01. (338) L'apparition d'êtres singuliers est regardée par les Chinois comme un présage de bon augure.

01. (339) Cf. Chou king, chap. I et Tsi, trad. Legge [css: édition/rechercher: 'phoenix'], Chinese Classics, t. III, p. 88 ; [trad. Couvreur].

01. (340) Proprement: de l'empereur $Y u$; nous avons écrit Choen pour éviter toute confusion avec $Y u$ dont il a été question dans le paragraphe précédent.

01. (341) C'est-à-dire après que le deuil de trois ans fut fini.

01. (342) On voit que, d'après les données de Se-ma Ts'ien, Choen mourut àgé de cent ans, après un règne personnel de trente-neuf ans. La chronologie du T'ong kien kang mou fait régner Choen quarante-huit ans et celle du Tchou chou ki nien cinquante-trois ans; toutes deux s'appuient sur le texte du Chou king (Choen tien, ad fin), qui dit que Choen mourut cinquante ans après avoir pris le pouvoir; mais le T'ong kien kang mou retranche de ce nombre les trois années de deuil, tandis que le Tchou chou ki nien les ajoute à ce nombre.

01. (343) Ts'ang-ou est le nom du lieu où se trouvait la montagne Kieou-i, c'est-à-dire des neuf doutes, ainsi nommée parce qu'elle avait neuf pics si semblables qu'on les confondait entre eux. Ts'ang-ou se trouvait dans l'actuelle sous-préfecture de Ning-yuen, préfecture de Yong-tcheou, province de Hou-nan.

01. (344) Au sud-est de la sous-préfecture de Ning-yuen.

01. (345) Mencius (V, b. 3, Legge, p. 225) dit que Siang fut nommé prince de $P i$ (près de la préfecture secondaire de Tao, préfecture de Yong-tcheou, province de Hou-nan). Dans ce passage de Mencius est discutée la question de savoir si Choen agit bien ou mal en donnant cette dignité à son frère, malgré sa méchanceté.

01. (346) C'est-à-dire de même que Tan-tchou, fils de Yao.

01. (347) Il le proposa au Ciel pour être empereur après lui.

01. (348) Nous voyons apparaître ici pour la première fois une idée fondamentale de la religion chinoise : pour que des fils de personnes souveraines puissent faire les sacrifices rituels à leurs ancêtres, il est nécessaire qu'ils aient un domaine, quelque restreint qu'il soit, où ils soient maîtres absolus. Le sacrifice est étroitement rattaché au sol.

01. (349) Cette situation privilégiée accordée à un descendant d'une dynas tie éteinte, chargé de représenter ses ancêtres auprès du souverain régnant, est mentionnée dans plusieurs autres textes. Dans le Chou king, le chapitre Wei tse tche ming nous montre le duc de Tcheou nommant le vicomte de Wei représentant de la dynastie Chang et lui annonçant qu'il serait traité comme un hôte dans la maison du roi. Voyez encore dans le Chou king, chap. I et Tsi (trad. Legge, p. 87), Tan-tchou appelé l'hôte de Choen; et encore Tso-tchoan, $24^{\mathrm{e}}$ année du duc $H i$, trad. Legge, p. 193, $1^{\mathrm{e}}$ col. ; - Che king, décade de Tch'en-kong, ode 3, trad. Legge, p. 585 ; [trad. Couvreur] ; - Li ki, chap. Kiao t'o cheng, trad. Legge, Sacred Books of the East, vol. XXVII, p. 422-428. 
01. (타) C'est-à-dire qu'il ne se séparait pas de ses ancêtres et ne se reconnaissait pas le droit de se conduire comme un maître envers les fils des anciens souverains. La phrase se retrouve dans le chapitre Tsi fa du Li ki.

01. (351) Leur mérite fit qu'on les distingua en les désignant par le nom de la principauté qui leur avait appartenu en fief avant leur accession au trône.

01. (352) La principauté de Hiong correspond à l'actuelle sous-préfecture de Sin-tcheng, préfecture de K'ai-fong, province de Ho-nan.

- - C'est dans ce texte que M. Terrien de Lacouperie a trouvé la preuve que Hoang-ti n'était autre que Nakhunte et voici comment il arrive à ce résultat : le mot Hiong est donné par le Dictionnaire de $K$ ang-hi comme se prononçant, dans certains cas (mais non pas dans celui où il est le surnom de Hoang-ti) Nai; M. Terrien de Lacouperie prend ce mot Hiong, prononcé à tort $\mathrm{Nai}$, et le place devant le nom de Hoang-ti, créant ainsi une expression Nai (lisez Hiong) Hoang-ti qui n'existe, à ma connaissance, dans aucun texte chinois ; c'est ensuite un jeu d'établir les équivalences $N a i=\mathrm{Na}$, Hoang $=$ khun ; $t i=$ te. Cet exemple suffit à expliquer pourquoi nous ne croyons pas nécessaire de surcharger nos notes en réfutant point par point les prétendues concordances sinico-élamites de M. Terrien de Lacouperie.

01. (ㅌ3) Sur l'emplacement des pays de Kao-yang et de Kao-sin, cf. note 155 ; sur T'ao et T'ang, cf. note 166 ; sur $Y u$, cf. note 206.

01. (354) C'est-à-dire prince de Hia. Le pays de Hia est identifié avec la préfecture secondaire de $Y u$, préfecture de Kai-fong, province de Ho-nan.

01. (355) Sié est l'ancêtre de la dynastie Chang; son fief de Chang correspond à la préfecture secondaire de Chang, province de Chàn-si. - K' $i$ est l'ancêtre de la dynastie Tcheou ; mais ce ne fut qu'un de ses descendants qui eut le fief de Tcheou (T'ong hien tsi lan, ch. II, p. 12 $\mathrm{v}^{\circ}$ ); lui-même eut le fief de T'ai, aujourd'hui sous-préfecture de Ou-kong, préfecture secondaire de K'ien, province de Chàn-si.

01. (56) Cette phrase est évidemment inspirée par un passage du Ou ti té où Kong-tse dit que Hoang-ti appartient à la haute antiquité et qu'il est difficile de bien le connaître.

01. (ㅌ5) Le Chang chou (Livre de l'Antiquité ou, suivant d'autres, Livre vénérable) est un nom du Chou king. On oppose les livres canoniques tels que le Chou king aux cent écoles qui comprennent les écrivains divers non classiques.

01. (ㅌ5) Dans l'expression encore en usage de nos jours, tsin chen, le texte de Se-ma Ts'ien remplace le premier caractère par un équivalent phonétique. L'expression tsin chen désigne les personnes qui ont une charge officielle; $t \sin$ signifie enfoncer et chen large ceinture ; $t$ sin chen a donc le sens de « ceux qui enfoncent dans leur ceinture » le hou, c'est-à-dire la tablette que tous les officiers tenaient à la main quand ils étaient reçus en audience par l'empereur.

01. (359) Ce sont les chapitres Ou ti té et Ti hi sing des Rites de Tai l'aîné. — Se-ma Ts’ien commence par montrer pour quels motifs certains lettrés de son temps se refusaient à faire remonter l'histoire de Chine au delà de Yao. Dans ce qui suit, il expose quelles raisons l'ont déterminé lui-même à accepter, en les choisissant avec critique, quelques-uns des récits relatifs aux cinq empereurs.

01. (6ㅜ) La montagne Kong-t'ong est dans la préfecture de P'ing-léang, province de Kan-sou.

01. ( $\underline{361)}$ Sur la montagne Tchouo-lou, cf. note 117. Le Kiang et le Hoai sont le Yang-tse Kiang et la rivière Hoai.

01. (362) Le Tch'oen ts'ieou ou Chronique de l'État de Lou attribuée à Confucius et les Discours des États attribués à Tso K'ieou-ming. Cf. mon Introduction, au chapitre des Sources de Se-ma Ts'ien.

01. (6ㅜ) Les idées de ces autres récits. 


\section{CHAPITRE II. LES HIA}

02. (101) Tchang Cheou-kié exprime l'opinion, aujourd'hui généralement acceptée, q ue Hia est un nom de lieu ; c'est le pays que $Y u$ reçut en fief et dont il était comte (cf. note 293) avant son avènement. Hia correspond à la préfecture secondaire de $Y u$, préfecture de Kai-fong, province de Ho-nan.

02. (102) Aux yeux de Se-ma Ts'ien, Wen-ming est le nom personnel de Yu, comme Fang-hiun est le nom personnel de Yao et Tch'ong-hoa le nom personnel de Choen. Le texte du Chou king est moins clair et c'est pourquoi le pseudo-Kong Ngan-kouo a pu soutenir que ces trois expressions n'étaient pas des noms propres, mais des noms communs ayant un sens dans la phrase ; son opinion ne s'accorde pas avec la leçon des Mémoires historiques.

02. (103) Le Che pen, cité par Se-ma Tcheng, dit que Koen épousa une fille de la tribu Chen qui s'appelait Niu-tche; elle enfanta Kao-mi : Kao-mi serait, d'après le commentateur Song Tchong, le nom du pays que $Y u$ reçut en fief.

- Se-ma Tcheng, citant le Chou wang pen ki de Yang Hiong (53 av. J.-C.-18 ap. J.-C.), fait naître $Y u$ auprès de la montagne Che-nieou; cette hauteur se trouve à l'ouest de la sous-préfecture de Min-tch'oan, préfecture de Tch'eng-tou, province de Se-tch'oan. Le T'ong kien tsi lan (chap. II, p. $1 \mathrm{r}^{\circ}$ ) donne le même renseignement, mais en le rapportant au Chou pen ki de Ts'ía Tcheou (qui vivait au temps de la dynastie Han du pays de Chou, 221-263 ap. J.-C.).

02. (104) Les Rites de Tai l'aîné (chap. Ti hi sing, p. 4 vº) disent :

«Tchoan-hiu engendra Koen; Koen engendra Wen-ming qui fut Yu.

De même on lit dans le Che pen que Tchoan-hiu fut le père de Koen. Se-ma Ts'ien est donc d'accord avec ces deux ouvrages ; au contraire, d'après Pan Kou (chap. Lu li tche, $2^{\mathrm{e}}$ partie, p. $15 \mathrm{v}^{\circ}$ ), Koen était le descendant de Tchoan-hiu à la cinquième génération, de même que Kouseou, père de l'empereur Choen.

02. (105) Chou king : Yao tien.

02. (106) Chou king : Choen tien.

02. (107) Chou king : Choen tien.

02. (108) Ta Tai li : chap. VII, Ou ti té.

02. (109) La voix de Yu, dit Se-ma Tcheng, avait le son que rend le tube musical appelé yng-tchong et pouvait être prise pour l'étalon de la gamme ; de même, pour les mesures de longueur, «le pas de $Y u$ » était l'unité ; les tireurs de sorts faisaient encore leurs calculs, au temps des T'ang, avec le pas de $Y u$.

02. (1ㅡ) Cf. note 01.299 .

02. (111) Cf. note 01.296 .

02. (112) Chou king : yu kong.

02. (113) La leçon de Se-ma Ts'ien est fou qui signifie «donner, confier »; c'est aussi la leçon des Rites de Tai l'aîné. $Y u$ remet les terres à ses subordonnés pour qu'ils les divisent par catégories. La leçon du Chou king est «diviser»; c'est alors Yu lui-même qui divise les terres.

02. (114) La leçon des Mémoires historiques est une glose de celle du Chou king, ts'ién mø ; en effet, le caractère $m \bullet u$ ne doit pas être pris dans son sens vulgaire de «couper »; il n'est ici que le substitut d'un vieux caractère, aujourd'hui perdu ; ce dernier caractère est expliqué comme signifiant « indications entaillées ». Il s'agit donc bien de marques faites sur les ar bres 
comme le dit Se-ma Ts'ien (H. T. K. K., chap. CCCXCII, p. $12 \mathrm{r}^{\circ}$ ). Ces marques étaient destinées à indiquer le chemin.

- Assurément le sens que donne M. Legge [css : édition/rechercher : 'cut down'] à cette phrase en traduisant « abattre les arbres » (Chinese Classics, t. III, p. 77) est beaucoup plus clair et plus satisfaisant pour un lecteur européen ; mais il nous semble qu'on n'a pas le droit de faire si bon marché des remarquables travaux de la critique chinoise moderne; cette critique a démontré que les textes anciens étaient obscurs, et que la simplicité de l'explication tradition nelle était un leurre; nous sommes obligés d'accepter ses conclusions, quelques embarras qu'elles puissent nous créer pour l'interprétation de ces vieux écrits.

02. (115) Mencius (trad. Legge [\$7], p. 127; [trad. Couvreur]) dit :

«Yu resta hors de chez lui huit années ; il passa trois fois devant sa porte et n'y entra pas.

02. (116) Ce sont là les «quatre modes de locomotion » auxquels il est fait allusion dans le Chou king, au chap. I et Tsi (trad. Legge, p. 77 ; [trad. Couvreur]).

* Pour aller sur la boue, on se servait d'un objet qui, d'après les commentateurs, devait ressembler à une sorte de van en osier ; on appuyait une jambe dessus et on glissait ainsi sur la boue sans y enfoncer.

* Pour gravir les montagnes, on se servait de crampons. Les noms de ces deux objets, le van et le crampon, sont orthographiés des manières les plus diverses dans les nombreux textes qui reproduisent ce passage (cf. le commentaire au IIe chapitre du livre de Che tse, p. $10 \mathrm{v}^{\circ}$.

- Che tse était originaire du pays de $T \sin$; son nom personnel était Kiao ; il fut l'hôte du conseiller de Ts'in, Wei Yang, dans la seconde moitié du IVe siècle avant notre ère.

02. (117) Ta Tai li : chap. VII, Ou ti té.

02. (118) A gauche et à droite, c'est -à-dire en toute occasion, toujours.

02. (119) Chou king : $\underline{\text { I et Tsi. }}$.

02. (120) Dans les paragraphes qui suivent, Se-ma Ts'ien reproduit le fameux chapitre du Chou king intitulé le Tribut de $Y u$. A le prendre tel qu'il est, ce chapitre se compose de deux parties distinctes : la première est une description des neuf provinces de l'empire, descrip tion qui suit généralement un ordre uniforme: limites de la province; travaux publics qui y furent exécutés; qualité de la terre; nature du tribut; routes par lesquelles il est apporté à la capitale; la seconde partie traite des neuf grandes chaînes de montagne et des neuf grands cours d'eau de l'empire ; puis elle expose les travaux hydrographiques de $Y u$; enfin elle trace un schème de l'empire mathématiquement organisé.

- Ed. Biot (Sur le chapitre Yu kong du Chou king et sur la géographie de la Chine ancienne, Journ. asiatique, août-sept. 1842, p. 152-224) a fait une bonne étude critique du Tribut de $Y u$; il a montré que

«le texte ne présente le nom de $Y u$ que deux fois, dans la phrase du commencement et dans celle de la fin ;

et que, par conséquent,

« si l'on retranchait du texte simplement deux phrases, on pourrait ne voir dans le $Y u$ kong que l'histoire des progrès d'une grande colonie qui s'étend peu à peu en desséchant un sol marécageux et chassant devant elle les premiers habitants de ce sol ;

les travaux dont il est question dans ce texte sont d'ailleurs bien trop considérables pour avoir été exécutés par un seul homme ; la tradition a donc

« fait honneur au seul $Y u$ des travaux continus de plusieurs générations. 
- M. von Richthofen (China, t. I, ch. VIII) s'est livré à de savantes recherches sur ce même sujet; d'après lui, le texte même du Yu kong nimplique point les gigantesques travaux d'hydrographie que les commentateurs y ont introduits en donnant aux mots des sens qu'ils ne comporteraient pas; il a constaté l'exactitude des notions géographiques de ce frag ment de l'antiquité ; enfin il a prétendu, mais c'est le point le plus sujet à caution de sa remarquable dissertation, retrouver, grâce au $Y u$ kong, des indications sur la marche qu'auraient suivie les envahisseurs chinois qui seraient venus de l'ouest.

- La traduction que M. Legge a donnée du Tribut de $Y u$ est une des parties les plus richement annotées de l'admirable monument qu'il a élevé à la gloire des lettres chinoises.

— Enfin M. Kingsmill a fait voir (China Review, t. IV, p. 13 et suiv. ; t. XIV, p. 17 et suiv.) que le Tribut de $Y u$ contient une partie en prose rythmée composée de phrases de quatre caractères et que cette partie se détache du contexte comme un document d'un âge différent.

- Pour notre part, tout en profitant des excellents travaux de nos devanciers, nous ne voyons pas trace dans le Tribut de $Y u$ de la prétendue migration des Chinois de l'ouest vers l'est ; il faut solliciter doucement et même violemment les textes pour y trouver des preuves à l'appui de cette hypothèse gratuite qui est devenue un dogme chez bon nombre de sinologues. La première partie du Tribut de $Y u$ se compose de deux éléments superposés, l'un étant une sèche géographie administrative, l'autre la légende des travaux de $\mathrm{Yu}$; la seconde partie est une géographie physique suivie d'une autre légende de $Y u$ et accompagnée d'une description idéale de l'empire qui doit provenir de quelque vieille utopie consacrée par les livres de rites.

Ce sont ces éléments divers du $Y u$ kong dont nous chercherons à marquer la distinction dans notre traduction et dans nos notes. Dans la première partie du $Y u$ kong, nous distinguerons pour le lecteur ce que nous appelons l'élément légendaire en plaçant un tiret après chaque phrase de quatre caractères ; ce n'est pas que le rythme des phrases de quatre caractères ne se retrouve souvent aussi dans la description administrative de l'empire, mais il y est mêlé à des phrases de longueur inégale. Au contraire, la légende est nettement caractérisée ; $1^{\circ}$ en ce qu'elle est toujours en phrases de quatre caractères; $2^{\circ}$ en ce qu'elle emploie la particule $k i$ qui implique l'idée d'une action passée et non d'un état de choses constant.

* en ce qu'elle est toujours en phrases de quatre caractères ;

* en ce qu'elle emploie la particule ki qui implique l'idée d'une action passée et non d'un état de choses constant.

\section{2. (121) Chou king : yu kong.}

02. (122) La province de $K i$ est la seule dont les limites ne soient pas indiquées, mais on peut les déterminer approximativement, puisqu'on con naît les frontières des huit autres provinces ; elle était comprise entre le Hoang-ho à l'ouest et la rivière Leao à l'est : au sud et au sud-est elle longeait le cours du Hoang-ho. En ce temps, le Hoang-ho quittait son lit actuel — à quelque distance à l'est de la préfecture de Hoai-k'ing, province de Ho-nan, passait à Weihoei-fou, puis, se dirigeant au nord, traversait le pays compris entre Tchang-te-fou et Ta-ming-fou : il arrivait dans le lac Ta-lou qui porte encore aujourd'hui ce nom et se trouve à peu de distance au nord-est.de Choen-té-fou (prov. de Tche-li) ; à partir du lac Ta-lou, il se divisait en neuf branches : la plus importante paraît avoir été celle qui décrivait l'arc le plus septentrional; elle passait à l'est de Pao-ting-fou, traversait à angle droit le Pei-ho actuel, à l'ouest de T'ien-tsin; puis elle coupait perpendiculairement le Pei-tang ho actuel et devait se jeter dans la mer non loin de la montagne Kié-che, sous-préfecture de Tch'ang-li, préfecture de Yong p’ing, province de Tche-li (cf. Richthofen, China, t. I, p. 321-323). .

La province de $K i$ était celle où se trouvait la capitale. Quelle était cette capitale ? Si les travaux de $Y u$ doivent être rapportés à l'époque où $Y a o$ était encre empereur (cf. note 01.242), la capitale était $P$ 'ing-yang, aujourd'hui sous -préfecture de Lin-fen préfecture de P'ing-yang, province de $C h \bullet n-s i$; au temps, du règne de Choen, la capitale était $P$ 'ou-fan, aujourd'hui sous-préfecture de Yong-tsi, préfecture de P'ou-tcheou, province de Chøn-si. Toutes deux étaient donc situées dans l'ancienne province de $K i$. 
02. (123) Il n'est pas certain que ces deux premières phrases se rattachent à la partie légendaire $\mathrm{du} Y u$ kong. Nous avons suivi dans notre traduction, la ponctuation du Chou king de Yong-tcheng et nous obtenons ainsi, après le nom de la province de $\mathrm{Ki}$, deux phrases de quatre caractères. Mais tous les anciens commentateurs placent le point après le quatrième mot et il faut alors traduire :

«Dans la province de $K i$, il fit des travaux ; Hou-k'eou ; il mit l'ordre sur (les monts) Leang et $K^{\prime} i$.

On remarquera que le nom de Hou-k'eou reste alors isolé et n'a plus aucun sens ; on peut se demander si le mot qui le suit n'est pas une interpolation destinée à rattacher à la légende des travaux de $Y u$ une simple énumération géographique des montagnes de la province qui sont Hou-k'eou, Leang et $K^{\prime} i$; le doute est d'autant plus permis que les commentateurs ont la plus grande peine à identifier les monts Leang et $K^{\prime} i$, de manière à rendre intelligible la relation qu'avaient ces montagnes avec les travaux hydrogra phiques de $Y u$; on va le voir dans ce qui suit.

La montagne Hou-k'eou était au sud-ouest de l'actuel $\mathrm{Ki}$-tcheou, préfecture de P'ing-yang, province de $C h \bullet n$-si. D'après Ts'ai Tch'en, la montagne Leang ou Lu-Leang est au nord-est de la préfecture secondaire de Yong-ning, préfecture de Fen-tcheou, province de Ch॰n-si; la montagne $K^{\prime} \boldsymbol{i}$ ou Hou-k'i est à l'ouest de la sous-préfecture de Hiao-i, dans la même préfecture que la précédente. - Si l'on adopte l'opinion de Ts'ai Tch'en, les montagnes Leang et $K i$ auraient alors été fort éloignées du Hoang-ho et on ne comprend plus quel rapport elles peuvent avoir avec les travaux qui sont attribués à $Y u$ pour la correction des eaux de ce fleuve. C'est pourquoi les commentateurs modernes adoptent volontiers l'opi nion plus ancienne de K'ong Yng-ta suivant qui les montagnes Leang et $K^{\prime} i$ étaient situées sur la rive droite du Hoang-ho, par conséquent dans l'ancienne province de Yong : dans cette hypothèse, la montagne Leang est au nord-ouest de la sous-préfecture de Han-tch'eng, préfecture de Si$n g a n$, province de Chàn-si; la montagne $K i$ est au nord de la sous-préfecture de $K i$-chan, préfecture de Fong-siang, même province.

Si nous considérons $H o u-k$ 'eou, Leang et $K^{\prime} i$ comme faisant partie primitivement de l'élément géographique du $\mathrm{Yu}$ kong, et comme ayant été rattaché d'une manière tout artificielle à l'élément légendaire et rythmique par l'intercalation du mot, nous n'avons plus besoin de recourir à la bizarre hypothèse de K'ong Yng-ta qui place dans la province de Yong des montagnes dont il est parlé à propos de la province de $K i$, et nous adoptons les identifications de Ts'ai Tch'en.

02. (124) Le nom de T'ai yuen se retrouve encore aujourd'hui dans celui de la préfecture de T'ai-yuen, capitale provinciale du $C h \bullet n-s i$.

- Yo-yang signifie proprement « au sud de la montagne »; la montagne dont il s'agit ici est le Houo-t'ai-chan, dans la préfecture secondaire de Houo, préfecture de P'ing-yang, province de $C h \bullet n-s i$.

Les commentateurs chinois, auxquels nous nous rattachons, expliquent cette phrase en disant que $Y u$ répara les digues élevées par son père Koen à T'ai-yuen et que les travaux auxquels il se livra depuis T'ai-yuen jusqu'à Yo-yang avaient pour but de régler le cours de la rivière Fen. M. von Richthofen (China, I, 351) dit que le cours de la rivière Fen n'a jamais eu besoin d'être corrigé ni endigué et que les travaux de $Y u$ ne peuvent se rapporter qu'à une réorganisation administrative.

Pour notre part, il nous semble que, d'un bout à l'autre du Yu kong, on distingue les débris d'une légende qui présente $Y u$ sous les traits d'un ingénieur hydrographe; la partie administrative est, au contraire, celle qui ne se rattache point au nom de $Y u$; au lieu d'interpréter le $Y u$ kong au moyen d'un seul système d'explication, com me le fait M. von Richthofen, nous y reconnaissons deux éléments hétérogènes qui demandent à être analysés suivant des principes différents: la partie rythmique qui traite des travaux de $Y u$ est une légende et doit être acceptée comme telle, c'est à -dire que, quelque fantastiques que puissent paraître ces travaux, il ne faut pas chercher à les dissimuler en donnant aux mots du texte des 
sens qu’ils n'ont point ; mais d'autre part, à côté de cet élément légendaire se trouve une géographie statistique de l'em pire dont il importe de bien mettre en lumière le caractère précis et positif. Nous n'expliquons pas toute la première partie du $Y u$ kong par les travaux de $Y u$, comme le fait $\mathrm{M}$. Legge à la suite des commentateurs chinois ; nous ne l'expli quons pas non plus tout entière par un plan administratif comme le tente $M$. von Richthofen ; mais nous désagrégeons ce texte en deux parties d'origine et de nature diverses et nous appliquons à chacune d'elles un mode d'interprétation spécial.

02. (125) Une partie du nom de T'an-hoai se retrouve dans celui de la préfecture actuelle de Hoai-k'ing (province de Ho-nan), avec laquelle d'ailleurs on identifie T'an-hoai.

02. (126) Le Tchang est une rivière composée de deux cours d'eau : le Tchang clair et le Tchang bourbeux.

* Le Tchang clair prend sa source à une quinzaine de kilomètres au sud-ouest de la sous-préfecture de Lo-p'ing, préfecture de T'ai-yuen, province de $C h \bullet n$-si ;

* le Tchang bourbeux prend sa source à environ 25 kilomètres à l'ouest de la sous-préfecture de Tch'ang-tse, préfecture de Lou-ngan, province de Ch•n-si.

* Tous deux se réunissent au lieu appelé Confluent des Tchang, dans la sous-préfecture de Ché, préfecture de Tchang-té, province de Ho-nan;

* puis le Tchang se dirige vers le nord-est et va se réunir à T'ien-tsin aux différents cours d'eau qui se jettent dans la mer sous le nom de Pei-ho. On verra plus loin qu'au temps du Yu -hong il se jetait dans le Hoang-ho.

- Le mot heng est expliqué assez arbitrairement par K'ong Ngan-kouo et Tcheng Hiuen comme l'équivalent de = transversal ; cette épithète ferait allusion à la direction de son cours qui est presque perpendiculaire à celui que suit le Hoang-ho dans le Ch॰n-si. Wang Sou est plus exact quand il dit que le Heng et le Tchang sont deux rivières différentes. En effet, $L i$ Tao yuen, dans son commentaire au Choei king, donne le nom de rivière Heng au Tchang bourbeux.

02. (127) Les neuf provinces sont rangées par ordre de valeur sous le rapport des redevances et sous le rapport des terres cultivées en deux séries où la place de chacune d'elles est indiquée par les trois subdivisions cháng tch ung hiá de trois catégories cháng tch ung hiá. Ainsi cháng cháng signifie la première subdivision de la première catégorie, c'est -à-dire le premier rang; tchøung tch ung signifie la première [css : deuxième ?] subdivision de la seconde catégorie, c'est-à-dire le cinquième rang. Voici la liste des rangs occupés par les neuf provinces dans les deux séries ; le premier chiffre indique le rang sous le rapport des redevances et le second le rang sous le rapport de la valeur des terres: Ki 1. 5 ; Yen 9. 6 ; Ts'ing 4. 3 ; Siu 5. 2 ; Yang 7. 9 ; King 3. 8 ; Yu 2. 4 ; Leang 8. 7 ; Yong 6. 1.

Le mot $t$ 'ou • est expliqué par K'ong Ngan-kouo comme signifiant que cette terre produit des redevances du premier degré et aussi du second; d'après $M a$ Yong, elle signifie que les terres sont les unes meilleures, les autres moins bonnes, mais qu'en somme les redevances qu'elles produisent sont du premier degré. Nous adoptons cette seconde interprétation ; en effet, si les degrés dont il s'agit ne sont pas des mesures absolues mais servent à établir un ordre de succession entre les provinces, ils doivent être assignés chacun à une province déterminée et une province ne peut être à la fois la première et la seconde sur la liste.

02. (128) Le nom de la rivière Tch'ang est écrit Heng dans le Chou king et c'est cette dernière orthographe qui est la bonne. En effet, le mot Heng n'a été modifié dans le texte de Se-ma Tsïen que parce qu'il était le nom personnel de l'empereur Wen (179-156 av. J.-C.). La rivière Heng, appelée aujourd'hui Cha ho, prend sa source dans la sous-préfecture de Feou-p'ing, préfecture de Tchen-ting, province de Tche-li. La rivière Wei prend sa source plus au sud, dans la sous-préfecture de Ling-cheou et ne tarde pas à se jeter dans la rivière Hou-t'ouo. Le Heng et le Wei font tous deux partie du système hydrographique très compliqué qui vient se déverser à T'ien-tsin. 
02. (129) Ta-lou est le nom d'un grand lac à l'ouest de la sous -préfecture de Kiu-lou, préfecture de Choen-té, province de Tche-li.

Autrefois on devait donner ce nom à un territoire beaucoup plus vaste qui s'étendait au nord jusqu'aux préfectures secondaires de Tchao et de Chen; les marécages qui le couvraient furent desséchés en partie et les eaux furent refoulées dans le lac qui seul aujourd'hui garde le nom de Ta-lou. On a vu plus haut (note 122) qu'au temps du Yu kong le Hoang-ho traversait le lac Ta-lou. — Les mots [] dans Se-ma Ts'ien et $t s^{\bullet}$ dans le Chou king ont ici le sens de « cultiver, mettre en culture », d'après tous les commentateurs.

02. (130) Nous avons déjà vu les barbares Niao mentionnés dans les Annales principales des cinq empereurs (p.• 89 ); le Chou king écrit Tao- $i=$ les barbares des îles ; mais les critiques modernes rejettent cette leçon et adoptent celle de Se-ma Ts'ien qui est aussi celle de Pan Кои. Le mot niao peut être regardé comme l'expression pho nétique du nom que se donnaient ces tribus barbres. Le fait qu'elles apportaient des fourrures et qu'elles passaient au large de la montagne Kié-che (sous-préfecture de Tch'ang-li, préfecture de Tong-p’ing, province de Tche-li) semble indiquer qu'elles devaient habiter le Leao-tong; Tchang Cheou-kié, en citant ici un intéressant passage du Kouo ti tche où sont décrites les mours des anciennes tribus de la Mandchourie, confirme cette manière de voir.

- Le Chou king dit que ces barbares laissent à leur droite la montagne Kié-che pour entrer dans le Hoang-ho dont l'embouchure la plus septentrionale ne devait pas être éloignée de ce lieu. Les Mémoires historiques disent qu'ils entrent dans la mer; la leçon est moins claire ; elle peut cependant se comprendre, si l'on admet que la mer dont il est question est le Po-hai ou golfe du Pé-tché-li.

- Il est à remarquer que les pelleteries des barbares Niao ne constituent pas un tribut régulier; la province de $K i$ est la seule qui ne paie pas de tribut parce qu'elle est celle à qui toutes les autres provinces apportent le leur.

02. (131) La rivière Tsi a presque entièrement disparu dans le Hoang-ho actuel ; le nom de la préfecture de $T s i$-nan, dans le Chan-tong, rappelle qu'elle coulait à l'endroit où se trouve maintenant le grand Fleuve. On verra, quelques pages plus loin, qu'en vertu de principes d'hydrographie propres à la science géographique chinoise, on ap pelait $T s i$ un affluent de la rive gauche du Hoang-ho et qu'on regar dait comme la continuation de cette même rivière $T s i$ un effluent de la rive droite du Hoang-ho; le Tsi était ainsi considéré comme traversant le Hoang-ho sans se confondre avec lui. Dans cette théorie, la source de la rivière Tsi se trouve à la montagne Wang-ou (au nord du Hoang-ho actuel, dans la province de Ho-nan, presque à la limite entre cette province et celle de $C h \bullet n$-si) et son embouchure est celle de la petite rivière Siao-ts’ing qui se jette dans la mer à quelque distance au sud du Hoang-ho actuel.

- On a vu plus haut (note 122) quel était le cours du Hoang-ho au temps du Tribut de $Y u$; en se reportant à la description que nous en avons donnée, on verra que la province de Yen, limitée au nord-ouest par le Hoang-ho, au sud-est par la rivière Tsi, devait comprendre la partie sud-est du Tche-li, la partie nord du Chan-tong et une partie de la préfecture de Weihoei, dans le Ho-nan.

02. (132) Le Eul ya mentionne huit de ces neuf branches; ce sont : le T'ou-hai, le T'ai-che, le Ma-kié, le Fou-fou, le Hou-sou, le Kien-kié, le Keou-p'an et le Ko-tsin. La neuvième branche serait le $H o$ proprement dit. On ferait des volumes avec les commentaires que les érudits chinois ont écrits pour identifier tous ces noms. M. von Richthofen fait à ce sujet une très juste remarque :

«Quelques commentateurs se sont efforcés de retrouver un à un les neuf Ho dans les divers cours d'eau du temps présent. C'est là naturellement du travail en pure perte, non seulement parce que des changements considérables se sont produits depuis ce temps, mais aussi parce que nous avons autant de peine à croire que le $H o$ coulait juste en neuf branches, que nous en avons à admettre que la Chine d'alors ne possédait que neuf fleuves. (China, t. I, p. 322, n.). 
02. (133) L'étang de Lei-hia n'est autre que l'étang de Lei dont il a été question dans la légende de Choen (cf. p. 72). Il est marqué sur les cartes chinoises au sud du Hoang-ho actuel, au nord-est de la préfecture de Ts'ao-tcheou, dans le Chan-tong. Ts'ai Tch'en explique le nom de ce lac en rappelant la légende suivante tirée du Chang hai king :

«Dans ce lac il y a le dieu du tonnerre $(l e i)$; il a le corps d'un dragon et la figure d'un homme ; lorsqu'il frappe sur son ventre, c'est le tonnerre.

Or le lac s'appelait à l'origine le lac Hia ; on l'appela aussi du nom de ce dieu et son nom fut Lei-hia.

02. (134) Le cours actuel du Hoang-ho paraît avoir fait disparaître les deux petites rivières appelées Yong et Tsiu; on n'en trouve plus qu'un ves tige dans le canal de Tsiu qui est sur le territoire de la préfecture secondaire de P'ou.

02. (135) D'après Ts'ai Tch'en, cette proposition et la précédente se rattachent aux travaux de $Y u$ : les vers à soie craignent l'humidité ; c'est pourquoi ils ne se multiplièrent que lorsque les eaux se furent retirées; c'est alors aussi que les hommes purent quitter les collines où ils s’étaient réfugiés et venir habiter dans la plaine auparavant inondée.

02. (136) La traduction que nous donnons de cette phrase s'appuie sur le commentaire de K'ong Ngan-kouo. On a vu plus haut (p. $\left.\bullet_{100-101}\right)$ que $Y u$ travailla treize années à combattre l'inondation ; la province de Yen fut la dernière dont il s'occupa et elle ne fut mise en culture que la treizième année; les redevances eurent le même rang que la province, c'est-à-dire qu'elles furent les dernières. qu'elles eurent le neuvième rang.

- Ts-ai Tch'en propose une autre interprétation qui est adopté par M. Legge : le mot [] signifie, d'après lui, que les redevances étaient exactement ce qu'elles devaient être ; comme d'ailleurs la pro vince de Yen avait beaucoup souffert de l'inondation, ce ne fut qu'au bout de treize années de culture qu'on exigea les redevances.

- Mais on ne voit plus, dans cette explication, comment le rang des redevances serait indiqué, car il est puéril de dire avec Ts'ai Tch'en que les redevances les plus légères sont considérées par le souverain comme les plus parfaites; il faut cependant que ce rang soit signifié d'une manière quelconque puisqu'il l'est pour to utes les autres provinces. D'autre part le nombre de treize années offre une coïncidence remarquable avec la durée attribuée aux travaux de $Y u$ et Ts'ai Tch'en n'en tient pas compte. Enfin le Che ki loen wen place le signe de ponctuation après le mot tcheng et non, comme le fait M. Legge, après le mot $t$ so.

- Telles sont les raisons qui nous ont amené à traduire cette phrase comme nous l'avons fait.

02. (137) Outre les redevances, toutes les provinces, sauf celle de $K i$ où se trouve la capitale, envoient à l'empereur un tribut, c'est -à-dire des échantillons en nature de leurs produits les plus remarquables. M. Richthofen (China, 1, p. 355) remarque que cette coutume existe encore de nos jours : le Ngan-hoei envoie du thé ; le Se-tch'oan, des drogues médicinales, etc.

02. (138) Voyez un dessin de ces mannes dans le Dictionnaire chinois-français du P. Couvreur, p. 68.

02. (139) Mot à mot : des ornements en tissu.

02. (140) Après avoir indiqué en quoi consiste le tribut, le $Y u$ kong décrit la route par laquelle on l'apportait jusqu'au Hoang-ho, c'est-à-dire jusqu'à la province où se trouvait la capitale.

— D'après les indica tions de Yng Chao, la rivière T'a prenait sa source à Tch'ao-tch'eng à la frontière ouest du Chan-tong, un peu au nord du Hoang-ho actuel ; il se jetait dans la mer non loin de la sous-préfecture de Kao-yuan, préfecture de Ts'ing-tcheou, au sud du Hoang-ho. Étant données les modifications qu'a subies le système hy drographique de cette région, il est difficile de savoir si les rivières $T s i$ et $T^{\prime} a$ communiquaient entre elles ou si elles sont deux voies différentes pour arriver au Hoang-ho. 
02. (141) La montagne Tai n'est autre que le célèbre T'ai-chan — préfecture secondaire de T'ai-ngan, province de Chan-tong.

02. (142) Les limites indiquées dans ce passage sont fort vagues; certains critiques chinois croient cependant pouvoir préciser toutes les préfectures et sous-préfectures qui sont situées dans cette province ; nous ne les suivrons pas dans leur minutie qui n'est qu'un trompe -l'qeil ; d'une manière générale, la province de $T$ s'ing comprenait toute la partie du Chan-tong au sud de la rivière Tsi. D'après une théorie mentionnée par Tchang Cheou-kié, cette province aurait eu une étendue beaucoup plus considérable, car on lui aurait rattaché les pays qui s'étendent au nord et à l'est de la presquîle du Chan-tong, par delà le golfe du Pe-tche-li. Cette bizarre assertion se fonde sur le fait que Choen aurait détaché une partie de la province de Ts'ing et l'aurait érigé en province de Yng : or, la province de Yng comprenait la contrée située à l'est et à l'ouest de la rivière Leao et s'étendait jusqu'en Corée.

Nous ne sommes pas obligés, comme les commentateurs chinois, de pousser l'ingéniosité jusqu'aux limites de l'absurde, pour concilier entre elles les légendes de Choen et celles de $Y u$. Si nous nous en tenons strictement au texte du Yu kong, la province de $T$ s'ing était nettement circonscrite dans la presquîle du Chan tong et ne passait pas d'un bond jusqu'au Leao-tong.

02. (143) Le territoire de Yu-i est cité dans le chap. Yao-tien du Chou king (cf. Annales principales des cinq empereurs, p.• $\left.{ }_{44}\right)$. Il correspond à la préfecture secondaire de Ning-hai, à l'extrémité de la presquîle du Chan-tong. Pour les commentateurs qui, comme Se-ma Tcheng, admettent que la province de Ts'ing comprenait aussi le sud de la Mandchourie, $Y u-i$ désignerait les territoires à l'ouest de la ri vière Leao.

02. (144) La rivière Wei est marquée sur les cartes modernes chinoises; elle prend sa source dans la montagne Ki-ou, passe à Tchou tch'eng et se jette dans la mer au nord de la sous-préfecture de Tch'ang-i, préfecture de Lai-tcheou.

— La rivière Tse se jette dans la mer plus à l'ouest, après avoir arrosé I-tou, Lin-tse, Lo-ngan et Cheou koang.

02. (145) Cette phrase ne se trouve pas dans le Chou king.

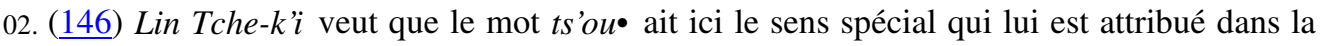
description de la province de Leang où il désigne certaines pierres à polir la jade. Le mot [] jouerait alors le même rôle que le mot wêi dans la description de la province de Yang où nous lisons que le tribut consiste en tels et tels objets et en bois (cependant, dans le texte de Se-ma Ts'ien ces deux mots sont omis). Cette opinion peut fort bien se soutenir.

02. (147) Le nom des barbares Lai s'est conservé dans celui de la préfecture de Lai-tcheou, province de Chan-tong; il existe d'autre part, plus à l'est, une montagne Lai, dans la sous-préfecture de Hoang, préfecture de Teng-tcheou. Ce peuple devait donc occuper toute l'extrémité de la presquîle du Chan-tong, à partir de Lai-tcheou.

- Nous suivons l'avis de la grande majorité des commentateurs en ne donnant pas au mot wei le sens spécial de «cultiver la terre » qu’il a parfois dans le $Y u$ kong ; la caractéristique des barbares est de n'être pas cultivateurs.

02. (148) Les mannes doivent être celles de la province et non celles des barbares, car dans la description des provinces de $Y e n$ et de $Y u$, on parle des mannes sans qu'il ait été question de barbares.

02. (149) D'après le Eul ya, le mot ién désigne une espèce de mûrier qui croît sur les montagnes ; Se-ma Ts’ien écrit [], qui doit avoir le même sens.

02. (150) La rivière Wen prennd sa source dans la sous-préfecture de Lai-tchou, puis passe tout près de T'ai-ngan tcheou; une partie de ses eaux se jette dans le Hoang-ho après avoir traversé Tong-p’ing Tcheou; une autre partie alimente le Grand Canal. D’après le texte que 
nous traduisons, cette rivière se serait jetée dans le $T s i$; mais nous avons vu que le $T s i$, tel que le décrit le Yu kong, a cessé d'exister.

02. (151) La mer était la limite de cette province à l'est ; la rivière Hoai, au sud ; le T'ai-chan au nord. Quant à la limite occidentale, elle n'est pas mentionnée ; le Eul ya dit : "A l'est de la rivière $T s i$, c'est la pro vince de $S i u$ »; mais il est à remarquer d'une part que, dans le Eul ya, la province de Siu compnrend aussi celle de Ts'ing dont il a été question plus haut, et d'autre part que l'ancien cours de la rivière $T s i$ est fort difficile à déterminer exactement; on ne peut donc s'appuyer sur ce texte pour dire que le $T$ si était la limite occidentale de la province de Siu telle qu'elle est décrite dans le Yu kong.

- Cette province devait comprendre le sud du Chan-tong et le nord du Kiang-sou et du Ngan-hoei.

- Par suite d'une faute d'impression, le nom de cette province est écrit $T s^{\prime} e u$ (= Ts'iu) dans la traduction de M. Legge ; mais dans les notes il est décrit correctement $\mathrm{Seu}$ (= Siu).

02. (152) La rivière Hoai prend sa source dans les montagnes de Tong-pe, à la limite commune des provinces de Ho-nan et de Hou-pe. Elle coule de l'ouest à l'est.

Au temps de $Y u$, quand le Hoang-ho ne déversait dans le golfe du Pe-tche-li, le Hoai se jetait directement dans la mer. Quand le Hoang-ho changea de cours et vint aboutir dans la province de Kiang-sou, son embouchure fut l'ancienne embouchure de la rivière Hoai et cette dernière ne fut plus considérée que comme un des affluents du grand Fleuve. Enfin depuis 1854, le Hoang-ho coule au nord du Chan-tong : le Hoai n'arrive plus jusqu'à la mer ; il se déverse dans le lac Hong-tse, qui communique avec le lac Kao yeou et celui-ci alimente le Grand Canal.

- La rivière $I$ prend sa source aux montagnes $I$, dans le Chan-tong, passe dans la souspréfecture de $I$-choei, puis dans la préfecture secondaire de $I$. Au temps de $Y u$, elle devait se jeter dans la rivière Hoai non loin de Hoai-ngan-fou. Aujourd'hui, d'après M. Richthofen (China, I, 338), un de ses bras se rend dans le Grand Canal, tandis qu'un autre se réunit au réseau de canaux qui relie à la mer les cours inférieurs de tous les fleuves de cette contrée.

- Se-ma Ts'ien remplace le mot [] du Chou king par le mot [] qui a le même sens, mais est d'un usage plus fréquent.

02. (153) Mong et $Y u$ sont les noms de deux montagnes. La montagne Mong se trouve à 4 kilomètres environ au sud de la sous-préfecture de Mong-yn, préfecture de Ts'ing-tcheou province de Chan-tong. - La montagne $Y u$ était située à l'extrémité nord -est de la province de Kiang-sou, dans la sous-préfecture de Kan-yu, préfecture de Hoai-ngan.

02. (154) Le lac Ta-yé n'existe plus aujourd'hui ; il devait se trouver, d'a près Ts'ai Tch'en, sur le territoire de l'actuelle sous-préfecture de Kiu-ye, préfecture de Yen-tcheou, province de Chan-tong.

- Se-ma Ts'ien remplace le mot tchøu du Chou king par le mot []. Kong Yng-ta explique le mot du Chou king et Kong Ngan-kouo celui du Che ki de la même manière : tous deux désignent un lieu où l'eau se fixe.

02. (155) Tong-yuen correspond à la préfecture secondaire de Tong-p’ing, préfecture de Yentcheou, province de Chan-tong.

- Tong-yuen (la plaine orientale) était ainsi appelé parce qu'il se trou vait à l'est de la rivière Tsi et en effet, au temps de l'empereur King de la dynastie Han, le royaume de Tong-p'ing qui occupait ce territoire était aussi appelé royaume de $T$ si-tong

02. ( 156$)$ D'après le commentaire de Li Tao-yuen au Choei king, les terres de cinq couleurs étaient fournies par la sous-préfecture de Tchou-tch'eng, préfecture de Ts'ing-tcheou, province de Chan-tong. Ces terres étaient un objet rituel dont on se servait dans la cérémonie de l'investiture conférée par le Fils du ciel aux seigneurs : sur l'autel du dieu de la terre, à la capitale, il y avait de la terre jaune au centre, de la terre verte à l'est, de la terre rouge au sud, 
de la terre blanche à l'ouest, de la terre noire au nord ; on donnait au nouveau seigneur un peu de la terre qui correspondait à la situation de son fief par rapport à l'un des quatre points cardinaux; à son retour dans ses États, le seigneur déposait cette terre sur un autel; elle devenait le dieu local qui légitimait son autorité sur la contrée. Cf. le livre des Tcheou trouvé dans une tombe de $K i$ (ce livre fait partie de la collection intitulée Han wei ts'ong chou), au $\S$ 48. La même coutume existait encore au temps des Han, comme on le verra plus loin en lisant les lettres d'investiture qui nous ont été conservées au chap. IX des Mémoires historiques et les Additions de Tchou Chao-suen à ce chapitre.

02. (157) D'après K'ong Yng-ta, le mot hià ne doit pas être séparé ici du mot t•; l'expression totale désigne une sorte de faisan. Il est probable qu'on recherchait surtout ces -oiseaux pour leurs plumes. D'après Tcheng Hiuen, le mot hià signifie « de couleurs variées ».

02. (158) La montagne $I$ dont il est ici question se trouvait dans la préfecture secondaire de P'ei, préfecture de Hoai-ngan, province de Kiang-sou. — L'arbre t'ôung est identifié par M. Bretschneider (Botanicon sinicum, $\mathrm{n}^{\circ}$ 515) avec le Paulownia imperialis. Le bois de cet arbre était fort estimé pour faire des boîtes d'instruments de musique à cordes. Le mot solitaires désigne probablement ceux de ces arbres qui, croissant isolés, étaient de la plus belle venue.

02. (159) La rivière $S e$ prend sa source dans la sous-préfecture de Se-choei; peu avant d'arriver à la ville préfecturale de Yen-tcheou, elle se divise en deux branches : l'une, plus septentrionale, traverse Yen-tcheou-fou et est appelée pour cette raison rivière de la préfecture ; l'autre coule plus au sud et garde le nom de rivière $S e$; toutes deux aboutissent au Grand Canal.

- La description que Ts'ai Tch'e $n$ fait du cours de cette rivière est différente ; d'après lui, la rivière $S e$, après avoir pris sa source dans la sous-préfecture de Pien (aujourd'hui sous-préfecture de $S e$-choei), aurait passé à P'ong-tch'eng (aujourd'hui préfecture secon daire de T'ong-chan, préfecture de Siu-tcheou, province de Kiang-sou) et se serait jetée dans la rivière Hoai à Hia-p'ei (aujourd'hui préfecture secondaire de P'ei préfecture de Siu-tcheou, province de Kiang-sou), peut-être une partie de ce que nous appelons aujourd'hui le Grand Canal n'était-elle autrefois que la continuation du cours de la rivière $\mathrm{Se}$.

- Les pierres que cette rivière déposait sur ses bords, ou, suivant d'antres commentateurs, qui semblaient flotter dans ses eaux, avaient une sonorité toute particulière; aussi les employait-on pour en faire des instruments de musique.

02. (160) Les deux mots Hoai $i$ désignent, d'après K'ong Ngan-kouo, deux rivières. Tcheng-hiuen est, au contraire, d'avis qu'ils signifient : les barbares du Hoai.

02. (161) D'après Ts'ai Tch'en, il s'agirait non de soies fines, comme l'ex plique K'ong-Ngan-kouo, mais d'étoffes dont la chaîne est noire et la trame blanche.

02. (162) De la rivière Hoai on gagnait la rivière Se (cf. note 159) et celle-ci, par ses communications soit avec la rivière $T s i$, soit avec la rivière Yong $i$, pouvait en définitive conduire jusqu'au Hoang-ho. Mais les éditeurs du Chou king de Yong-tcheng montrent que cette explication de Ts'ai Tch'en n'est pas très satisfaisante. La question sera toujours de savoir quelles transformations le Grand Canal a opérées dans l'hydrographie de cette contrée.

- Certains critiques modernes (H. T. K. K., ch. CCCXCII, p. $15 \mathrm{r}^{\circ}$ ) substituent au mot [] le mot [] en se fondant sur la leçon donnée par le Chouo wen; l'étang de Ko était au sud, de la sous-préfecture de Hou-ling aujourd'hui sous-préfecture de Yu-tai, préfecture de Tsi-ning, province de Chan-tong); il communiquait avec la rivière $\mathrm{Se}$. - Mais cette correction de texte est inadmissible, car il est évident qu'ici, comme dans la description des autres provinces, on trace la route par laquelle le tribut était apporté au Hoang-ho et par suite à la capitale.

02. (163) K'ong Ngan-kouo dit :

«Au nord cette province avait pour limite la rivière Hoai ; au sud elle s'étendait jusqu’à la mer. 
- Si on prenait cette seconde phrase au pied de la lettre, la province de Yang aurait eu une aire immense qui aurait compris jusquà la Cochinchine. Mais M. Legge a bien montré les raisons qui semblent prouver que cette province ne dépassait pas la chaîne de montagnes appelée Nan-ling, au nord du Koang-tong.

02. (164) Le lac P'ong-li est plus connu des Européens sous le nom de lac Po-yang (il s'y trouve en effet une petite île montagneuse de ce nom). Le lac Po-yang est une immense nappe d'eau qui s'étend dans le nord de la province de Kiang-si, immédiatement au sud du Yang-tseKiang avec lequel elle communique.

- Les oiseaux migrateurs (proprement: les oiseaux du soleil, c'est-à-dire, ceux qui se conforment aux saisons déterminées par le cours du soleil peur émigrer du nord vers le sud ou inversement) sont les oies sauvages qui, en hiver, venaient se réfugier dans les provinces méridionales de l'empire.

02. (165) Les érudits chinois ont beaucoup écrit sur les trois Kiang. On trouvera un écho de leurs discussions dans les notes de M. Legge au Yu kong (p. 109), dans l'article de M. Edkins intitulé : On the ancient mouths of the Yang-tse-Kiang (Journ. North. China Branch As. Soc., vol. II, 1860, p. 77-84), et dans Richthofen (China, t. I, p. 331-334).

M. Richthofen a étudié la question avec la compétence d'un géologue et voici la c onclusion à laquelle il aboutit :

* le Kiang du nord était le Yang-tse-Kiang actuel, de Ou-hou à la mer ;

* le Kiang central était une branche du Yang-tse-Kiang qui se détachait à Ou-hou, traversait le lac T'ai-hou et se jetait dans la mer près de Hang-tcheou-fou ;

- le troisième Kiang était le Tche-Kiang (appelé Tsien-tang-Kiang par Richthofen et Wells Williams, mais je n'ai pas pu découvrir ce nom sur les cartes chinoises) qui aboutit aussi. à la baie de Hang-tcheou-fou.

02. (166) Le lac de Tchen n'est autre que le T'ai-hou, qui se trouve en partie dans la province de Kiang-sou et en partie dans celle de Tche-Kiang.

02. (167) Le Chou king écrit [] ; ces mots désignent deux sortes de bambous, le premier plus petit que le second ; Se-ma Ts'ien donne la leçon [] qui est l'explication du premier des deux mots du Chou king.

02. (168) D'après K'ong Ngan-kouo, les métaux des trois sortes étaient l'or, l'argent et le cuivre ; le reste du tribut consistait en pierres estimées, en bambous, en défenses d'éléphants, en peau de rhinocéros, en plumes d'oiseaux et en queues de yak. - On se servait de la peau de rhinocéros pour faire des cuirasses et des queues de yak pour faire des guidons. - Le Chou king ajoute encore les deux mots [] = et des bois. Mais Se-ma Ts'ien omet cette mention.

02. (169) Le Che ki et le Chou king s'accordent pour écrire []. La traduction «barbares des îles » est ici beaucoup plus admissible que lorsqu'il s'agissait de la province de $K i$ (voyez plus haut, p. 98, note 3). Tchang Cheou-kié veut qu'il s'agisse du Japon ; mais il est bien peu croyable que des relations aient existé à une époque aussi reculée entre la Chine et le Japon. Il serait plus problable qu'il est fait allusion ici soit à l'archipel des Tcheou-chan (Chusan), soit même à Formose.

02. (170) Cette traduction de [] est justifiée par le sens de l'expression [] dans le Che king (Legge, Chinese Classics, t. V, p. 346).

02. (171) On doit donner ici à $s^{\bullet}$ le sens qu'il a dans l'expression $s^{\bullet}[]=$ conférer un ordre (en parlant de l'empereur).

02. (172) En descendant le Yang-tse-Kiang, puis en longeant la côte, on arrivait à l'embouchure de la rivière Hoai ; nous avons vu plus haut que, par le moyen des rivières Hoai et $S e$, on parvenait au Hoang-ho et ainsi à la capitale. 
— Le mot A est, d'après Tcheng Hiuen, l'équivalent du mot iên, qui est la leçon du Chou king. Tous deux signifient « descendre un fleuve en en suivant le courant».

02. (173) Au nord, cette province s'étendait jusqu'à la montagne King (à quelque distance au nord de la sous-préfecture de Nan-tchang, préfecture de Siang-yang, province de Hou-pe).

Au sud, elle comprenait la montagne Heng (sous-préfecture de Heng-chan, préfecture de Heng-tcheou, province de Hou-nan) et la dépassait, car c'est ainsi que K'ong Yng-ta explique l'expression «le sud de la montagne Heng ». Cette province comprenait essentiellement le Hou-pe et le Hou-nan actuels.

02. (174) La rivière Han arrose dans son cours supérieur le sud de la province de Chàn-si ; elle débouche dans le Hou-pe à l'ex trémité nord-ouest de cette province et se jette dans le Yangtse à Ou-tch'ang .

02. (175) Cette comparaison fait allusion soit à la majesté, soit à la rapidité de leur cours.

02. (176) L’identification des neuf fleuves a donné lieu à une multitude de discussions entre les érudits chinois. Se-ma Ts'ien lui-même devait les placer dans les environs immédiats du lac Po-yang, car, dans son annotation au Traité sur les canaux, il dit qu'il est monté sur la montagne Lou, située auprès de ce lac, et que de là il a vu les neuf fleuves ; cette identification a joui longtemps d'un grand crédit et il en est resté une trace durable dans le nom de Kieou-kiang donné à une villé qui se trouve sur le Yang-tse au point où il communique avec le lac Po-yang.

- Cependant nous avons vu que le lac Po-yang était expressément mentionné, sous le nom de P'ong-li, par le $Y u$ kong comme se trouvant dans la province de Yang; puisque les neuf fleuves étaient dans la province de King, ils ne sauraient donc se confondre avec le système hydrographique du lac Po-yang. L'opin ion généralement adoptée aujourd'hui est que les neuf fleuves doivent être identifiés avec le lac Tong-t’ing ; c'est celle à laquelle se rattachent aussi MM. Legge et Richthofen; ce dernier explique de la manière suivante comment le lac Tong-t’ing peut être appelé les neuf fleuves :

«Le sens de l'expression «les neuf fleuves» ne pouvait jusqu'ici pas être compris par les commentateurs européens parce que la nature du lac Tong-t’ing ne leur était pas connue. En effet, lorsque les eaux sont basses, ce lac est une vaste étendue de sable coupée par de nombreux canaux dans lesquels se précipitent avec un cours rapide les rivières qui viennent du sud et de l'est rangées comme des rayons. Il n'y a plus alors apparence de lac et on pouvait, si on ne s'attache pas trop strictement au dénombrement, nommer en fait ce pays celui des neuf fleuves.

02. (177) Le Eul ya dit :

«Une rivière qui sort de Kiangs s'appelle T'o ; une rivière qui sort du Han s'appelle Ts'ien.

— Les Mémoires historiques remplacent le mot ts'ien par le mot [].

- Dans la sous-préfecture de Tche-Kiang, préfecture de King-tcheou, il y a bien une rivière T'o, mais elle se jette dans le Yang-tse au lieu d'en sortir. C'est pourquoi Tcheng K'ang-tc'heng préfère identifier le T'o avec la rivière Hia qui, dit-il, sort du Yang-tse pour se jeter dans la rivière Mien, nom que porte la rivière Han dans une partie de son cours. Inversement, la rivière Tch'en ou Ts'ien sortait du Han pour se jeter dans le Yang-tse. Quoiqu'il soit di fficile de déterminer avec précision le cours du T'o et du Tch'en, on verra, en regardant une carte chinoise du Hou pe, que les eaux du Han et celles du Yang-tse communiquent entre elles par des ramifications compliquées avant leur confluent définitif à Ou-tch'ang.

02. (178) On appelait Yun-mong une contrée marécageuse qui s'étendait au nord du Yang-tse, depuis la sous-préfecture de Kien-li dans la préfecture de King-tcheou, jusqu'à celle de Yun-mong dans la préfecture de Té-ngan. Peut-être distinguait-on deux lacs, celui de Yun et 
celui de Mong, ce qui justifierait la leçon du Chou king. Quoi qu'il en soit, ce qui est certain c'est que, même en admettant que Yun et Mong soient deux lacs, ils devaient être tous deux au nord du Yang-tse; c'est par erreur que M. Legge place Kiang-hia (aujourd'hui dans la sous-préfecture de Yun mong) et Hoa-yong (aujourd'hui dans la sous -préfecture de Kien-li) au sud du Yang-tse.

02. (179) L'arbre tch'oen paraît être le même que celui qui est mentionné par le Pen ts'ao sous le nom de [] : ce dernier est le Cedrela sinensis (Bretschneider, Jour. China Br. of the R. As. Soc., vol. XXV, p. 354).

- K'ong Ngan-kouo identifie l'arbre kan avec l'arbre Cudrania triloba (Bretschneider, loc. cit., p. 332) ; le bois de cet arbre était fort dur et servait à faire des arcs.

— L'arbre koai paraît à M. Bretschneider (loc. cit., p. 339) être le Juniperus chinensis.

— L'arbre po est une sorte de cyprès, le Thuya orientalis (Bretschneider, loc. cit., p. 336).

02. (180) Ce sont deux sortes de bambous dont on se servait pour faire des flèches (cf. Bretschneider, art. cit., $\mathrm{n}^{\circ}$ 564).

— L'arbre hou était employé aux mêmes usages ; M. Bretsohneider (ibid., $\mathrm{n}^{\circ}$ 543) renonce à l'identifier.

02. (181) Les trois royaumes sont synonymes de la province de King ou peut-être seulement d'une partie de cette province. Les commenta teurs chinois n'expliquent pas d'une manière satisfaisante l'or igine de cette expression.

02. (182) Cette herbe devait être une sorte de graminée : elle avait trois côtes ; elle était employée pour filtrer le vin dans le sacrifice que l'empereur rendait à ses ancêtres (M. Bretschneider, $\mathrm{n}^{\circ} 459$ ).

02. (토 $)$ Cf. note 176 .

02. (184) D’après le chapitre CXXVIII des Mémoires historiques, cette tortue vit mille années; elle est longue d'un pied deux pouces. - On en faisait chauffer l'écaille et les craquelures qui se produisaient à la surface étaient interprétées par les devins. — Le mot paraît avoir ici le sens d'offrande extraordinaire. L'animal en question étant rare, on ne l'apporte que lorsqu'on a eu la chance de le trouver.

02. (185) Le texte des Mémoires historiques répète le mot [] devant le mot Hán, ce qui rend le sens de la phrase plus clair que dans le Chou king; pour aller de la province de King à la capitale, on naviguait, suivant le lieu d'où on pa rtait, soit sur le Kiang, soit sur le T'o, soit sur le Tch'en; mais il fallait ensuite de toute nécessité remonter le cours de la rivière Han; puis on devait faire un portage par terre pour passer du bassin du Han dans celui du Lo, affluent du Hoang-ho.

02. (186) La montagne King était la limite de cette province au sud; le Hoang-ho l'était au nord; à l'est, la province de $Y u$ était contiguë de celle de Siu. Elle devait comprendre la majeure partie de la province de Ho-nan et les parties avoisinantes des provinces de Tche-li, Chan-tong, Ngan-hoei et Hou-pe.

02. (187) La rivière Lo prend sa source dans la sous-préfecture de Lo-nan, préfecture de Chang, province de Chàn-si. Elle pénètre dans le Ho-nan sur le territoire de la sous-préfecture de Lou-che; elle passe au sud de Ho-nan-fou et se jette dans le Hoang-ho, non loin de la sous-préfecture de Fan-choei, préfecture de K'ai-fong.

— La rivière $I$ est un affluent de droite du Lo; les rivières Tch'en et Kien en sont des affluents de gauche. Voyez pour plus de détails les notes de M. Legge à ce passage du Yu kong, qui n'offre d'ailleurs pas de difficultés.

02. (188) K'ong Ngan-kouo explique le mot po du Chou king dans son sens ordinaire de «flot ». Se-ma Tcheng interprète le mot Po du Che ki comme signifiant « eaux débordées ». Il n'y a donc pas lieu de supposer deux lacs dont l'un s'appellerait Yong et l'autre Po, ni, d'autre 
part, d'appeler Yong-po le lac qui a toujours eu simplement le nom de Yong. Le lac de Yong était desséché et avait cessé d'exister dès l'époque des Han, comme nous l'atteste Tcheng Hiuen ; il se trouvait sur le territoire des sous-préfectures actuelles de Yong-tse et Yong-yang, préfecture de Kai-fong, province de Ho-nan.

02. (189) D'après les indications du Kouo ti tche, le lac Ming-tou (ou Mong-tchou, leçon du Chou king) se trouvait dans la sous-préfecture actuelle de Ting-t'ao, préfecture de Ts'ao-tcheou, province de Chan-tong. Quant à l'étang de Ko, il est marqué par les cartes chinoises modernes au lieu même où est située la ville préfecturale de $T$ s'ao-tcheou.

02. (190) Au lieu du mot, le Chou king écrit sì qui signifie « chanvre ».

02. (191) Sur le sens exact du mot, voyez note 161.

02. (192) Le sud de la montagne Hoa (qui est appelée plus loin T'ai-hoa) était la limite de la province à l'est. Cette montagne se trouve à peu de distance au sud de la sous-préfecture de Hoa-yn, préfecture de T'ong-tcheou, province de Chàn-si; elle est au sud de la rivière Wei, à $60 l i$ environ au sud-ouest du grand coude que fait le Hoang-ho.

02. (193) - La rivière Hei est donnée ici comme la limite occidentale de la province de Leang ; au paragraphe suivant, une rivière du même nom est indiquée comme bornant à l' ouest la province de Yong. Enfin, quelques pages plus loin, dans la description générale des cours d' eau, nous lisons que la rivièrWWei ou rivière Noire passe à San-wei et va se jeter dans la mer $\mathrm{du}$ Sud. Si nous faisons abstraction pour un moment de la foule de renseignements contradictoires que prétendent nous donner les érudits chinois, nous tirerons de ces textes les conclusions suivantes : la rivière $\mathrm{Hei}$ dont il est parlé dans le $Y u$ kong est unique ; elle limite successivement à l' ouest les provinces deleang (Kan-sou) et de Yong (Se-tch' oanpar son cours dirigé du nord au sud qui se déroule depuis la montagne San-wei (auprès de Toen-hoang au sud-ouest de Ngan-si-tcheou, Kan-sou) jusqu' à la mer du Sud.

- Maintenant, qu' un pareil cours d' eau n' existe pas en réalité, c' est ce qui est manifeste. Mais on comprend comment les Chinois ont pu se faire cette idée erronée ; auprès de la montagne San-wei coule le Tang-ho dont la direction est celle du sud au nord, c' esì-dire qu' elle est perpendiculaire à celle des fleuves de Chine (le Tang-ho est un affluent de gauche de la rivière Pou-loun-ki (Bouloungir) qui se jette dans le lac Kara-nor). D' autre part, à l' ouest du Se-tch' oancoule du nord au sud le Kin-cha-Kiang dont les Européens font le cours supérieur du Yang-tse-Kiang). Or, le Tang-ho et le Kin-cha-Kiang se trouvent tous deux dans des régions que les Chinois ne connaissaient point à l' époque duYu kong; ils ne possédaient à leur sujet que les quelques vagues données qu' ils avaient pu acquérir dans leurs expéditions contre les peuples barbares de ces contrées ; ils avaient ainsi appris que, soit au nord, soit au sud, on rencontrait du côté de l' ouest des cours d' eau dont la direction était perpendiculaire à celle des fleuves de Chine ; ils imaginèrent donc une rivière unique appelée le Hei-choei ou rivière Noire qui formait à l' ouest la limèt du monde connu depuis la montagne San-wei au nord jusqu' à la mer au sud. $C^{\prime}$ est bien ainsi que les anciens commentateurs se représentaient la rivière $\mathrm{Hei}$, comme on peut le voir sur la carte reproduite dans le Chou king de Yong-tcheng ; ce sont les commentateurs modernes qui, faisant intervenir dans l' interprétation duYu kong des données géographiques inconnues autrefois, ont distingué deux rivières Hei, l' une à l' ouest de la province de Yong, l' autre à l' ouest de la province deang.

- M. von Richthofen voit dans la mention de la rivière Hei et de la rivière $J o$ dont il va être parlé au paragraphe suivant, la preuve que les Chinois avaient dû primitivement habiter dans l' ouest et que, lorsqu' ils s' étaientgedlement avancés vers l' est, ils avaient gráe le souvenir de leur ancienne résidence (China, t. I, p. 317) ; à nos yeux, au contraire, la fausse idée qu' ils se faisaient de la rivière $\mathrm{Hei}$ montre que les régions de l' ouest leur étaient presque entièrement inconnues et qu' ils n' en parlaient que panï-dire.

02. (194) Le massif des montagnes Min sert de ligne de démarcation entre le Kan-sou, le Se-tchouan et la région du Koukou-nor ; la rivière Min (considérée par les Chinois comme le cours supérieur du Yang-tse-Kiang) y prend sa source. 
— Le nom de Pouo ou Pouo-tchong est donné à deux montagnes :

* l'une, qui est celle dont il est ici question, est au sud de la préfecture secondaire de Ts'in, province de Kan-sou; une branche de la rivière Kia-ling, appelée le Han occidental, y prend sa source.

* L'autre montagne Pouo-tchong est au nord de la préfecture secondaire de Ming-Kiang, province de Chàn-si; la rivière Han (qui n'a rien de commun avec le Han occidental) y prend sa source.

02. (195) D'après K'ong Ngan-kouo, le T'o et le Tch'en dont il est ici parlé seraient ceux-mêmes que nous avons vus mentionnés à propos de la province de King. Si nous rejetons cette opinion comme insoutenable, nous n'en sommes guère plus avancés, car un regard jeté sur la carte nous fera voir que les systèmes du Kiang et du Han ne s'anastomo sent point dans la province de Leang. Peut-être les noms de T'o et de Tch'en sont-ils appliqués ici à des ramifications qui font communiquer entre eux le Kiang et un autre de ses affluents, par exemple le Kia-ling-Kiang ; mais ce n'est là qu'une pure hypothèse.

02. (196) Se-ma Tcheng dit que la montagne Mong se trouvait dans la sous-préfecture de Han-hia (aujourd'hui Ya-ngan, préfecture secondaire de Ya, province de Se-tch'oan), mais qu'il ne sait pas où était la montagne Ts-ai. Нou Wei suppose que la montagne Ts'ai était plus au sud, dans le groupe des Ngo-mei-chan, à l'ouest de Kia-ting-fou.

— Le mot $l u$ désigne le sacrifice fait aux montagnes.

02. (197) Certains commentateurs veulent voir dans Ho-i soit le nom d'une contrée, soit les noms de deux rivières; les autres soutiennent quill faut donner au mot $i$ son sens ordinaire de barbares et traduire : «les barbares qui habitent les bords de la rivière $H o$ ». Il n'est pas douteux que cette dernière interprétation ne donne le sens primitif de l'expression ; mais on peut admettre aussi que, longtemps après la disparition des barbares, le nom de Ho-i était resté attaché à la contrée qu'ils avaient autrefois occupée. Il nous semble peu vraisem blable que ce soit dans les régions encore habitées par des barbares que $Y u$ aille mettre les champs en culture et élever des digues.

02. (198) Cette traduction s'appuie sur l'autorité de K'ong Ngan-kouo. M. Legge remarque que, si on l'adopte, le sol de la province se trouve déterminé seulement quant à sa couleur et non quant à sa qualité ; c'est pourquoi il adopte la manière de voir de Ma Yong qui veut que le mot $l i$ signifie « léger et fin ». La seule objection à faire à cette interprétation est que le mot $l i$ n'a jamais eu ce sens.

02. (199) Les redevances étaient, suivant les saisons de l'année, au sep tième, au huitième ou au neuvième rang; en moyenne donc, on pouvait les considérer comme étant au huitième rang; telle est l'explication de l'expression.

02. (200) D'après K'ong Ngan-kouo, est le nom d'une sorte de jade ; Tcheng Hiuen écrit ce même mot avec la clef du métal et prétend y voir le nom d'une excellente qualité d'or.

02. (201) D'après les indications données par le traité géographique (Ti li tche) du Livre des premiers Han, l'argent se trouvait au sud-ouest de l'actuelle sous-préfecture de I-Pin, préfecture de Siu-tcheou, province de Se-tch'oan.

02. (202) La montagne Si-k'ing est une chaîne fort étendue qui s'étend à travers la région du Koukou-nor et le Kan-sou jusqu'à la préfecture de Kong-tch'ang; il en sera parlé plus en détail dans la description orographique qui suivra.

- La rivière Hoan est identifiée par les commentateurs chinois avec la rivière Blanche; si cette identification est exacte, le Choei king a tort de dire que la rivière Hoan prend sa source au sud des monts Si-k'ing ; en effet, la rivière Blanche prend sa source dans le Se-tch'oan, au pied des montagnes Min; elle traverse l'extrémité sud du Kan-sou, puis rentre dans le Se-tch'oan et, sur le territoire de la sous-préfecture de Tchao-hoa, elle se jette dans la rivière Kia-ling; c'est cette dernière (qu'on appelle quelquefois le Han occidental, cf. note 195), dont le cours supérieur est désigné sous le nom de Ts'ien dans notre texte. Ainsi les porteurs de 
tribut devaient aller par terre des monts Si-k'ing jusqu'à la rivière Hoan (ou rivière Blanche) ; ils descendaient ce cours d'eau jusqu'à Tchao-hoa; de là ils remontaient la rivière Kia-ling (ou rivière $T$ s'ien) jusqu'au point où son cours se trouvait le plus rapproché de celui de la rivière Han (dont l'une des branches supérieures est la rivière Mien il de notre texte) ; ils faisaient alors un portage par terre pour passer d'un bassin dans l'autre. De la rivière Han, le texte ne nous dit pas comment on pouvait gagner le Wei, affluent du Hoang-ho; il devait être nécessaire cependant de faire encore un transport par terre.

02. (203) Cf. note 193 .

02. (204) Le Ho est appelé ici occidental parce qu'il s'agit de la par tie du Hoang-ho située à l'ouest de la province de $K i$ où se trouvait la capitale.

02. (205) La province de Yong devait comprendre la majeure partie du Chàn-si et du Kan-sou actuels.

02. (206) Le nom de la rivière Jo est écrit [] dans le Chouo wen. Ce cours d'eau passait, lisons-nous plus loin, à Ho-li . Ho-li est le nom de la chaîne de montagnes le long de laquelle se déroule aujourd'hui la Grande Muraille, depuis Kan-tcheou jusqu'à Sou-tcheou, dans le Kan-sou, La rivière $J o$ doit donc être identifiée avec le Hei-ho qui passe à Kan-tcheou et se dirige du sud-est au nord-ouest (ce qui explique la phrase : la rivière Jo se dirigea vers l'ouest. Le Hei-ho se réunit en dehors de la Grande Muraille à la rivière Tola (T'ao-lai); après leur jonction, elles portent le nom d'Etsina ; celle-ci se dirige vers le nord et aboutit au lac Sogok (Souo-k'o-ngo-mo; ce lac est aussi appelé lac d'Etsina ; sous les Han, c'était le marais de Kiu-yen).

- Quoique la rivière Jo ou Hei ho n'ait été comprise dans les limites de l'empire qu'au temps de l'empereur $O u$ (140-87 av. J.-C.), il n'est pas surprenant que les Chi nois l'aient connue dès l'époque du Yu kong; en effet, le bassin de cette rivière a de tout temps été une des grandes routes par lesquelles se sont précipitées les invasions barbares ; on n'a qu'à lire le récit de la lutte des empereurs Han contre les Hiong-nou pour s'en convaincre et d'ailleurs le seul fait qu'on a construit la Grande Muraille tout le long de cette rivière prouve qu'on avait senti la nécessité d'en défen dre l'accès. Dès les temps les plus reculés, les Chinois ont donc dû, soit repousser les assaillants venus de ce côté, soit lancer eux-mêmes des expéditions par cette voie et c'est ainsi que no us expliquons que cette rivière soit mentionnée dans le $Y u$ kong.

02. (207) Dans notre traduction du mot [], nous adoptons le sens indiqué par le Chouo wen qui dit : On appelle [] deux rivières qui se réunissent.

- La rivière Wei est un des principaux cours d'eau du Chàn-si ; elle prend sa source dans la sous-préfecture de Wei-Yuen, préfecture de Lan-tcheou, province de Kan-sou; elle passe à Kong-tch'ang-fou dans la même province; dans le Chàn-si, elle passe au nord de Si-ngan fou ; elle se jette dans le Hoang-ho au point exact où il change son cours du nord au sud pour prendre la direction de l'ouest à l'est.

- La rivière King est un affluent de gauche de la rivière Wei ; elle prend sa source dans la sous-préfecture de P'ing-leang, préfecture de P'ing-leang, province de Kan-sou; dans la province de Chàn-si, elle arrose la préfecture de $P$ 'in et se jette dans la rivière Wei au nord-est de Si-ngan-fou.

02. (208) Les rivières $T s^{\prime} i$ et $T s i u$, ont été l'objet de longues dis russions entre les érudits chinois (cf. Choei king tchou che, chap. XVI, p. $25 \mathrm{v}^{\circ}$ et suiv.). De leurs travaux il résulte :

1. que les rivières $T s i$ et $T$ siu du $Y u$ kong ne doivent pas être confondues avec les rivières $T$ siu et $T s ’ i$ du Che king (III, 1, première strophe de la $3^{\mathrm{e}}$ ode, traduction Legge, p. 437); les rivières citées par le Che king se trouvaient entre la préfecture secondaire de $P^{\prime} i n$ et la montagne $K^{\prime} i$ (à l'est de Fong-siang-fou), c'est-à-dire qu'elles étaient à l'ouest de la rivière King ; au contraire, les deux rivières citées par le $\mathrm{Yu}$ kong sont, comme on le verra quelques pages plus loin, à l'est de la rivière King ; 
2. même à l'est de la rivière King, deux identifications sont encore possibles, les uns disant avec K'ong Ngan-kouo que les rivières $T s i$ et $T$ siu se réunissent pour former la rivière $L o$ qui passe par les préfectures secondaires de Fou et de T'ong et confond son confluent dans le Hoang-ho avec celui de la rivière Wei; les autres soutenant que la rivière $T$ siu est la branche occidentale et la rivière $T s i$ la branche orientale du cours d'eau qui traverse la sous -préfecture de Fou-p'ing et vient aboutir dans la rivière Wei à l'est de la sous -préfecture de Lin-t'ong. C'est cette dernière opinion qu'adopte M. Legge et que nous croyons aussi la plus plausible,

02. (209) D'après le Kouo ti che, la rivière Fong prend sa source à la montagne Tchong-nan dans la sous-préfecture de Hou, au sud-ouest de Si-ngan-fou; cette rivière était donc un affluent de droite du Wei.

02. (210) La montagne King se trouvait sur le territoire de la sous-préfecture de Fou-p’ing, préfecture de Si-ngan; c'est là que, suivant la légende, Hoang-ti et plus tard $Y u$ lui-même fondirent des trépieds. Cette montagne ne doit pas être confondue avec celle qui portait le même nom dans la province de King (cf. note 173) ; c'est sur celle de la province de King que Pien $\mathrm{Ho}$ trouva la pièce de jade qui devint si célèbre sous le nom de l'anneau de $H o$ (cf. Mayers, Manual, $\mathrm{n}^{\circ} 551$; Mémoires historiques, chap. LXXXI).

— La montagne $K^{\prime} i$ est au nord de la sous-préfecture de Ki-chan, préfecture de Fong-siang ; c'est celle ntème que quelques commentateurs ont voulu à tort ret rouver dans la montagne $K$ ' $i$ mentionnée à propos de la province de $K i$ (cf. note 123).

— Sur le sacrifice $l u$, cf. note 196.

02. (211) Le Tchong-nan est, d'après le Ti li kin che, une chaine de montagnes qui s'étend à l'est depu is la sous-préfecture de Lan-lien (au sud-est de Si-ngan-fou), jusque dans le territoire de la préfecture de Fong-siang, à l'ouest.

- Le nom de la montagne Toen-ou est écrit Choen-ou dans le Chou king; cette hauteur devait faire partie de la chaîne du Tchong-chan, car elle se trouvait dans la sous-préfecture de $M e i$, préfecture de Fong-siang, mais sur la rive droite de la rivière Wei.

— La montagne Niao-chou était située à la source de la rivière Wei, dans la sous-préfecture de Wei-yuen, province de Kan-sou.

- Le texte ne nous dit pas ce qui fut fait sur ces trois montagnes et probablement la phrase n'était à l'origine que la simple énumération des hau teurs de la province ; si on veut rattacher cette phrase à ce qui précède et à ce qui suit, il faut admettre que le mot $l u$ est sous-entendu ; $Y u$ fit des sacrifices sur le Tcheng-nan, le Toen-ou et le Niao-chou comme il l'avait fait sur les monts King et $K^{\prime} i$.

02. (212) Le mot [] a ici le sens de «terrain haut et plat». On sait que ce mot a aussi le sens de « source ». S’il a deux accep tions si différentes, c'est parce qu'il représente en réalité deux anciens caractères très distincts à l'origine, mais que l'orthographe actuelle a unifiés ( $H . T . K$. $K$., ch. CCCXCII, p. $3 \mathrm{v}^{\circ}$ ).

02. (213) L'étang de Tou-yé (le Che ki écrit tou partout où le Chou king écrit tchou) se trouvait situé, d'après les commentateurs, sur le territoire de la sous-préfecture de Tchen-fan, au nord de la préfecture secondaire de Leang, province de Kan-sou. Il est à remarquer que, sous les premiers Han, le territoire de Leang-tcheou appartenait à la tribu Hiong-nou de Hieou-tch'ou ; l'empereur $O u$ fut le premier qui le rattacha à l'empire en 115 avant J. -C. et en fit la commanderie de $\mathrm{Ou}$-wei ; il est donc hautement improbable que l'étang de Tou-yé fût connu des Chinois à I'é poque où l'on écrivit le $Y u$ kong : il faut, ou que nous ayons affaire ici à une interpolation, ou que les commentateurs aient identifié arbitrairement le nom de Tou-yé au moyen de notions qu'on ne put avoir qu'après le règne de l'empereur $\mathrm{Ou}$.

02. (214) On a vu plus haut que le peuple de San-miao passait pour avoir été transféré dans le pays de San-wei par Choen (cf. note 01.254). 
02. (215) Ces trois sortes de pierres étaient fort estimées, mais on ne peut savoir exactement quelle en était la nature. D'après K'ong Ngan-kouo les pierres k'ieou et lin étaient des espèces de jades, tandis que le long-han était une pierre qui ressemblait aux perles.

02. (216) Le nom de Tsi-che (pierres entassées) est donné à deux chaînes de montagne : l'une, qui est la plus importante, est au sud du lac Kouhou-nor, sur la rive gauche du Hoang-ho ; la seconde est beaucoup plus à l'ouest ; elle est située au nord de la préfecture secondaire de Ho Îfa, préfecture de Lan-tcheou, province de Kan-sou, et marque la fin du cours montagneux du Hoang-ho ; c'est de cette der nière qu'il est ici question, puisque c'e st seulement après l'avoir dépassée au lieu appelé Tsi-che-koan (passe du Tsi-che que le Fleuve devient navigable. La montagne long-men est au nord de Han-tch'eng, préfecture de T'ong-tcheou, province de Chàn-si.

02. (217) D'après Ts'ai Tch'en, les gens qui naviguaient (apparemment sur le Hoang-ho), depuis le Tsi-che-chan jusqu'à Long-men, étaient les habitants du nord de la province de Yong ; les autres, c'est-à-dire les habitants du sud-ouest, les retrouvaient au confluent de la rivière lh'ei avec le Hoang-ho, parce qu'ils venaient en descendant la rivière R'ei.

02. (218) Les Koen-loen doivent ètre les habitants du massif montagneux lui portait ce nom. On a vu mentionnés plus haut (p. 89), les Jong de l'ouest, les Si-tche et les Kiu-seou. D'après l'histoire des T'ang, le pays de Tang-hiang au temps des T'ang, correspondait à l'ancien $\mathrm{Si}$-tche.

02. (219) Ici commence la seconde partie du tribut ; elle se compose d'abor d d'une description des montagnes et des cours d'eaux. M. von Rich thofen (China ; t. I, p. 303, n. 11 veut qu'on traduise la phrase de Se-ma Ts'ien : tao kieou chan comme signifiant : "disposition des neuf chaînes de montagnes. » Mais pour qu'une telle traduction fût possible, il faudrait qu'on eût en chinois kieou chan lao; la règle de position nous oblige à faire du mot tao un verbe actif dont le complément direct est kieou chan et dont le sujet ne peut être Yu. La phrase tao kieou chan est analogue à la phrase ton kieou chan que nous avons rencontrée plus haut (p. 101 ; pour niveler (ton) les neuf montagnes, $Y u$ les parcourt (tao).

- Cette réserve faite, nous adoptons pour ce qui suit l'interpréta tion de M. von Richthofen ; ce savant a montré avec une rare ingéniosité que les neuf montagnes et les neuf fleuves ne sont pas des termes vagues, mais que le Yu kong décrit exactement neuf chaînes de montagnes et neuf cours d'eau et que, dans tout ce traité de géo graphie physique, l'intervention de $Y u$ n'es t point supposée.

- On voit quelle est la position que nous prenons entre MM. Legge et von Richthofen; M. Legge mentionne $Y u$ partout ; M. von Richthofen ne le voit nulle part ; nous les concilions en distinguant dans le $Y u$ kong une partie légendaire qui se rapporte à $Y u$ et une partie scientifique qui en est indépendante : à côté de phrases où le sujet est $Y u$, nous en découvrons d'autres qui sont de simples énoncés scientifiques. Si notre traduction a quelque incohérence, n'est-elle pas par là-même une image plus fidèle du texte ? plutôt que de chercher à satisfaire la logique par une interprétation unilatérale ne vaut-il pas mieux suivre pas à pas la composition de ces vieux écrits anonymes qui ne furent assurément l'œuvre ni d'un seul homme, ni d'une seule époque, mais qui sont souvent une étrange synthèse de fragments disparates?

02. (220) Les montagnes $K$ 'ien, $K$ 'i et King sont des collines sur la rive gauche de la rivière Wei, dans la province de Chàn-si: le K'ien est le plus occidental : il donne son nom à la rivière K'ien et à la sous-préfecture de K'ien-rang (dans la préfecture de Fong-siang); sur les montagnes $K^{\prime} i$ et King, cf. p. 132, n. 2. - M. von Richthofen rattache à cette phrase les cinq mots suivants et traduit : « et franchit le Ho à Hou-k'eou »; mais la position de Hou-k'eou après le mot $H o$ me paraît rendre cette traduction inexacte ; je fais donc de ces cinq mots le commencement de la phrase suivante : « en traversant le Ho (c'est-à-dire en passant du Chànsi dans le $C h \bullet n-s i)$, on trouve le Hou-k'eou..., etc. » Il me semble d'ail leurs que le Ilou-k'eoct se rattache mieux au système du $C h \bullet n-s i$ qu’à celui du $C h \bullet n-s i$. 
02. (221) Sur le Hou-k'eou, cf. p. 104, n. 1. - Le Lei-cheou est l'important ma ssif que contourne le Hoang-ho à P'ou-tcheou, Ch॰n-si. — Le T'ai yo n'est autre que le Hoao-T'aichan cf. note 124.

02. (222) Les trois montagnes Ti-tchou, Si-tch'eng et Wang-ou sont marquées par les cartes chinoises au sud de la sous-prefecture de Yang-tch'eng, préfecture de Tsé-tcheou, province de $C h \bullet n$-si ; elles sont situées à la limite entre les provinces de $C h \bullet n$-si et de Ho-nan et se succèdent, dans l'ordre de l'énumération, de l'est à l'ouest.

- Les cartes chinoises marquent au beau milieu du Éoang-ho, à quelque distance en amont de la sous-préfecture de Yuen-k'iu (préfecture secondaire de Kiang, Ch•n-si), une autre montagne Ti-tchou; c'est elle que M. Legge choisit pour l'identifier avec celle qui est mentionnée dans ce texte ; M. von Richthofen a montré (China, t. I, p. 306, n. 2) qu'il avait tort et que la montagne Ti-tchou dont il est ici question est à l'est et non à l'ouest de la montagne Wang-ou.

02. (223) Cette chaîne est celle qui limite la grande plaine du Tche-li à l'ouest et au nord. Elle porte le nom de T'ai-hang-chan (c'est-à-dire la grande chaîne) depuis la préfecture de Hoaik'ing dans le Ho-nan jusqu'à la sous-préfecture de houo-lou préfecture de Tcheng-ting, province de Tche-li. Le Heng-chan (Se-ma Ts’ien écrit Tch'ang-chan, cf. p. 108, n. 1) a donné lieu à de nombreuses hypothèses de la part des critiques chinois ; MM. Legge et Richlhofen fixent son emplacement dans la sous-préfecture de $K^{\prime} i u-y a n g$, au nord de la préfecture de Tchengling, province de Tche-li.

- Pour le Kié-che, cf. p. 108, n. 1. Les contreforts de cette montagne devaient s'avancer dans la mer et c'est ce qui explique l'expression du texte : « elle entre dans la mer ».

02. (224) Le Niao-chou-chan, comme on l'a vu plus haut (p. 133, n. 1), est à l'ouest de la préfecture de Kong-tch'ang, province de Kan-sou ; c'est un massif isolé qui ne fait pas, à vrai dire, partie du système auquel ce texte le rattache ; mais il en est fort rapproché et en est comme un poste avancé vers le nord.

- Toutes les autres montagnes qui sont ici mentionnées appartiennent au système appelé par M. von Richthofen le Koen-loen oriental ; le Si-k’ing -chan continue la chaîne du Tsi-che-chan à l'est du Hoang-ho ; elle passe au nord de T'ao-tcheou (sur la rivière T'ao, province de Kansou), puis se termine a environ $60 \mathrm{li}$ au sud du Niao-chou-chan. En continuant à suivre les ramifications de ce système montagneux vers l'est, on trouve la montagne Tchou-yu 70 li à l'ouest de la préfecture secondaire de Ts'in, province de Kan-sou. Le mont T'ai-hoa (cf. p. 126 , n. 1) peut être regardé comme l'extrémité orientale de la branche de ce système qui ferme sur la rive droite le bassin de la rivière Wei.

02. (225) Le système de cette chaîne est moins net que les autres; voici cependant comment on peut l'exposer: Hiong-eul est à l'ouest de la sous-préfecture de Lou-che (préfecture secondaire de Chàn, province de Ho-pan) et sépare le bassin de la rivière Tan, affluent de la rivière Han, de celui de la rivière Lo. Le Hiong-eul se rattache à l'est au système du Song-chan qui, quoique ayant son pic principal dans la sous-préfecture de Teng-fong, au sud-est de Ho-pan-fou, s'étend aussi beaucoup plus à l'ouest, comme l'atteste le nom de la sous-préfecture de Son au sud-ouest de Ho pan-fou, non loin du Hiong-eul ; le Wai-fang était un des pics du Song-chan; il séparait ainsi le bassin de la rivière Lo de celui de la rivière Jou. Le T'ong-pe est dans la sous-préfecture du même nom, au sud-est de la préfecture de N'an-yang, province de Ho-pan; il sépare le bassin de rivière Han de celui de la rivière Hoai; Enfin le P'ei-wei est identifié avec le Heng-wei, au nord de la sous-préfecture de Ngan-lou qui fait partie intégrante de la ville préfecturale de Té-ngan, province de Hou-pe (ne pas confondre cette sous-préfecture de Ngan-lou avec la préfecture de même nom qui est située plus à l'ouest, sur la rivière Han); cette identification du P'ei-wei est indiquée par le Kouo-ti-tche, par Se-ma Tcheng, Tcheng Hiuen, T'soi Tch'en et en général tous les commentateurs; elle est très plausible puisqu'ainsi le P'ei-wei continue la délimitation orientale du bassin de la rivière Han. Seul l'ouvrage de critique moderne assez médiocre intitulé Ti li kin che place le P'ei-wei dans la sous-préfecture de Se-choei, province de Chan- 
tong ; la seule raison qu'il en donne est l'absurdité inhérente à un passage du pseudo K'ong Ngan-kouo où il est dit que le P'ei-wei est auprès de la sous-préfecture de Innn-lou. mais que la rivière Hoai passe (Chou king, ch. V, p. $4 \mathrm{r}^{\circ}$ ); cette absurdité est une des nombreuses preuves qu'on peut donner de l'inauthenticité du commentaire dit de K'ong Ngan-kouo) ; pour résoudre la contradiction, le Ti li kin che place la montagne P'ei-wei clans le Chan-tong, auprès de la rivière $S e$, autrefois affluent de la rivière Hoai (cf. note 159). Mais on peut trancher le problème d'une autre manière en ni.tnt simplement l'affirmation at tribuée à K'ong Ngan-kouo et en disant que ni la rivière Hoai ni aucun de ses affluents ne passent auprès du $P$ 'ei-wei dont il est ici question. - Les quatre massifs montagneux mentionnés dans cette phrase ne constituent pas, si nos identifications sont exactes, une chaîne continue ; mais ils ont entre eux un étroit rapport puisquils établissent une ligne de démarcation du nord au sud entre les rivières Lo, Tan et Han qui sont à l'ouest de cette ligne et le bassin de la ri vière Hoai qui est à l'est.

02. (226) Le mot [] (auquel, pour ne pas rompre la suite des idées, je donne arbitrairement pour sujet la chaîne de montagnes) doit être en réalité une interpolation destinée à intercaler la tournée de $Y u$ dans cette description orographique qui en est manifestement inciépendante.

02. (227) La montagne Pouo-tchong est à l'ouest de la sous-préfecture de Han-tchong et au nord de la préfecture secondaire de Ning-hiang, province de Chàn-si; elle donne naissance à la rivière Yang qui se grossit de deux cours d'eau de moindre importance au relais de T'aingan (à l'ouest de la sous -préfecture de Hien) et prend alors le nom de rivière Han.

- La montagne King (cf. note 173) est beaucoup plus bas sur la rive droite du Han; elle marque la fin de la partie montagneuse de ce bassin, comme la montagne Pouo-tchong en marquait le commencement.

02. (228) Le Nei-fàng et le Ta-Pié continuent la délimitation du bassin du Han; mais ce ne sont que des collines. Le Nei fang n'a guère que 600 pieds d'élévation au -dessus de la plaine ; il est, sur la rive droite du Han, au sud-ouest de la ville préfecturale de Ngan-lou, province de Hou pe. La colline Ta pié est exactement au confluent du Han et chi Yatzg-tse-kictizg, à côté cle la ville préfectorale de Han-yang.

02. (229) Dans cette phrase sont comprises toutes les montagnes sur la rive droite du Kiang depuis sa source qui est pour les Chinois celle de la rivière Min. Elles ne forment point un système continu; M. von Richthofen a fort bien expliqué la raison de cette incohérence en disant que le $Y u$ kong rejette dans cette phrase tout l'ensemble des montagnes du sud-ouest et du sud qui étaient alors presque entièrement ignorées des Chinois. La montagne Min est le massif au nord du Se-tch'oan ; il donne naissance à la rivière de mcme nom qui est considérée comme le cours supérieur du Yang-tse-Kiang. Le Heng-chan est généralement identifié avec la célèbre montagne au nord de Heng Tcheou-fou province de Ho-nan. - Les neuf Kiang nous amènent au lac Tong-ting (cf. note 176) et quant au plateau de Fou-ts'ien, le commentateur P'ei Yn s'appuie sur un texte du Коио уи pour l'identifier avec la montagne Po yang, près du lac du mème nom, dans le Kiang-si.

02. (230) Ici, comme plus haut (cf. note 219), Se-ma Ts'ien ajoute une phrase au texte du Chou king, et cette phrase (il parcourut les neuf cours d'eau) nous oblige à faire intervenir $Y u$; mais elle est une interpolation évidente; il en est de même du mot qui se trouve en tète de quelques-unes des phrases de la description hydrographique qui suit; nous ne pouvons pas, à cause des règles de la syntaxe chinoise, traduire ce mot par « cours de (tel ou tel fleuve) », comme le fait M. von Richthofen ; nous devons lui donner pour sujet $Y u$, comme le propose M. Legge, mais, une fois cette concession faite à l'élément légendaire, nous croyons que $Y u$ est entièrement absent dans toutes les autres phrases qui nous décrivent le cours des fleuves et non les voyages de ce personnage.

- Comme dans la description orographique qui précède, nous suivrons ici pas à pas $M$. de Richthofen dont les savantes analyses ont découvert dans ce texte, sous le fatras des commentaires chinois, une lumineuse exposition du système hydrographique de la Chine 
réparti en neuf bassins, à savoir : la rivière $J o$, la rivière $H e i$, le Hoang-ho, la rivière Han, le Yang-tse-Kiang, la rivière $T$ si, la rivière Hoai, la rivière Wei et la rivière Lo.

02. (231) Cf. note 206. Les sables mouvants sont le grand désert à l'ouest de Kia-yu-koan.

02. (232) Cf. note 193 .

02. (233) Sur le Tsi-che et Long-men, cf. note 216 : sur la montagne Hoa ou Tei-hoa, cf. note 192 ; la montagne Hoa marque le point où le Hoang-ho tourne de la direction sud vers l'est.

- La montagne Ti tchou est celle qui est au milieu du Hoang-ho, en amont de la souspréfecture de Yuen-k’iu, province de $C h \bullet n$-si ; cf. note 222.

- Le gué de Mong se trouve entre la sous-préfecture de Mong-tsin sur la rive droite du fleuve, et celle de Mong sur la rive gauche, à l'ouest de la préfecture de Hoai-k'ing, province de Ho-nan ; c'est un lieu célèbre dans les Annales chinoises.

- C'est peu après son confluent avec la rivière Lo que le Hoang-ho quittait le lit où il coule aujourd'hui et se dirigeait vers le nord-est; la montagne Ta-p'ei est au nord de la sous-préfecture de Siun, elle-même au nord-est de la préfecture de Wei-hoei, province de Honan.

— La rivière Kiang est identifiée avec le cours supérieur de la rivière Tchang actuelle ; la rivière Tchang est constituée par la jonction de deux branches, le Tchang clair, et le Tchang bourbeux ; toutes deux ont leur source dans le $C h \bullet n$-si, la première au nord de la préfecture secondaire de Leao, la seconde à l'ouest de la préfecture de Lou-ngan ; elles se réunissent au lieu appelé Kiao tchang-k'eou, tout au nord du Ho-nan; le Tchang ainsi formé devait, au temps du Yu kong, se jeter dans le Hoang-ho sur le territoire de la préfecture de Koang-p'ing, province de Tche-li.

— Sur le lac Ta-lou, cf. note 129. — Sur les neuf Ho, cf. note 132.

- Le nom du Ni-ho donne à entendre que les neuf fleuves s'y réunissaient en heurtant leurs cours opposés; M. von Richthofen (I, p. 323) pense que les diverses branches du Ho se réunissaient peu avant de se jeter dans la mer, de la même manière que nous voyons de nos jours tout un système compliqué de cours d'eau confluer à T'ien-tsin; M. von Richthofen admet que l'embouchure unique du Ho devait être au delà même de T'ien-tsin, dans les environs de la montagne Kié-che (cf. note 130).

02. (234) Le mont Pouo-tchong dont il est ici question est celui qui se trouve dans la province de $C h \bullet n$-si, cf. note 227 . — En traversant le territoire de la préfecture secondaire de Kiun (en amont de la préfecture de Siang-yang, province de Hou pe), le Han prenait le nom de rivière de Ts'ang-lang, suivant certains commentateurs parce qu'il se trouvai t là une grande ile ainsi appelée. - Les trois Che — - ont donné lieu à de nombreux commentaires ; d'après le Choei king, c'était le nom d'une localité qui était dans la sous -préfecture de $K^{\prime} i$, (au nord de l'actuelle sous -préfecture de I-tch'eng, préfecture de Siang-yang, province de Houpe) ; suivant Tcheng Muen on appelait les trois Che trois petits affluents du Han qui arrosaient le territoire de la préfecture de Ngan-lou; Se-ma Tcheng se rattache à cette dernière opinion. - Sur la montagne Ta-Pié, cf. p. 139, n. 3. - Le marais de Hoei (nous l'avons vu plus haut désigné sous le nom de Hoai - cf. p. 67, n. 2) n'est qu'un autre nom du lac P'ong-li ou Po-yang ; peut-être ici est-il plus particulièrement la partie supérieure du lac, les marais qui lui donnent en quelque sorte naissance. Il est assez curieux d'ailleurs de voir comment l'hydrographie chinoise continue à suivre le cours du Han, même après son confluent avec le Yang-tse-Kiang, en lui rattachant le système du lac Po-yang et en le retrouvant dans la branche septentrionale du Kiang ; c'est une idée admise par la géographie chinoise que des fleuves peuvent se traverser sans se confondre. - Sur le Kiang septentrional, cf. p. 119, n. 2.

02. (235) Nous avons déjà souvent eu l'occasion de remarquer que la rivière Min, est regardée par les Chinois comme formant le cours supérieur du Yang-tse-Kiang. C'est donc le grand Fleuve dont nous avons ici la description. 
— Sur la montagne Min, cf. p. $1 \mathrm{~W}$ n. 1. - Dans le territoire de la préfecture de Tch'eng-tou, capitale du Se-tch'oan, le grand Fleuve, c'est-à-dire la rivière Min) se divise en une multitude de ramifications qui se réunissent plus bas en deux branches principales, l'une qui est la continuation du grand Fleuve, l'a utre qui en reste séparée jusqu'à son confluent avec le Yang-tse-Kiang, auprès de la préfecture secondaire de Lute, et qui porte, comme au temps du $Y u$ kong, le nom de T'o t' -û îl :. Ce singulier phénomène de bifurcation est très nettement indiqué dans notre texte. - $-L i$ est le nom d'une préfecture secondaire à l'ouest du lac Tong t'ing, province de Ho-nan; elle prend son nom de la rivière $L i$ qui, venant de la préfecture secondaire de Houo-fong, dans le Hou-pe, vient aboutir dans le lac Tong-t'ing. - Sur l'identification des neuf Kiang avec le lac Tong-t'ing, cf. p. 121, n. 4. Le Fong-ling ou colline de l'Est est dans la ville préfecturale de Yo-tcheou laquelle se trouve à la jonction du lac Tong-t'ing avec le Yang-tse-Kiang. — Le Hoei n'est autre que le lac Po-yang (cf. la note précédente); ce lac est mentionné aussi bien à propos du Han qu'à propos du Kiang, parce qu'il se trouve sur la partie de leur parcours qui leur est commune, c'est -à-dire après leur jonction à Han-yang et avant leur nouvelle séparation sous les noms de Kiang septentrional et de Kiang central.

02. (236) Sur le cours du Tsi, cf. note 131. - A sa sortie de la montagne Wang-ou, le Tsi s'appelait Yen; mais il ne devait pas tarder à perdre ce nom, comme le prouve l'existence de la sous-préfecture de Tsi-yuen (c'est-à-dire source du Tsi), dans la préfecture de Hoai-k'ing, province de Ho-nan. Le Tsi se jetait dans le Ho tout près de la sous-préfecture de Mong. A une grande distance de là, en face de la sous-préfecture de Ou-tché, le Hoang-ho, au moment de tourner vers le nord, laissait échapper vers le sud-est un embranchement qui était considéré comme la continuation de la rivière Tsi ; cet embranchement formait l'étang de Yong (cf. note 188).

- L'étang de Ko est dans le voisinage immédiat de la ville préfecturale de Ts'ao-tcheou à l'extrême ouest du Chan-tong; comme l'étang de Yong et celui de Ko sont tous deux sur le bord même du Hoang-ho actuel, il est évident que le Hoang-ho coule maintenant dans l'ancien lit du $T$ si.

— D'après le texte du Yu kong, il est évident que la colline - appelée T'ao-kieou devait se trouver entre les lacs de Fong et de Ko; on ne saurait donc la placer auprès de la sous-préfecture actuelle de Ting-t'ao, car celle-ci est au sud-est et non à l'ouest de l'étang de Ko ; on ne peut pas savoir quelle était sa situation exacte.

— Sur la rivière Wen, cf. note 150. — L'embouchure du Tsi devait être celle de l'actuel Siao ts'ing-ho.

02. (237) Sur le mont T'ong -pe, cf. note 225.

— Le système hydrographique de la rivière Hoai a été entièrement modifié par la construction du Grand Canal (cf. notes 152 et 159).

02. (238) Le Niao-chou-t'ong-hiue (c'est-à-dire le trou commun de l'o iseau et du rat) était le nom d'une montagne sur laquelle, d'après une légende, un oiseau et un rat avaient cohabité dans le même trou. C'est la montagne que nous avons vu appeler plus haut Niao-chou-chan (cf. note 224).

- Sur la rivière Fong, cf. note 208.

— Sur le King, le Ts'i et le Tsiu, cf. notes 206 et 207.

02. (239) Sur le Hiong-eul, cf. note 225. Sur le Lo et ses affluents, cf. note 186.

02. (240) Pour marquer le chemin. Cf. note 114. Le sens que nous adoptons ici est celui qui est indiqué par Kiang Cheng (H. T. K. K., ch. CCCXCII, p. $43 \mathrm{v}^{\circ}$ ).

02. (241) M. Legge, en se fondant sur un passage du Loen yu (Chinese Classics, t. I, p. 112), donne aux deux mots [] [] le sens tout spécial d'audiences privées et audiences générales à la cour. J'ai suivi l'ex plication plus simple et plus naturelle de Kiang Cheng. 
02. (242) Dans le Tso tchoan, à la $7^{\mathrm{e}}$ année du duc Wen (trad. Legge, p. 250), on lit :

« L'eau, le feu, le métal, le bois, la terre et les céréales sont ce qu'on appelle les six domaines.

02. (243) Ce sont les trois catégories comportant chacune trois subdivisions entre lesquelles nous avons vu que les neuf provinces étaient réparties. Cf. note 127.

02. (244) M. Legge, se conformant à la ponctuation du Chou king de Yong-tcheng, rapporte les deux mots [] [] à la phrase précédente. Mais cette lecture n'est approuvée par aucun autre commentateur. Le royaume du Milieu comprend les neuf provinces; il s'oppose aux royaumes-barrières, qui sont en dehors des neuf provinces.

02. (245) Le mot [] est l'équivalent du mot « se réjouir ».

02. (246) Cette phrase est une addition de Se-ma Ts'ien au texte du Chou king; elle sert à introduire l'étrange division administrative dont la description va suivre. Les commentateurs chinois se sont ingéniés à tracer des diagrammes géométriques de l'empir e distingué en cinq domaines. Le diagramme le plus simple et le plus conforme au texte sera celui qu'on construira de la manière suivante : tracez une croix dont chaque branche représentera une longueur de 2,500 li ; la capitale est censée au centre de la croix ; à partir de la capitale prenez une longueur de 500 li sur chacune des branches de la croix et faites passer par les quatre points ainsi déterminés des droites parallèles aux branches de la croix ; ces quatre droites en se coupant détermineront un carré dont la superficie sera $(500+500) \times(500+500)=$ $1,000,000$ de $l i$; c'est le domaine impérial ; prenez maintenant une nouvelle distance de $500 l i$ sur chacune des branches de la croix et tracez un autre carré dont les côtés soient parallèles au premier, la zone comprise entre le premier et le second carré constituera le domaine des seigneurs. Les branches de la croix ayant 2,500 li, on pourra déterminer sur chacune d'elles cinq points de $500 \mathrm{li}$ en $500 \mathrm{li}$ et tracer ainsi cinq carrés concentriques dont les distances mutuelles représenteront les cinq divisions de l'empire. Le plus grand carré aura 5,000 li de côté.

- Dans le Tcheou li, à l'article du Ta se ma et à l'article du Tche fang che (trad. Biot, t. II, p. 167 et 276), on trouve un schème analogue de l'empire, mais il comprend neuf divisions en outre du domaine impérial; chacune des branches de la croix doit donc s'éten dre à une distance de 5,000 li et le plus grand carré aura 10,000 li de côté.

02. (247) Ts'ai Tch'en soutient que les corvées (qui consistent à faire le transport des grains à la capitale) sont le propre des trois premières classes et non, comme on pourrait le croire, de la troisième seulement.

02. (248) Le grain décortiqué a plus de valeur sous un moindre volume que le grain non décortiqué ; une redevance d'une certaine valeur en grain décortiqué est donc d'un transport plus facile que la même redevance en grain non décortiqué ; c'est ce qui explique pourquoi ce sont les sujets les plus éloignés qui paient leur impôt en riz décortiqué.

02. (249) Ce sens est celui qui est indiqué par Kiang Cheng (H. T. K. K., ch. CCCXCII, p. 46 $\mathrm{r}^{\circ}$ ) ; on apporte des présents au lieu des céréales que livraient les zones plus rapprochées de la capitale.

02. (250) Le texte des Mémoires historiques est [] « ceux qui ont des charges dans l'État ». Le texte du Chou king donne la leçon [] mais la plupart des commentateurs expliquent [] comme ayant le sens de [] (H. T. K. K., ch. CCCXCII, p. $46 \mathrm{r}^{\circ}$ ); l'explication de Ts'ai Tch'en (Chou king, ch. V, p. $26 \mathrm{v}^{\circ}$ ), qu'a suivie M. Legge en tradui sant ce terme par «les royaumes des barons », me paraît insoutenable, car les barons sont compris au nombre des seigneurs qui occupent la zone suivante.

02. (251) Ce domaine est celui qui assure la paix de l'empire et sert d'in termédiaire entre le monde civilisé et le monde barbare; dans la première zone de ce domaine, on polit les murs encore rudes des hommes par l'instruction; dans la seconde zone, on les tient en bride au moyen des soldats. 
02. (252) Les Man sont, dans ce texte, des peuples barbares plus éloignés que les $I:$ on a vu que, dans d'au tres textes, les Man sont les barbares du sud et les I ceux de l'est (cf. p. 68),

02. (253) Ce sens de est celui qui est indiqué par Ma Yong. M. Legge l'entend comme désignant des criminels condamnés à un exil plus lointain encore que les bannis dont il a été question dans le domaine de la paix.

02. (254) Nous suivons pour le sens et la ponctuation de cette phrase les indications du commentaire de Tcheng Hiuen (H. T. K. K., ch. CCCXCII, p. $47 \mathrm{v}^{\circ}$ ). La traduction serait alors :

«Au nord et au sud il parvint ; sa renommée et ses enseignements pénétrèrent jusqu'aux quatre mers.

Mais la phrase «Au nord et au sud il parvint » est bien peu satisfaisante, car on est en droit de se demander jusqu'où il parv int, puisqu'à l'est et à l'ouest le texte dit très nettement jusqu'où il alla.

02. (255) Le mot $i=$ fin, est ici l'équivalent du caractère $k i=$ aller droit.

02. (256) Cette phrase commence par les mots et la phrase précédente finit par les deux mêmes mots. Certaines éditions de Se-ma Ts'ien ne laissent subsister qu'une seule fois cette expression. Le commentateur de l'époque de Kien-long, Tchang Tchao pense (Che ki, ch. II, annot. crit., p. $2 \mathrm{r}^{\circ}$ ) que la première phrase devait se terminer par le mot [] et la phrase suivante commencer par [] : si l'on admet cette correction de texte, l'empereur confère à $Y u$ un insigne en jade noir afin d'annoncer au Ciel (et non pas au monde) que son ouvre était bien accomplie. Ce sens est en effet plus satisfaisant.

- Dans le texte du Chou king, c'est $Y u$ qui présente à l'empereur l'insigne de jade noir pour lui annoncer qu'il a terminé ses travaux ; la leçon des Mémoires historiques est préférable, car les insignes sont conférés par l'empereur à ses sujets et l'inverse ne sau rait avoir lieu. Cette phrase termine le $Y u$ kong.

02. (257) Chou king : Kao yao mo.

02. (258) Dans la traduction de cette dernière phrase, nous suivons le sens indiqué par Tch'en Ta-yeou (Chou king, ch. III, p. 23 r $^{\circ}$ ) qui seul nous paraît faire un mot-à-mot rigoureux. Le caractère est pris dans le sens qu'il a fréquemment de « ce qui peut passer, ce qui est bon, digne d'approbation ». Kao-yao, sur la demande de $Y u$, développe sa pensée ; il montre que si le souverain est vertueux, au près la famille sera bien disciplinée et digne d'éloge, et les sages aideront le prince ; au loin, l'empire tout entier lui sera soumis comme sỉl était sous sa main.

02. (259) L'empereur dont il est ici question doit être l'empereur Yao qui, malgré sa vertu, n'avait pas été capable de nommer aux charges publi ques les huit fils excellents de Kao-yang et les huit fils excellents de $\mathrm{Kao}$-sin (cf. p. ${ }_{77}$ ) et qui attendit Choen pour exiler les quatre grands criminels.

— Kiang Cheng (H. T. K. K., ch. CCCXCII, p. $3 \mathrm{v}^{\circ}$ ) condamne cependant cette interprétation en disant que, Yao étant mort, un sujet comme $Y u$ ne pouvait se permettre de critiquer sa conduite ; d'après Kiang Cheng, l'empereur est ici Choen; Yu fait son éloge en disant que, quoique exerçant fort bien le gouvernement, il trouve sa tâche difficile et par conséquent il donne ses plus grands soins à l'accomplir.

02. (260) Quoique ni les commentateurs chinois ni M. Legge n'appellent l'attention sur le mot $t s^{\prime} i \bullet$, ce mot me paraît assez difficile à traduire. Il est impossible de le rendre par « exiler » car c'est le souverain et non San-miao qui éprouve l'action exprimée par ce verbe, comme le montrent les phrases symétriques qui précèdent et suivent celle-ci. Je traduis donc le mot ts'ien comme signifiant «faire passer d'un État à un autre (au moral), émouvoir, troubler »; mais je dois reconnaître que je n'ai jamais trouvé ce mot employé avec ce sens dans aucun autre texte. 
02. (261) Hoan-teou et San-miao sont deux des quatre grands criminels (cf. p. • $67-68$ ); aussi les commentateurs chinois supposent-ils que l'homme trompeur n'est autre que Kong-kong ; $Y u$ passe sous silence le quatrième criminel, Koen, parce que c'est son propre père.

02. (262) Le mot •, en tête de cette phrase et de la suivante répond bien à notre expression « d'une part... de l'autre... ». Si d'une part on dis tingue en théorie neuf vertus dans la conduite humaine, d'autre part pour définir ces vertus dans la pratique, on sera obligé de décrire la conduite ; c'est en effet ce que fait Kao-yao dans ce qui suit.

02. (263) Ce discours de Kao-yao traite de la manière dont le souverain se connaît en hommes ; les neuf vertus qu'il décrit ne sont pas celles que doit posséder le souvera in pour bien juger de la valeur des hommes, ce sont celles qu'il recherche chez ceux qu'il se propose d'appeler aux charges publiques.

02. (264) Le mot $k i \bullet$ ne désigne pas simplement ici une famille quelconque; il a le même sens que dans l'expression « maison héréditaire ». Le chef d'une telle maison ne peut être qu'un haut dignitaire, c'est-à-dire un k'ing ou un ta-fou; ainsi, celui qui a trois des neuf vertus énumérées plus haut sera digne d'être mis à la tête d'une maison, ou, en d'autres termes, d'être nommé haut dignitaire ; de même celui qui possède six de ces vertus sera digne d'être mis à la tête d'un royaume, ou, en d'autres termes, d'être nommé seigneur.

02. (265) [] est l'équivalent de répa ndre (sous-entendu = le gouvernement et l'enseignement). C'est l'idée que nous traduisons par le mot « administrer ».

02. (266) Hoai-nan-tse (chap. T'ai tsou hiun) et le Chouo wen disent tous deux que le mot désigne un homme qui en vaut mille autres; - d'après Tcheng K'ang-tch'eng, le mot $i$ désigne un homme qui en vaut cent autres.

02. (267) Cette phrase est substituée par Se-ma Ts'ien à d'assez longs dé veloppements du Kao yao mo dans le Chou king.

02. (268) Kao-yao dit par modestie qu'il ne sait pas si ses conseils sont dignes d'être mis en pratique, et qu'il cherche seulement à aider le souverain à se bien conduire. Tout ce texte est notablement différent de celui du Chou king.

- Dans le Chou king traditionnel, le Kao yao mo et le I et Tsi sont deux chapitres distincts ; au contraire, dans Se-ma Ts’ien, le texte du I et Tsi suit celui du Kao yao mo sans aucune solution de continuité ; c'est une confirmation du fait dé jà connu que ces deux chapitres n'en formaient qu'un seul dans le texte mo derne du Chou king.

02. (269) Chou king : I et Tsi.

02. (270) Cf. n. 116. - Dans le texte du Chou king, tout ce développement est remplacé par la phrase : Je me servis des quatre modes de locomotion.

02. (271) Cf. note 114 .

02. (272) Tous les commentateurs disent que cette nourriture fraîche est de la viande. Le mot paraît en effet avoir à l'origine le sens de viande fraîche ou crue. — Sur I, cf. note 01.299.

02. (273) Le kiuen était un canal de 1 pied de largeur et de 1 pied de profondeur; le koei était un canal de 16 pieds de largeur et de 16 pieds de profondeur; entre ces deux dimensions il y avait le soei de 2 pieds de largeur sur 2 de profondeur, le keou de 4 pieds de largeur sur 4 de profondeur, le $\operatorname{siu}=$ de 8 pieds de largeur sur 8 de profondeur.

- Notre texte, en citant les canaux de la plus petite et ceux de la plus grande catégorie, donne à entendre qu'il s'agit de tous les canaux.

02. (274). Cf. note 01.296 .

02. (275) Le sens de cette phrase est simple et clair dans le texte de Se-ma Ts'ien; la leçon du Chou king [] est plus obscure; les uns (H.T.K. K., ch. CCCXCI, p. $\left.13 \mathrm{v}^{\circ}\right)$... expliquent l'expression comme signifiant : la nourriture qui a des tiges, c'est-à-dire les céréales ; - 
d'autres opposent la nourriture qu'on ne se procure qu'avec effort, c'est -à-dire les produits de la culture, à la nourriture fraîche dont il a été question plus haut, c'est-à-dire aux produits de la chasse et de la pêche.

02. (276) Tout ce passage est d'une intelligence assez difficile ; le texte présente de notables différences avec celui du Chou king. Le sens général est le suivant : les fonctions d'empereur ont la plus grande importance ; si celui qui les remplit est attentif à ses devoirs, il aura le calme pour lui-même parce qu'il aura atteint le but de sa destinée ; par une conséquence naturelle, ses ministres seront vertueux et tout l'empire sera d'accord avec ses désirs, témoignant ainsi, en vertu de l'axiome : Vox Populi vox Dei, quil règne par droit divin ; le Ciel prouvera d'ailleurs de nouveau qu'il l'a investi de ce droit en le comblant de bienfaits.

— Dans la dernière phrase, le mot [] est le signe du futur (cf. Stan. Julien, Syntaxe chinoise, t. I, p. 173).

02. (277) Après que $Y u$ a montré à l'empereur quelle est l'importance de sa charge, l'empereur à son tour rappelle à ses ministres la gravité de leurs fonctions.

02. (278) Les ministres doivent donner toute leur attention aux manifestations visuelles et auditives de la régularité. Pour la vue, on a imaginé de peindre sur les vêtements de cour divers symboles (douze exactement; les Mémoires historiques ne citent que les premiers, le soleil, la lune et les étoiles, qui étaient réservés aux vêtements impériaux) et l'ordre dans lequel ces symboles doivent apparaître aux audiences de la cour est fort important, car ils sont la marque visible de l'har monie ; les ministres ont donc à veiller à ce que le cérémonial concernant les objets qu'on voit soit observé avec exactitude. Pour l'ouïe, la musique et les chants sont la pierre de touche du bon ou du mauvais gouvernement; ils sont la marque auditive de l'harmonie ; les ministres doivent donc écouter avec attention la musique et les chants.

- Dans ce passage fort difficile, le texte de Chou king paraît n'avoir pas toujours été bien compris par Se-ma Ts'ien lui-même; c'est ainsi que les trois caractères par lesquels il remplace la phrase observer les qualités et les défauts du gouvernement) du Chou king, n'ont, de l'aveu de Se-ma Tcheng, absolument aucun sens; il faut reconnaître d'autre part que la leçon du Chou king à son tour ne se comprend qu'à grand renfort de commentaires ; Kiang Cheng (H. T. K. K., ch. CCCXCI, p. $18 \mathrm{r}^{\circ}$ ) propose d'adopter la leçon qui est indiquée par le chap. Lu li tche du Ts'ien Han chou — les chants des sept principes.

02. (279) Plusieurs commentateurs se fondent sur un passage du grand commentaire de Fou Cheng, pour dire que cette expression désigne quatre catégories de ministres :

* ceux de devant étaient appelés $i=$ (celui qui propose ou supprime) le doute ;

* ceux de derrière étaient appelés tch'eng = celui qui aide ;

* ceux de gauche étaient appelés fou = celui qui seconde ;

* ceux de droite étaient appelés $p i=$ celui qui soutient.

02. (280) Le début seul de cette phrase se trouve dans le Chou king. Se-ma Ts'ien est ici plus obscur encore que le livre classique,

02. (281) Dans le Chou king, il n'y a pas la phrase «l'empereur dit... » et les paroles qui suivent se trouvent donc dans la bouche de $Y u$.

- La leçon de Se-ma Ts'ien semble être la meilleure, car elle est confirmée par un texte de la monographie du roi Yuen de Tch'ou, dans le Ts'ien Han chou et par deux textes du Loen heng de Wang Tch'ong (H. T. K. K., chap. CCCXCI, p. $22 \mathrm{r}^{\circ}$ et v ${ }^{\circ}$ ).

- Ajoutons que le Chou king ne présente plus ici aucun sens suivi, tandis que la rédaction de Se-ma Ts'ien est à la rigueur intelligible; voici comment on peut, je crois, exposer l'enchainement des idées : Choen se propose de prendre $Y u$ pour successeur; $Y u$ commence par montrer qu'il en est digne en rappelant ses travaux antérieurs; il disserte ensuite sur les devoirs du souverain et fait voir ainsi qu'il en comprend l'importance ; Choen appelle son attention sur le soin extrême avec lequel il devra choisir les hommes dont il fera ses ministres, 
car ce sont les ministres qui font réussir le gouvernement. $Y u$ approuve cette parole. Choen lui fait alors une dernière recommandation (c'est le passage où nous nous sommes arrêtés en ce moment) ; il craint que $Y u$ ne transmette l'empire à son fils (le fils de Choen, Chang-kiun), quoiqu’il en soit indigne ; prenant Tan-tchou, fils de Yao, comme exemple, il engage $Y u$ à ne point favoriser la mauvaise conduite d'hommes de cette sorte et à en user envers Chang-kiun comme lui-même, Choen, en a usé envers Tan-tchou. Yu répond en rappelant que dans toute sa vie passée, il a mis son devoir au-dessus de ses affections et a su distinguer entre les hommes de bien et les méchants. Choen le reconnaît alors capable de lui succéder.

02. (282) Quoique les eaux débordées eussent été ramenées dans le lit des fleuves, Tan-tchou voulait encore aller en bateau là où la terre ferme avait réapparu.

02. (283) Les jours sin, jen, koei et kia sont quatre jours consécutifs (les trois derniers d'une série de dix jours et le premier de la série suivante) ; le texte de Se-ma Ts'ien est donc fort étrange, car le fils de $Y u$ serait né le lendemain de son mariage et, comme le fait gravement remarquer Kiang Cheng, « c'est bien court. » Le texte du Chou king est plus admissible, car il donne simplement à entendre que $Y u$ n'eut que quatre jours pour se marier.

02. (284) T'ou-chan est le nom d'une principauté que l'opinion généralement admise par les commentateurs place dans la sous-préfecture actuelle de Hoai-yuen, préfecture de Fong-yang, province de Ngan-hoei.

02. (285) $K ’ i$ succéda plus tard comme empereur à son père, $Y u$.

02. (286) Sur les cinq domaines, cf. note 246. On a vu que le domaine le plus lointain devait avoir 5000 li de côté.

02. (287) Pour un lecteur non prévenu, il est évident que les douze maîtres sont les douze pasteurs de peuples dont il a été parlé plus haut, note 01.303. Les Chinois épiloguent à l'infini sur ce texte parce qu'ils veulent mettre d'accord le chiffre de douze provinces attribué à l'em pire de Choen et le chiffre de neuf provinces dont il est question dans le Tribut de $Y u$ (cf.p. 65, n. 2). Voyez Legge, Chou king, p. 85-86.

02. (288) L'expression « les quatre mers » désigne ici les barbares des quatre points cardinaux.

02. (289) L'expression désigne, d'après Ou Tch'eng (commencement du IIe siècle), les cinq degrés de noblesse, kong, heou, po, tse, nan. Pour d'autres explications, voyez Legge.

02. (290) Par cette phrase, $Y u$ montre quil a su distinguer entre les bons et les mauvais, récompenser les uns et punir les autres.

02. (291) Choen déclare $Y u$ digne de lui succéder. - Le sens que nous donnons à cette phrase n'est point celui que lui attribuent les com mentateurs chinois ; mais il nous paraît être imposé par la suite des idées (cf. note 291) ; en outre nous ferons remarquer que nous avons eu à traduire le texte de Se-ma Ts'ien et non celui du Chou king; nous avons donc cherché à pénétrer, non la signification du Chou king traditionnel, mais celle que Se-ma Ts ien attribuait à sa citation et qu’il indique par les modifications mêmes qu'il fait sub ir à l'original.

02. (292) La musique dont il est question est celle qui se faisait dans le temple ancestral ; aussi les mânes des ancêtres viennent-ils assister à la cérémonie.

02. (293) Le mot siao désigne proprement une flûte à plusieurs tuyaux; mais l'expression siao chao est le nom de la musique de Choen. - Sur les neuf airs, cf. note 01.337.

02. (294) Dans les trois strophes qui suivent, la tête représente l'empe reur, les jambes et les bras sont ses ministres. - Dans la première strophe, les rimes sont, dans le système de Toan Yu-ts'ai, au p'ing cheng de la première catégorie (H.T.K.K., ch. DCLX, p. $\left.1 \mathrm{v}^{\circ}\right)$; dans la seconde strophe, les rimes sont au p’ing cheng de la dixième catégorie (loc. cit., p. $9 \mathrm{v}^{\circ}$ ); dans la troisième strophe, les rimes sont au p’ing cheng, de la dix-septième catégorie (loc. cit., p. $15 \mathrm{r}^{\circ}$ ).

02. (295) Fin du chap. I et Tsi. 
02. (296) L'expression, chen tchou = proprement: président des dieux, s'explique par le fait qu'on appelait président ( $t c h o u$ ou tchou jen) celui qui présidait aux rites et aux cérémonies religieuses.

- Le titre de président des dieux (qui attestait, chez celui qui le possédait, le droit de sacrifier aux dieux de toutes les montagnes et de tous les cours d'eau de l'empire et non pas seu lement à telle ou telle divinité déterminée) était l'apanage de l'empe reur. Ainsi, dans le chapitre du Chou king intitulé Hien yeou i té (trad. Legge, p. 214), pour exprimer l'idée que le Ciel cherche un nouveau souverain, il est dit que le Ciel cherche quelqu'un qui possède la pure vertu pour en faire le président des dieux. Dans le Che king (décade Cheng min, trad. Legge, p. 492) le duc de Chao souhaite au roi Tch'eng d'aller jusqu'au bout de sa destinée en restant président des dieux. Dans le Li ki (chap. Tsi fa, trad. Legge, Sacred Books of the East, t. XXVIII, p. 203),. on lit :

«Celui qui exerce l'empire sacrifie aux cent dieux (c'est-à-dire à tous les dieux) ; les seigneurs n'honorent que leurs dieux locaux.

- Cf. plus haut, note 01.228 .

02. (297). Mencius, V, a, 6, trad. Legge, p. 234 ; [trad. Couvreur].

02. (298) Yang-tch'eng, c'est-à-dire la ville au sud (de la montagne) était ainsi appelée parce qu'elle était située à $23 \mathrm{li}$ au sud de la fameuse montagne Song; elle était à $35 \mathrm{li}$ au sud-est de l'actuelle sous -préfecture de Teng-fong, préfecture et province de Ho-nan.

02. (299) On a vu plus haut (note 101) que Hia était le nom du fief que possédait $Y u$ avant qu'il fait empereur. Le nom du royaume devint celui de la dynastie.

02. (미) Les descendants de Kao-yao avaient pour nom de famille Yen. Leou est aujourd'hui la préfecture secondaire de Leou-ngan, province de Ngan-hoei; Yng correspond à la sous-préfecture de Yng-chan, dans le territoire de cette même préfecture secondaire. Hiu correspond à la préfecture secondaire de ce nom, dans la province de Ho-nan.

02. (301) La montagne Koei-ki est au sud-est de la sous-préfecture de Koei-ki, préfecture de Chao-hing, province de Tche-Kiang.

— Le premier caractère [a] doit être prononcé comme le caractère [], c'est-à-dire Koei et non $H o e i$ : cependant on verra plus loin que l'étymologie dont Se-ma Ts’ien fait dériver le nom de cette montagne conserve au mot [a] son sens de « réunir ».

02. (으) Cf. note 01.299 .

02. (ㅁ3) Mencius, V, a, 6, trad. Legge, p.234 ; [trad. Couvreur]

02. (연) Le texte de Mencius porte : au nord de la montagne $K i$. Cette leçon paraît préférable ; en effet, la montagne $K i$ était au sud de la ville de Yang-tch'eng (cf. note 298) tandis que la montagne Song était au nord; comme c'est vraisemblablement à Yang-tch'eng ou près de cette ville que se retira $I$, il faut donc dire : au nord de la montagne $K i$.

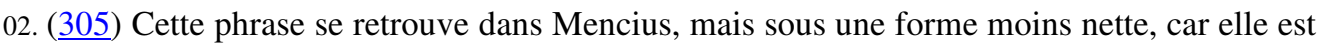
ainsi conçue : «Il est le fils de l'empereur $Y u$, » ce qui n’indique pas que les seigneurs le choisissent pour empereur.

02. (으) $K i$ hérite du titre de son père et c'est ainsi qu'apparaît la dynas tie Hia.

02. (이) Cf. note 284 .

02. (308) Hou est aujourd'hui la sous -préfecture de Hou, préfecture de Si-ngan, province de Chàn-si.

— Le prince de Hou ... était parent de l'empereur qui avait le même nom de famille.

02. (무) Le portique de Kan, au sud-ouest de la sous-préfecture de Hou, marque le lieu où $K^{\prime} i$ tint son discours avant de livrer bataille. 


\section{2. (1ㅡ) Chou king: $\underline{\text { Kan che. }}$.}

02. (311) Les six hauts dignitaires Il sont les commandants des six corps d'armée qui composaient les troupes impériales. On lit en effet dans le Tcheou li (liv. XXVIII, Ministère de l'été ; trad. Biot, t. II, p. 142) :

«L'empereur a six corps d'armée,... Les généraux d'armée ont tous la charge de k'ing.

02. (312) $K ’ i$ s'adresse non seulement aux généraux, mais à tous les sol dats.

02. (313) Les cinq éléments sont ici conçus dans leur relation avec les quatre saisons; le prince de Hou est accusé de ne point observer les ordonnances pour chaque mois que le souverain a promulguées et qui sont d'accord avec la prédominance alternée des cinq éléments.

— Les trois principes sont, d'après Tcheng K'ang -tch'eng, le Ciel, la Terre et l'Homme dont l'harmonie mutuelle est le principe de l'ordre universel ; Ma Yong veut voir dans les trois principes les trois commencements différents de l'année qui furent successivement adoptés par les Chinois ; mais cette explication est beaucoup trop compliquée.

02. (314) Celui de gauche et celui de droite sont les deux soldats qui étaient placés l'un sur la gauche, l'autre sur la droite du char de guerre, tandis que le cocher (dont il est question à la phrase suivante) était au milieu. On trouve dans le Tso tchoan $\left(2^{\circ}\right.$ année du duc Tch'eng, trad. Legge, p. $345,2^{\mathrm{e}}$ col.) un autre exemple de [] [] désignant l'homme de gauche et l'homme de droite sur le char.

02. (315) Lorsque le souverain allait faire une expédition guerrière, il emportait avec lui ses dieux ; les principales divinités de l'État étaient celles du temple ancestral à gauche et celles de la terre et des moissons à droite. Le souverain prenait donc les tablettes représentant son ancêtre et le dieu de la terre. La tablette de l'ancêtre était placée dans un char spécial appelé le char du respect; il est probable qne la tablette du dieu de la terre avait aussi un véhicule particulier. La présence de ces divinités donnait au prince un mystérieux prestige: les récompenses qu'il distribuait étaient comme conférées par l'ancêtre, génie tutélaire et bon ; les punitions qu'il infligeait semblaient édictées par le dieu de la terre, per sonnification de la sévère justice.

- Sur la coutume d'emport er les tablettes des divinités dans le camp, cf. Li ki, chap. Tseng tse wen, trad. Legge, Sacred Books of the East, t. XXVII, p. 324; [trad. Couvreur] - Tso tchoan, $4^{\mathrm{e}}$ année du duc Ting, trad. Legge, p. 754, - et d'autres passages des Mémoires historiques que nous signalerons lorsqu'ils se présenteront. - Sur la tablette était inscrit seulement le nom du dieu ; mais, par suite du caractère idéographique de l'écriture chinoise, le nom même était en quelque manière la représentation figurée des qualités essentielles de la divinité et jouait ainsi le rôle d'une véritable idole.

02. (316) La harangue se termine par trois vers dont les rimes sont au chang cheng de la cinquième catégorie $\left(H . T . K . K\right.$. , ch. DCLX, p. $\left.7 \mathrm{r}^{\circ}\right)$. Il semble bien que nous ayons là sous sa forme concise et énergique une vieille imprécation rituelle où respire encore la sauvagerie des premiers temps de la civilisation chinoise. La harangue de Kan me paraît, malgré sa brièveté, un des monuments les plus remarquables, et à coup sûr les plus authentiques, de la haute antiquité ; elle est singulièrement plus vivante que les Règles de Yao et de Choen ou que le Tribut de $Y u$.

- Cette harangue se trouve reproduite avec quelques variantes par Mo-tse qui l'intitule la Harangue de $Y u$ et l'attribue à $Y u$ et non à $K^{\prime} i$.

02. (317) Chou king, Préface.

02. (318) Les Chants des cinq fils forment le troisième des livres de Hia dans le Chou king traditionnel ; ils appartiennent au pseudo-texte antique et leur authenticité est fort contestable. On remarquera que Se-ma Ts'ien paraît n'en connaître que le titre. 
02. ( $\underline{319})$ Les $H i$ et les $H o$ sont les descendants des personnages de même nom que Yao chargea de présider aux principes yn et yang et aux quatre saisons. Cf. note 01.176.

02. (320) Le Châtiment de Yn est le quatrième des livres de Hia; sous sa forme actuelle, son authenticité est plus que douteuse, cf. note 318.

— Le royaume de $Y n$ correspond à la sous-préfecture de Koang-yuen, préfecture de Pao-ning, province de Se-tch'oan.

02. (321) Se-ma Tcheng et Tchang Cheou-kié remarquent qu'entre le règne de l'em pereur Siang et celui de l'empereur Chao-k'ang il s'écoula de trente à quarante années pendant lesquelles le trône fut occupé successivement par deux usurpateurs, I et Tcho. Nous trouvons des renseignements étendus sur ces faits dans le Tso tchoan ( $4^{\mathrm{e}}$ année du duc Siang, trad. Legge, p. 424 ; [trad. Couvreur]). Dans le chapitre du Chou king intitulé les Chants des cinq fils, I est donné comme ayant supplanté l'emper eur T'ai-k'ang et non l'empereur Siang, mais nous avons vu plus haut (note 318) que ce témoignage ne saurait avoir grande valeur.

Si nous nous en tenons aux indications du Tso tchoan, en les complétant par les autres textes cités par les commentateurs, voici quels événements se seraient passés :

le prince $I$, descendant d'un célèbre archer qui portait le même nom au temps de l'empereur K'ou, força l'empereur Siang à quitter sa capitale et à s'enfuir à Chang-k'ieou (aujourd'hui sous-préfecture de ce nom, préfecture de Koei-té, province de Ho-nan). I s'empara du pouvoir, mais, comme il passait tout son temps à la chasse, son conseiller, nommé Tcho, en profita pour gagner l'esprit du peuple : Tcho fit alors assassiner $I$; il bouillit son corps et le donna à manger à ses fils qui tous en moururent. Tcho put ainsi monter sur le trône ; il envoya son fils, Kiao, attaquer et tuer l'empereur Siang auparavant dépossédé par $I$. Cependant un fidèle serviteur de la dynastie légitime, un nommé $\mathrm{Mei}$, rassembla tous les mécontents, vainquit Tcho et proclama empereur Chao-k'ang, fils de l'empereur Siang. Ainsi se termina le règne des usurpateurs.

02. (322) Le nom de cet empereur se prononce aussi Hoang.

02. ( $\underline{323})$ On trouve, dans le Tchou chou ki nien, un écho de cette bizarre légende ; cf. Legge, Chinese Classics, t. III, Prolég., p. 124.

02. (324) Celui qui entretient les dragons était un fonctionnaire à la cour de l'empereur Choen. D'après le Tso tchoan, Chou-ngan, prince de Liou, eut un descendant qui s'appelait Tong-fou ; celui-ci savait apprivoiser et nourrir les dragons; c'est à ce titre qu'il fut au service de Choen; Choen lui conféra le nom de famille Tong et le surnom de «Celui qui entretient les dragons » (T'ong kien tsi lan, chap. II, p. $10 \mathrm{r}^{\circ}$ ).

02. (25) T'ao-t'ang n'est autre que l'empereur Yao (cf. note 01.166). Les descendants de Yao ne furent point empereurs et tombèrent donc en déchéance; c'est pourquoi l'un d'eux, Lieou-lei, apprit l'art d'élever les dragons.

02. $(\underline{326})$ 《Celui qui dirige les dragons » ne saurait être à proprement parler un sing, comme le dit ici Se-ma Ts'ien; c'est un titre devenu un nom de famille.

02. (327) Les princes de Che-wei (sous-préfecture de Hoa, préfecture de Wei-hoei, province de Ho-nan) passaient pour des descendants de Tchou-yong (cf. note 00.133). D'après Kia K'oei, ce ne serait que sous la dynastie $Y n$, au temps de l'empereur Ou-ting, que le prince de Che-wei fut supprimé et que son apanage fut donné au descendant de Lieou-lei.

02. (르) Il faut entendre : à son insu.

02. (329) Lieou-lei s'enfuit à Lou (aujourd'hui sous-préfecture de Lou-chan, préfecture secondaire de Jou, province de Ho-nan); ses descendants eurent le nom de famille Fan.

02. (330) Ce nom de Li-koei est assez suspect; en effet, d'une part K'ong Ngan-kouo, dans son commentaire au Loen yu $\left(H . T . K . K\right.$, ch. XXII, p. $\left.18 \mathrm{r}^{\circ}\right)$, nous apprend que le nom 
personnel de T'ang, fondateur de la dynastie $Y n$, était $L i$ et les historiens modernes, auteurs du Tong kien kang mou et du Tong kien tsi lan, ont fait de $\mathrm{Li}$, sur la foi de cette autorité, le nom de T'ang et non celui de Kié; d'autre part, Se-ma Ts'ien lui-même nous dit, au chapitre suivant, que le père de T'ang s'appelait Tchou-koei. Ainsi le nom de Li-koei paraît être formé du nom de T'ang suivi de celui de son père. D'ailleurs, il serait assez singulier que Kié fût le seul de tous les souverains de la dynastie Hia dont le nom se terminât par un des dix caractères cycliques kia, $i$, ping, ting... ; ce n'est que sous la dynas tie $Y n$ que les noms des souverains présentent cette particularité. Nous croyons donc que Se-ma Ts'ien fait une confusion en donnant à Kié le nom de Li-koei.

02. (331) D'après Hoang-fou Mi, Hia-T'ai, ou la terrasse de Hia, était à Yang-ti, aujourd'hui préfecture secondaire de $Y u$, préfecture de K'ai-fong, province de Ho-nan. - Cette légende de l'emprisonnement de T'ang qui devait fonder une nouvelle dynastie est évidemment calquée sur celle de l'emprisonnement du chef de l'ouest par Tcheou-sin, dernier souverain de la dynastie $Y n$ (voyez le chapitre suivant, ad fin.).

02. (332) Ming-t'iao est le nom d'une colline escarpée dans la sous-préfecture de Ngan-i, préfecture secondaire de Kié, province de Chàn-si.

- Le Chou king (chapitre Tchong hoei tche kao) dit d'autre part que Kié fut exilé à Nan-tch'ao aujourd'hui sous-préfecture de Tch'ao, préfecture de Lu-tcheou, province de Ngan-hoei).

- Le T'ong kien tsi lan concilie ces deux témoignages en disant que Kié fut battu à Ming-t'iao, mais qu'il s'en fuit et fut exilé à Nan-tch'ao .

02. (333) C'est le roi $O u$ de la dynastie Tcheou qui donna au duc de Tong-leou, descendant des $H i a$, le fief de $K \hat{i}$ (aujourd'hui sous-préfecture de $K \hat{i}$, préfecture de Kai-fong, province de Ho-nan).

02. (334) Cette énumération comprend les princes féodaux qui se prétendaient descendants de la dynastie Hia. Sur la principauté de Hou, cf. note 308 ; sur celle de $K$ ’ , cf. note 333 ; la principauté de Tchen-siun était à $50 l i$ au sud-ouest de la sous-préfecture de Wei, préfecture de Lai-Tcheou, province de Chan-tong; la principauté de Tchen-ko (dont le nom est écrit Tchen-koan dans le Tch'oen ts'ieou ) se trouvait dans la même province, à 40 li au nord-est de la sous-préfecture de Cheou-koang, préfecture de Ts'ing-tcheou. La principauté de Fei correspond à la sous-préfecture de $Y u$-T'ai, préfecture secondaire de Tsi-ning, province de Chan-tong. La principauté de Ming se trouvait dans la vice-royauté des deux Koang, sans qu'on en sache l'emplacement exact ( H. T. K. K., ch. CCCIV, p. $\left.39 \mathrm{v}^{\circ}\right)$. Je ne suis pas parvenu à identifier les autres noms.

02. (335) Le petit calendrier des Hia nous a été conservé dans les Rites de Tai l'aîné ; il a été traduit en français par Biot (Journal asiatique, 1840, p. 551-560) et en anglais par M. Douglas.

02. (르) Cf. note 301 .

\section{CHAPITRE III. LES YN}

03. (101) Sié fut le premier ancêtre de la seconde dynastie. Cette dynastie s'appela d'abord Chang, du nom de la terre qui, comme on le lira quelques lignes plus bas, fut donnée à Sié par l'empereur mm Choen; elle prit ensuite le nom de Yn lorsque $P$ 'an-keng transféra son peuple dans la terre de ce nom.

03. (102) D'après le commentaire Tcheng $i$, Song est une localité correspondant à la circonscription de P'ou. Aujourd'hui, préfecture de P'ou-tcheou, province de Chan-si. 
— L'expression [] signifie proprement « la famille qui possède Song » et c'est pourquoi je traduis : la famille princière de Song.

— Sur les quatre femmes de K'ou, cf.note 01.162.

03. (103) L'oiseau de couleur sombre est l'hirondelle.

— Le Che king $\left(3^{\mathrm{e}}\right.$ des odes sacrificatoires des Chang, trad. Legge, p. 636 ; [trad. Couvreur]) rappelle aussi cette légende :

«Le Ciel ordonna à l'oiseau de couleur sombre de descendre et de donner naissance à Chang (c'est-à-dire à Sié, ancêtre des Chang).

- Dans l'annotation que Se-ma Ts'ien a placée à la fin de ce chapitre, on verra quill dit lui même qu'il s'est servi des odes sa crificatoires du Che king pour rédiger ce qui concerne Sié.

03. (104) Le Che king ( $4^{\mathrm{e}}$ des odes sacrificatoires des Chang, trad. Legge, p. 638 ; [trad. Couvreur]) réunit de même les noms du grand $Y u$ et de l'ancêtre des Chang.

03. (105) L'allocution de Choen à Sié fait partie du Choen tien et nous l'avons traduite dans les Annales principales des cinq empereurs, $\mathrm{p} \cdot{ }_{83}$. Dans le texte présent, nous notons deux variantes [qui] rendent le texte plus facile à comprendre.

03. (106) Chou king: Choen tien.

03. (107) D'après la géographie de l'époque des T'ang intitulée Kouo ti tche; le fief de Chang correspondait à la sous-préfecture de Chang lo. Cette sous-préfecture est à 85 li à l'est de l'actuel Chang-tcheou, province de Chàn-si.

- D’après le chapitre Kiu pien du Che pen, la résidence de Sié aurait été dans la ville de P'an.

03. (108) Tang et $Y u$ ne sont autres que Yao et Choen. Le grand $Y u$ est le fondateur de la dynastie des Hia.

03. (109) Siang-t'ou est mentionné dans le Che king ( $4^{\mathrm{e}}$ des odes sacrificatoires des Chang, trad. Legge, p. 640 ; [trad. Couvreur]) comme un des princes les plus éminents parmi les premiers souverains de la dynastie $Y n$.

03. (110) D'après le chapitre Ti hi du Che pen, Ts'ao-yu s'appellerait Leang-yu. En outre, entre ce prince et le suivant s'en trouverait un, nommé Ken-kouo te.

- Pan Kou, dans le Kou kin jen piao du Ts'ien Han chou a essayé de combiner le système de Se-ma Tsien et celui du Che pen en faisant de Ts'ao-yu et de Ken-kouo un seul personnage qu'il appelle Ken-yu, fils de Tch'ang-jo.

03. (111) Le Tchou chou ki nien, $13^{\mathrm{e}}$ année de l'empereur Tch'ou de la dynastie Hia, dit que Ming mourut noyé dans le Fleuve.

03. (112) Le Che pen (chap. Ti hi) dit que le fils de Ming s'appela Ho.

03. (113) D'après Hoang-fou Mi, l'appellation de Wei était Chang-kia. Le mot kia est un des dix termes du cycle kia, i, ping, ting, ou, ki, keng, sin, jen, koei. A partir du roi Wei, tous les souverains de la dynastie $Y n$ ont, dans leur nom, un de ces dix caractères cycliques. D'après les commentateurs (qui s'appuient sur le Po hou t'ong de Pan Kou), ces caractères servaient à désigner le jour de leur naissance. - On remarque cette même particularité dans les noms des ancêtres des princes de Ts'i (cf. Mém. hist., Ts'i T'ai kong che kia, chap. XXXII).

03. (114) T'ang est un titre posthume qui, d'après le Che fa, signifie: Celui qui écarte la cruauté et qui supprime le tyran.

- Les historiens modernes disent tous que le nom personnel de ce souverain fut $L i$; mais le nom de Tien-i, indiqué par Se-ma Ts'ien, nous semble préférable, car il renferme un des dix caractères cycliques (cf. la note précédente et aussi note 02.330). 


\section{3. (115) Chou king: Préface.}

03. (116) D'après le T'ong kien tsi lan (ch. II, p. $11 \mathrm{v}^{\circ}$ ), Sié résida à Chang Tchao-ming à Tiche ; Siang-t'ou, à Chang-k'ieou ; T'ang, à Po. Les quatre autres capitales sont inconnues. Ce qu'il est essentiel de noter, c'est que les ancêtres de la dynastie passaient pour avoir habité le Chàn-si, tandis que Tang avait sa capitale dans le Ho-nan.

03. (117) Il existe trois localités appelées Po qui toutes trois se trouvent dans le Ho-nan. Le Po méridional était à $40 l i$ à l'est de la sous-préfecture actuelle de Chang-k'ieou, préfecture de Koei-té ; le Po occidental correspond à la ville de Yen-che, préfecture de Ho-nan ; enfin le Po septentrional, qui était aussi appelé King Po, parce qu'il était voisin de la montagne Ning, correspond à la ville de Ta-mong, préfecture de Koei-té.

- T'ang, qui avait d'abord ré sidé au Po méridional, transféra sa résidence au Po occidental, et, comme le $P o$ occidental avait été la capitale de son ancêtre l'empereur $K$ 'ou, père de Sié (cf. note 01.156), T'ang fit, à l'occasion de ce déplacement, l'Annoncement à l'empereur, c'est-à-dire à l'empereur K'ou. L'Annoncement à l'empereur devait faire autrefois partie du Chou king, mais, dès le temps de Se-ma Ts'ien, il était perdu. D'après Se-ma Tcheng, ce chapitre avait pour titre, non pas Ti kao, mais Ti Kou, c'est-à-dire, non pas « Annoncement à l'Empereur », mais «l'Empereur K'ou».

03. (118) Le pays de Ko correspond à la sous-préfecture de Ning-ling, préfecture de Koei-té, province de Ho-nan. L'expédition de T'ang contre le comte de Po est mentionnée dans le Chou king (chap. Tchong hoei tche kao, trad. Legge, p. 180 ; [trad. Couvreur]) ; Mencius en a aussi parlé et a raconté les causes qui menèrent cette guerre (III, a. 5, trad. Legge, p. 148 ; — cf. I, b. 11, trad. Legge. p. 47; [trad. Couvreur]).

03. (119) Le Châtiment infligé par T'ang est le titre d'un chapitre perdu du Chou king. Les paroles qui précèdent doivent en avoir fait partie. En effet, un peu plus loin, Se-ma Ts'ien donne le texte de la harangue de T'ang et ajoute aussitôt après : « il fit la harangue de Tang »; dans les deux passages la méthode de composition, ou plutôt de compilation, est la même.

- Kiang Cheng (H. T. K. K., ch. CCCXCIII, p. 1 et 2) reconstitue le « Châtiment infligé par rang » au moyen du texte de Se-ma Ts'ien et de celui de Mencius. Il est à remarquer que ce chapitre ne se trouvait ni dans le texte moderne de Fou Cheng, ni dans le texte antique de K'ong Ngan-kouo (cf. Introduction, ch. III, § 1, listes A et B) ; Se-ma Ts'ien a donc dû l'emprun ter à une source qui nous est inconnue.

03. (120) Soen-tse, cité par P'ei Yn, dit que le nom personnel de I Yn était Tche; aussi la plupart des commentateurs rejettent-ils le témoignage de Se-ma Ts'ien et considèrent-ils Ngo-heng, non pas comme le nom personnel de I Yn, mais comme le titre de sa fonction; Ngo-heng signifierait alors : l'appui et le justicier. Quant aux deux mots I Yn, on les explique de la manière suivante : la mère de ce personnage demeurait près de la rivière $I$ et c'est de là que lui vient le nom de $I$; quant au mot $Y n$, il signifie « rectifier »; en effet T'ang chargea $I$ $Y n$ de rectifier ce qui était mal dans son royaume.

03. (121) Le pays de Sin correspond à la sous-préfecture actuelle de Tch'en-lieou, préfecture de Kai-fong, province de Ho-nan.

03. (122) Mencius (V, a, 7, trad. Legge, p. 240 ; [trad. Couvreur]) a nié qu'I Yn se soit jamais déguisé en cuisinier pour parvenir jusqu'à T'ang :

« J'ai entendu dire, écrit-il, qu'I Yn chercha à s’introdu ire auprès de T'ang, par le moyen des doctrines de Yao et de Choen; je n'ai pas entendu dire qu'il l'ait fait par le moyen de ses connaissances en cuisine.

- Il est à remarquer d'ailleurs que Se-ma Ts'ien lui-même ne semble pas attacher beaucoup de valeur à cette tradition puisqu'il en cite une autre aussitôt après.

- Le discours d'I Yn sur les saveurs nous a été conservé dans le Tch'oen ts'ieou de Lu Pouwei, ch. XIV, p. $6 \mathrm{r}^{\circ}$. 
03. (123) D'après Mencius (V, a. 7, trad. Legge, p. 239 ; [trad. Couvreur]), T'ang n'envoya que trois fois des messagers à $I Y n$.

03. (124) Le Roi simple paraît être un personnage fictif qui représente le souverain idéal des théories taoïstes ; c'est le prince dont la conduite est simple et vraie. Le commentaire Souo yn explique les neuf Maîtres en disant que ce sont les trois souverains, et les cinq empereurs de la haute antiquité, auxquels on ajoute $Y u$, le fondateur de la dynastie des Hia. Lieou Hiang cependant en donne une autre explication : les neuf Maîtres seraient :

1. les princes de la loi (c'est-à-dire les princes qui règnent en appliquant des lois sévères, comme Hiao, duc de Ts'in, ou Ts'in Che hoang ti);

2. les princes de la peine (c'est-à-dire les princes qui s'épuisent en efforts pour le bien du peuple, comme $Y u$ le grand ou le prince $T s i$, promoteur de l'agriculture) ;

3. les princes équitables (c'est-à-dire ceux qui font sentir leur prestige avec justice et qui récompensent avec équité, comme Kao-tsou, fondateur de la dynastie des Han) ;

4. les princes qui donnent (c'est-à-dire ceux qui ne gouvernent pas suivant leur bon plaisir, mais confient le pouvoir à leurs sujets) ;

5. les princes autocrates (tel fut l'empereur Siuen, de la dynastie des premiers Han);

6. les princes destructeurs (c'est-à-dire ceux qui bataillent inconsidérément et en arrivent à perdre leur royaume et leur propre vie) ;

7. les princes temporaires (c'est-à-dire ceux qui, par leur arrogance, amènent dans un temps plus ou moins prompt une rupture entre eux et leur peuple) ;

8. les princes obstinés (c'est-à-dire ceux qui ne songent qu'à élever des remparts et à préparer des cuirasses et des armes de guerre sans pratiquer la vertu);

9. les princes des dieux de la terre triennaux (l'explication de ce terme est obscure ; ce sont, d'une manière générale, les princes qui vénèrent les dieux de la terre et des moissons ; mais on ne voit pas ce que signifient les mots : de trois années),

03. (125) Chou king: Préface.

03. (126) Le Jou Kieou et le Jou Fang sont deux chapitres perdus du Chou king.

03. (127) Pour comprendre cette anecdote, il faut se rappeler que les filets étaient employés à la chasse dans les battues; il est évident que quand on étendait des filets de manière à cerner une plaine, tout le gibier de poil qui s'y trouvait était pris. Les anciens rois se contentaient de rabattre un filet sur une seule ligne de façon que beaucoup d'animaux pouvaient échapper, soit à droite, soit à gauche ; ceux qui se laissaient prendre dans le filet étaient considérés comme l'ayant fait volontairement et on avait alors le droit de les tuer. T'ang remit en vigueur cette ancienne coutume (T'ong kien kang mou, ch. III, p. $14 \mathrm{r}^{\circ}$ ).

03. (128) Le nom de Koen-ou est mentionné par le Che pen (chap. Ti hi) qui rapporte la légende suivante :

Lou Tchong, descendant de l'empereur Tchoan-hiu, épousa une sour cadette du chef de la tribu Koei-fang (les ancêtres des Hiong-nou, cf. note 01.124). Cette femme fut enceinte trois années ; comme elle n'accouchait pas, on lui ouvrit le côté gauche et il en sortit troi s fils ; puis on lui ouvrit le côté droit et il en sortit aussi trois fils. L'un de ces enfants était Koen-ou. On trouvera plus de détails sur ce mythe dans la traduction et les notes du chapitre XL des Mémoires historiques (Tch'ou che kia, au début).

- D’après la géographie Kouo ti tche, le pays de Koen-ou correspondait à la sous-préfecture de P'ou-yang; il devait donc être au sud de l'actuel K'ai-tcheou, préfecture de Ta-ming, province de Tche-li.

03. (129) La traduction qu'on va lire de la harangue de T'ang est notablement différente de celle qu'a donnée M. Legge (Chinese Classics, t. III, p. 173 et suiv.) ; d'après M. Legge, 
T'ang aurait eu pour but, en prononçant ce discours, de couper court aux murmures de son peuple qui blâmait son expédition contre Kié. Je crois au contraire que T'ang ne fait que rappeler les griefs du peuple contre Kié, afin de montrer que le Ciel l'a chargé de punir le souverain pervers.

03. (130) Chou king: T'ang che.

03. (131) Le prince dont il est question est Kié.

03. (132) Le texte du Che ki transpose ici l'ordre des phrases tel qu'il se trouve dans le Chou king. Dans le Chou king nous lisons :

«Le souverain Hia est fort coupable et le Ciel ordonne de le mettre à mort. Maintenant, parmi vous, la multitude ; il en est qui disent : « Notre prince n'a pas pitié de nous, la multitude ; il interrompt nos travaux de la moisson et c'est avec cruauté qu’il gouverne Hia. » J'ai entendu en effet votre multitude dire : « Hia est coupable ». Or je crains l'Empereur d'en haut. .. »

03. (133) Le Che ki donne la leçon $k \bullet[]$, qui n'offre aucune difficulté de traduction. Le Chou king écrit $k \bullet$ tchéng Hià ; l'addition du mot Hia est embarrassante ; c'est sans doute le désir d'expliquer ce mot qui a engagé $\mathrm{M}$. Legge à transformer toute l'allure du chapitre et à changer les plaintes du peuple contre Kié en murmures contre T'ang lui-même. Cependant Hia peut être ici l'équivalent de [], que nous trouverons quelques lignes plus bas, et signifier « le pays ou le peuple de Hia. » En outre, tous les commentateurs admettent que le mot tchéng est ici pour le mot []. On peut alors traduire : C'est avec cruauté qu'il ( Kié, de la dynastie Hia) gouverne (le pays de) Hia.

- Kiang Cheng (H. T. K. K., ch. CCCXCIII, p. $3 \mathrm{r}^{\circ}$ ) admet l'exactitude absolue de la leçon de Se-ma Ts'ien et regarde le caractère Hia comme une interpolation.

03. (134) La plupart des commentateurs adoptent l'explication du ta tchoan de Fou Cheng et mettent cette parole dans la bouche de Kié ; c'est un blasphème par lequel il se déclare impérissable comme le soleil. Il est à remarquer cependant que Mencius (I, a, 2, trad. Legge [§ 4], p. 5 ; [trad. Couvreur] ) n'entend p as ainsi ce passage et c'est pourquoi Kiang Cheng (H. T. K. K., ch. CCCXCIII, p. $4 \mathrm{r}^{\circ}$ ) attribue cette phrase au peuple sujet de Kié : le peuple sait qu'il périra en même temps que son sou verain ; mais il déteste si fort celui-ci qu’il souhaite la mort, pourvu que le monstre disparaisse en même temps. Il faut alors traduire, comme l'a fait M. Legge :

«Quand ce soleil (c'est-à-dire Kié) expirera-t-il ? Nous voulons tous mourir avec toi. »

03. (135) Au début de son discours, Tang a dit en parlant de lui-même : Moi, petit enfant ; ici, il dit: Moi, l'homme unique. Le commentateur Ts'ai Pien explique cette différence par la raison que, dans le premier cas, T'ang se compare au Ciel dont il reçoit les ordres, tandis que, dans le second cas, il parle à son peuple dont il se distingue par la situation de chef unique.

03. (136) Le mot [] est ici l'équivalent du mot lái qui se trouve dans le texte du Chou king. Cette phrase et les deux autres qu'on lit tro is lignes plus bas forment trois vers dont les rimes sont $[\ldots]$, au chang cheng de la $5^{\mathrm{e}}$ catégorie (H.T.K.K., ch. DCLX, p. $6 \mathrm{r}^{\circ}$ ). On a vu plus haut, dans la harangue à Kan, que l'annonce des récompenses et des punitions était aussi mise sous une forme rimée (cf. note 02.316).

03. (137) Cette expression signifie : je ne dis pas des paroles inconsidérées et vides de sens.

03. (138) La harangue se termine ici au même point que dans le Chou king. Mais Kiang Cheng (H. T. K. K., ch. CCCXCIII, p. $4 \mathrm{v}^{\circ}$ et 5) ajoute à ce discours un fragment qui se trouve dans le Loen yu (trad. Legge, Chinese Classics, t. I, p. 214) et dans Me-tse (chap. $3^{\text {e }}$ partie, p. 12 $\left.\mathrm{r}^{\circ}\right)$ -

03. (139) Le titre de Roi guerrier où wâng, appliqué à T'ang, est mentionné dans le Che king ( $4^{\mathrm{e}}$ ode sacrificatoire des Chang, trad. Legge, Chinese Classics, t. IV. p. 642). 
03. (140) Cf. note 102 .

03. (141) Cf. note 332. Ming-t'iao était à peu de distance au sud-ouest de Song.

03. (142) Chou king: Préface. Ce paragraphe et le suivant se retrouvent dans la préface du Chou king, mais leur ordre de succession est renversé.

03. (143) La géographie Kouo ti tche dit: La sous-préfecture de Tsi-yn (aujourd'hui au nord-ouest de la sous-préfecture de Ts'ao, préfecture de Ts'ao-tcheou, province de Chantong), dans le Ts'ao-tcheou, est l'ancien Ting-t'ao. A l'est se trouve le re lais de San-tsong; c'est le lieu dont il est ques tion dans ce passage. — C'était là que Kié était venu se réfugier.

03. (144) Le dieu de la terre des Hia était Keou-long, fils de Kong-Kong. T'ang ne put le remplacer parce qu'il ne trouva parmi ces ancêtres personne dont les mérites pussent atteindre ceux de Keou-long; il changea du moins le dieu des moissons qui, sous les Hia, avait été Tchou, fils de Lié-chan, et qui, à partir du règne de T'ang, fut $K^{\prime} i$, l'ancêtre de la fut ure maison royale des Tcheou (cf. Ts'ien han chou, traité 5, sur les Sacrifices ; cf. notes 01.296 et $00.154)$.

— Ce passage rappelle l'anecdote de l'histoire romaine sur le dieu Terme qui ne se laissa pas supplanter.

— «Le dieu de la terre des Hia » et, au paragraphe précédent « Le Joyau perpétuel », sont les titres de deux chapitres perdus du Chou king.

03. (145) Chou king : Préface.

03. (146) ... On explique le mot [] de la manière suivante : la localité appelée Ta-t'ong reçut plus tard le nom de Ting-t'ao ; un commentateur aura écrit à côté de l'ancien nom le nom plus moderne et, par une erreur de copiste, le second mot de la glose aura passé dans le texte même.

— Ting-tao correspond à la sous-préfecture actuelle de Ts'ao dans la province de Chan-tong.

03. (147) Le nom de Tchong Lei est écrit Tchong Hoei dans le Chou king. La Proclamation de Tchong Hoei forme le second des livres de la dynastie Chang dans ce qui nous a été conservé du Chou king (trad. Legge, Chinese Classics, t, III, p. 177 et suiv. [css : édition/rechercher : 'II.'] ; [trad. Couvreur] $)$.

03. (148) La Proclamation de T'ang est le troisième des livres des Chang dans le texte du Chou king (trad. Legge, p. 191 et suiv. [css : édition/rechercher : 'III.'] ; [trad. Couvreur]). Mais, de l'avis des critiques chinois les plus autorisés, elle n'est qu'une compilation faite à l'époque des Tsin orientaux (317-420 ap. J.-C.). D'après Kiang Cheng (H. T. K. K., ch. CCCXCIII, p. 7 $\mathrm{v}^{\circ}$ et $8 \mathrm{r}^{\circ}$ ) et Wang Ming-cheng (H.T.K. K., ch. CCCCXXXIV b., p. 27 et 28), le vrai texte de la Proclamation de T'ang est celui que nous trouvons ici dans les Mémoires historiques, depuis les mots : «C'était le troisième mois... » jusqu'à « Par ces paroles, il donna.. »

- Il est à remarquer que ce chapitre est le seul du texte antique de K'ong Ngan-kouo que Sema Ts'ien reproduise ; or, comme il est entièrement différent du chapitre qui nous est donné sous le même titre dans le Chou king traditionnel, c'est une forte preuve à l'appui de la théorie qui veut que le prétendu texte antique du Chou king traditionnel ne soit point celui de Kong Ngan-kouo (cf. notre Introduction, ch. IV, § 1).

03. (149) Wang Ming-cheng (loc. cit.) fait observer que, d'après le traité sur les Sacrifices du Livre des Han postérieurs, les quatre cours d'eau sont. comme ici, le Kiang, le Tsi, le Ho et le Hoai ; mais le Kiang est appelé le fleuve du Sud et le Hoai est appelé le fleuve de l'Est, ce qui est en effet plus rationnel. D'après Wang Ming-cheng, cette différence aurait peu d'importance, car les anciens confondaient sou vent le nord avec l'ouest et le sud avec l'est.

03. (150) Le prince Tsi est celui qui fut adoré comme le dieu des moissons sous la dynastie $Y n$ (cf. notes 144 et 01.296 ).

03. (151) Les trois sages dont il est question sont $Y u, K a o-y a o$ et le prince Tsi. 
03. (152) Le mot traduit par «descendants », est le mot heóu qui, dans les textes anciens, se substitue souvent au caractère []. Cf. le Ta hio (trad. Legge, Chinese Classics, t. I, p. 220 et 222).

03. (153) D'après Se-ma Tcheng, l'Empereur dont il est ici question est le Ciel.

03. (154) Chou king : Préface.

03. (155) Tous, c'est-à-dire le prince et ses sujets.

03. (156) Sous les $Y n$, le mois initial fut le douzième mois, celui qui est marqué du caractère cyclique.

03. (157) Hoang-fou Mi dit: T'ang était au pouvoir, comme prince de Chang, depuis dix-sept années quand il prit le titre de Fils du ciel ; il fut Fils du ciel pendant treize années et mourut âgé de cent ans.

03. (158) L'édition de 1596 et le Che ki loen wen écrivent «trois années ». La leçon « deux années » est celle de l'édition de 1747 ; elle est d'accord avec un passage de Me ncius (trad. Legge, Chinese Classics, t. II, p. 236) et avec le Tchou chou ki nien. D'après la préface du Chou king (trad. Legge, Chinese Classics t. III, p. 5, § 18), ni Wai ping ni Tchong-jen n'auraient régné et le successeur immédiat de T'ang aurait été T'ai-kia; c'est cette donnée qu'a acceptée la chronologie de T'ong kien kang mou, tandis que le Tchou chou ki nien admet comme Se-ma Ts'ien, les règnes de ces deux princes (cf. notre Introduction, chap. IV, § 2).

03. (159) Le mot [] désigne les enfants de l'épouse principale, par op position aux enfants des femmes de second rang et des concubines ; faute d'une autre expression, je traduis ce mot par « légitime », ce qui ne veut pas dire que les autres enfants étaient des bâtards, mais que ceux de l'épouse étaient seuls les héritiers légitimes du souverain.

03. (160) Chou king : Préface.

03. (161) De ces trois dissertations qui faisaient autrefois partie du Chou king, les deux dernières ont disparu. Quant à la première, le texte qui nous en est presenté par le Chou king traditionnel passe pour inauthentique. Kiang Cheng a essayé de reconstituer le texte véritable (H. T. K. K., ch. CCCXCIII, p. 9 et suiv.).

— Dans le titre d'une de ces dissertations, « le prince décédé » dont il est question est T'ang.

03. (162) D'après le T'ong kien kang niou et le T'ong kien tsi lan, T'ai-kia fut relégué dès la première année dans le palais de T'ong ; il faudrait donc peut-être traduire : «Pendant les trois premières années que T'ai-kia fut au pouvoir..., pendant trois ans, I Yn exerça la régence. » Mais cette traduction ne me paraît pas suivre d'assez près le texte.

03. (163) D'aprè s le T'ong hien tsi lan, le palais de Tong se trouvait près de la tombe de T'ang, dans la sous-préfecture actuelle de Yong-ho, préfecture de P'ou-tcheou, province de Chàn-si.

03. (164) Les «Instructions de T'ai-kia» ont simplement pour titre, dans le Chou king traditionnel, le T'ai-kia. C'est un des chapitres du pseudo Kong Ngan-kouo.

03. (165) T'ai-tsong est le premier des noms de temple [] que nous rencontrons dans l'histoire de Chine.

03. (166) MM. Legge et Mayers appellent tous deux ce souverain Yuh (=Yeou)-ting; mais le Dictionnaire de K'ang - $h i$ range le mot Ou-ting parmi les cas où le caractère [] se prononce $\mathrm{Ou}$.

03. (167) Chou king : Préface.

03. (168) Le caractère [a], qui se prononce aujourd'hui ou, se lisait autrefois meou. En 907 après J.-C., on interdit l'usage de ce caractère qui faisait partie du nom d'un souvera in et on le remplaça provisoirement par le caractère [b] ou. C'est cette dernière prononciation qui subsista, même après qu'on eût recommencé à employer le caractère [a]. 
03. (169) K'ong Ngan-kouo dit que I Tche était le fils de ce I Yn dont il a été souvent parlé plus haut.

03. (170) Le texte de Se-ma Ts'ien et celui de la préface au Chou king donnent les deux mots [a] [b] qui signifieraient: un mûrier et une céréale; mais cette interprétation n'est pas admissible, car on ne voit pas une céréale devenant si grosse qu'on ne peut l'embrasser avec les deux mains, et, d'autre part, quelques lignes plus bas, Se-ma Ts'ien dit que, lorsque T'aimeou eut corrigé sa conduite, les mûriers périrent, mais il ne parle plus d'une céréale. L'explication de cette difficulté nous est fournie par le traité sur les Cérémonies fong et chan (chap. XXVIII des Mémoires historiques) où ce passage est aussi cité ; en effet, le mot [b] y est écrit avec un trait de moins, et ce caractère, dit Yen Che-kou, désigne un tch'ou chou, sorte de mûrier.

03. (171) Chou king: Préface.

03. (172) Certains commentateurs veulent que le mot ou qui signifie devin soit un nom de famille. Il faudrait dire alors «Ou Hien » et non le devin «Hien». Ce devin Hien eut un fils qui s'appela Hien; d'après Tch'ang Cheou-kié, leur deux tombes se trouvaient dans la sous-préfecture de Tchang-chou, préfecture de Sou-tcheou, province de Kiang-sou; c'est en effet de cette localité qu'ils étaient originaires.

03. (173) Le chapitre T'ai meou n'est pas mentionné dans la préface du Chou king. Il y est remplacé par le chapitre I Tche, peut-être par erreur (H. T. K. K., ch. CCCLXIII, p. 14 r $\left.^{\circ}\right)$.

03. (174) Les commentateurs sont muets au sujet de ce passage : T'ai-meou paraît avoir voulu imiter Yao et Choen qui se désistèrent du pouvoir pour le remettre à celui qu'ils jugeaient le plus sage ; mais I Tche refusa l'honneur qu'on voulait lui faire.

03. (175) D’après Ma Yong, Yuen est le nom d'un personnage.

03. (176) Le T'ong kien kang mou et le T'ong kien tsi lan écrivent Hiao au lieu de Ngao. La capitale de Tchong-ting était au nord-ouest de la sous-préfecture de Yong-tsé, préfecture de K'ai-fong, province de Ho-nan.

03. (177) Chou king : Préface.

03. (178) En parlant ici de Ho-tan-kia et de Tsou-i, Se-ma Ts'ien anticipe un peu sur ce qui suit, afin d'énumérer en même temps les change ments de résidence.

- Siang devait être au sud de la sous-préfecture de Nei-hoang, préfecture de Tchang-té, province de Ho-nan.

- Keng était dans la sous-préfecture de Ho-tsin, préfecture de P'ou-tcheou, province de Ch॰n-si. D'après le T'ong kien tsi lan, il faudrait faire une distinction entre [] qui fut d'abord la capitale de Tsou- $i$ et qui répondrait à la localité que nous venons d'indiquer et [] où Tsou -i transféra ensuite sa résidence et qui serait aujourd'hui la so us-préfecture de Hing-T'ai, préfecture de Choen-té, province de Tche-li; mais cette distinction paraît n'être qu'un raffinement de subtilité.

03. (179) Le livre sur Tchong-ting est mentionné dans la préface du Chou king (trad. Legge, p. $6, \S 24)$; on voit que $S e-m a T s ' i e n$ déclare expressément que, dès son époque, il avait disparu.

03. (180) Le devin Hien est le fils du devin dont il a été parlé plus haut (cf. note 172).

03. (181) C'est-à-dire fils de Ou-hia, frère cadet de Tsou-sin.

03. (182) Cf. note 159.

03. (183) Plus exactement, pendant neuf règnes, à savoir ceux de Tchong-ting, Wai-jen, Ho-tan-kia, Tsou-i, Tsou-sin, Ou-hia, Tsou-ting, Nan-keng et Yang-kia.

03. (184) On a vu plus haut que Tsou-i avait transféré sa capitale à Keng, au nord du Hoang-ho (cf. note 178). 
- P'an-keng passa de nouveau au sud du fleuve et établit sa résidence dans le Po occidental (cf. note 117) qu'il appela $Y n$. C'est à partir de ce moment que la dynastie changea de nom et s'appela $Y n$ au lieu de Chang (cf. note 101).

03. (185) Les cinq transferts de capitale ont été expliqués de diverses manières. Nous nous bornerons à donner ici l'opinion de Tchang Cheou-kié :

1. T'ang se transporta du Po méridional au Po occidental (cf. note 117);

2. Tchong-ting émigra à Ngao (cf. note 177) ;

3. Ho-tan kia se fixa à Siang ;

4. Tsou-i se fixa à Keng (cf. note 178);

5. Le cinquième transfert fut celui qu'opéra P'an-keng en retournant à Po, au sud du fleuve.

03. (186) Ce discours ne fait point partie du chapitre intitulé P'an keng dans le Chou king. Comme on le verra quelques lignes plus loin, le P'an keng, d'après Se-ma Ts'ien, n'aurait été composé qu'après la nort du souverain de ce nom.

03. (187) Le texte des Mémoires historiques est très concis, mais il est éclairci par celui du Tong kien tsi lan, ch. II, p. $23 \mathrm{r}^{\circ}$.

03. (188) La présence de ce sage en si mauvaise compagnie est expliquée par le désir qu’il avait de se cacher loin du monde.

- La localité de Fou devait se trouver dans la sous-préfecture de P'ing-lou, préfecture secondaire de Kié, province de $C h \bullet n$-si.

03. (189) Chou king : Préface.

03. (190) On ne connait ce personnage que par ce texte.

03. (191) Chou king : Kao-tsong yong je.

03. (192) C'est-à-dire que, avertis par le Ciel, les hommes cherchent alors à se corriger.

03. (193) Le roi est le représentant du Ciel sur la terre, car c'est le Ciel qui est le.principe de tout ordre.

03. (194) Dans ce discours, Tsou-ki interprète l'apparition du faisan comme un avertissement donné au roi qui commettait la faute de trop multiplier certains sacrifices au détriment de certains autres. Le texte du Chou king est ici plus clair que celui de Se-ma Tsien, car il spécifie de quelle exagération il s'agit ; Ou-ting se montrait trop zélé pour les sacrifices à son père défunt, au détriment de ses autres ancêtres qui avaient cependant droit aux mêmes honneurs, puisque tous étaient également les continuateurs du Ciel.

03. (195) Le nom de temple Kao-tsong attribué à Ou-ting se retrouve dans le chapitre Sang fou se tche du Li ki qui donne sur ce souverain quelques renseignements conformes à ce que nous en apprend Se-ma Ts'ien (cf. Legge, Sacred Books of the East, t. XXVIII, p. 468-469).

03. (196) Les Instructions de Kao-tsong sont un chapitre du Chou king qui est mentionné dans la Préface, mais qui est aujourd'hu i perdu. Le jour du sacrifice supplémentaire de Kao-tsong faisait au contraire partie du texte moderne de Fou Cheng et c'est pourquoi Se-ma Ts'ien a pu le reproduire. Dans ce dernier titre, le mot indique le sacrifice qui se faisait le lendemain du jour où avait eu lieu le sacrifice principal; ce mot se prononce ici yong (T'ong kien tsi lan, ch. II, p. $23 \mathrm{v}^{\circ}$ ), comme le mot dont il n'est que le substitut (H.T.K. K., ch. CCCXCIII, p.. 38 $\left.\mathrm{v}^{\circ}\right)$.

03. (197) D'après le Tong kien tsi lan, la capitale de $O u-i$ se serait trouvée dans la sous-préfecture actuelle de $K^{\prime} i$, préfecture de Wei-hoei, province de Ho-nan. 
03. (198) Cf. J. Darmesteter : La flèche de Nemrod en Perse et en Chine (Journal asiatique, fév.-mars-avril 1885, p. 220-228). D'après M. Dar mesteter, ce récit chinois aurait émigré en Perse où on le retrouve dans le cycle de Kai Ka ous (cf. L'Avesta et Firdousi). La même légende fut empruntée à la Perse par les Arabes qui lui donnèrent pour héros Nemrod ; Tabari (839-923) raconte que Nemrod se fit enlever en l'air dans une caisse tirée par des vautours ; il lança trois flèches contre le ciel qui les lui renvoya teintes de sang. Enfin le Livre du Juste, compilation d'un Juif espagnol du XIIe siècle de notre ère, dit que lorsque Nemrod bâtissait la tour de Babel, les hommes, du haut de la tour, tiraient des flèches contre le ciel; elles retombaient sanglantes et ils se disaient les uns aux autres : «Ah ! nous avons tué tout ce qui est dans le ciel. »

03. (199) C'est-à-dire dans le Chàn-si. Sur la rivière Wei, cf. p. 131, n. 1.

03. (200) Tcheng Hiuen, se fondant sur un passage de Tch'oen ts-ieou de Lu Pou-wei, dit que $K ' i$ et $\operatorname{Sin}$ avaient la même mère, mais que cette femme ne fut promue au rang d'impératrice qu'après la naissance de $K^{\prime} i$; c'est donc le fils qu'elle eut après son élévation, c'est -à-dire Sin, qui fut considéré comme l'héritier, quoiqu'il fût le cadet.

- D'après Mencius, $K^{\prime} i$ et un autre personnage nommé Pi-kan, dont il sera question plus loin, étaient les oncles de Sin et par conséquent les fils de l'empereur T'ai-ting (Mencius, VI, a. 6 ; trad. Legge, p. 277 ; [trad. Couvreur]).

03. (201) Ta-ki était une prisonnière que Tcheou avait emmenée après avoir défait le prince de Sou, dont les États étaient dans la sous-préfecture de Tsi yuen, préfecture de Hoai-k’ing, province de Ho-nan. Le nom de famille des princes de ce royaume était $K i$ c'est pourquoi il est dit dans le Коио уи que, dans le nom de Ta-ki, Ta est le surnom et $K i$ le nom de famille.,

03. (202) Si on s'en rapporte à un passage du traité de la Musique (Mémoires historiques, ch. XXIV, vers la fin), il faudrait lire : maître Yen, au lieu de : maître Kiuen. L'anecdote racontée dans ce texte du traité de la Musique est fort curieuse.

03. (203) Le Pei-li est cité dans le traité sur les Sacrifices fong et chan (p. 15 de ma première trad.) comme le lieu d'où l'on tirait une céréale employée pour ces cérémonies. Mais je n'ai pas pu déterminer où se trouvait ce pays.

03. (204) La Terrasse du Cerf était étendue de $3 l i$ et haute de 1000 pieds; d'après le T'ong hien tsi lan (ch. II, p. $27 \mathrm{r}^{\circ}$ ), on en voit encore les traces dans la sous-préfecture de $K^{\prime} i$, préfecture de Wei-hoei, province de Ho-nan.

03. (205) Le grenier de Kiu-kiao était au nord-est de la sous-préfecture de K'iu-tcheou, préfecture de Koang-p’ing, province de Tche-li.

03. (206) Cha-k'ieou était au nord-est de la sous-préfecture de P'ing-hiang préfecture de Choen-té, province de Tche-li.

03. (207) Ce supplice est décrit de la manière suivante par le T'ong kien tsi lan (ch. II, p. 27 $\mathrm{v}^{\circ}$ ) : une colonne de cuivre était enduite de graisse, puis placée horizontalement au-dessus d'un brasier ; les condamnés devaient marcher le long de cette colonne et lorsqu'ils tombaient dans le brasier, le roi et Ta-ki s'en amusaient.

03. (208) Nous retrouverons souvent dans l'histoire chinoise cette expression san kong qui désigne les trois plus hauts fonctionnaires après le souverain. Je la traduis par l'expression « ducs du palais », afin de distinguer ces personnages de ceux des seigneurs qui avaient le titre de « ducs ».

03. (209) Le Chef de l'ouest, Tch'ang, est le père de Ou-wang, fondateur de la dynastie des Tcheou, et reçut lui-même le titre posthume du Wen-wang. Dans l'expression [..], le mot si n'est pas un nom de lieu et désigne l'ouest en général ; c'est pourquoi le mot po ne peut être pris dans le sens précis de « comte ».

03. (210) La ville de Kieou se trouvait dans la sous-préfecture de Ché, préfecture de Ho-nan. Certains textes remplacent, le nom de Kieou par celui de Koei. 
03. (211) Le nom de la ville de $N g o$ est écrit parfois $Y u$; or il avait une ancienne ville de $Y u$ dans la sous-préfecture de Ho-nei, préfecture de Hoai-k'ing, province de Ho-nan (T'ong kien tsi lan, ch. II, p. $27 \mathrm{v}^{\circ}$ ).

03. (212) Le fief de Tch'ong est aujourd'hui la sous -préfecture de Ngo, préfecture de Si-ngan, province de Chàn-si. Sous les Hia, ce fief avait été celui de Hou.

03. (213) Yeou-li était à $9 l i$ au nord de la sous-préfecture de T'ang-yn, préfecture de Tchang-té, province de Ho-nan.

- C'est dans sa prison de Yeou-li que Wen-wang passe pour avoir fait ses travaux sur le $I$ king (cf. note 00.149).

- D'après une légende peu vraisemblable rapportée par le Ti wang che ki de Hoang-fou Mi (cité par Tchang Cheou-kié), Tcheou aurait fait bouillir le fils aîné de Wen-wang et le lui aurait donné à manger pendant qu'il était en prison.

03. (214) La rivière Lo dont il est ici question est la rivière Tsiu-lo, dans le Chàn-si (cf. note $02.208,1^{\mathrm{e}}$ hypothèse $\mathrm{du} \mathrm{n}^{\circ} 2$ ). Le pays à l'ouest de la rivière $L o$ correspond donc à la sous-préfecture de I-tch'oan et aux territoires avoisinants, préfecture de Yen-ngan, province de Chàn-si.

03. (215) Le mot dans le texte de Se-ma Ts'ien me paraît inexplicable. Le T'ong hien kang mou et le T'ong kien tsi lan le remplacent par le mot [] qui signifie «spécial» et est parfaitement intelligible.

- Wen-wang fut chargé par Tcheou de repousser les barbares de l'ouest.

03. (216) Cette phrase et la glose qu'en donne le T'ong kien hang mou (il fut le chef des seigneurs des régions occidentales) prouvent que le mot [] n'a pas le sens de « comte » (cf. note 209)

03. (217) Ngo-lai passe pour un des ancêtres des princes de Ts'in cf. Mém. hist., chap. V, au commencement); son frère, Ki-cheng, fut l'ancêtre des princes de Tchao (Mém. hist., chap. XLIII, p. 1).

03. (218) On a vu plus haut que, d'après Mencius, Pi-kan était le fils de l'empereur T'ai-ting et c'est pourquoi il est appelé ici le fils du roi (cf. note 200).

03. (219) Ce pays de $K i$ est appelé $K$ 'i dans le Tchou chou ki nien et dans Fou Cheng, et $L i$ dans le Chou king (chap. Si po k'an Li). C'est aujourd'hui la sous -préfecture de Li-tch'eng, préfecture de Lou-ngan, province de Ch॰n-si.

- Se-ma Ts'ien attribue l'expédition contre le pays de $L i$ à Wen-wang ; il en est de même du Tchou chou ki nien. Au contraire, la chronologie adoptée par le T'ong kien hang mou et le T'ong hien tsi lan, place cette campagne onze ans après la mort de Wen-wang et l'attribue par conséquent à son fils Ou-wang. Comme la plupart des problèmes qui résultent des divergences entre les deux grands systèmes chronologiques du Tchou chou ki nien d'une part et du T'ong hien hang mou d'autre part, la question est insoluble ; mais il est intéressant de remarquer une fois de plus l'accord de Se-ma Ts'ien avec le Tchou chou ki nien (cf. notre Introduction, chap. IV, seconde partie).

03. (220) Notre système de transcription ne pouvant faire aucune distinction entre Tcheou, nom de la dynastie qui supplanta les $Y n$, et Tcheou dernier souverain des $Y n$, nous ajoutons quelques mots entre parenthèses pour préciser de quel Tcheou il s'agit.

03. (221) Chou king : Si po k'an Li.

03. (222) Le texte des Mémoires historiques est ainsi conçu [....].

Dans le Chou king, le premier de ces quatre mots est écrit [] et il faut alors traduire, comme le fait M. Legge : les plus sages des hommes et la grande tortue n'osent rien prévoir d'heureux. 
Kiang-Cheng (H. T. K. K., ch. CCCXCIII, p. $43 \mathrm{r}^{\circ}$ ) propose d'écrire [] par analogie avec un passage du chap. K'iu li du Li ki (trad. Legge, p. 94) ; mais on ne voit plus le sens que pourrait avoir cette phrase ; dans le $L i k i$, en effet, c'est une formule d'invocation : je m'en rap porte à toi, grande tortue...; ici au contraire Tsou-i s'adresse au roi. Si nous nous en tenon s au texte de Se-ma Ts’ien, il faut traduire comme nous l'avons fait.

— La tortue dont la carapace servait au Fils du ciel était longue de 1 pied 2 pouces : c'était la plus grande de toutes.

— D’après le Loen heng de Wang Tch'ong, au moment où parlait Tsou-i, on avait consulté soixante-dix fois les sorts sans obtenir une seule réponse favorable ; c'est ce qui explique la phrase : nous n'osons rien prévoir d'heureux.

03. (223) Kiang Cheng dit que la leçon du Chou king est une erreur et que le mot donné par Se-ma Ts'ien est correct.

03. (224) En donnant à ces deux phrases le roi pour sujet, je suis l'inter prétation de Kiang Cheng (H. T. K. K., ch. CCCXCIII, p. $43 \mathrm{v}^{\circ}$ ).

03. (225) C'est-à-dire : Pourquoi quelqu'un ne reçoit-il pas du Ciel le mandat de fonder une nouvelle dynastie ?

03. (226) Cf. note 02.233 .

03. (227) Le vicomte de Wei n'est autre que Ki (cf. note 200). La ville de Wei-tse se trouve dans la sous-préfecture de Lou-té-h'eng, préfecture de Lou-ngan, province de Ch•n-si.

03. (228) Le grand précepteur et le second précepteur sont mentionnés dans le chapitre du Chou king intitulé Wei tse et la plupart des commentateurs sont d'avis que le grand précepteur est le vicomte de $K i$ et que le second précepteur est Pi-kan. Mais il est évident que $S e-m a$ $T$ s'ien ne l'entend pas ainsi puisqu'il dit qu'après que $P i$-kan eût été mis à mort et après que le vicomte de $K i$ eût simulé la folie, le grand précepteur et le second précepteur s'enfuirent ; on verra au chapitre suivant que le grand précepteur s'appelait $T s^{\prime} e$ et que 1e second précepteur s’appelait K’iang .

03. (229) La ville de $K i$ se trouve dans la sous-préfecture de $Y u$, préfecture secondaire de Leao, province de $C h \bullet n-s i$.

03. (230) La campagne de Mou s'étendait au sud de la sous -préfecture de $K$ ’, préfecture de Wei-hoei, province de Ho-nan. - Tous ces événements seront racontés plus en détail au chapitre suivant.

03. (231) Cf. note 204.

03. (232) Chou king: Ou tch'eng.

03. (233) Cf. p. ${ }^{\bullet} 203$.

03. (234) Le T'ong kien tsi lan (ch. III, p. $1 \mathrm{v}^{\circ}$ ) dit que Ou-keng est le nom personnel de ce personnage, mais il ne nous renseigne pas sur le rôle que jouent les deux caractères Lou-fou. Quoi qu'il en soit, le fils de Tcheou est appelé indifféremment par les historiens Ou-keng et Lou-fou, ou, comme ici, Ou-keng Lou-fou.

03. (235) Cf. p. • $193-194$.

03. (236) Koan-chou et Ts'ai-chou étaient les frères cadets du roi Ou. Voyez sur ces événements le chapitre suivant et le chapitre XXXV des Mémoires historiques.

03. (237) Song est aujourd'hui la sous-préfecture de Chang-k’ieou, préfecture de Koei-té, province de Ho-nan.

03. (238) Cf. notes 103,104 et 109. 
03. (239) A l'exception des princes de Song (cf. note 237), toutes les autres familles qui sont ici énumérées paraissent avoir été peu importantes et ne sont pas mentionnées dans le Tch'oen ts’ieou.

03. (240) Se-ma Ts’ien réunit ici deux textes classiques différents. Dans le Loen yu, on lit: Montez le char des $Y n$; — dans le Li ki: Au temps des $Y n$, on mit en honneur le blanc.

\section{CHAPITRE IV. LES TCHEOU}

04. (101) Sur l'appellation de heou tsi — prince Millet, donnée à $K$ 'i, cf. note 01.296 — Le texte des Mémoires historiques est connu : Tcheou Heou tsi; mais il est à remarquer que $K^{\prime} i$ n'eut pas de son vivant le nom de Tcheou et qu'il ne peut être considéré que comme l'ancêtre de la famille de ce nom. C'est seulement Tan-fou, qui fut le grand-père de Wen-wang et qui est plus connu sous le nom de T'ai-wang, qui fixa sa résidence à Tcheou-yuen (dans la sous-préfecture de $K^{\prime} i$-chan, préfecture de Fong-siang, province de Chàn-si) et donna par suite à son royaume le nom de Tcheou.

04. (102) T'ai correspond à la sous-préfecture de Ou-kong, préfecture secondaire de K'ien, province de Chàn-si. Les princes de ce petit État avaient pour nom de clan Kiang et c'est pourquoi certains commentateurs disent que, dans le nom de Kiang yuen, Kiang est le nom de clan et Yuen le surnom. D'autres auteurs sont d'avis que Kiang yuen est un titre posthume.

- Sur les quatre femmes de l'empereur K'ou, cf. note 01.162.

04. (103) Le caractère $K^{\prime} i$ signifie « abandonner ».

04. (104) Chou king : Choen tien.

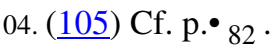

04. (106). note 102 .

04. (107) Le nom de clan Ki est celui qu'avait eu Hoang-ti (cf. note 01.105).

04. (108) T'ao-t'ang n'est autre que Yao (cf. note 01.166); Yu n'est autre que Choen (cf. note 01.206). Quant à Hia, ce nom, qui est celui de toute une dynastie, ne désigne ici que le premier des souverains Hia, Yu le Grand.

04. (109) D'après le commentateur Ts'iao Tcheou, le titre de Heou-tsi aurait été donné à plusieurs représentants successifs de la famille Tcheou et Pou-tchou ne serait pas le propre fils de $K i$, mais son descendant éloigné. En effet, si l'on admet avec Se-ma Ts'ien que Heou-tsi est un personnage unique qui fut le père de Pou-tchou, on trouve que, depuis Heou-tsi jusqu'à Wen-wang exclusivement, il n'y a que quatorze générations ; d'autre part cependant, depuis Yao et Choen jusqu'à Wen-wang, il s'est écoulé, d'après la chronologie du T'ong kien kang mou, environ 1,200 années et, d'après celle du Tchou chou ki nien, environ 1,000 années ; par conséquent, chacun des quatorze représentants de la famille Tcheou n'aurait pu en moyenne avoir son fils aîné qu'à l'âge de quatre -vingt-cinq ou de soixante-dix ans. C'est pourquoi Ts'iao Tcheou suppose qu'il y eut plusieurs personnes qui portèrent successivement le titre de Heou-tsi.

- En réalité, la difficulté que nous signalons ici prouve simplement le désaccord qui existe entre les listes généalogiques par lesquelles on a prétendu reconstituer l'histoire de ces temps éloignés.

04. (110) D'après Wei Tchao, l'empereur était alors T'ai-k'ang . Cf. p. • 166 •

04. (111) Se-ma Tcheng considère Pou-tchou comme le sujet de cette phrase ; Pou-tchou aurait abandonné la surveillance du millet et ne s'en serait plus occupé. Il me semble plus logique de prendre, comme le fait Wei Tchao, le roi pour sujet. 
04. (112). Le Kouo ti tche dit: L'ancienne ville de Pou-tchou est à 3 li au sud de la sous-préfecture de Hong-hoa, dans l'arrondissement de K'ing.

- La géographie administrative de l'époque yuen-ho (806-820 ap. J.-C.) dit aussi : La tombe de Pou-tchou est à 2 li à l'est de la sous-préfecture de Choen-hoa) (qui est identique à la sous-préfecture de Hong-hoa; le nom fut changé en l'an 756), dans l'arrondissement de K’ing .

- La sous-préfecture de Choen-hoa ou de Hong-hoa se trouvait sur le territoire de la préfecture actuelle de K'ing-yang W, province de Kan-sou.

- Cependant ces indications sont contestées par plusieurs critiques; en effet, d'après les commentateurs de l'ode sur le duc Lieou (cf. note 114), petit-fils de Pou-tchou, ce serait ce duc qui le premier aurait émigré à Pin (aujourd'hui préfecture secondaire de Pin, province de Chàn-si). Pou-tchou aurait eu, comme ses prédécesseurs, sa résidence à T'ai (au sud de l'actuelle sous -préfecture de $O u$-kong, préfecture secondaire de K'ien, province de Chàn-si).

04. (113) Les rivières $T s ' i$ et $T$ siu sont des affluents du cours supérieur de la rivière Wei, dans la partie occidentale du Chàn-si; il ne faut pas les confondre avec les rivières du même nom qui sont mentionnées dans le Tribut de $Y u$ (cf. note 02.208).

04. (114) Une des odes du Che king est en l'honneur du duc Lieou (ode 6 de la décade Cheng min ; trad. Legge, Chinese Classics, t.IV, p. 483-489 ; [trad. Couvreur]).

04. (115) La localité de Pin correspond à la préfecture secondaire de Pin, province de Chàn-si.

04. (116) Ce nom est difficile à analyser. Le San tai che piao (chap. XIII du Che ki) écrit simplement Chou-lei; le Che pen dit: le duc illustre Tsou-kan-tchou-tcheou, et considère Chou-lei comme son appellation.

- Toute cette généalogie est peu claire (cf. T'ong kien kang mou, chap. IV, p. 14 r $^{\circ}, 26^{\mathrm{e}}$ année de l'empereur Yang-kia).

04. (117) Cf. note 01.124 .

04. (118) Ce discours de Tan-fou est rapporté sous une forme assez différente par Mencius (I, b, 15 ; trad. Legge, p. 52 ; [trad. Couvreur]). Dans ce texte, Mencius désigne Tan-fou par son titre posthume de T'ai-wang.

- Sur l'Ancien duc Tan-fou, voyez encore :

* Mencius, I, b, 3, trad. Legge, p. 31; [trad. Couvreur] — I, b, 5, trad. Legge, p. 39 ; [trad. Couvreur] — I, b, 14, trad. Legge, p. 50 ; [trad. Couvreur]

* et surtout Che king, $3^{\mathrm{e}}$ ode de la décade du roi Wen, trad. Legge [css : édition/rechercher : 'ode 3.'] , p. 437. ; [trad. Couvreur]

04. (119) Cf. note 115 .

04. (120) Cf. note 113 .

04. (121) La montagne Leang est à peu de distance au nord-ouest de la préfecture secondaire de K’ien, province de Chàn-si. Elle est au sud de la préfecture secondaire de Pin (cf. note 112 ) et au nord-est de la sous-préfecture de $K^{\prime} i$-chan; elle était donc sur la route de Tan-fou quand il quitta $P$ in pour émigrer vers le sud et aller s'établir au pied de la montagne $K \dot{i}$. La ville fondée par Tan-fou s'appela Tcheou ou Tcheou-yuen et c'est de -là que vint plus tard le nom de la dynastie.

04. (122) Ce texte montre nettement l'époque où s'opéra, pour les Tcheou, le passage de l'état nomade à l'état sédentaire.

04. (123) P'ei Yn cite ici un texte du Li ki d'après lequel les cinq fonctionnaires sont le se t'ou, le se ma, le se kong, le se t'ou et le se k'eou. 
04. (124) Dans les noms de T'ai-Kiang et de T'ai-jen, Kiang et Jen sont des noms de clan. Ces deux femmes sont mentionnées dans le Lié niu tchoan ou Biographies des femmes remarquables.

04. (125) Tch'ang est le nom personnel de celui qui devait être plus tard le Chef de l'ouest et recevoir le titre posthume de Wen wang. Sa mère était T'ai-jen, ce qui n'est pas nettement indiqué dans le texte de Se-ma Ts’ien.

04. (126) D'après le Chang chou ti ming yen (qui est sans doute un wei du Chou king, cf. note 00.165), le miracle fut le suivant : un moineau rouge qui tenait dans son bec un écrit vermillon s'arrêta dans la mai son de Tch'ang ; sur ce livre on lisait quelques préceptes de morale.

04. (127) D'après Tchang Cheou-kié, T'ai po se retira dans le lieu où s'éleva plus tard la capitale du royaume de $\mathrm{Ou}$; c'est le village de $\mathrm{Mei}$-li, à $50 \mathrm{li}$ au nord-ouest de Sou-tcheou, à la limite du territoire de la sous-préfecture de $O u$-si, préfecture de Tch'ang-tcheou, province de Kiang-sou.

- Cependant cette localité ne se trouve pas dans la province de King, mais dans celle de Yang, si l'on se reporte à la division de l'empire qui existait au temps de Yu; Tchang Cheoukié lève cette difficulté en disant que les royaumes de $O u$ et de Yue furent détruits par celui de Tch'ou ; or le caractère tch'ou était interdit au temps des $T$ s'in et on le remplaçait par le caractère king; comme le Kiang-sou avait fini par tomber sous la dépendance du pays de Tch'ou, on pouvait donc dire qu'il était dans le pays de King $=$ Tch'ou .

04. (128) Les auteurs chinois répètent à satiété que les barbares qui vivent au bord de l'eau se tatouent le corps et se coupent les cheveux afin de ressembler à des enfants de dragons et d'éviter ainsi tout mal quand ils sont dans l'eau.

04. (129) Les commentateurs ne disent rien sur les noms de Po-i et de Chou-ts'i ; il me semble que leurs noms étaient simplement $I$ et $T s^{\prime} i$; en effet $p o$, chou, ainsi que les mots tchong et $k i$, étaient de simples désignations appliquées aux hauts fonctionnaires et indiquant leur rang; c'est avec ce sens que les mots Po et chou sont employés dans le Che king, $14^{\mathrm{e}}$ ode du pays de Tch'eng, trad. Legge, p. 141 ; [trad. Couvreur] (cf. H. T. K. K., chap. XIX, p. $9 \mathrm{v}^{\circ}$ ). - Se-ma Ts 'ien a consacré à $P o-i$ et à Chou-ts'i la première de ses monographies (Mém. hist., chap. LXI).

— Le pays de Kou-tchou correspond à la préfecture de Yong-p’ing, province de Tche-li.

04. (130) Yu-tse avait pour nom personnel Hiong (T’ong k’ien tsi lan, ch. II, p. 26 r $^{\circ}$ ). Sin-kia était un ministre de l'empereu r Tcheou qui abandonna son maître après avoir vu que soixante-quinze réprimandes étaient restées sans effet.

04. (131) Cf. note 03.212 .

04. (132) Cf. note 03.213 .

04. (133) L'ancien royaume de Sin avait son centre au lieu où se trouve encore aujourd'hui le village de $\mathrm{Sin}$, sous-préfecture de Ho-yang, préfecture de T'ong-tcheou, province de Chàn-si. - Ce pays de Sin ne doit pas être confondu avec l'État du même nom qui a été mentionné dans les Annales des Yn (cf. note 03.121).

04. (134) Le Kouo ti tché dit :

«L'ancienne ville du royaume de Li-jong est à 16 li au sud-est de la sous-préfecture de Sin-fong, arrondissement de Yong.

La sous-préfecture de Sin-fong était au nord-est de la sous-préfecture actuelle de Lin-t'ong, préfecture de Si-ngan, province de Chàn-si.

04. (135) Cf. note 01.352 .

04. (136) Ce présent de valeur singulière était la femme du pays de Sin.

04. (137) Cf. note 03.212 . 
04. (138) Cf. note 03.214 .

04. (139) $Y u$ est identifié avec la ville de ce nom dans la sous-préfecture de P’ing-lou, préfecture secondaire de Kié, pro

vince de Chàn-si.

- Joei correspond à la sous-préfecture de Joei-tch'eng, préfecture secondaire de Kié, province de $C h \bullet n-s i$.

- D'après le T'ong kien tsi lan, le terrain en contestation devint une zone neutre ; ce terrain est celui de la ville de Kien-yuen qu'on appelle vulgairement la ville de la limite concédée, et qui se trouve dans la sous-préfecture de P’ing-lou.

04. (140) Le nom de K'iuen Jong signifie « les Jong-chiens ».

- Tchang Cheou kié rappelle l'origine de cette peuplade, d'après le Chan hai king (chap. Ta hoang pei king), dans les termes suivants :

Hoang-ti engendra Miao-long ; celui-ci engendra Yong-ou ; celui-ci engendra Ping-ming ; Ping-ming engendra les Chiens blancs qui étaient deux, un mâle et une femelle ; ce furent les K'iuen Jong .

- D'après l'histoire des Han postérieurs, les K'iuen Jong étaient descendants d'un certain P'an-hou. Ils occupaient la plus grande partie des commanderies de Tch'ang-cha et de Ou-ling, c'est-à-dire la province actuelle de Hou-nan.

04. (141) Ce pays est identifié avec l'ancienne ville de Yn-mi, dans la sous-préfecture de Ling-t'ai, préfecture de P'ing-Leang, province de Kan-sou.

04. (142) Ce pays de $K$ ’i est le même que Se-ma Ts'ien a appelé $K i$ dans le chapitre précédent, et qui apparaît dans le Chou king sous le nom de $L i$; cf. note 219.

04. (143) On a vu précédemment cette anecdote racontée avec plus de détails ; cf. p. • 204-205 •

04. (144) D'après Siu Koang, Yu correspond à la sous-préfecture de Yé-wang : c'est aujourd'hui la sous -préfecture de Ho-nei, préfecture de Hoai-k’ing, province de Ho-nan.

04. (145) Sur Hou, marquis de Tch'ong, cf. note 03.212.

- Fong était située à l'ouest de la rivière de ce nom, dans la sous-préfecture de Hou, préfecture Si-ngan, province de Chàn-si.

04. (146) Le mot [], d'après Tchang Cheou-kié, donne ici à la phrase un sens dubitatif.

- Linvention des huit trigrammes qui sont le principe du I king ou Livre des Changements est attribuée à Fou-hi (cf. p. • ${ }_{6}$ et note 00.149) .

04. (147) A la suite de l'heureuse issue du débat entre les pays de Yu et de Joei, plus de quarante seigneurs proclamèrent roi le Chef de l'ouest.

- Tchang Cheou-kié cite un passage du grand commentaire du $\mathrm{Li}$ ki, d'après lequel le roi $\mathrm{Ou}$ aurait été le premier à conférer à ses ancêtres jusqu'à la troisième génération le titre de roi, décernant le titre de t'ai wang à l'ancien duc, Tan-fou, le titre de wang au duc Ki et le titre de wen wang à Tch'ang. D'après ce texte, le Chef de l'ouest n'au rait donc pas pris de son vivant le titre de roi. Cependant le dire de Se-ma Ts'ien est d'accord avec d'autres textes cités aussi par Tchang Cheou-kié.

04. (148) L'édition de 1596 et le Che ki loen wen donnent tous deux la leçon « dix ans ». L'édition de K'ien-long donne la leçon «sept ans ». Les deux chiffres semblent d'ailleurs inexacts; Tchang Cheou-kié dit qu'il faut écrire «neuf ans »; en effet, Mao Tch'ang, le célèbre éditeur du Che king, dit que le roi Wen vécut quatre-vingt-dix-sept ans et ne porta le titre de roi que pendant les neuf dernières années ; Hoang-fou Mi, dans son Ti wang che ki, dit aussi que le Chef de l'ouest prit le titre de roi la quarante-deuxième année de son règne, et, comme il régna en tout cinquante ans, c'est donc bien pendant neuf ans qu'il fut appelé « roi ». 
04. (149) Nous voyons apparaître ici pour la première fois, d'une manière sûre, l'institution des titres posthumes. Il convient de distinguer soigneusement les titres posthumes des noms de temple (cf. note 03.165) ; la confusion a été souvent faite par les auteurs européens entre ces deux séries d'appellations ; c'est ainsi que Mayers, dans les tables placées à la fin de son Chinese Reader's Manual, mentionne comme noms de temple une foule de titres posthumes ; pour prendre un exemple, l'empereur sous le règne duquel vécut Se-ma Ts'ien eut pour titre posthume Hiao-ou, mais son nom de temple fut Che-tsong.

04. (150) T'ai wang.

04. (151) C'est le mot que nous traduisons par « devoir», afin de donner à la phrase une tournure d'affirmation moins absolue (cf. note 146).

- C'est lorsque Tan-fou quitta Pin pour venir au pied de la montagne $K^{\prime} i$ et que son peuple le suivit que se manifesta pour la première fois la destinée royale de la famille (cf. p. ${ }_{214}$ ).

04. (152) T'ai-kong-wang est le surnom de Lu Chang qui avait été conseiller du roi Wen. Quand le roi Wen rencontra cet homme dans des circonstances assez singulières (cf. Mém. hist., chap. XXXII), il lui dit que son père, l’illustre duc, avait prévu et espéré sa venue ; c'est pourquoi le surnom de $L u$ Chang fut T'ai-kong-wang, ce qui signifie : L'illustre duc l'a espéré. $L u$ Chang passe pour l'ancêtre des princes de $T s$ 'i.

- La charge que lui conféra le roi $O u$ fut celle de che chang fou, c'est-à-dire grand précepteur.

04. (153) Tan, duc de Tcheou, était le frère cadet du roi Ou. Cf. Mém. hist., chap. XXXIII.

04. (154) Sur Che, duc de Chao, cf. Mém. hist., chap. XXXIV.

04. (155) Kao, duc de Pi, passe pour l'ancêtre des princes de Wei. Cf. Mém. hist., chap. XLIV. $P i$ est aujourd'hui la sous -préfecture de Hien-yang, préfecture de Si-ngan, province de Chànsi.

04. (156) C'est à partir des mots « La neuvième année... » que commence la grande harangue aux yeux des critiques qui estiment que le texte authentique de ce chapitre du Chou king se trouve en partie dans les lignes qui vont suivre et non dans le Chou king traditionnel (cf. notre Introduction, chap. III, partie 1 ; — voyez aussi le fragment de la grande harangue cité par Se-ma Ts'ien au chap. XXXII des Mém. hist., - et les essais de reconstitution de la grande harangue par Kiang Cheng, H. T. K. K., ch. CCCXCIV, p 1 et suiv., et Wang Koang lou, H. T. $K . K .$, ch. CCCCXIV, p. 1 et suiv.).

- Qu'est-ce que la neuvième année dont il est ici question ? Si l'on fait abstraction de tous les autres textes, il faut évidemment entendre que c'est la neu vième année du règne du roi $O u$; c'est bien là le sens que Se-ma Ts'ien devait avoir en vue. Cependant la question a été fort compliquée par les commentateurs qui ont rapproché du texte de Se-ma Ts'ien celui de la préface du Chou king (d'après lequel la grande harangue aurait été prononcée la onzième année) et celui de la grande harangue elle-même dans le Chou king traditionnel (texte d'après lequel il faudrait rapporter ces événements à la treizième année). La onzième et la treizième année sont comptées par les commentateurs à partir du moment où le roi Wen reçut le mandat céleste, c'est à-dire neuf ans avant la mort de ce souverain. Cette question est une des plus difficiles de la chronologie chinoise et je ne crois pas qu'on ait les moyens de la résoudre d'une manière satisfaisante.

04. (157) D'après P'ei $Y n, P i$ serait le nom du lieu où fut enterré le roi Wen (cf. Mencius, IV, b,1 ; trad. Legge; [trad. Couvreur]). — Mais Se-ma Tcheng appelle l'attention sur le mot [] = en haut, qui se trouve dans la phrase et en conclut que $P i$ est ici le nom d'une constellation. C'est à la constellation $\mathrm{Pi}$ et non à la tombe de son père que le roi $\mathrm{Ou}$ offre un sacrifice.

04. (158) Cf. note 02.233 .

04. (159) Cf. note 02.315 . 
04. (160) Fa était son nom personnel. En se désignant ainsi, le roi donnait à entendre qu'il considérait son père comme encore vivant.

04. (161) Le se ma ou généralissime, le se t'ou ou ministre de l'Instruction et de l'Intérieur et le se k'ong ou ministre des Travaux publics, étaient, si l'on s'en rapporte au Ta tchoan de Fou Cheng, les trois grands officiers appelés san hong. Wang Koang-lou rejette cependant cette explication et dit que ces trois fonctionnaires étaient les seuls des six hauts dignitaires qui eussent des devoirs à remplir en temps de guerre ; c'est pourquoi ils sont spécifiés à l'ex clusion des trois autres. Cette opinion est plus conforme à ce que nous savons de l'organisation administrative des Tcheou: au temps des Tcheou, les san kong étaient le t'ai che, ou grand précepteur, le t'ai fou ou grand maître et le t'ai pao ou grand gouverneur. C'est à la fin de la dynastie des premiers Han que le se ma, le se t'ou et le se k'ong furent considérés comme les san kong; sous les Tcheou, ils étaient au nombre des six hauts dignitaires (leou k'ing) qui comprenaient en outre le tchong tsai, le tsong po et le se k'eou (cf. Couvreur, Dict. chinois-fiançais, p. 382 et 450).

04. (162) Je suis ici la ponctuation du Che ki loen wen; le texte donné par Kiang Cheng et Wang Koang-lou, d'après le Ta tchoan de Fou Cheng, nécessite une ponctuation différente.

04. (163) Le Che ki loen wen donne la leçon $l i=$ force ; l'édition de K’ien long donne la leçon $l i=$ être au pouvoir ; ce dernier texte ne me paraît pas correct ; si on l'admet cependant, il faudra traduire : «tant que je serai au pouvoir, je récompenserai ... »

04. (164) Le grand précepteur ou che chang fou n'est autre que Lu Chang (cf. note 152). On pourrait aussi traduire : le précepteur qui était le vénérable Chang ; mais Lieou Hiang, dans son ouvrage intitulé Pié lou, dit [...] : on le prend pour précepteur; on le vénère ; on le prend pour père ; c'est pourquoi il s'appelle che chang fou. Dans son commentaire à l'ode ta ming du Che king, Mao Tch'an, donne une explication analogue. Dans l'expression che chang fou, chang n'est donc pas le nom de Lu Chang, mais les trois mots réunis désignent une fonction.

- Il est à remarquer cependant qu'on trouve plus loin dans Se-ma Ts’ien l'expression qui ne peut plus être le nom d'une fonction et doit signifier : le vénérable Chang.

- Les deux interprétations qu'on donne de l'expression che chang fou sont donc également plausibles.

04. (165) Cette allocution commence dans le XXXIIe chapitre des Mémoires historiques par les deux mots, répétés: ils signifient «rhinocéros vert». D’après le loen heng de Wang Tch'ong, un monstre à neuf têtes se serait en effet montré au milieu des eaux et c'est son apparition que le che chang fou signalerait à ses hommes pour les engager à passer la rivière au plus vite, de crainte d'être mis à mal par cet être terrible. Se-ma Tcheng donne une explication beaucoup plus raisonnable en disant qu'on appelait rhinocéros verts les officiers préposés aux bateaux; le che chang fou les interpelle pour leur donner l'ordre de se hâter.

04. (166) Les commentateurs se sont ingéniés pour trouver des interprétations subtiles de ce prodige ; la seule qui paraisse avoir quelque valeur est celle-ci ; le blanc était la couleur mise en honneur par les $Y n$; le poisson blanc qui saute dans la barque du roi et y reste sans défense est donc, le présage que les $Y n$ tomberont au pouvoir des Tcheou.

04. (167) Le corbeau est l'emblème de la piété filiale et le rouge est la couleur mise en honneur par les Tcheou; l'apparition du corbeau rouge était donc la gage que le roi $\mathrm{Ou}$ serait capable de mener à bien l'ouvre entreprise par son père, le roi Wen; en outre, la voix de cet oiseau était douce, ce qui donnait à entendre que l'empire jouirait du calme sous le règne du futur souverain.

04. (168) Cette indication est en complet désaccord avec le Chou king traditionnel d'après lequel la revue passée au gré de Mong et la harangue faite par le roi $\mathrm{Ou}$ au moment d'attaquer Tcheou seraient des événements consécutifs qui auraient eu lieu dans le cours d'une seule et même année. 
04. (169) Le jour ou ou est aussi celui qui est indiqué dans le Chou king traditionnel, mais ces événements y sont rapportés à la treizième année et non à la onzième, comme cela résulterait de Se-ma Tsien.

04. (170) Le caractère [] est ici l'équivalent du caractère [] = s'appli quer avec ardeur. C'est cette dernière leçon que donne Wang Koang-lou. Pour cet emploi du mot tse, cf. Mencius, VII, a, 25 ; trad. Legge, p. 340.

04. (171) Kiang Cheng (H.T.K. K., ch. CCCXCIV, p. $7 \mathrm{v}^{\circ}$ ) remarque que Se-ma Ts'ien donne expressément ce qui suit comme étant la grande harangue et qu'en outre $P$ 'ei $Y n$ explique ce texte au moyen des commentaires de Ma Yong (79-166 ap. J.-C.) et de Tcheng Hiuen (127200 ap. J.-C.), ce qui prouve que, sous les Han, c'était bien là ce qu'on regardait comme la grande harangue; quoique le Chou king traditionnel présente en son lieu et place une rédaction entièrement différente.

04. (172) La trop fameuse Ta-ki (cf. note 03.201).

04. (173) Les trois principes sont le ciel, la terre et l'homme. Voyez la même expression dans la harangue à Kan, note 02.313 .

04. (174) Mot à mot: les pères du roi et les frères cadets nés de la même mère. Cette expression désigne d'une manière générale les parents consanguins et utérins de Tcheou.

04. (175) D'après Tcheng K'ang-tch'eng, la revue des troupes au gué de Mong avait été une première tentative ; celle que le roi $\mathrm{Ou}$ allait faire était donc la seconde; si elle échouait, une troisième attaque serait impossible. Le sens de la phrase serait donc : c'est une entreprise qu'on ne peut tenter deux fois, - et le roi, se reprenant, ajoute : ou plutôt trois fois, si l'on considère que c'est déjà le second essai que nous faisons.

04. (176) D'après Siu Koang, le second mois dont il est ici question est le mois marqué du signe tch'eou ; c'est le douzième mois dans la supputation qui a cours aujourd'hui. Dans le calendrier des Tcheou, c'était le deuxième mois ; dans le calendrier des Yn, c'était le premier.

04. (177) Chou king : Mou che.

04. (178) La campagne de Mou s'étendait au sud de la sous -préfecture de $K^{\prime} i$, préfecture de Wei-hoei, province de Ho-nan. - Sur la bataille décisive qui se livra en ce lieu, voyez aussi les stances 7 et 8 de la fameuse ode ta ming du Che king, trad. Legge, p. 436; [trad. Couvreur]

04. (179) Chang est la capitale de la dynastie de ce nom; elle se trouvait à peu de distance de la sous-préfecture de $K^{\prime} i$ (cf. la note précédente ; sous les Han, ce fut la sous-préfecture de Tchao-ko. La plaine de Mou était à $70 l i$ au sud de la capitale ; à parler exactement, elle n'était donc pas dans la banlieue de la ville, puisque cette banlieue n'avait que $50 \mathrm{li}$; je ne crois pas cependant qu’il faille pour cela altérer le sens de la phrase, comme le fait Tcheng K'ang-tch'eng qui dit: Sur le point d'aller livrer bataille dans la banlieue de Chang, il s'arrête dans la campagne de Mou (en dehors de la banlieue) et fait une harangue.

04. (180) La grande hache jaune était ainsi nommée parce qu'elle était cou verte d'or. D'après K'ong Ngan-kouo, le roi tient de la main gauche la hache pour montrer qu'il n'a pas l'intention de tuer en ce moment et de la main droite le fanion pour montrer qu'il a quelque chose à annoncer.

04. (181) Se-ma Ts'ien donne la leçon [a], tandis que, le Chou king écrit [b] ; avec ce second texte, il faut traduire : Chefs illustres des royaumes alliés.

04. (182) Sur le se t'ou, le se ma et le se k'ong, cf. note 161.

04. (183) L'expression [] signifie «multitude secondaire» et désigne les officiers immédiatement au-dessous du se t'ou, du se ma et du se k'ong.

04. (184) Les fonctions des officiers appelés [] sont décrites dans le Tcheou li (chap. XIII, trad. Biot, t. I, p. 291) ; mais elles ne répondent guère à ce que nous attendrions d'un commandant 
militaire. Aussi K'ong Ngan-kouo a-t-il peut-être raison quand il dit que les che che sont simplement ceux qui gardent les portes avec des soldats.

04. $(\underline{185})$ :

* Le pays de Yong était au sud-est de la sous-préfecture actuelle de Tchou-chan, préfecture de Yun-yang, province de Hou-pe.

* Le pays de Chou correspond à la préfecture de Tch'eng tou, province de Se-tch'oan .

* Le nom de Kiang était donné aux tribus qui habitaient l'ouest du Chàn-si, le Kan-sou et même le Tibet.

* Le pays de Meou occupait le territoire de la préfecture de Tch'ong-k’ing dans le Se-tch'oan, mais s'éten dait vraisemblablement jusque dans le Yun-nan, car, sous la dynastie des T'ang, on trouve dans cette dernière province l'arrondissement de Meou qui est aujourd'hui la préfecture de Tch'ou-hiong.

* Le grand commentaire de Fou Cheng place aussi le pays de Wei dans le pays de $P a$, c'est-à-dire dans le Se-tch'oan .

* Le pays de Lou (dont le nom est écrit dans le Chou king) correspond à la sous-préfecture de Siang-yang, préfecture de Siang-yang, province de Hou-pe.

* Le pays de P'ong correspond à la préfecture secondaire de Mei, province de Se-tch'oan.

* Enfin le pays de Pou est la sous-préfecture actuelle de Che-cheou, préfecture de King-tcheou, province de Hou-pe.

Il est à remarquer que ces huit royaumes étaient considérés, au temps des Tcheou, comme faisant partie des barbares de l'ouest et du sud. Les Tcheou durent être une tribu barbare qui fit irruption dans le royaume du Milieu.

04. (186) Le coq mais non la poule, annonce le point du jour par son chant. Ce proverbe signifie donc que, si la femme s'occupe des affaires de l'homme, tout ira mal.

04. (187) Kiang Cheng (H. T. K. K., ch. CCCXCIV, p. $14 \mathrm{v}^{\circ}$ ) remarque ici que dans toute la grande harangue du pseudo-K'ong Ngan-kouo, le nom de Tcheou est remplacé par celui de Cheou; mais cette modification n'a aucune raison d'être.

04. (188) [] est ici l'équivalent de [] disposer, et non la désignation d'un sacrifice d'une espèce particulière, comme le dit Tcheng Hiuen.

04. (189) Je suis ici le sens fort bien indiqué par M. Legge, Chinese Classics, t. III, p. 303.

04. (190) Cf. note 174 .

04. (191) Dans le chapitre Ou tcheng du Chou king, Tcheou est appelé le chef de tous les fugitifs de l'empire et cette phrase est citée dans le Tso tchoan, $7^{\mathfrak{e}}$ année du duc Tchao, trad. Legge, p. 616.

04. (192) Sur le sens de l'expression [], cf. note 01.314.

04. (193) Les quatre mots « six coups ou sept coups » ne se trouvent pas dans les citations que les commentateurs de l'époque des Han font de ce passage; c'est donc peut-être une interpolation (H. T. K. K., clt. CCCXCIV, p. $16 \mathrm{r}^{\circ}$ ).

04. (194) Aujourd'hui encore il y a un commandement analogue dans l'armée chinoise. Sur un ordre donné par le général, tous les soldats prennent un air terrible, afin d'effrayer l'ennemi.

04. (195) D'après Siu Koang, le mot [] est ici l'équivalent de [] qui désigne une espèce d'anirnal féroce (H.T.K.. K., ch. CCCXCIV, p. $\left.16 \mathrm{r}^{\circ}\right)$.

04. (196) En ne rattachant pas cette phrase à ce qui précède, je suis la division des paragraphes indiquée par les éditeurs des Mémoires historiques et par Kiang Cheng. Il faut avouer 
cependant que, puisque la plaine de Mou se trouvait déjà dans la banlieue de Chang, on ne comprend pas bien pourquoi le roi Ou donne l'ordre à ses soldats d'en trer maintenant dans cette banlieue (cf. note 178). C'est pourquoi Wang Koang-lou rapporte cette phrase à ce qui précède et il faut alors traduire comme l'a fait M. Legge : Soyez comme des tigres... ici, dans la banlieue de Chang. Mais le sens n'est guère plus satis faisant.

04. (197) J'ai suivi le sens indiqué par Wang Sou (H. T. K. K., ch. CCCCXIV, p. $15 \mathrm{r}^{\circ}$ ). Tchen K'ang-tch'eng explique : «Ne mettez pas à mort avec cruauté ceux qui fuient. » Mais, malgré les autorités dont cette interprétation peut se réclamer, elle me paraît faire violence au sens des mots.

04. (198) Tcheou chou, $\S 36, K^{\prime}$ o Yn. Cette phrase et celles qui, dans ce qui suit, sont mises entre crochets, se retrouvent, avec quelques variantes, dans le livre intitulé Tcheou chou. Ce livre est mentionné dans le I wen tche du Ts'ien Han chou et il est probable quil existait avant Se-ma Ts'ien; les parties qui nous en ont été conservées sont réimprimées dans le Han Wei ts'ong chou. C'est par erreur qu'on appelle quelquefois ce livre Ki tchong Tcheou chou, car il ne se trouve point au nombre des ouvrages qui furent retrouvés dans une tombe princière à $K i$, en l'an 281 de notre ère.

04. (199) Le grand précepteur ou che chang fou n'est autre que Lu Chang (cf. note 152). Sur le rôle de Lu Chang à la bataille de Mou, cf. l'ode ta ming du Che king, trad. Legge, p. 436 ; [trad. Couvreur].

04. (200) C'était une coutume dans l'antiquité d'envoyer un cer tain nombre de braves provoquer l'ennemi pour engager la bataille. Le Tso tchoan raconte une anecdote curieuse qui montre bien comment se pratiquait cet usage $\left(12^{\mathrm{e}}\right.$ année du duc Siuen, trad. Legge, $1^{\mathrm{e}}$ col., $\S$ 2 ; [trad. Couvreur] $)$.

04. (201) On appelait [], dit Siu Koang, une unité militaire qui se composait de 350 chars de guerre, de 26,250 fantassins et de 3,000 guerriers vaillants comme des tigres. - Cette explication semble s'insp irer du passage où Mencius (VII, b, 4 ; trad. Legge, p. 356 ; [trad. Couvreur]) dit que lorsque le roi $\mathrm{Ou}$ triompha des $\mathrm{Yn}$, il avait avec lui 300 chars de guerre et 3,000 guerriers vaillants comme des tigres. - Mais ce témoignage de Mencius ne s'accorde pas avec celui de Se-ma Ts'ien, d'après qui le roi $O u$ avait 4,000 chars de guerre ; c'est pourquoi j'ai mis le terme « grand bataillon » au pluriel.

04. (202) Dans ce passage et dans ce qui suit, nous avons sans doute des fragments du chapitre Ou tch'eng du Chou king. Quoique le texte du Chou king traditionnel soit fort différent, il présente cependant quelques phrases analogues; ici en particulier il donne une leçon plus claire que celle de Sema Ts’ien : les premiers rangs retournèrent leurs armes et attaquèrent ceux qui étaient derrière eux.

04. (203) Cf. p. 200, n. 2.

04. (204) Se-ma Tcheng s'étonne fort de cette phrase : il est indigne du roi Ou, dit-il, de se prosterner devant le peuple ; en outre, pourquoi se prosternerait-il devant le peuple, alors qu'il s'est borné à saluer les seigneurs ?

04. (205) Proprement: avec son épée légère. Le Tcheou chou écrit King-lu, qui est le nom propre d'une épée.

04. (206) L'une de ces deux femmes était Ta-ki, d'après l'annotateur du Tcheou chou.

04. (207) Ces étendards étaient ceux que portaient les hommes d'avant-garde pour annoncer la venue du souverain et faire écarter la foule. Le nom complet paraît être, non pas han, mais yun han (rareté des nuages ?). On voit mentionnés les neuf étendards Yun han dans le poème de Tchang Heng (78-139 ap. J.-C.) sur la capitale orientale (Wen siuen, édition lithographique du Hong wen chou kiu, chap. III, p. 5 r ${ }^{\circ}$ ).

04. (208) Sur les frères cadets du roi Ou, cf. Mém. hist., chapitre XXXV, au début.

04. (209) Cf. note 155. 
04. (210) On a vu ces trois personnages mentionnés plus haut, p. $\bullet_{217}$.

04. (211) C'était, d'après le Tcheou li, la rosée qu'un fonctionnaire appelé le se hoei che recueillait pendant la nuit au moyen d'un miroir en métal ; on croyait que cette eau émanait de la lune. On s'en servait pour les sacrifices.

04. (212) Cf. Mém. hist., chap. XXXVII. — L'enveloppe que portait Kang et la seconde étoffe que portait le duc de Chao devaient servir à entourer les objets présentés en offrande.

04. (213) Cf. Mém. hist., chap. XXXIV.

04. (214) Lu Chang, cf. note 199.

04. (215) Cette prière, comme l'indique Tchang Cheou-kié, fut prononcée pendant le sacrifice au dieu de la terre.

04. (216) Nous trouvons ici l'expression [abcd]; le Tcheou chou présente l'expression beaucoup plus usuelle [eacd] On sait que l'explication exacte de ces mots a donné lieu à de nombreuses discussions entre les sinologues. Le commentateur du Tcheou chou dit qu'il s'agit ici des cinq empereurs qui sont en haut dans le ciel ; mais il nous a semblé que la théorie des cinq empereurs n'existait pas encore au temps des premiers rois Tcheou (cf. p. 59, n.1, ad fin.,) ; par conséquent nous serions tentés de voir dans les quatre mots précités deux termes en apposition : le Souverain céleste, Empereur d'en -haut, avec la leçon de Se-ma Ts'ien — le Ciel auguste, Empereur d'en -haut, avec la leçon du Tcheou chou.

04. (217) Une note du Che ki loen wen montre que la phrase qui suit est mise dans la bouche du prieur.

04. (218) Cf. note 01.225 .

04. (219) Cf. Mém. hist., chap. XXXV. - Le roi Ou divisa l'ancien royaume des Yn en trois États ; celui de Pei fut donné à Lou-fou; celui de Yong, à Sien, prince de Koan, et celui de $W e i$, à $T o u$, prince $T s^{\prime} a i$. Ces trois principautés étaient dans le voisinage de la préfecture de Wei-hoei, province de Ho-nan.

04. (220) Voyez un passage analogue dans le chapitre Ou tch'eng du Chou king; trad. Legge, p. 315. - Sur Chang Yong, cf. p. $\bullet_{203}$ et $\bullet_{207}$ •

04. (221) Le Kоио уи appelle ce personnage Nan-kong T'ao. Son appellation était Tse-yong (Dict. Chang yeou lou, chap. XIII, p. $25 \mathrm{v}^{\circ}$ ).

04. (222) Cf. note 204.

04. (223) Cf. note 205 .

04. (224) On trouve aussi dans le Tchan kouo ts'é l'expression avec le sens de plèbe, bas peuple. Cf. Couvreur, Dict. chinois-français, p. 530.

04. (225) C'est sans doute le Yn I qui avait prononcé la prière sur l'autel du dieu de la terre. Cf. p. ${ }^{\bullet} 236$ •

04. (226) Le texte de Tcheou chou est ici beaucoup plus clair : le roi Ou donne l'ordre « de transporter les neuf trépieds à San-ou.

04. (227) Fin du ch. K'o Yn de Tcheou chou.

04. (228) Cette phrase semble indiquer que, dans ce qui précède, doit se trouver tout ou partie de ce qui était considéré, au temps de Se-ma Ts'ien, comme le chapitre Ou tch'eng du Chou king.

04. (229) On trouve dans le Dictionnaire chinois-français du P. Couvreur, p. 176, le dessin d'un des vases rituels appelés $i$.

04. (230) Ce chapitre du Chou king est aujourd'hui perdu ; la préface seule nous en rappelle l'existence. 
04. (231) L'ancien État de Tsiao était au lieu où se trouve aujourd'hui la ville de ce nom, dans la préfecture secondaire de Chàn, province de Ho-nan.

04. (232) L'emplacement de Tchou est marqué par la ville de Tchou-ngo, sous-préfecture de Tch'ang-ts'ing, préfecture de Tsi-nan, province de Chan-tong.

04. (233) $K i$ est aujourd'hui la sous -préfecture de Ta-hing, préfecture de Choen-tien (Péking), province de Tche-li.

- D'après le T'ong kien tsi lan (ch. III, p. $2 \mathrm{r}^{\circ}$ ), c'est le descendant de Hoang-ti qui reçut en fief $K i$, et le descendant de Yao qui reçut en fief Tchou; c'est aussi ce qu'on lit dans le chapitre Yo ki du Li ki (trad. Legge, Sacred Books of the East, t. XXVIII, p. 123).

04. (234) Tch'en correspond à la préfecture de Tch'en Tcheou, province de Ho-nan. La capitale de cet État s'appelait Wan-k'ieou

04. (235) Aujourd'hui, la sous -préfecture de Ki, préfecture de K'ai-fong, province de Ho-nan.

04. (236) Cf. note 152, ad fin.

04. (237) Yng-k'ieou, qui était la capitale de l'État de $T s$ 'i, correspond à la sous-préfecture de Tch'ang-lo, préfecture de Ts'ing-tcheou, province de Chan-tong.

04. (238) La sous-préfecture de K'iu-feou dépend aujourd'hui de la préfecture de Yen-tcheou, province de Chan-tong.

04. (239) Tchang Cheou-kié dit que le duc de Chao s'établit dans la sous -préfecture de $O u$ tchong et qu'il nomma son royaume du nom de la montagne Yen.

- La sous-préfecture de Ou-tchong est aujourd'hui la préfecture secondaire de $K i$, préfecture de Choen-tien (Péking).

- Il semble que le fief de Yen et celui de $K i$ (cf. note 233) se soient trouvés à peu près au même endroit et qu'il y ait là une répétition difficile à expliquer.

04. (240) Aujourd'hui, la ville de Koan, préfecture secondaire de Tcheng, préfecture de K'ai fong, province de Ho-nan.

04. (241) Aujourd'hui, l'ancienne ville de Ts'ai, dans la sous-préfecture de Sin Ts'ai, préfecture de Jou-ning, province de Ho-nan.

04. (242) Tcheou chou: $\S 44$, Touo $i$.

04. (243) Les difficultés du texte qui va suivre sont considérables. Ce texte se retrouve dans le Tcheou chou (cf. note 198), mais avec des variantes qui dénaturent parfois entièrement le sens des phrases et avec plusieurs développements qui manquent chez Se-ma Ts'ien. L’idée principale me paraît être celle-ci : quoique le roi $O u$ ait vaincu les $Y n$, il n'a point encore osé s'établir dans leur pays et c'est pour quoi il est inquiet et ne peut dormir; il projette donc d'établir une ville auprès des rivières $L o$ et $I$, immédiatement au sud de ce qui avait été la résidence des $Y n$, afin de pouvoir surveiller le pays nouvellement conquis et empêcher qu'il ne s'y produise des rébellions. La précaution n'était pas inutile puisqu'à la mort du roi $O u$ le peuple, qui avait autrefois obéi aux souverains $Y n$, se souleva aussitôt.

- En lisant les textes qui sont tirés du Tcheou chou, on reconnaît aisément qu’ils doivent avoir une haute antiquité, mais en même temps qu'ils sont d'une interprétation très ardue à cause de l'état, défectueux où ils nous sont parvenus et de l'absence presque totale de commentaires.

04. (244) Cf. note 116.

04. (245) Pin avait été autrefois la résidence du duc Lieou; il était absolument impossible de voir depuis là le territoire des Yn qui était situé dans la partie du Ho-nan qui est au nord du fleuve Jaune. Le Tcheou chou est mieux avisé en rapportant l'anecdote du roi Ou contemplant 
le pays de Chang au moment où le roi vainqueur ne s'en était pas encore éloigné et n'avait pas regagné ses terres à l'ouest, dans le Chàn-si.

04. (246) Le mot est ici, comme cela arrive souvent dans ces anciens textes, le synonyme de [].

04. (247) D'après Tchang Cheou-kié, la capitale du roi Ou était dès ce moment la ville de Hao (aujourd'hui, sous -préfecture de Tch'ang -ngan, dans la cité préfecturale de Si-ngan, province de Chàn-si). La ville de Hao tirait son nom de l'étang de Hao ; cet étang fut agrandi et transformé par l'empereur $\mathrm{Ou}$, de la dynastie Han, qui voulait exercer sur ses eaux des troupes aux combats navaux afin de combattre les tribus Koen-ming, dans la Chine méridionale ; à partir de ce moment, cet étang fut appelé l'étang Koen-ming.

04. (248) Il faut sans doute sous-entendre : mais où ma mère m'avait déjà conçu. - Cette phrase attribuerait au roi $\mathrm{Ou}$ soixante ans à l'époque où il vainquit Tcheou; cette donnée est en désaccord complet avec les chronologies reçues qui estiment en général que le roi $O u$ avait quatre-vingt-quatre ans quand il prit le pouvoir.

04. (249) D'après Tchang Cheou-kié, les cerfs de grande taille dans la banlieue étaient un symbole que les courtisans et les flatteurs remplissaient la cour; les oies sauvages dans la campagne (c'est-à-dire plus loin que la banlieue) étaient un symbole que les sages étaient chassés et exilés. Tchang Cheou-kié veut voir un sens analogue dans l'ode du Che king où les oies sauvages représentent les sages $\left(7^{\mathfrak{c}}\right.$ ode de la décade T'ong kong; trad. Legge, Chinese Classics, t. IV, p. 292-293 ; [trad. Couvreur]). Tcheng Hiuen dit: Les oies sauvages connaissent le yn et le yang et prévoient le chaud et le froid; à ce point de vue, elles sont comparables aux hommes qui savent quels sont les méchants quil faut éviter et les bons auprès de qui il faut aller.

— D'après Se-ma Tcheng, les deux mots (que nous avons traduits : des vols d'oies sauvages) désigneraient des moustiques dont les vols s'abattant sur la campagne étaient un présage de mauvais augure.

04. (250) Pour cette phrase dont le sens est très controversé, ma traduction se conforme aux explications de Se-ma Tcheng. Il faut admettre que [] est l'équivalent de [] qui signifie : chasser, exclure. - Le sens est que, quoique les $Y n$ ne fussent pas vertueux, cependant les 360 hommes de valeur qui avaient apparu de leur temps rendaient leur gouvernement tolérable et prévenaient leur ruine immédiate.

- Remarquer ce nombre de 360 qui paraît avoir quelque rapport avec le nombre des jours de l'année.

04. (251) Au lieu du mot [] = pas encore, le Tcheou chou écrit le mot qui est la marque du futur : je m'assurerai...

04. (252) D'après le Che ki loen wen, la résidence céleste n'est autre que le pays de Chang, résidence de la dynastie $Y n$.

04. (253) Cheou était, dit-on, le surnom de Tcheou; mais cette explication n'a pas grande valeur. Cf. note 187.

04. (254) Tel est le programme que veut remplir le roi $O u$ avant de se permettre de prendre du repos.

- Après cette phrase, on trouve dans le Tcheou chou une page entière qui est supprimée par Se-ma Ts'ien .

04. (255) La rivière $I$ est un affluent de droite de la rivière $L o$, dans le Ho-nan; c'est non loin de leur confluent que s'éleva la ville de Lo, ou Lo-yang. Cette cité devait devenir plus tard la capitale de douze rois de la dynastie Tcheou, depuis le roi P'ing (770-720 av. J.-C.) jusqu'au roi King (544-520) exclusivement.

04. (256) D'après le Kouo ti tche, depuis $Y u$ le Grand jusqu'à T'ai-k'ang, les souverains Hia auraient résidé à Yang-tch'eng (aujourd'hui sous-préfecture de Teng-fong, préfecture et 
province de Ho-nan). Mais il est à remarquer que cette opinion est loin d'être universellement adoptée.

04. (257) San-fou, dit Tou Yu, est au sud de Lou-t'se ; or Lou-ts'e est aujourd'hui la préfecture secondaire de Chen, province de Tche-li. — D'après le T'ong kien tsi tan (ch. III, p. $10 \mathrm{v}^{\circ}$ ), San-t'ou est le nom d'une montagne au sud-ouest de la sous-préfecture de [], préfecture et province de Ho-nan.

04. (258) Les montagnes dont il s'agit sont la chaîne appelée T'ai-hang-chan (cf. note 02.223).

04. (259) Cf. note 250.

04. (260) Fin du chap. Touo i de Tcheou chou.

04. (261) Cf. note 255 .

04. (262) La montagne Hoa est celle qui est au sud de la sous-préfecture de Hoa-yn, dans le Chàn-si, non loin du confluent de la rivière Wei avec le Hoang-ho; Tao-lin, c'est-à-dire la forêt des pêchers, était un peu plus à l'est, sur la rive droite du Hoang-ho, au sud-est du lieu qui est aujourd'hui l'arrondissement indépendant de T'ong-koan, province de Chàn-si.

04. (263) Sur ce sens du mot, cf. Che king, $4^{\mathrm{e}}$ ode de la décade T'ong kong; trad. Legge, Chinese Classics, t. IV, p. 287.

04. (264) Tout ce paragraphe se retrouve avec plus de détails dans le chapitre Yo ki du Li ki; trad. Legge, Sacred Books of the East, t. XXVIII, p. 123-124 ; [trad. Couvreur].

04. (265) Le vicomte de $K i$ (cf. p. 206, n. 3) était un ancien sujet de la dynastie $Y n$; il ne voulait pas mal parler d'elle et c'est pourquoi il discourut sur la politique en général.

04. (266) La réponse du vicomte de Ki constitue le chapitre Hong fan du Chou king.

04. (267) Voyez le chapitre Kin t'eng du Chou king et le chap. XXXIII des Mémoires historiques.

04. (268) On a vu plus haut (p. $\bullet_{237}$ ) que Sien, prince de Koan, et Tou, prince de Ts'ai, avaient été chargés par le roi $\mathrm{Ou}$ d'administrer avec Ou-keng Lou-fou, descendant de l'empereur Tcheou, le territoire des $Y n$.

— D’après le T'ong kien kang mou (ch. VII. p. 4 v ), le puîné Tch'ou, prince de Houo, était aussi au nombre des rebelles et c'est ce qui justifie l'expression [].

04. (269) D'après le T'ong kien tsi lan (chap. VII, p. 5 ro) les calomnies répandues secrètement par les futurs rebelles réussirent pendant quelque temps à éveiller la défiance du roi Tch'eng contre le duc de Tcheou qui dut quitter la cour et résider dans l'est ; mais le roi s'aperçut ensuite de son erreur et chargea le duc de Tcheou de punir les coupables.

04. (270) Le vicomte de Wei avait pour nom personnel, non pas $K^{\prime} a i$ mais $K^{\prime} i$ (cf. note 03.227) ; mais, comme $K ’ \dot{i}$ était le nom personnel de l'empereur Han King-ti (156-141 av. J.-C.), les Mémoires historiques le remplacent par le mot K'ai (cf. Mém. hist., chap. XXXVIII, p. $1 \mathrm{r}^{\circ}$, note de Se-ma Tcheng).

— Le vicomte de Wei, étant un ancien sujet de la dynastie $Y n$, était qualifié pour remplacer le descendant des $Y n$, c'est -à-dire pour accomplir les sacrifices à la dynastie déchue.

- Ce vicomte de Wei passe pour le premier ancêtre de Confucius.

04. (271) Song est aujourd'hui la sous -préfecture de Chang-k'ieou, préfecture de Koei-té, province de Ho-nan.

04. (272) Le nom personnel de ce frère cadet du roi $O u$ était Fong, il est fort vraisemblable que K'ang était le nom de son apanage, de même que dans les expressions Koan chou et Ts'ai chou, Koan et Ts'ai sont les apanages de Sien, prince de Koan, et Tou, prince de Ts'ai. 
- La capitale de l'État féodal de Wei était Tchao-ko aujourd'hui sous-préfecture de $K \hat{\imath}$, préfecture de Wei-hoei, province de Ho-nan.

04. (273) T'ang était à l'ouest de la sous-préfecture de I-tch'eng, préfecture de P'ing-yang, province de $C h \bullet n$-si.

— Ce ne fut que le fils de $Y u$, prince de T'ang, qui donna à son fief le nom de Tsin (cf. Mém. hist., ch. XXXIX).

04. (274) D’après la préface du Chou king, cette céréale merveilleuse consistait en deux tiges de chaume qui se réunissaient pour ne porter qu'un seul épi.

04. (275) Le duc de Tcheou exposa l'ordre que lui avait donné le roi dans le chapitre, aujourd'hui perdu, du Chou king, intitulé : La céréale de bon augure.

04. (276) Parmi tous ces chapitres du Chou king, l'« Épi offert » et l'« Épi de bon augure »ont disparu ; la « Charge donnée au vicomte de Wei » n'existe que dans le texte antique du pseudo Kong Ngan-kouo. Les quatre autres font partie du texte moderne de Fou Cheng.

04. (277) Cf. Mém. hist., chap. XXXIII.

04. (278) Le Fils du ciel, quand il rend audience, est tourné vers le sud. Tous ceux qui viennent lui apporter leurs hommages sont tournés vers le nord; être tourné vers le nord est donc le synonyme d'être sujet.

04. (279) Cf. note 145 .

04. (280) Cf. p. ${ }_{243}$.

04. (281) C'est encore aujourd'hui une locution usuelle que de dire que de tel endroit à tel autre endroit les $l i$ sont longs, c'est-à-dire que pour parcourir une distance d'un demikilomètre environ on met plus de temps que pour franchir la même distance sur une bonne route.

04. (282) La ville construite par le duc de Tcheou se composait de deux cités : l'une était appelée Tch'eng-tcheou ou la capitale inférieure et c'est là que fut transporté le reste du peuple des $\mathrm{Yn}$; l'autre était appelée Kia-jou ; c'est là que furent déposés les neuf trépieds et que les rois Tcheou résidèrent depuis le roi P’ing (770-720 av. J.-C.), jusqu'au roi King (519-476) qui, le premier, fixa sa demeure à Tch'eng -tcheou (cf. Legge, Tso tchoan, p. 694). Un des faubourgs de la ville à l'est s'appelait Ti-ts'iuen; c'est là que se trouvaient les tombes des rois.

04. (283) Chou king : Préface.

04. (284) Sur la rivière Hoai, cf. note 02.152. Les barbares de la rivière Hoai sont les tribus qui habitaient sur les deux rives de ce cours d'eau, non loin de son embouchure dans la mer.

04. (285) Le pays de Yn était situé dans le territoire de la sous-préfecture de K'iu-feou, préfecture de Yen-tcheou, province de Chan-tong.

04. (286) Aujourd'hui, sous -préfecture de Po p’ing, préfecture de Ts'ing-tcheou, province de Chan-tong.

04. (287) Le Tcheou ancestral est la ville de Hao (cf. Legge, Chou king, p. 525).

04. (288) Chou king: Préface.

04. (289) Cf. note 01.336 .

04. (290) Ce comte de Yng (ou de Yong, car les deux prononciations sont indiquées par le Dictionnaire de K'ang - hi) ne m'est connu que par ce texte.

04. (291) Le mot [], d'après Tcheng Hiuen, a le sens de : sur le point de mourir.

04. (292) Le mot [], d'après Yng Chao, a ici le sens de [] = établir, disposer. 
04. (293) Tch'eng-tcheou est le nom qui était alors donné à la ville de Lo-yang.

04. (294) D'après le Ti wang che ki, c'est sur la rivière Han que le roi Tchao trouva la mort ; les gens du pays qui le haïssaient, le firent entrer dans un bateau dont les planches étaient jointes avec de la colle ; au milieu de la rivière, les planches se disjoignirent et le roi fut noyé.

04. (295) Le sens exact de l'expression a donné lieu à de nom breuses discussions qui sont fort bien résumées par M. Legge, Chou king, p. 583-584; d'après M. Legge, la fonction désignée par cette expression serait celle de grand chambellan. Ici cependant le mot pou a un complément direct et est un verbe ; il faut donc le prendre dans le sens de «diriger, conduire ».

04. (296) Kоио уи: Tсhеои уи, $1^{\text {er }}$ discours.

04. (297) Cf. note 140. - Le discours qui va suivre a pour but de dissuader le roi de faire une expédition guerrière contre les K'iuen Jong ; il est le développement de deux arguments : en premier lieu, les anciens rois de la dynastie des Tcheou n'étaient pas des rois guerriers ; ils s'occupaient d'instruire et de nourrir le peuple ; si le roi $O u$ a combattu la dynastie des $Y n$, ce n'est pas par amour de la guerre, c'est par pitié pour les souffrances du peuple. En second lieu, les K’iuen Jong ne doivent pas être attaqués ; en effet ils sont rangés dans la catégorie des vassaux barbares : or, les règlements royaux veulent que lorsque les vassaux barbares manquent à leurs devoirs on leur adresse une proclamation, mais ils ne veulent pas qu'on les combatte ; d'ailleurs les K'iuen Jong n'ont p as manqué au devoir des vassaux barbares qui est de venir à la cour à chaque nouvel avènement. Le roi $M o u$ a donc tort de projeter une attaque contre les K'iuen Jong. - Nous rappellerons ici que la plupart des discours de la section Tcheou yu, dans le Kоио-yu, ont été traduits par M. de Harlez, Journal asiatique, nov.-déc1893 et janv.-fév. 1894.

04. (298) D'après le Dictionnaire de K'ang-hi, le mot [], qui se prononce d'habitude tsi, a ici le même son que le caractère tchai. Le pays de Tchai était compris dans le domaine impérial ; si on s'en rapporte au Kouo ti tche, il avait son centre à $15 \mathrm{li}$ au nord-est du relais de poste de Koan-tch'eng, préfecture secondaire de Tcheng, province de Ho-nan.

- Le duc de Tchai était un descendant du duc de Tcheou, car nous lisons dans le Tso tchoan ( $24^{\mathrm{e}}$ année du duc Hi ; trad. Legge, p. 192 ; [trad. Couvreur]) : les princes de Fan, Tsiang, Hing, Mao, Tsou et Tchai étaient des descendants du duc de Tcheou.

- D'après Yng Chao, Meou-fou était l'appellation du duc de Tchai; ce personnage est cité dans le Mou t'ien t'se tchoan (cf. trad. Eitel, China Review, t. XVII, p. 227, $2^{\mathrm{e}}$ col.) sous le nom de Tchai-fou, c'est-à-dire (Meou)-fou, (duc de) Tchai.

04. (299) Le duc Wen est le titre posthume qu'on décerna à Tan, duc de Tcheou.

04. (미) Mot à mot : pour faire un déploiement dans cette grandeur.

04. (301) Cette ode est la huitième de la décade $t$ s’ing miao ; trad. Legge, p. 577-578 [trad. Couvreur]. Elle offre cette particularité qu'elle n'est pas rimée.

- Dans ma traduction, j'ai suivi les explications de Wang Yuen-soen (Koио yи fa tcheng, chap. I, p. $\left.2 \mathrm{v}^{\circ}\right)$ qui s'appuie sur un texte du Tso tchoan $\left(12^{\mathrm{e}}\right.$ année du duc Siuen, trad. Legge, p. 320). D'après le Tso tchoan, c'est le roi $O u$ qui parle et non le duc de Tcheou.

- En second lieu, le mot hià est traduit par M. Legge comme signifiant ce grand pays, c'est -à-dire la Chine, et cette opinion est fort soutenable. - Cependant Wei Hong explique ce mot comme désignant un grand paragraphe d'une ode chantée ; en effet, on appelait kiòu hià les neuf paragraphes ou les neuf airs qui étaient en honneur au temps des Tcheou ; il faudrait alors traduire : Je recherche la belle vertu — et je l'expose dans cette ode.

- Mais le texte précité du Tso tchoan semble bien prouver que hià est simplement l'équivalent de tà = grand, grandeur ; on y lit en effet : 
«être guerrier consiste à réprimer la cruauté, à rassembler les armes et à préserver la grandeur,

et plus loin :

«si on est cruel et qu'on ne rassemble pas (les armes), comment pourra-t-on préserver la grandeur?

- Quel que soit le sens qu'on donne à ces trois derniers vers, soit qu'on suive ave c M. Legge l'explication traditionnelle, soit qu'on admette l'exac titude des observations de Wang Yuen-soen, la raison d'être de cette citation est évidente : elle prouve que le roi $\mathrm{Ou}$, quelque guerrier qu'il fût, ne se plaisait pas aux combats et s'empre ssait de remettre dans les magasins ses armes, dès qu'il n'était plus pressé de s'en servir par une nécessité urgente.

04. (302) D'après Wang Yuen-soen, [] signifie : faire usage des richesses.

04. (303) Le mot [] désigne tout l'ensemble des vertus et des arts qui dérivent de la paix. L’idée essentielle est toujours que les ancêtres de la dynastie Tcheou, ont été grands par leurs qualités pacifiques plus que par leurs talents à la guerre.

04. (304) D'après Wang Yuen-soen (op. cit., ch. I, p. $2 \mathrm{v}^{\circ}$ ), cette phrase est le commentaire des deux derniers vers de l'ode citée plus haut.

04. (305) Proprement : la charge de Prince Millet. On a vu que $K^{\prime} i$ avait été honoré de ce titre au temps de Choen (qui est appelé ici $Y u$ ) et de $Y u$ le Grand, fondateur de la dynastie Hia.

- Ce texte est un de ceux qu'on invoque pour prouver que Pou-tchou n'est pas le fils de $K i$, mais son descendant après plusieurs générations dont les représentants eurent les uns après les autres le titre de heou tsi ou Prince Millet (cf. note 109).

04. (066) Cf. p. $\bullet_{211-212}$.

04. (307) Le dernier empereur des Yn, Tcheou.

04. (308) Le paragraphe qui suit se rapporte à la division schématique de l'empire en carrés concentriques; mais on y trouve un assez singulier mélange de la division en cinq domaines qui prévalait au temps de $Y u$ (cf. note 02.246) et de la division en dix domaines que nous trouvons dans le Tcheou li. Le premier domaine est appelé ici [], nom qui se trouve dans la nomenclature du $Y u$ kong, tandis que, dans le Tcheou li, il est appelé []; le second domaine, celui des seigneurs, est le même que dans le $Y u$ kong; le troisième domaine est, lisons-nous dans ce texte, celui des seigneurs et des protecteurs ; pour comprendre cette définition, il faut recourir à la division du Tcheou li ; ainsi les seigneurs et les protecteurs constituent les uns le premier, les autres le dernier de ces cinq termes ; on en conclut que le domaine appelé par le Коио уи domaine des seigneurs et des protecteurs embrassait l'ensemble de ces cinq domaines ; cette réunion des cinq domaines en un seul ne doit pas nous surprendre, car on les retrouve énumérés simultanément dans le chapitre K’ang hao du Chou king (trad. Legge, p. $381)$; quelque ingénieuse que soit cette explication qui est celle de Kia K'oei, on ne comprend pas comment le Коио уи peut parler d'abord du do maine des seigneurs et ensuite d'un autre domaine dont le premier n'aurait été qu'une partie. Le quatrième et le cinquièm e domaines cités par le Kоио yи ont les mêmes noms que dans le Yu kong.

04. (309) Lieou min (commencement du Ier siècle de notre ère) a cité, dans un rapport au trône, ce passage du Koиo yu et l'a com menté de la manière suivante (Ts'ien Han Chou, chap. LXXIII, biographie de Wei Hiuen-tch'eng, p. 13 v $^{\circ}$ ):

« Au grand-père et au père décédé, on fait chaque jour le sacrifice tsi: au bisaïeul et au trisaïeul, on fait chaque mois le sacrifice se ; aux deux chambres qui contiennent les tablettes des autres ancêtres plus éloignés, on fait à chaque saison le sacrifice hiang; sur l'autel (con sacré au ciel) et sur l'aire (consacrée à la terre), on fait chaque année le sacrifice kong ; (sur l'emplacement du) grand sacrifice impérial c'est lorsque (le deuil est) fini qu'on fait le sacrifice (de l'avènement du) roi. 
- Voyez aussi même chapitre, p. $6 \mathrm{v}^{\circ}$.

— Le sens du mot tchong = quand le deuil de trois ans est fini, nous est indiqué par Hia Chen, cité par Wang Yuen-soen (Коио yu fa tcheng, chap. I, p. $9 \mathrm{v}^{\circ}$ ).

- Les redevances payées par les vassaux étaient censées être des contributions aux sacrifices faits par le Fils du ciel ; plus les vassaux étaient éloignés de la capitale, moins fortes étaient leurs redevances et par conséquent moins fréquents étaient les sacrifices auxquels ils contribuaient.

04. (310) La gradation qui précède se règle sur l'éloignement plus ou moins grand où les vassaux se trouvaient de la capitale ; ceux qui étaient les plus rapprochés pouvaient connaître les pensées intimes du roi ; s'ils manquaient à leur devoir, le roi devait faire retour sur lui même et réformer ses pensées, car c'est peut -être à leur imperfection qu'était due l'infraction de ses sujets à la règle; de même les vassaux du deuxième domaine connaissaient le roi par ses ordres verbaux ; ceux du troisième domaine le connaissaient par ses mandements écrits, etc.

04. (311) C'est-à-dire lorsqu'il avait eu recours aux deux seuls moyens d'action qu'i 1 eût sur les vassaux des deux domaines les plus éloignés.

04. (312) Ta-pi et Po-che sont, d'après Wei Hong, les noms de deux chefs des K'iuen Jong .

04. (1ㅡ) Ils n'étaient pas tenus d'y venir, puisq u'ils ne devaient contribuer qu'aux sacrifices faits aux avènements de rois.

04. (314) Meou-fou reprend les deux arguments qui sont à la base de tout son discours (cf. note 297) et montre que le roi, en dirigeant une expédition contre les K'iuen Jong, manquerait doublement aux préceptes de ses ancêtres.

04. (315) D'après Wei Hong, le mot chou serait le synonyme de [] dresser, établir ; la phrase K'iuen Jong chou toen signifierait alors les K'iuen Jong ont établi (parmi eux) la sincérité. Mais Wang Yuen-soen (Kouo yu fa tcheng, chap. I, p. $10 \mathrm{r}^{\circ}$ ) avance avec beaucoup d’ingéniosité que Chou-toen doit être le nom du chef des K'iuen Jong ; en effet, dit-il, dans le Pei che (biographie de Che Ning, chap. LXI) et dans l'histoire des T'ang (Tang chou, biographie de Wang Nan-té, chap. CXLVII) on voit mentionnée la ville de Chou-toen qui fût la capitale des T'ou-yu-hoen; le nom de cette ville doit évidemment venir de ce que l'ancien chef des K'iuen Jong, Chou-toen y demeura. Cette cité de Chou-toen se trouvait au nord de la montagne Si-man-t-eou, préfecture de Si-ning, province de Kan-sou.

04. (316) Malgré les remontrances de Meou-fou, le roi Mou use envers des K'iuen Jong de la correction qui était, d'après les règles de l'État, réservée aux vassaux du troisième domaine ; il ne rapporte de son expédition qu'un butin dérisoire et ne réussit qu’à détacher entière ment de lui les barbares.

04. (317) Fin de Коио yи: Tcheou yu, $1^{\mathrm{er}}$ discours.

04. (318) Dans la phrase [], les trois derniers mots ne peuvent être, si l'on considère la manière dont Se-ma Ts'ien ne manque jamais de s'exprimer dans des cas analogues, que le titre d'un chapitre du Chou king; il est à remarquer cependant que, dans le Chou king, le chapitre dont il est ici question n'est pas intitulé « Réforme des peines et des supplices», mais le «Code pénal de $\mathrm{Lu}$ »

- Ce dernier titre se retrouve dans Mé tse, chap. II, Chang hien, $3^{\mathrm{e}}$ partie, p. $13 \mathrm{v}^{\circ}$ ); cependant le Hiao king et le Li ki (trad. Legge, Sacred books of the East, t. XXVIII, p. 330, 334 et passim) appellent ce même texte le «Code pénal de Fou » : en effet, le personnage auquel est attribuée la rédaction de ce code est appelé tantôt le marquis de $L u$, tantôt $1 \mathrm{e}$ marquis de $\mathrm{Fou}$. C'est la première déno mination qui paraît être la plus ancienne et qui devait être en usage au temps du roi Mou; mais, vers l'époque du roi Siuen (827-782 av. J.-C.), les marquis de $L u$ changèrent de fiefs et devinrent les marquis de Fou; ils sont mentionnés sous ce nom dans une ode du Che king qui date du roi Sinen $\left(5^{\mathrm{e}}\right.$ ode de la décade de Tang, trad. Legge, p. 535). Cette famille princière passait pour descendre des officiers qui avaient été 
chefs des quatre montagnes au temps de Yao et de Choen et la même filiation était réclamée par les princes de $T s^{\prime} i$ de et de Chen. Les seigneurs de $L u$ et ceux de Chen sont mentionnés simultanément dans un grand nombre de textes : la raison en est que les terres de Chen et de $L u$ étaient fort voisines, la première se trouvant à $30 l i$ au nord de la sous-préfecture actuelle de Nan-yang qui fait partie de la ville préfecturale du même nom, dans la province de Ho-nan, et la seconde étant à 40 li à l'oues t de la même localité. - Quant au pays de Fou, on n'en connaît pas la situation exacte.

- Se-ma Ts'ien ne cite ici qu'une petite partie du chapitre Lu hing du Chou king ; c'est celle qui correspond au commencement de la section V dans la traduction de M. Legge.

04. (319) Chou king : chap. Lu hing.

04. (320) D'après Kiang Cheng (H.T.K. K., ch. CCCXCIX, p. 15 vº), [] désigne les vassaux qui sont en dehors du domaine royal et sont assez indépendants pour avoir des royaumes ; [] désigne ceux qui sont dans le domaine impérial et ne peuvent avoir que des terres.

- Ts'ai Tch'en (Chou king, ch. XXI, p. $13 \mathrm{r}^{\circ}$ ) donne une autre explication [...]; aux yeux des Chinois, toute autorité régulière a pour mission, d'une part, de gouverner le peuple ( $\mathrm{min}$ ) et à ce titre elle dirige le royaume, et, d'autre part, de servir les dieux locaux (ché) et à ce titre elle est préposée à la terre.

04. (321) Le mot [] est écrit [] par Tcheng Hiuen, et il faut alors traduire : Je vous parlerai en détail des châtiments.

04. (322) Tchang Cheou-kié est d'avis que [] est le synonyme de []; cette dernière expression est expliquée par le Hing fa tche du Ts'ien Han chou comme désignant les cinq modes d’informations auxquels le juge peut avoir recours : informations par les témoignages, par les apparences, par les sentiments, par les oreilles, par les yeux. - Mais cette explication n'est pas satisfaisante, car il y a parallélisme évident entre les cinq témoignages et les cinq châtiments ; les fautes peuvent être de cinq ordres et les témoignages qui les attestent sont répartis aussi en cinq catégories, non pas suivant leur nature (orale, visible, etc.), mais suivant celle des fautes. Il importe que le juge écoute ces témoignages pour prononcer sa sentence : soit par exemple un meurtre ; le juge entend un témoignage au criminel; d'après la gravité de ce témoignage, il décidera que le coupable est passible de mort, ou qu'il est au bénéfice des circonstances atténuantes et peut se racheter, ou enfin qu'il a péché par inadvertance.

04. (323) Le mot [], qui revient souvent dans ce chapitre, signitie simplement : établir la certitude ; ici il faut entendre : établir la certitude de la faute.

04. (324) C'est -à-dire s'il y a des circonstances atténuantes.

04. (325) C'est -à-dire dans les fautes commises par inadvertance, sans mauvaise intention..

04. (26) En d'autres termes, il est mal, de la part du juge, de se laisser entraîner dans certains cas par des considérations d'intérêt person nel et de déclarer faute par inadvertance ce qui en réalité est crime et mérite châtiment.

- Le Che ki loen wen donne la leçon nei yu qui est d'accord avec le texte du Chou king et que j'ai adoptée ; l'édition de K'ien-long donne la leçon k'ieou yu = la cause impliquant des prisonniers ; cette leçon ne me paraît pas conciliable avec la suite des idées.

04. (327) Ce texte est assez différent de celui du Chou king et demande une autre traduction que celle qui est indiquée par les commentateurs du livre classique.

04. (328) La leçon de Se-ma Ts'ien est [], mot à mot : sans certitude pas de doute ; c'est-à-dire si le juge n'a pas de doute, quoi qu'en réalité il ne soit pas certain...

— La leçon du Chou king, qui est aussi celle du Li ki, dans le chapitre Wang tche, est [], c'est-à-dire : si la certitude n'est pas établie, on ne décide pas la cause.

- Dans le texte de Se-ma Ts'ien, l’idée me parait être celle-ci : si les magistrats ne doivent pas faire abus de l'indulgence, ils ne doivent cependant appli quer les châtiments qu'avec la 
plus grande circonspection ; s'ils se persuadent sans examen suffisant de la culpabilité d'un accusé, ils seront punis par le Ciel.

04. (329) Se-ma Ts'ien donne la leçon du texte moderne qui est: cent choa; le Chou king traditionnel donne la leçon du texte antique qui est : cent hoan. Kiang Cheng (H. T. K. K., ch. CCCXCIX, p. $18 \mathrm{r}^{\circ}$ ) dit que choa est l'équivalent de choe; le choe est un poids de 6 Leang (onces) et $2 / 3$; cent choe équivalent à 41 kin (livres) 10 Leang et $2 / 3$. Ce poids était un poids de cuivre; mais il paraît trop considérable à Kiang Cheng qui adopte la leçon du texte antique ; le hoan vaut 11 chou (vingt-quatrième partie du leang) et 13/25; cent hoan valent environ 3 kin (livres).

04. (330) Le Chou king dit simplement que l'amende sera du double ; Se-ma Ts'ien ajoute le mot [] qui, d'après Se-ma Tcheng, se prononce ici $l i$; mais je ne vois pas que ce mot puisse avoir ici aucun sens ; d'après Siu Koang, un texte substitue à ce mot le caractère si qui signifie le quintuple ; on trouve l'expression [] = le double ou le quintuple, dans Mencius (III, a, 4 et VI, a, 6 ; trad. Legge, p. 132 et 279).

— La leçon du Chou king paraît bien préférable, car on ne saurait admettre que l'amende soit tantôt du double, tantôt du quintuple ; elle n'est que du double et le mot surajouté dans le texte de Se-ma Ts'ien est une superfétation.

04. (331) La leçon des Mémoires historiques est [] = ablation des rotules; la leçon du Chou king est [] ou [] = ablation des pieds.

04. (332) Le texte est ici assez ambigu; d'après Ma Yong, l'amende est le double de l'amende précédente, plus un tiers de ce double : elle est donc égale à $(200 \times 2)+(200 \times 2) / 3=$ hoan 533,333 . Mais cette amende serait à peu près égale à celle qui correspond à la peine plus grave de la castration; on ne peut donc pas admettre cette explication. D'après Tchang Cheou kié et Kiang Cheng, l'amende est le double de l'amende précédente, moins un tiers de cette amende ; elle est donc égale à $(200 \times 2)-200 / 3=333$ hoan et $1 / 3$.

04. (333) Le mot de «castration» ne répond pas absolument au mot chinois si cette peine, impliquait la castration pour l'homme, elle n'était pour la femme qu'un emprisonnement.

04. (334) Le Chou king dit que l'amende sera de six cents hoan.

- D’après Siu Koang, un texte du Che ki donne la leçon : six cents choa.

04. (335) Ce passage établit une moyenne de la criminalité : sur trois mille coupables, il y en a mille qui ont mérité la marque ; mille, l'ablation du nez ; cinq cents, l'ablation des rotules ; trois cents, la castration; deux cents, la mort.

04. (336) On a vu plus haut (note 318) que le Chou king appelle ce même texte le code criminel de $L u$.

04. (337) Nous avons vu (p. $\left.\bullet_{250}\right)$ que le roi Mou avait cinquante ans lorsquil prit le pouvoir ; il aurait donc atteint l'âge de cent cinq ans. Ce témoignage est d'accord avec le texte du Chou king (code criminel de $L u$, au début) qui dit que le roi Mou avait cent ans lorsquill réfor ma la législation.

- Dans ce chapitre, Se-ma Ts'ien passe sous silence la fameuse légende du voyage du roi Mou dans les contrées occidentales et de sa visite à la reine d'Occident ou plutôt, s'il faut en croire les plus anciens textes, au chef barbare appelé Si wang mou. Cette légende nous a été conservée dans le petit livre intitulé Mou t'ien tse tchoan; le Mou t'ien tse tchoan a été traduit en anglais par le Dr Eitel (China Review, vol. XVII, p. 223-240 et 247-258). Se-ma Ts'ien fait cependant allusion à ce voyage au commencement des Annales principales des $T s^{\prime} i n$; nous en reparlerons plus longuement dans nos notes à ce chapitre.

04. (338) Коио уи : Tcheou yu, $2^{\mathrm{e}}$ discours. 
04. (339) La rivière King prend sa source dans la montagne Ki-t'eou, sous-préfecture de P'ing-Leang, province de Kan-sou. Elle se jette dans la rivière Wei, non loin de la sous-préfecture de Kao-ling, préfecture de Si-ngan, province de Chàn-si.

04. (340) Wei Tchao dit que ce prince de $M i$ avait pour nom de famille $K i$ mais c'est une erreur. Il y avait deux États de $M i$; l'un, dont le prince avait pour nom de famille $K i$, se trouvait à $70 l i$ à l'est de la sous -préfecture actuelle de $M i$, préfecture de Kai-fong, province de Ho-nan. L'autre, dont le prince avait pour nom de famille $K i$, était dans la sous-préfecture de Ling-ta, préfecture de P'ing-leang, province de Kan-sou ; c'est l'État de Mi-siu dont il a été parlé plus haut (cf. note 141) ; c'est celui dont il est question dans ce passage, puisque la tombe du duc K'ang se trouve à $50 \mathrm{li}$ à l'ouest de la sous-préfecture de Ling-T'ai (Wang Yuen-soen: Kouo yu fa tcheng, chap I, p. $11 \mathrm{v}^{\circ}$ ).

04. (341) Le sens du mot [] est épouser sans l'assentiment du préposé aux mariages. Voyez l'article consacré à ce fonctionnaire dans le Tcheou li (trad. Biot, t. I, p. 307) et le passage de cet article cité par le Dictionnaire de K'ang-hi, au mot pen.

- Le mariage du prince de $M i$ était contraire aux rites parce qu'il avait épousé des femmes du même nom de clan que lui ; en effet nous savons que le nom d'une de ces trois femmes était $P o-k i$, le second caractère de ce nom représentant le nom de clan ; cette femme avait donc le même nom de clan que le prince (cf. la note précédente). Le texte qui nous donne le nom de $P o-k i$ se trouve dans le Tcheou yu. $2^{\mathrm{e}}$ partie, $1^{\text {er }}$ discours; nous y lisons : « (L'État de) Mi-siu fut perdu par Po-ki. »Wang Yuen-soen, dans son commentaire à ce passage (Kouo yu fa tcheng, chap. II, p. $2 \mathrm{r}^{\circ}$ ) dit que les princes de l'État de $M i$ et ceux des autres États qui eurent un sort analogue se perdirent tous pour avoir épousé des femmes qui avaient le même nom de clan qu'eux.

04. (342) Le caractère [], quand il désigne trois femmes, a, dit le Chouo wen, le sens de beau.

04. (343) D'après les anciens rites, le roi n'avait pas le droit de prendre à la chasse plus de deux animaux. Cet exemple est invoqué par la mère du prince de $M i$ pour lui montrer que le nombre de trois est excessif.

04. (344) Cette phrase est rendue fort obscure par la présence de la négation ; je crois que cette négation est une interpolation maladroite d'un copiste qui aura voulu établ ir entre les trois phrases une sorte de symétrie. Le texte du Koиo yи ne comporte pas la négation.

- un duc, dans sa conduite, se soumet à une assemblée, c'est-à-dire que lorsque trois personnes ou plus ont un avis différent de celui d'un duc, celui -ci leur cède ; c'est encore une preuve de l'im portance que prend une réunion dès qu'elle compte trois personnes,

04. (345) Le mot [] désigne ici les concubines du Fils du ciel, celles qui sont appelées [] dans le Tcheou li (trad. Biot, t. I, p. 156). — C'est ici le second argument : non seulement trois concubines sont un nombre excessif, mais encore il est interdit qu'elles soient du même clan que le prince.

04. (346) Le commentaire de Wei Tchao à cette phrase a été fort altéré ; voyez la restitution qu'en fait Wang Yuen-soen (Kouo yu fa tcheng, chap. I, p. $11 \mathrm{r}^{\circ}$ ).

04. (347) Il faut se rappeler les définitions précédentes: trois personnes constituent une assemblée ; trois femmes constituent un luxe ; un luxe constitue une chose magnifique.

- ...vous est revenue $=$ vous appartient.

04. (뇨) Le roi I transféra sa capitale à Kiuen-k'ieou ; cette localité, qui s'appelait Hoai-li au temps des Han, se trouvait au sud-est de la sous-préfecture de Hing-p’ing, préfecture de $\mathrm{Si}$ ngan, province de Chàn-si.

04. (349) Le T'ong hien kang mou remarque qu'il y a dans le Che king un grand nombre d'odes satiriques, mais qu'on ne sait pas 1 esquelles furent composées au temps du roi I 
04. (다) D'après le Tchou chou ki nien, c'est le roi I qui fit périr le duc Ngai du pays de Ts'i, en le jetant dans un liquide bouillant. Cf. Mém. hist., chap. XXXII.

04. ( $\underline{351})$ I est un titre posthume; ce personnage était un descendant du duc de Yng que la préface du Chou king mentionne au temps du roi Tch'eng (cf. note 290). Par Mé-tse, nous savons que son nom personnel était Tchong.

04. (352) Kоио уи: Tcheou yu, $4^{\mathrm{e}}$ discours.

04. (5ㅕ $)$ Joei correspond à la sous-préfecture actuelle de Joei-tch'eng, préfecture secondaire de Kié, province de $C h \bullet n$-si. Les princes de ce petit État avaient pour nom de clan $K i$; ils étaient comtes.

04. (5ㄴ) Le discours qu'on va lire se retrouve dans le Kouo yu, mais placé après celui qui le suit dans les Mémoires historiques. Il est fait allusion à ce même discours dans Mé-tse, au chapitre So jan et le Tch'oen ts'ieou de Lu Pou-wei, au chapitre Tang jan.

04. (ㅌ5) Je suis ici l'explication de Wei Hong.

04. (ㄷ6) Dixième ode de la décade $t$ 'ing miao — trad. Legge, p. 580.

04. (357) L'ancêtre des Tcheou qui fut célèbre par ses talents pour l'agri culture, au temps de l'empereur Choen.

04. ( $\underline{358})$ Le mot [] = être mis en corrélation avec, indique la place qu'occupait la tablette du défunt au moment du sacrifice. La tablette de Heou-tsi étant à côté de celle du Ciel occupait le rang le plus élevé qu'elle pût avoir.

04. (359) Ce vers se trouve dans la $1^{\mathrm{e}}$ ode du IIIe livre du Ta ya (Che king, trad. Legge, p. 428). Dans sa traduction, M. Legge admet que le sujet de la phrase est [] qu'il traduit par «Dieu » et il condamne l'opinion de K'ong Yng-ta qui veut que ce sujet soit « le roi Wen ». Il est évident cependant que, dans ce passage du Коио уи, la manière même dont la citation est amenée prouve qu'il s'agit du roi Wen ; ce qu'il s'agit de démontrer, en effet, c'est que les souverains vertueux se sont efforcés de répandre leurs bienfaits sur le peuple et n'ont pas voulu leur intérêt personnel.

04. ( $\underline{360}$ ) Ce sens est celui qu'indique Wei Tchao. Wang Yuen-soen (Kouo yu fa tcheng, chap. I, p. $15 \mathrm{r}^{\circ}$ ) propose de considérer comme l'équivalent de [] ; il faut alors traduire :

« Il a peu de chances de parvenir jusqu’à la fin de sa (destinée)

et la phrase répond à celle que nous avons plus haut :

«Comment Votre Altesse pourrait-elle mener longtemps cette conduite ?

A l'appui de sa thèse, Wang cite deux passages du Tso tchoan: $7^{\mathrm{e}}$ année du duc $H i$, trad. Legge, p. 149 et $11^{\mathrm{e}}$ année du duc Siuen, trad. Legge, p. 310, où le sens de tchong et de koei est identique. Cette explication me paraît un peu subtile.

04. (61) Коио уи: Tсhеои уи, $3^{\mathrm{e}}$ discours.

04. (362) Parmi les odes du Che king il en est quelques-unes qui sont considérées comme contenant des reproches au roi $\mathrm{Li}$; ce sont l'ode Min lao $\left(9^{\mathrm{e}}\right.$ de la décade cheng min; trad.

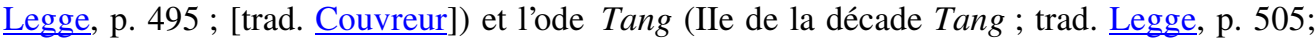
[trad. Couvreur]) qui sont attribuées au duc Mou, de Chao; l'ode Pan (10 de la décade cheng min, trad. Legge, p. 499; [trad. Couvreur]) attribuée au comte de Fan et l'ode Sang yeou ( $3^{\mathrm{e}}$ de la décade Tang; trad. Legge, p. 519; [trad. Couvreur]) attribuée au comte de Joei.

04. (63 $)$ Le duc de Chao était le descendant de ce Che, duc de Chao, qui reçut le titre posthume de Kang et joua un grand rôle au temps des rois $O u$ et Tch'eng. Cette famille avait le fief de Yen qui était un marquisat, mais en même temps, elle jouissait des revenus de la terre de Chao (aujourd'hui le relais de Chao, sous-préfecture de $K i$-chan, préfecture de Fong-siang, province de Chàn-si) ; c'est pourquoi le chef de la maison pouvait être appelé indifféremment duc de Chao ou marquis de Yen. C'est de la même manière que les ducs de 
Lou avaient pour fief le pays de Lou, mais avaient aussi les revenus de la terre de Yong (aujourd'hui sous-préfecture de Fong-siang, province de Chànsi) et étaient nommés pour cette raison ducs de Tcheou.

- D'après Wei Tchao, le duc de Chao qui vivait au temps du roi $L i$ a pour nom personnel Hou In et pour titre posthume Mou; d'après Se-ma Ts'ien (Mém. hist., chap. XXXIV), c'était le marquis de Yen dont le titre posthume est Hoei; je ne vois pas comment on peut accorder ces deux témoignages.

04. (364) Le [] dont il est ici question n'est pas celui du prince, c'est -à-dire ses ordres ou son gouvernement, mais celui du peuple, c'est -à-dire sa destinée ou son sort.

04. (365) Les connaissances surnaturelles du devin lui permettaient de découvrir ceux qui parlaient mal du roi,

04. (366) Je traduis ici le mot [] par « duc du palais », parce qu'il dési gne uniquement les trois grands personnages appelés « les trois ducs », et non les ducs de la hiérarchie féodale. Cf. note 03.208 .

04. (367) Les divers officiers sont appelés «divers» parce qu'ils se distinguent en trois catégories.

04. (368) Le Kouo yu donne, au lieu du mot [], le mot [] et il faut alors traduire : ceux qui n'ont pas d'yeux présentent les chants.

Sous les Tcheou, les aveugles étaient préposés à la musique (Tcheou li, trad. Biot, t. I, p. 405). On les divisait, suivant la nature de leur cécité, en trois classes : ceux qui n'avaient pas d'yeux étaient appelés kou ;ceux qui avaient conservé la prunelle de leurs yeux étaient appelés mong ; ceux qui avaient des yeux sans prunelles étaient appelés seou.

04. (369) D'après Wei Tchao, les annalistes dont il est ici parlé sont les annalistes de l'extérieur ; le Tcheou nous apprend que ces fonctionnaires étaient préposés aux Livres des trois Souverains et des cinq Empereurs.

04. (370) D’après Wei Tchao, ils récitaient les poésies des ducs du palais, des hauts dignitaires et des divers officiers. D'après le I wen tche du livre des Han antérieurs, le mot signifie : réciter sans chanter.

04. (371) Ils chantaient les avertissements et les critiques.

04. (372) L'expression $p \bullet k \bullet u n g$ dans le sens de «les cent fonctionnaires » se trouve dans le Chou king (Yao tien, trad. Legge, p. 22 ; Lo kao, trad. Legge, p. 439).

04. (373) Ils n'avaient pas accès auprès du souverain en personne et c'est pourquoi il s lui faisaient transmettre leurs requêtes.

04. (374) Wang Yuen-soen a bien établi, contre l'avis de Wei Tchao, que [] désigne le roi luimême et non les instructions des annalistes et des aveugles.

04. (375) Le duc de Chao explique ici la comparaison dont il s'est servi quelques lignes plus haut, quand il a dit que les bouches du peuple étaient comme la terre qui produit ce dont on se sert, ce dont on s'habille et ce dont on se nourrit.

04. (376) Le Kоио уи ajoute ici la phrase : «Comment pourrait-on y faire obstacle ? »

04. (377) Tel est le sens indiqué par Wei Tchao.

04. (378) La ville de Tche se trouvait dans la préfecture secondaire de Houo, préfecture de P'ing-yang, province de Ch॰n-si.

04. (379) Ce nom de Tsing est écrit [] dans le livre des Han antérieurs.

04. (8ㅜ) Коио уи: Tcheou yи, $5^{\mathrm{e}}$ discours. 
04. (381) L'expression hong ho signifie « la commune harmonie ». D'après ce que nous dit $\mathrm{Se}$ ma Ts'ien, les ducs de Tcheou et de Chao auraient exercé simultanément la régence, comme leurs ancêtres, Tan, duc de Tcheou, et Che, duc de Chao, l'avaient fait au temps du roi Tch'eng.

- Cependant Tchoang-tse et le Tchou chou ki nien disent que Kong est le nom d'un fief et Ho le nom personnel du comte de ce pays; ce serait donc Ho, comte de Kong, qui aurait exercé la régence et non les ducs de Tcheou et de Chao. — Les historiens modernes adoptent la version de Se-ma Ts'ien.

- La première année kong ho (841 av. J.-C.) est une date fort importante, car elle est celle à partir de laquelle, d'après Se-ma Ts'ien, commence la chronologie exacte. Nous indiquerons dorénavant entre parenthèses les dates avant notre ère auxquelles correspondent les indications données par Se-ma Ts'ien. Cf. note 500.

04. (382) Cette visite fait l'objet du septième discours dans le premier chapitre du Tcheou yu. Le duc $O u$, de $L o u$, avait deux fils ; il désirait que le cadet, $H i$, lui succédât au détriment de l'aîné Kоио. Le roi Siuen y consentit, malgré les représentations de Tchong Chan-fou. Hi prit dont le pouvoir ; ce fut le duc $I$; neuf ans après son avènement, Po-yu, fils de Kouo, le tua et prit le pouvoir (cf. Mém. hist., chap. XXXIII).

04. (ㅈ3) Коио уи: Tсhеои уи, 6 e discours.

04. (타) Le meou est une mesure de superficie qui, dans l'antiquité, avait 100 pas de côté, le pas étant lui-même de 6 pieds. - On lit dans le Li ki (trad. Legge, Sacred Books of the East, t. XXVIII, p. 222)

«C'était ainsi qu'autrefois le Fils du ciel avait son champ de mille meou, dans lequel il tenait lui-même la charrue, portant le chapeau carré avec des attaches rouges. Les seigneurs avaient aussi leur champ de cent meou, dans lequel ils faisaient de même, portant le même chapeau avec des attaches vertes.

04. (385) D'après Kia K'oei, ce duc de Kouo était un descendant de Kouo ; d'après Wei Tchao, c'était un descendant de Kouo-tchong. Kouo-tchong et Kouo-chou étaient tous deux fils du duc $K i$ et par conséquent frères du roi Wen (cf. Tso tchoan, $5^{\mathrm{e}}$ année du duc $\mathrm{Hi}$; trad. Legge, p. 145, § 9 ; [trad. Couvreur]). Kouo-tchong reçut en fief le Kouo oriental (à l'ouest de la sous-préfecture de Se-choei, préfecture de Kai-fong, province de Ho-nan) ; Kouo-chou reçut en fief le Коио occidental (à $60 \mathrm{li}$ à l'est de la sous-préfecture de Pao-hi, préfecture de Fong-siang, province de Chàn-si). Il est difficile de savoir qui a raison, de Kia K'oei ou de Wei Tchao.

04. (탕) Après ces mots, on lit dans le Коио уи un assez long discours qui est supprimé par Se-ma Ts'ien .

04. (387) Cette localité, dont le nom signifie précisément «(le champ de) mille meou », se trouvait à la limite est du Chøn-si, dans la préfecture secondaire de Leao. Une allusion est faite à cette bataille dans le Tso tchoan, $2^{\mathrm{e}}$ année du duc Hoan.

04. (료) Коио уи: Tcheои уи, $9^{\mathrm{e}}$ discours.

04. (389) Les royaumes du sud sont ceux qu'arrosent la rivière Han et la rivière Min considérée comme le cours supérieur du Yang-tse-Kiang (cf. Che king, $10^{\mathrm{e}}$ ode de la décade siao-min, $6^{\mathrm{e}}$ strophe; trad. Legge, p. 358; [trad. Couvreur]). Wei Tchao dit que les mots désignent les soldats qui furent tués par les Kiang Jong. Mais Wang Yuen-soen remarque qu'on ne saurait désigner les Kiang Jong sous le nom de royaumes du sud; peut-être l'identification de $T$ s'ien-meou avec une localité du $C h \bullet n$-si est-elle erronée et faut-il placer ce lieu dans le sud.

04. (390) Wang Yuen-soen (Kouo yu fa tcheng, chap. I, p. $23 \mathrm{v}^{\circ}$ ) montre que toutes les identifications qu'on a faites de T'ai-yuen avec des localités qui portent aujourd'hui ce nom sont erronées; selon lui, la position exacte de T'ai-yuen ne peut pas être déterminée ; elle devait être au nord de la province où se trouvait la capitale. 
04. (391) Chan-fou est l'appellation, et Tchong le nom de famille de ce personnage qui était marquis de Fan.Une ode du Che king célèbre ses mérites $\left(6^{\mathrm{e}}\right.$ de la décade tang; trad. Legge, p. 541; [trad. Couvreur]).

04. (392) Se-ma Ts'ien ne reproduit pas tout le discours qui se trouve ici dans le Коио уи. A la fin de ce texte, le Коио уи ajoute : « et le roi Yeou fut donc battu et anéanti », c'est-à-dire que la perte du roi $Y e o u$, fils du roi Siuen, aurait été la conséquence du recensement fait par son père contre l'avis de Tchong Chan-fou.

04. (393) Tchang Cheou-kié rapporte, d'après le tch'oen ts'ieou de Tcheou la légende suivante sur la mort du roi Siuen:

«Le roi Siuen mit à mort le comte de Tou, quoiqu'il fût innocent. Trois ans plus tard, le roi Siuen assembla des seigneurs pour chasser à Pou. Au milieu du jour le comte de Tou se dressa sur la gauche du chemin; il avait un vêtement et un bonnet rouges et il tenait à la main un arc et des flèches rouges ; il tira sur le roi Siuen et l'atteignit au cour ; le roi eut l'épine dorsale brisée et mourut.

04. (394) Коио уи: Tсhеои уи, $10^{\mathrm{e}}$ discours.

04. (395) Au lieu de [], le Коио уи écrit : (le pays des) Tcheou occidentaux; dans les deux textes, le sens est le même ; le pays dont il s'agit est celui où se trouvait la ville de Hao (cf. p. 241, n. 2) qui était la capitale des Tcheou avant qu'ils eussent émigré du côté de l'orient.

04. (무) Les trois rivières furent soulevées par un tremblement de terre; ces trois rivières sont : la rivière Wei, la rivière King (cf. note 02.207 ) et la rivière $L o$; celle-ci est aussi un cours d'eau du Chàn-si ; elle se jette dans le Hoang-ho à peu près au même point que la rivière Wei, en sorte que plusieurs commentateurs la considèrent comme un affluent de gauche du Wei : elle ne doit pas être confondue avec la rivière du même nom qui se trouve dans le Ho-nan et sur les bords de laquelle s'élevait la ville de Lo-yang.

04. (397) Les commentateurs ne disent pas comment il faut analyser le nom de Po-yang-fou. Ce personnage était grand astrologue à la cour des Tcheou; T'ang Kou (qui vivait sous la dynastie $O u, 222-265$ ap. J.-C.) l'identifie avec le célèbre Lao-tse; mais son opinion ne s'accorde pas avec la tradition qui veut que Lao-tse ait eu une entrevue avec Confucius, car Confucius ne vécut que trois siècles après le roi Siuen.

— Le discours de Po-yang-fou est rapporté non seulement par le Kouo yu, mais aussi par le chapitre $\mathrm{Ou}$ hing tche du Livre des Han antérieurs (Ts ïen Han chou, chap. XXVII, $1^{\mathrm{e}}$ section de la $3^{\mathrm{e}}$ partie, p. $5 \mathrm{v}^{\circ}$ ).

04. (398) La leçon du Kоио yи me paraît préférable : min tche loan ye, au lieu de min loan tche ye : «c'est l'indice de troubles chez le peuple. »

04. (399) Wei Tchao explique le mot [] comme l'équivalent du mot [] qui est la leçon du Chou king.

04. (400) La construction de la phrase chinoise est ici assez obscure.

04. (401) Le Коио уи dit : «Lorsque l'eau et la terre... »

04. (402) Le $I$ et le Lo sont les deux rivières du Ho-nan près du confluent desquelles était la ville de Lo-yang. On a vu (note 256) que la résidence des premiers empereurs Hia passe pour avoir été dans le Ho-nan. Mais il n'est point sûr que la résidence du dernier de ces souve rains, Kié, ait été au sud du Hoang-ho ; c'est cependant ce qui est supposé par ce texte.

04. (403) La dynastie Chang résidait dans la partie du Ho-nan qui est au nord du Hoang ho et était donc voisine de ce fleuve.

04. (404) Le cycle de dix a joué de tout temps un grand rôle dans les calculs du temps, comme le prouve l'antique existence de la série des termes kia, $i$, ping, ting... 
04. (405) C'est la montagne qui a donné son nom à la sous-préfecture de $K$ 'i-chan, préfecture de Fong-siang, province de Chàn-si.

04. (406) Dans l'antiquité, on désignait les femmes par deux caractères dont le premier indiquait 1e pays d'où elles étaient originaires et dont le second était leur nom de clan. Pao-se signifie donc : la femme qui avait pour nom de clan $S e$ et qui était originaire du pays de Pao (aujourd'hui sous-préfecture de Pao-tch'eng, préfecture de Han-tchong, province de Chànsi) ; on verra quelques lignes plus bas pourquoi $\mathrm{Pao}$-se passait pour originaire du pays de $\mathrm{Pao}$, quoiqu'elle n'y fût point née.

04. (407) Le pays de Chen correspond à la sous-préfecture de Nan-yang, préfecture de Nan-yang, province de Ho-nan. Les princes de cet État avaient pour nom de clan Kiang et étaient descendants des Chefs des quatre montagnes (cf. notes 00.159 et 00.160).

04. (408) C'est sans doute le mêm e personnage que le Po-yang-fou dont il a été question plus haut (cf. note 396).

04. (0ㅗ) Kоио yu: Tcheou yu, $1^{\text {er }}$ discours.

04. ( $\underline{410})$ Les mémoires des annalistes sont désignés ici par l'expression que Se-ma Ts’ien a donnée pour titre à son œuvre.

04. (411) Le Коио уи dit: «Les âmes d'hommes (du pays) de Pao se transformèrent en deux dragons... »

04. (412) Deux anciens princes décédés.

04. (413) Wei Tchao dit que cette écume était celle qui sortait de la bouche des dragons. Lieou Hiang, dans le Ou hing tche du Ts'ien Han chou, estime que c'était une écume de sang.

04. (414) Le Коио уи écrit : «Elle fut placée dans un coffret qu'on cacha. »

04. (1ㅗ) Le père du roi Siuen.

04. (416) Proprement: «crier toutes ensemble contre elle». - Pourquoi les femmes étaient-elles nues ? c'était peut-être afin que l'écume sur naturelle entrât dans l'une d'elles et que le prodige fût ainsi exorcisé ; l'hypothèse est plausible puisque nous voyons que c'est cette écume, transformée en lézard, qui produit la grossesse de la petite fille du sérail. Cette écume semble avoir été le liquide spermatique des dragons.

04. (417) Le mot a le sens de tortue ou celui de lézard. Certains textes donnent la variante [] ; c'est donc le sens de lézard qu'il faut adopter.

04. (1ㅗ) A l'âge de sept ans.

04. (419) C'est l'àge où les jeunes filles sont nubiles, c'est -à-dire à quinze ans suivant les rites.

04. (420) Le Kоио уи ajoute ici la phrase : «Au temps du roi Siuen, elle enfanta. »

04. (421) A partir des mots «Au temps du roi Siuen... » jusqu’à « ... l'en fant qui avait été abandonné par la jeune femme du sérail », ce paragraphe est placé par le Коио уи avant tout ce qui précède. Se-ma Ts'ien a mis un ordre plus régulier entre les diverses parties du récit.

04. (222) Cf. note 396.

04. (423) Le bûcher destiné au jour était fait avec des matières qui, en brûlant, produisent beaucoup de fumée ; c'est ainsi qu'aujourd'hui encore, en Mongolie, on se sert de crottes de loup pour donner des signaux. Le bûcher destiné à la nuit était fait avec des matières qui produisent une vive flamme.

04. (424) Se-ma Ts'ien ne mentionne pas la fameuse éclipse du soleil qui eut lieu la $6^{\mathrm{e}}$ année du roi Yeou et fut l'occasion d'une des odes du Che king $\left(9^{\mathrm{e}}\right.$ de la décade de Ki-fou; trad.

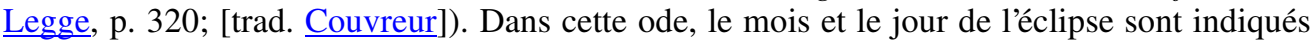
et sont trouvés exacts par les calculs des astronomes ; l'éclipse eut lieu le 29 août 776 (775 en style astronomique). 
04. (2ㄷ) D'après le T'ong kien tsi lan (ch. III, p. 24 r ${ }^{\circ}$ ), ce personnage était prince du Kouo oriental (cf. note 385).

04. (르) Cf. note 407.

04. (427) Les princes de Tseng avaient pour nom de clan $S e$ et se prétendaient descendants de $Y u$ le Grand, fondateur de la dynastie Hia. Le pays de Tseng était à $80 l i$ à l'est de la sous-préfecture de $I$, préfecture de Yen-tcheou, province de Chan-tong.

- Cette identification, qui est faite d'ap rès les indications du Kouo ti tche, est cependant peu plausible. Puisque le marquis de Chen s'allia aux barbares occi dentaux et puisque le roi P'ing, successeur du roi Yeou, transféra sa capitale sur les bords de la rivière Lo pour éviter le danger qui le menaçait à l'ouest, il semble peu probable qu'un État tout oriental ait aussi attaqué le roi de la dynastie Tcheou.

04. (녕) Cette montagne est au sud-est de la sous-préfecture de Lin-t'ong, préfecture de Singan, province de Chàn-si.

04. (429). Celui qui est chargé des sacrifices aux ancêtres est regardé comme le chef actuel de la famille.

04. (430) C'est la ville qui avait été construite par le roi Tch'eng (cf. p. 247).

04. (431) Cf. Mém. hist., chap. XXXII, XL, V et XXXIX.

04. (432) Le mot [] désigne un seigneur qui avait acquis assez de puissance pour commander à tous les autres. L'expression [] paraît avoir un se ns plus restreint et désigner non pas les seigneurs qui commandaient à tout l'empire, mais ceux qui avaient la suprématie dans une région plus ou moins étendue.

04. (333) Ce synchronisme est très important; l'année 722 avant $\mathrm{J}$.-C, est la première de la période tch'oen ts'ieou.

04. (434) L’incident auquel il est fait ici allusion est raconté dans le Tso tchoan, 6 e année du duc Yn; trad. Legge, p. 21 ; [trad. Couvreur].

- Le premier prince de Tcheng était un frère cadet du roi Siuen et reçut de lui un fief qui correspond à l'ancienne sous -préfecture de Tcheng, préfecture secondaire de Hoa, province de Chàn-si. Lorsque le roi P'ing transféra sa capitale à Lo-yang, les princes de Tcheng émigrèrent aussi dans l'est, et leur nouveau royaume eut son centre sur le territoire de la sous-préfecture actuelle de Sin-tcheng, province de Ho-nan.

04. (435) L'édition de K'ien-long change le mot yuen= irrité, contre le mot yuen qui est, d'après le Tso tchoan ( $8^{\mathrm{e}}$ année du duc $\left.Y n\right)$, le nom du haut dignitaire de Tcheng qui vint à Lou pour négocier l'échange des deux territoires.

04. (366) Si l'on s'en rapporte au Tso tchoan ( $8^{\mathrm{e}}$ année du duc Yn) et au commentaire de Tou $Y u$, le texte de Se-ma Ts'ien renfermerait ici une erreur, car Hiu-tien n'appartenait pas au Fils du ciel, mais au duc de Lou. Voici comment les faits doivent être rétablis :

Le roi Tch'eng avait eu quelque temps le projet d'aller se fixer à Lo-yang (cf. p. • 247 ); c'est pourquoi il donna au duc de Tcheou la terre de Hiu-tien comme résidence pour les ducs de Lou quand ils viendraient rendre hommage à la cour ; Hiu-tien, dont le nom signifie le champ (voisin de) Hiu, se trouvait sur le territoire de la préfecture secondaire de Hiu, province de Ho-nan, et était en effet assez voisin de Lo-yang. D'autre part, le roi Siuen avait donné au prince de Tcheng la terre de Pong) afin qu'il pût s'y établir quand il devrait aider le Fils du ciel à faire le sacrifice au T'ai-chan; Pong se trouvait dans la sous-préfecture actuelle de $P i$, préfecture de Tcheou, province de Chan-tong. La cinquième année du roi Hoan, Tchoang, duc de Tcheng, donna à $Y n$, duc de Lou, la terre de Pong qui était voisine de l'État de Lou et reçut en échange la terre de Hiu-tien qui était proche de son fief. Cette transaction ne faisait en réalité aucun tort au roi, mais elle était illicite, car les seigneurs ne possédant leurs terres que par une investiture du Fils du ciel n'auraient pas dû en trafi quer à leur guise. 
- Ce récit nous montre que les seigneurs possédaient, en outre de leurs fiefs, d'autres terres qui leur avaient été données en dédommagement de telle ou telle corvée à laquelle ils étaient astreints ; ces terres, d'ordinaire peu étendues, ne payaient aucun impôt au roi et on les désignait sous le nom de t'ang mou tche $i$, proprement : territoires pour le bain, c'est-à-dire territoires dont les revenus étaient affectés aux bains ou, d'une manière plus générale, aux dépenses privées du seigneur; le mot mou désigne le lavage de la chevelure; quant au mot t'ang, c'est, nous dit un commentateur du Tcheou li, l'eau chaude dont on se servait pour les bains du corps (cf. K'ang hi tse tien, au mot mou).

04. (437) Cf. Tso tchoan, $5^{\mathrm{e}}$ année du duc Hoan ; trad. Legge, p. 46 ; [trad. Couvreur].

04. (438) Ce Hei-kien, duc de Tcheou, ne nous est connu que par deux textes du Tso tchoan ( $5^{\mathrm{e}}$ et $18^{\mathrm{e}}$ années du duc Hoan; trad. Legge, p. 45 [trad. Couvreur] et 71 [trad. Couvreur), dont le second raconte en détail les faits que Se-ma Ts'ien se contente d'indiquer ici.

04. (439) K'o avait pour appellation $T s e-i$; il était le fils du roi Hoan et, par conséquent, le frère cadet du roi Tchoang.

04. (4ㅇ) Cet État de Yen est le Yen méridional, dont les princes avaient pour nom de clan $K i$; c'est aujourd'hui la sous -préfecture de Yen-tsin, préfecture de Wei-hoei, province de Ho-nan.

04. (441) Le nom posthume de ce roi est généralement écrit Hi. Se-ma Ts'ien l'écrit [], mais Tchang Cheou-kié dit que ce caractère doit être prononcé comme le caractère hi.

04. (442) Cf. note 00.162 .

04. (443) Nous trouvons ici pour la première fois une tournure de phrase qui est très fréquente chez Se-ma Ts'ien; quand il veut raconter un événement, il en cite la date, puis il s’interrompt brusquement pour exposer les faits antécédents qui sont la raison d'être de celui qu'il a en vue.

04. (444) Nous apprenons, par le Tso tchoan $\left(19^{\mathrm{e}}\right.$ année du duc Tchoang; trad. Legge, p. 99 [trad. Couvreur]), que ce grand officier s'appelait Wei Kouo ; irrité de ce que le roi lui avait ravi son jardin, il fomenta une rébellion avec quatre autres grands officiers appelés Pien Po, Tchan-fou, Tse-k’in et Tchou Koei ; les conjurés s'appuyèrent sur les soldats des pays de Wei (sous-préfecture de $K^{\prime} i$, province de Ho-nan) et de Yen méridional (cf. note 440) pour chasser le roi Hoei et mettre T'oei à sa place. - Le texte du Tso tchoan donne à entendre au contraire que les rebelles furent battus, mais cela ne s'accorde guère avec ce qui suit.

04. (445) Aujourd'hui, sous -préfecture de Wen, préfecture de Hoai-k'ing, province de Ho-nan.

04. (446) Tou Yu nous apprend que la ville de $L i$ était, au temps des $T$ sin, la sous-préfecture de Yang-ti: elle se trouvait donc sur le territoire qui est aujourd'hui celui de la préfecture secondaire de $Y u$, préfecture de K'ai-fong, province de Ho-nan.

04. (447) T'oei était le fils du roi Tchoang, le frère cadet du roi Hi et par conséquent l'oncle du roi Hoei.

04. (448) Le pays de Kouo est appelé Kоио-chou par le Tso tchoan; c'était donc le Kouo occidental (cf. note 385 ).

04. (449) Ils s’indignèrent, dit le Tso tchoan (20ªnnée du duc Tchoang [trad. Couvreur]), de ce que T'oei se livrait aux réjouissances en faisant faire des chants et des danses en un temps où tous les esprits étaient inquiets.

04. (5ㅜ) Cf. note 00.162 .

04. (451) La mort du roi Hoei eut lieu en réalité la $24^{\text {e }}$ année (653 av. J.-C.), mais son fils, qui fut le roi Siang, craignant les troubles que pourrait susciter Chou-tai (voyez le paragraphe suivant), n'annonça la mort de son père que le douzième mois de l'année suivante. C'est pourquoi le Tso tchoan assigne la mort du roi Hoei à la $7^{\mathfrak{e}}$ année du duc $H i$, de $L o u$ (653 av. J.C.), tandis que le Lch'oen ts'ieou la rapporte, comme Se-ma Ts'ien, à l'année suivante. 
04. (452) Cette femme était originaire du pays de Tch'en dont les princes avaient pour nom de clan Koei ; c'est pourquoi on l'appelait Tch'en Koei (cf. note 406).

04. (453) Chou-tai reçut le fief de Kan (non loin de la sous-préfecture de Lo-yang, préfecture et province de Ho-nan) et eut le titre posthume de duc Tchao. Chou-tai signifie : le puîné Tai.

04. (5ㄴ) Tso tchoan, $12^{\mathrm{e}}$ année du duc $\mathrm{Hi}$.

04. (455) Cf. Mém. hist., chap. LXII, et Mayers, Manual, $\mathrm{n}^{\circ} 293$.

04. (456) Le prince de Tsin avait secouru le roi en attaquant à son tour les Jong.

- On voit que le duc Hoan, de Ts'i, prenait au sérieux son rôle d'hégémon, et était comme l'arbitre suprême de l'empire.

04. (457) Kouo et Kao sont les noms de famille de deux personnages, parents du duc de Ts'i, qui étaient hauts dignitaires de premier rang à sa cour et avaient reçu du Fils du ciel le titre de Surveillants.

04. (458) C'est -à-dire sujet d'un seigneur qui est lui -même sujet du Fils du ciel.

04. (459) Le roi $O u$, fondateur de la dynastie Tcheou, avait épousé une fille du premier duc de $T s$ 'i. Les ducs de $T s$ 'i pouvaient ainsi être considérés comme les beaux-pères des rois Tcheou.

04. (누) Il y fut rappelé par le roi lui-même.

- D'après le Tso tchoan ( $22^{\mathrm{e}}$ année du duc $\mathrm{Hi}$ ), Chou-tsi revint la quatorzième et non la douzième année du roi Siang.

04. (461) Hoa était un petit royaume dont les princes avaient pour nom de clan $K i$; il était sous la dépendance du pays de Tcheng et c'est pour avoir voulu secouer ce joug et se mett re sous la protection du pays de Wei que le marquis de Tcheng l'attaqua (cf. Tso tchoan, $20^{\mathrm{e}}$ année du duc Hi). La capitale de l'État de Hoa était à $25 l i$ au sud-est de la ville de Kou-che, près de la ville préfecturale de Ho-nan.

04. (462) Yeou Suen et Po Fou étaient deux grands officiers de la cour du roi.

04. (녀) Tso tchoan, $24^{\mathrm{e}}$ année du duc $\mathrm{Hi}$.

04. (464) D’après le Si ts’ing kou kien (publié en 1749), qui donne quatre représentations graphiques de coupes $t$ sio, ce vase aurait eu la forme d'un casque renversé monté sur trois pieds; il avait de 5 à 6 pouces de hauteur.

- L’incident auquel Se-ma Ts'ien fait allusion est raconté dans le Tso tchoan $\left(21^{\mathrm{e}}\right.$ année du duc Tchoang): en l'an 673, le roi Hoei avait été fêté par le duc Li, de Tcheng, et lui avait donné une ceinture ornée d'un miroir ; puis il se rendit auprès du prince de Kouo à qui il fit présent d'une coupe tsio; le duc $\mathrm{Li}$, de Tcheng, fut jaloux de ce cadeau qu'il trouvait supérieur à celui qu'il avait reçu et le duc Wen, fils et successeur du duc $L i$, hérita de son ressentiment.

04. (465) Cf. note 461. Le roi avait encouragé le prince de Hoa à se détacher du pays de Tcheng et à reconnaître l'État de Wei comme son protecteur.

04. (466) Le discours de Fou Tchen se trouve dans le $\underline{\text { Tso tchoan }}$ ( $24^{\mathrm{e}}$ année du duc Hi) et dans le Коио уи (Tсhеои уи, $2^{\mathrm{e}}$ partie, $1^{\circ}$, discours) ; mais les paroles qu'on lui attribue dans ces deux ouvrages sont fort différentes ; quant à Se-ma Ts'ien, il se borne à résumer l'argumen tation en quelques mots.

- On remarquera que Se-ma Ts'ien assigne pour date à ces faits la $13^{\mathrm{e}}$ année du roi Siang (639 av. J.-C.), tandis que le Tso tchoan les rapporte à la 24e année du duc Hi (636 av. J.-C.). Se-ma Ts'ien est d'accord avec le Коио уи, mais tous deux sont dans l'erreur et c'est le Tso tchoan qui a raison, s'il faut en croire Wang Yuen-soen. A ce propos, il est à remarquer que les commentateurs du Kоио уu font concorder la $13^{\mathrm{e}}$ année du roi Siang avec la $20^{\mathrm{e}}$ du duc 
$\mathrm{Hi}$; mais c'est avec la $21^{\mathrm{e}}$ qu'elle concorde d'après tous les chronologistes et d'après les tableaux de Se-ma Ts'ien lui-même (Mém. hist., chap. XIV).

04. (467) Коио уи: Tcheou yu, $2^{\mathrm{e}}$ partie, $1^{\mathrm{er}}$ discours.

04. (468) Ceci n'est encore que le résumé des discours qui se trouvent dans le Tso tchoan et le Коио уи.

04. (469) Il la dégrada, dit le Tso tchoan ( $21^{\mathrm{e}}$ année du duc $H i$ ), parce qu'elle avait eu des relations illicites avec le frère du roi, Chou-tai.

04. (470) T'an Po était un grand officier de la cour des Tcheou.

04. (471) L'expression est fort elliptique. Wei Tchao la commente en disant : Il se mit à la tête des siens.

04. (472) Cette phrase est destinée à expliquer l'immixtion des barbares dans les affaires du royaume du Milieu. Autrefois la reine femme de l'empereur Hoei avait noué des relations avec les $T i$ pour mettre son fils Tai sur le trône; le projet échoua, mais Tai conserva des rapports avec les barbares; ce fut lui qui suggéra au roi l'idée de se servir d'eux : pour combattre Tcheng ; puis, quand le roi dégrada la femme quil avait prise chez les $T i$ parce qu'elle avai t commis adultère avec Tai, ce fut encore celui-ci qui se mit à la tête des troupes barbares, chassa le roi de sa capitale et s'arrogea le pouvoir.

04. (473) La ville de Fan, étant devenue la résidence du roi Siang, prit le nom de ville de Siang (aujourd'hui encore sous-préfecture de Siang-tch'eng, préfecture secondaire de Hiu, province de Ho-nan).

04. (474) Cf. note 445.

04. (475) Ce fut le second des cinq hégémons (cf. note 00.162). — Le caractère désigne le plus souvent un vin parfumé dont on se servait aux sacrifices. Cependant on le trouve dans le Che king ( $4^{\mathrm{e}}$ des odes du pays de Tcheng; trad. Legge, p. 131 ; [trad. Couvreur]) avec le sens de fourreau d'arc ; cette acception me parait mieux convenir ici, car il est évident que les présents que le roi fait au duc sont les insignes de l'hégémo nie et symbolisent sa suprématie guerrière.

04. (476) Le Ho-nei est une division administrative de l'époque des Han ; il correspond assez exactement à la partie du Ho-nan qui est au nord du Fleuve.

04. (477) D'après le Tch'oen ts'ieou, la réunion à Tsien-t'ou aurait eu lieu au cinquième mois et la réunion à Ho-yang en hiver.

— Tsien-t'ou correspond à la sous-préfecture de Yong-tsé, préfecture de K'ai-fong, province de Ho-nan.

- Ho-yang était sur le territoire de la sous-préfecture de Mong, préfecture de Hoai-k’ing, province de Ho-nan.

04. (478) C'est-à-dire le Tch'oen ts'ieou de Confucius (cf. $28^{\mathrm{e}}$ année du duc Hi); c'est le Tso tchoan qui remarque que le livre classique dénature ici les faits ; comme il était indigne du roi d'obéir à un ordre d'un de ses sujets, le Tch'oen ts'ieou explique sa venue auprès du duc de $T \sin$ en disant qu'il faisait une tournée d’inspection des fiefs.

04. (479) Toutes les éditions de Se-ma Ts'ien donnent la leçon : trente-deux. Cependant les historiens modernes et Se-ma Ts'ien lui-même dans ses tableaux chronologiques (chap. XIV) disent que le roi Siang mourut dans la $33^{\mathrm{e}}$ année de son règne (619).

04. (480) Cette tribu Jong avait pour nom de clan Yun: elle résidait primitivement sur le territoire de la préfecture secondaire de Koa, dans le Kan-sou, et une de ses branches s'appelait la tribu Lou-hoen; elle était donc au nord-ouest des pays de Ts'in et de Tsin. En l'an 638 avant J. -C., les princes de $T$ s'in et de $T$ sin l'engagèrent à venir s'établir auprès de la rivière $I$ (cf. Tso tchoan, $22^{\mathrm{c}}$ année du duc $\mathrm{Hi}$ ), La localité où ils se fixèrent prit le nom de la 
principale tribu et s'appela Lou-hoen; elle se trouvait à l'ouest de la sous -préfecture de Song, préfecture et province de Ho-nan (cf. T'ong kien tsi lan, $14^{\mathrm{e}}$ année du roi Siang); c'est là que le roi de Tch'ou les attaqua: puis, comme il se trouvait tout près de la rivière $L o$ et de la résidence du Fils du ciel, il envoya des gens interroger le roi sur les dimensions et le poids des trépieds.

04. (481) Les neuf trépieds étaient considérés comme une sorte de palladium qui sauvegardait la dynastie. D'après certains auteurs, sur chacun d'eux était représenté l'une des neuf provinces de $Y u$.

04. (482) Wang-suen Man était un grand officier de la cour des Tcheou : il est mentionné dans le Коио уи (Tcheou yu, $2^{\mathrm{e}}$ partie, p. $8 \mathrm{v}^{\circ}$ ). Ce personnage réussit à éluder la question indiscrète du roi de $T$ ch'ou en lui disant que le poids et les dimensions des trépieds variaient avec la plus ou moins grande vertu du Fils du ciel (cf. Tso tchoan, $3^{\mathrm{e}}$ année du duc Siuen).

04. (483) Cf. Tso tchoan, $12^{\mathrm{e}}$ année du duc Siuen. Quoique le prince de Tcheng se fût rendu à discrétion, le roi de Tch'ou lui fit grâce et lui permit de conserver l'intégrité de ses États.

04. (484) Tous les événements auxquels Se-ma Ts'ien fait allusion brièvement dans ces pages sont racontés dans la section des Mémoires historiques intitulés Maisons héréditaires.

04. (485) Le Tso tchoan nous apprend que l'héritier présomptif, Cheou, mourut le cinquième mois, et la reine $M o u$ le huitième mois $\left(15^{\mathrm{e}}\right.$ année du duc Tchao $)$.

04. (486) Tchao était, nous dit Kia K'oei, l'aîné des fils nés de femmes se condaires.

04. (87) La vingt-cinquième année de son règne (525 av. J.-C.).

04. (488) Kai était le frère cadet de la reine Mou, qui avait été la première épouse du roi King.

04. (489) Mong était le second fils de la reine Mou, le frère de l'héritier pré somptif Cheou (cf. note 485). - Les troubles qui s'élevèrent après la mort du roi King sont racontés en détail dans le $\underline{\text { Tso tchoan }}\left(23^{\mathrm{e}}\right.$ année du duc Tchao).

04. (490) Quoiqu’il ait reçu un titre posthume, ce souverain ne figure pas dans la liste des rois de la dynastie Tcheou.

04. (91) Cette localité de Tsé devait être voisine de la capitale (Lo-yang), mais je n'ai pas pu en déterminer la situation exacte.

04. (492) Voyez le Коио уи: Tcheои уи, $3^{\mathrm{e}}$ partie, dernier discours.

04. (493) D'après le Tso tchoan, Confucius mourut le $18^{\mathrm{e}}$ jour du $4^{\mathrm{e}}$ mois, ce jour étant désigné par les caractères cycliques ki tch'eou ; il y a d'ailleurs là une difficulté, car le jour ki tch'eou n'est pas le $18^{\mathrm{e}} \mathrm{du} 4^{\mathrm{e}}$ mois cf. Legge, Tso tchoan, p. 846).

04. (494) Se-ma Ts'ien dit ici que le roi King mourut après quarante-deux ans de règne, soit en 478 avant J.-C.; cependant, dans son tableau chronologique (chap. XIV), il lui assigne quarante-trois ans de règne et le fait donc mourir en 477 avant J. -C. - Tou Yu, dans son commentaire au Tch'oen ts-ieou, adopte le chiffre de 42 années; mais il semble bien que ce soit une erreur de sa part et Wang Ming-cheng (Che ts'i che chang tsio, chap. III, § 9), après une longue discussion de la question se prononce en faveur du nombre 43. Il est à remarquer cependant que le T'ong kien kang mou et le T'ong kien tsi lan, se fondant sur le Tchou chou ki nien, attribuent 44 années de règne au roi King et rapportent donc sa mort à l'an 476 avant J.-C. ; cette divergence avec les données de Se-ma Ts'ien ne fausse pas cependant le reste de la chronologie, car, tandis que Se-ma Ts'ien assigne huit années de règne au roi Yuen, les ouvrages que nous venons de citer ne lui en attribuent que sept, ce qui rétablit l'accord (cf. note 500).

04. (495) D'après Se-ma Ts'ien, le successeur du roi King aurait été Jen, roi Yuen et le successeur du roi Yuen, aurait été Kié, roi Ting. Or le $21^{\mathrm{e}}$ roi de la dynastie Tcheou s'appelait déjà Ting wang; il y aurait eu ainsi deux rois qui eurent le même titre posthume. 
- D'autre part, le Che pen dit que le successeur du roi King fut Kié, roi Tcheng et que le successeur du roi Tcheng fut Tch'e, roi Yuen. Hoang-fou Mi, désireux de concilier Se-ma Ts'ien et le Che pen, assimile le roi Tcheng au roi Ting et en fait le roi Tcheng-ting, mais il conserve l'ordre de succession indiqué par le Che pen et place le roi Tcheng-ting avant le roi Yuen. Enfin les historiens modernes ont adopté la dénomination de roi Tcheng-ting forgée par Hoang-fou Mi, mais ils sont revenus à l'ordre des Mémoires historiques qui placent le roi Yuen immédiatement après le roi King. En définitive, le texte du Che pen paraît ne mériter aucune confiance et il faut adopter purement et simplement ce que nous dit Se-ma Ts'ien : le prétendu roi Tcheng-ting s'appelle en réalité le roi Ting et a le même titre posthume que l'un de ses prédécesseurs; il est d'ailleurs le fils, et non le père, du roi Yuen (cf. Wang Ming-cheng, loc. cit.).

04. (496) Tche-po avait pour nom de famille Siun et pour nom personnel Yao ; il avait pris une influence prépondérante dans le pays de $T \sin$ et projetait de s'emparer du gouvernement. Les chefs des trois familles Han, Tchao et Wei le prévinrent en l'assassinant ; eux-mêmes détrônèrent quelques années plus tard le dernier duc de $T$ sin et se partagèrent son royaume pour en faire les États de Han, de Tchao et de Wei; ces trois États formés des débris du pays de $T \sin$ furent appelés les trois $T \sin$.

04. (497) Voici, d'après le T'ong kien kang mou, quels changements s’in troduisirent alors dans le royaume des $T$ cheou :

Le roi $K$ 'ao avait obtenu le pouvoir en assassinant son frère, qui lui-même avait tué son aîné ; il craignait que son frère cadet, Kié, ne lui fit subir le même sort ; c'est pourquoi il partagea la capitale avec lui : il lui donna la partie occidentale qui s'appelait Ho-nan (ce qui est l'origine du nom de Ho-nan que porte aujourd'hui la ville préfectorale qui s'élève en ce lieu), et il garda pour lui la partie orientale appelée Tch'eng -tcheou (cf. note 293) ou aussi ville basse ; la partie occidentale de la cité avait porté autrefois le nom de Wang-tch'eng (ville du roi) ou de Kia-jou (cf. note 282) ; c'est parce qu'il y était maître absolu que le duc Hoan donna à sa maison le nom de Tcheou occidentaux; pour dissimuler sa demi-abdication, le roi Kao imagina de dire qu'il rétablissait au profit de son frère la situation privilégiée qu'avait eue le duc de Tcheou, au temps des roi Ou et Tch'eng. Ces faits se passaient en 441 avant J.-C.

En 376, le pouvoir royal s'étant affaibli encore davantage, le duc Hoei, des Tcheou occidentaux, chargea son fils cadet de prendre le pouvoir dans la ville orientale qui était restée jusqu'alors en possession d u roi ; pour déguiser cette usurpation, il donna à son fils le titre de «celui qui est chargé du roi ». Ce fils eut le même nom posthume que son père et fut le duc Hoei, des Tcheou orientaux. La ville de Kong (aujourd'hui sous -préfecture de Kong, à l'est de la préfecture de Ho-nan) n'était pas sa résidence, mais seu lement la terre dont les revenus lui appartenaient.

04. (498) Cf. note 496. - C'est à cette date de 403 que Se-ma Koang commence sa fameuse histoire intitulée T'ong kien, qui est le noyau du T'ong kien kang mou .

04. (99) Cette prédiction est assez obscure ;

- En premier lieu elle est présentée avec diverses variantes ;

* ici, nous avons la leçon : après 17 ans ;

* dans le chapitre XXVIII des Mémoires historiques et dans le chapitre XXV du Ts'ien Han chou, nous lisons 70 ans ;

* enfin, dans le chapitre V des Mémoires historiques, nous lisons 77 ans.

— La leçon : 17 ans est la seule qui soit expliquée par les commentateurs, mais elle se prête à deux interprétations :

* suivant la première, il s'écoula cinq cents ans depuis le moment où Fei-tse reçut le fief de $T s^{\prime}$ ’in et acquit ainsi pour sa famille une situation indépendante des Tcheou, jusqu'à la $2^{\mathrm{e}}$ année du duc Hiao (360 av. J.-C.) : en cette année-là, le roi Hien envoya de la viande sacrée au duc Hiao et scella ainsi la réconciliation ou la réunion avec 
lui ; dix-sept ans après, c'est-à-dire en 343 avant J.-C., le roi Hien conféra au duc Hiao le titre d'hégémon, c'est -à-dire de chef supérieur en force à tous les autres seigneurs (cf. p. $\bullet_{303}$ );

* d'après l'autre interprétation, il s'écoula cinq cents ans depuis le moment où le duc Siang, de $T s^{\prime}$ in , se proclama lié heou, jusqu'à la $52^{\mathrm{e}}$ année du roi $T c h a o$, de $T s^{\prime}$ 'in (255 av. J.-C.), époque où le souverain triompha complètement de la dynastie Tcheou, s'annexa la majeure partie de ses États et réunit ainsi les deux royaumes ; dix-sept ans plus tard (238 av. J.-C.), le prince Tcheng, qui devait être T'sin Che-hoang-ti, tua l'amant de sa mère et établit ainsi son autorité qui fut celle d'un roi qui s'impose par la force.

Dans les deux interprétations, le chiffre de 500 ans n'est qu'une approximation très vague.

- Dans le chapitre LXIII des Mémoires historiques, Se-ma Ts'ien cite l'opinion de certains auteurs d'après lesquels ce Tan, grand astrologue des Tcheou, ne serait autre que Lao-tse ; mais cette identification ne s'accorderait pas avec l'entrevue que Lao-tse passe pour avoir eue avec Confucius, lequel mourut en 479 avant J.-C. ; nous avons vu plus haut (note 397) que le commentateur T'ang Kou identifie au contraire Lao-tse avec Po-yang-fou qui vécut trois siècles avant Confucius.

04. (00) D'après la chronologie de Mayers, qui coïncide avec celle du XVe chapitre des Mémoires historiques, le roi Lié ne régna que sept ans et mourut donc en 369 avant J.-C. Les dates que nous avons indiquées entre parenthèses dans ce chapitre sont celles de la chronologie commune qui est exposée dans les tables de Mayers et qui ne diffère qu'en un seul point peu important (cf. note 494) de la chronologie établie par Se-ma Ts'ien lui-même dans les chapitres XIV et XV de son ouvrage; mais si l'on s'en tenait uniquement aux Annales principales des Tcheou, il faudrait dresser une autre chronologie; le tableau cidessous en rend compte :

\begin{tabular}{|c|c|c|c|c|c|c|c|c|c|}
\hline \multicolumn{4}{|c|}{$\begin{array}{c}\text { D'après les Annales principales } \\
\text { des Tcheou }\end{array}$} & \multicolumn{3}{|c|}{$\begin{array}{c}\text { D’après le chapitre XV } \\
\text { des Mém. hist }\end{array}$} & \multicolumn{3}{|c|}{ D’après Mayers } \\
\hline & $\begin{array}{l}\text { règne } \\
\ldots . \text { ans }\end{array}$ & de & à & $\begin{array}{l}\text { règne } \\
\ldots . \text { ans }\end{array}$ & $\mathrm{de}$ & à & $\begin{array}{l}\text { règne } \\
\ldots . \text { ans }\end{array}$ & $\mathrm{de}$ & à \\
\hline Siuen & 46 & 828 & 783 & 46 & 827 & 782 & 46 & 827 & 782 \\
\hline Yеои & 11 & 782 & 772 & 11 & 781 & 771 & 11 & 781 & 771 \\
\hline P’ing & 51 & 771 & 721 & 51 & 770 & 720 & 51 & 770 & 720 \\
\hline Hoan & 23 & 720 & 698 & 23 & 719 & 697 & 23 & 719 & 697 \\
\hline Tchoang & 15 & 697 & 683 & 15 & 696 & 682 & 15 & 696 & 682 \\
\hline$H i$ & 5 & 682 & 678 & 5 & 681 & 677 & 5 & 681 & 677 \\
\hline Hoei & 25 & 677 & 653 & 25 & 676 & 652 & 25 & 676 & 652 \\
\hline Siang & 32 & 652 & 621 & 33 & 651 & 619 & 33 & 651 & 619 \\
\hline K'ing & 6 & 620 & 615 & 6 & 618 & 613 & 6 & 618 & 613 \\
\hline K'oang & 6 & 614 & 609 & 6 & 612 & 607 & 6 & 612 & 607 \\
\hline Ting & 21 & 608 & 588 & 21 & 606 & 586 & 21 & 606 & 586 \\
\hline Kien & 14 & 587 & 574 & 14 & 585 & 572 & 14 & 585 & 572 \\
\hline Ling & 27 & 573 & 547 & 27 & 571 & 545 & 27 & 571 & 545 \\
\hline King & 25 & 546 & 522 & 25 & 544 & 520 & 25 & 544 & 520 \\
\hline King & 42 & 521 & 480 & 43 & 519 & 477 & 44 & 519 & 476 \\
\hline Yиеn & 8 & 479 & 472 & 8 & 476 & 469 & 7 & 475 & 469 \\
\hline Ting & 28 & 471 & 444 & 28 & 468 & 441 & 28 & 468 & 441 \\
\hline K'ao & 15 & 443 & 429 & 15 & 440 & 426 & 15 & 440 & 426 \\
\hline Wei lié & 24 & 428 & 405 & 24 & 425 & 402 & 24 & 425 & 402 \\
\hline Ngan & 26 & 404 & 379 & 26 & 401 & 376 & 26 & 401 & 375 \\
\hline Lié & 10 & 378 & 369 & 7 & 375 & 369 & 7 & 375 & 369 \\
\hline Hien & 48 & 368 & 321 & 48 & 368 & 321 & 48 & 368 & 321 \\
\hline Chen-tsing & 6 & 320 & 315 & 6 & 320 & 315 & 6 & 320 & 315 \\
\hline Ngan & 59 & 314 & 256 & 59 & 314 & 256 & 59 & 314 & 256 \\
\hline
\end{tabular}


Tcheou rapporte la $1^{\mathrm{e}}$ année du roi Siuen à l'an 828 avant J. -C. Or nous savons (cf. p. • 275 ) que la $1^{\mathrm{e}}$ année du roi Siuen fut l'année qui suivit la $14^{\mathrm{e}}$ année kong ho : la $1^{\mathrm{e}}$ année kong ho coïnciderait donc avec l'année 842 avant J. -C. et non avec l'année 841 avant J. -C., comme le veut la chronologie généralement admise ; Se-ma Ts'ien en effet était indécis entre ces deux dates: le tableau chronologique des douze seigneurs commence à la $1^{\mathrm{e}}$ année kong ho et donne comme synchronisme la $5^{\mathrm{e}}$ année (841 av. J.-C.) du duc Tcheng de Lou ; mais Se-ma Ts'ien ajoute : D'après une autre autorité, c'est la $14^{\mathrm{e}}$ année (842 av. J.-C.). On le voit, la chronologie qu'on peut établir au moyen de la liste des rois Tcheou est assez différente de la chronologie vulgaire qui est fondée sur les durées des règnes des ducs de Lou. Comme la chronologie vulgaire repose sur l'autorité du Tch'oen ts'ieou, c'est elle que nous suivrons dans la pratique.

04. (501) Nan n'est pas un nom posthume, mais un simple surnom : celui qui a honte, le timide.

04. (502) On a vu (cf. note 497) que, lors du partage de la capitale entre les Tcheou occidentaux et les Tcheou orientaux, c'est ces der niers qui furent « chargés du roi ». Le roi Nan se remet maintenant entre les mains des Tcheou occidentaux.

04. (03) Tchan kouo ts'é : chap. 1er.

04. (504) Le se-ma était un haut fonctionnaire à la cour du roi de Tch'ou .

- Tsien, dit le commentateur du Tchan k'ouo ts'é, avait probablement pour nom de famille Tchao.

04. (05) Le roi Hoai (328-295 av. J.-C.).

04. (06) [] désigne ici le généralissime Tsien.

04. (507) Tchang Cheou-kié dit que le roi de Tch'ou ordonna à Tsien de se rendre auprès du duc de Tcheou pour tâcher d'apprendre qui il voulait nommer héritier présomptif ; le duc le lui dit à mots couverts en demandant que le roi de Tch'ou lui donnât une terre en guise de félicitations. Dans le Tchan kouo ts'é, ces deux phrases appartiennent encore au discours de Tso Tch'eng qui est plus long que dans les Mémoires historiques.

04. (0ㅛ) Aujourd'hui, sous -préfecture de I-yang, préfecture et province de Ho-nan.

04. (509) Sou Tai était originaire de Lo yang; comme son frère aîné, Sou Ts'in (cf. Mayers, Manual, $\mathrm{n}^{\circ}$ 626), il fut un habile machinateur de combinaisons politiques au temps des royaumes combattants.

04. (10) Se-ma Tcheng commente cette phrase en ces termes :

Sou-Tai, parlant en faveur de Tcheou au roi de Tch'ou, lui dit :

- O roi, pourquoi pensez-vous que Tcheou est du parti de Ts'in ? Tcheou n'est point en réalité du parti de Ts'in ; si maintenant Votre Majesté accuse Tcheou d'être du parti de Ts'in, Tcheou redoutera Tch'ou et ne manquera pas de s’incorporer à $T s$ 'in, ce qui sera une calamité.

04. (511) C'est-à-dire : ils réunissent dans le langage Tcheou et Ts'in, comme si ces deux États n'en faisaient déjà plus qu'un.

04. (512) C'est -à-dire : à Tch'ou. Yng était la capitale du royaume de Tch'ou; cette ville était à $10 l i$ au nord de la sous-préfecture de Kiang-ling qui fait partie de la ville préfecturale de King Tcheou, province de Hou-pe.

04. (13) Tchan kouo ts'é : Tong Tcheou, § 6. 
04. (514) La ville de I-yang (cf. note 508), qui était la capitale de l'État de Han, était l'objet constant des attaques du roi de Ts'in; Lo-yang, résidence des Tcheou occidentaux et des Tcheou orientaux se trouvait placée entre les deux rivaux.

04. (15) Au duc Ou, des Tcheou occidentaux, d'après Se-ma Tcheng. Cependant le Tchan houo ts'é place ce discours dans le chapitre consacré aux Tcheou orientaux.

04. (516) Tchan kouo ts'é : Si Tcheou, § 10.

04. (517) Le Tchan kouo ts'é dit que ce discours fut adressé au roi de Wei; en effet, la ville de Nan-yang se trouvait sur le territoire du royaume de Wei, et non dans le royaume de Han. Nan-yang correspondait à l'arrondissement de Hoai, au temps des T'ang (au sud-ouest de l'actuelle sous -préfecture de Ou-tché, préfecture de Hoai-k'ing, province de Ho-nan).

04. (518) Le Tchan kouo ts'é dit : "Pourquoi Votre Majesté ne fait-elle pas sortir des soldats devant Ho-nan ? » On a vu (note 497) que Ho-nan était la partie occidentale de la capitale et que c'est là que le roi Nan avait transporté sa résidence.

04. (1519) Tchan kouo ts'é : Tong Tcheou, § 3.

04. (520) Si le roi de Han n'aide pas les Tcheou occidentaux, les Tcheou orientaux lui en sauront gré et, d'autre part, les Tcheou occidentaux, pour obtenir son appui, lui feront présent de tous leurs trésors.

04. (521) Le texte me paraît présenter ici une lacune.

04. (522) Le Kono ti tche dit que la ville de Yong-che était à $25 l i$ au nord-est de la sous-préfecture de Yang-ti (cf. note 446). D'après Pao Piao, ce siège eut lieu pendant la $15^{\mathrm{c}}$ année (310) du roi Nan.

04. (523) Tchan kouo ts'é : Si Tcheou, § 4.

04. (24) Cf. note 509.

04. (525) Kao-tou était une ville de l'État de Han; d'après le Kouo ti tche, elle se trouvait à 35

$l i$ au nord de la sous-préfecture de I-kiune (aujourd'hui sous-préfecture de Song province de Ho-nan). Le nom de I-k'iue vient de ce qu'il y avait là deux montagnes qui se faisaient vis-à-vis comme les montants d'une porte ( $k^{\prime} i u e$ ) et qu'entre elles deux coulait la rivière $I$.

04. (526) Ce personnage s'appelait Kong-tchong Tch'e li. La charge de conseiller d'État était une institution administrative du pays de $T s^{\prime}$ 'in, mais la plupart des seigneurs avaient imité les princes de Ts’in et avaient aussi leurs conseillers d'État.

04. (527) Se-ma Tcheng dit que [] est ici le synonyme de arrêter.

04. (528) Tcheou se décidera entre Ts'in et Han, les deux rivaux qui cherchaient chacun de leur côté à gagner son appui.

04. (529) Le Tchan kouo ts'é présente ici une variante intéressante; il écrit : il brûlera les lettres de créance (des envoyés) de Tcheou.

04. (30) Tchan kouo ts'é : Si Tcheou, § 6.

04. (531) Sou Li était, comme Sou Tai, frère cadet de Sou Ts'in. - Le discours qui va suivre est le sixième paragraphe du chapitre consacré aux Tcheou occidentaux, d'après la table des matières du Tchan kouo ts'é, mais il n'occupe en fait que la onzième place dans le texte de ce chapitre. De pareilles anomalies sont assez fréquentes dans le Tchan kouo ts'é; nous indiquerons toujours le numéro d'ordre de la table des matières.

04. (532) Che Ou était un général du pays de Wei que Po Ki avait battu en 293 avant J.-C à Ikiue (cf. p. 309, n. 4). Le nom de ce personnage est écrit par le Tchan kouo ts'é. - Sur les pays de Han et de Wei, cf. Mém. hist., chapitres XLV et XLIV. 
04. ( $\underline{533})$ La ville de $\mathrm{Li}$-che fut une sous-préfecture sous plusieurs dynasties ; aujourd'hui, elle se trouve sur le territoire de la préfecture secondaire de Yong-ning, préfecture de Fen-tcheou, province de $C h \bullet n$-si.

— La ville de Lin était fort voisine de celle de $\mathrm{Li}$-che.

04. (534) Dans le Tchan kouo ts'é, le mot Ts'in, qui est en tête de la phrase dans Se-ma Ts'ien, est supprimé. Le pronom relatif domine alors tout ce qui le précède et rend la construction plus régulière : Celui qui a écrasé $H a n$ et Wei, qui a battu Che-ou, qui, au nord .... celui qui a fait tout cela, c'est $P o K^{\prime} i$.

04. (535) Sur Po $K^{\prime} i$, prince de Ou ngan, et général du roi de Ts’in, cf. Mém. hist., chap. LXXIII.

04. (36) De la frontière ou de la barrrière de I-k'iue (cf. note 525).

04. (537) Leang était un petit État dont le centre se trouvait à Han-tch'eng, dans le Chàn-si.

04. (538) Yang Yeou-ki avait été général du roi Kong de Tch'ou (590-560 av. J.-C.).

04. (39) L'apologue est terminé et envoyé supposé du prince Tcheou s'adresse maintenant à Po K’i.

04. (40) Tchan kouo ts'é.

04. (541) D'après le Kouo ti tche, la ville de Hoa-yang était à 40 li au sud de la sous-préfecture de Koan-tch'eng.

- Koan-tch'eng n'est plus aujourd'hui qu'un relais de poste, non loin de la préfecture secondaire de Tcheng, province de Ho-nan.

- Hoa-yang appartenait à l'État de Wei; le roi de $T s$ 'in l'attaqua et la prit, au mépris des traités.

04. (4ㄹ) Cf. note 537.

04. ( $\underline{543})$ Il faut entendre cette phrase au figuré : Ts'in, ayant pris la ville de Hoa-yang, se trouve fort près de Tcheou et le menace ; Tcheou, comme nous dirions en langage vulgaire, est donc bien malade. Ma Fan dit au roi de Leang qu'il craint d'être enveloppé dans la ruine de la maison des Tcheou ; il feint d'être traître à s on pays et propose au roi de lui donner les neuf trépieds, gages de la suzeraineté sur l'empire, à la condition que le roi avisera aux moyens de le sauver, lui, Ma Fan; en réalité, comme on le verra plus loin, il ne cherche qu'à duper le roi de Leang.

04. ( $\underline{544)}$ Dans l'idée du roi de Leang, ces soldats étaient destinés à prêter main-forte à $M a$ Fan qui, au moment où le prince de Tcheou serait dans une situation critique, s'emparerait des neuf trépieds et se réfugierait dans le pays de Leang.

04. (545) Se-ma Tcheng dit: Leang méditait en réalité de s'emparer des neuf trépieds des Tcheou, mais il feignait de n'envoyer des soldats que pour tenir garnison à Tcheou et pour avoir avec lui des rapports cordiaux. $T$ s'in fit avancer ses soldats dans l'intention d'attaquer Tcheou (on a vu que c'était une ruse suggérée par Ma Fan lui-même au roi de $T$ s'in, afin que ce dernier pût s'assurer des vrais sentiments du prince de Leang); Leang ne vint pas au secours de Tcheou; ce fut la preuve qu'il ne prenait pas en main les intérêts de Tcheou, mais qu'il désirait seulement que Tcheou fût en péril afin de s'emparer des neuf trépieds.

- C'est pourquoi les seigneurs se mirent à suspecter Leang ; (afin de dissiper ces soupçons) et de cacher son vrai projet, le roi de Leang n'eut rien de mieux à faire que d'ordonner à ses soldats de construire un rempart pour le compte de Tcheou.

04. (546) Tchan kouo ts'é : Si Tcheou, § 5.

04. (547) Le caractère se prononce ici siu, d'après Se-ma Tcheng. Tcheou Siu était un membre de la famille princière des Tcheou. 
04. (48) Le Tchan kouo ts'é écrit Yuen au lieu de Yng; mais c'est la leçon de Se-ma Ts'ien qui est la bonne. La ville de Yng était autrefois une principauté ; elle se trouvait non loin de la sous-préfecture actuelle de Yé, préfecture de Nan-yang, province de Ho-nan.

04. (549) C'était la reine-douairière Siuen, mère du roi Tchao.

04. (ㄷ5) Le mot [] = rapports, ne me paraît avoir ici aucun sens. Dans le Tchan kouo ts'é, il est absent et le discours devient aussitôt beaucoup plus clair ;

voici le résumé de l'argumentation, si on se conforme au texte du Tchan kouo ts'é :

en faisant ce présent à la reine-mère, vous obtiendrez $T s$ 'in, c'est-à-dire vous jouirez de sa faveur. Or il est essentiel pour vous que vous gagniez cette faveur, car alors le prince de Tcheou vous sera reconnaissant des bons rapports que vous lui assurerez avec $T$ s'in ;

si, au contraire, vous ne faites rien pour capter les bonnes grâces de $T s^{\prime}$ in, les rapports entre $T s$ in et Tcheou seront mauvais, et, comme Tcheou est le plus faible, il risquera d'être annexé par $T s$ 'in : vous serez coupable d'avoir contribué à ce désastre.

Faites donc ce présent à la reine-mère.

04. (51) Tchan kouo ts'é : Si Tcheou, § 13.

04. (552) Le territoire des Tcheou est fort peu étendu et par conséquent $T$ s'in n'a pas grand profit à le conquérir. D'autre part, les Tcheou représentent la monarchie du droit divin, et les attaquer est un crime ; quand $T s$ 'in aura vaincu les Tcheou, il aura en réalité abaissé sa propre puissance aux yeux de l'empire.

04. (553) Tchan kouo ts'é : Tong Tcheou, § 19.

04. (554) Les royaumes de Han, Tchao et Wei formée des débris de celui de Tsin.

04. (555) C'est -à-dire : chez les trois royaumes qui s'étaient ligués contre Ts in .

04. (566) Siu Koang dit que le caractère [] est ici l'équivalent du caractère [] ; c'est donc le même Tcheou Siu dont il a été question plus haut (cf. note 545). Grâce au conseiller d'État, $T c h e o u$ sera honoré par $T$ s'in ; grâce à $T$ cheou Siu, il a déjà obtenu la faveur de $T s$ 'i ; il pourra donc maintenir de bonnes relations avec les deux puissants rivaux. Dans le texte du Tchan kouo $t s^{\prime} e$, il n'est plus question de Tcheou Siu = l'estime de $T s$ 'i est depuis longtemps acquise à Tcheou ; vous vous êtes donc déjà gagné $T s ’$.

04. (557) Cette dernière phrase ne se trouve pas dans le Tchan kouo ts'é.

04. (5ㅛ) Fou-chou appartenait autrefois à l'État de Tcheou, comme l'atteste un texte du Tso tchoan cité par Tchang Cheou-kié. Mais, au temps dont parle Se-ma Ts'ien, cette localité faisait partie du royaume de Han. Elle se trouvait à 35 li au sud-ouest de la ville de Yang-tch'eng qui est aujourd'hui encore une sous-préfecture dépendant de la préfecture de Tsé-tcheou, province de Chøn-si.

04. (559) Nous rencontrons ici pour la première fois, dans le sens particulier qu'il eut au temps des royaumes combattants, le mot tsong;

d'une manière générale, le mot tsong désigne les coalitions formées par les seigneurs contre $T s^{\prime}$ in, tandis que le mot heng désigne les efforts fait par $T s$ ’in contre le reste des seigneurs.

Les commentateurs expliquent pourquoi ces mots ont pris ce sens :

* Wen Yng dit : A l'est des passes (les passes montagneuses qui limitaient le pay s de Ts'in à l'est), c'est tsong ; à l'ouest des passes, c'est heng.

* Mong Kang dit : Du nord au sud, c'est tsong ; de l'est à l'ouest, c'est heng. 
* Se-ma Tcheng concilie ces deux opinions en disant: A l'est des passes, le territoire était long du nord au sud; la longueur est ce qu'exprime le mot tsong; les six royaumes (Yen, Tchao, Han, Wei, Ts'i et Tch'ou) demeuraient tous là ; à l'ouest des passes, le territoire était large de l'ouest à l'est ; la largeur est ce qu'exprime le mot heng; Ts'in était seul à demeurer là.

04. (다) Cf. note 525 .

04. (61) D'après Se-ma Tcheng, c'était le duc Ou.

04. (62) C'était le duc Wen, fils aîné du duc $O u$.

- D'après le Kouo ti tche, Tan-hou était un village à 15 li au sud-ouest de la sous-préfecture de Leng ; celle-ci n'existe plus aujourd'hui en tant que sous -préfecture, mais elle se trouvait à $40 l i$ à l'ouest de la préfecture secondaire de Jou, province de Ho-nan.

04. (63) A Lo-yang (aujourd'hui Ho-nan-fou).

04. (564) Cf. p. ${ }^{2} 243$.

04. (ㅌ5) Cf. p. ${ }^{\bullet} 247$.

04. (ㅌ6) Cf. notes 145 et 247.

04. (ㅌ6) Cf. p. $\bullet^{285} \cdot$

04. (568) D'après le T'ong hien tsi lan, la sépulture du duc de Tcheou est au nord-est de la sous-préfecture de Hien-yang, préfecture de Si-ngan, province de Chàn-si. Pi est aussi le lieu où fut, dit-on, enterré le roi Wen (cf. note 157). Sur la ville de Hao, cf. note 247.

04. (569) L'empereur Ou, en l'an 113 avant J. -C., prit la mesure dont parle Se-ma Ts'ien. Cf. ma première traduction du Traité sur les sacrifices fong et chan, p. 59.

04. (570) Ho-nan, aujourd'hui Ho-nan-fou, est l'ancienne ville de Lo-yang.

04. (571) Le commentateur du Ts'ien Han chou qu'on désigne par son nom personnel, Tsan, veut que Tse-nan soit un nom de famille: Mais Se-ma Tcheng fait remarquer que tous les descendants de Kia eurent pour nom de famille $K i$ (l'ancien nom de clan des Tcheou); il se range donc à l'opinion de Yen Che-kou, d'après qui Tse-nan est le nom de la terre qui fut donnée au descendant des Tcheou. 
Se- ma Tcheng : Les trois souverains, avec notes

Mémoires historiques : I. Les cinq empereurs - II. Les Hia - III. Les Yn - IV. Les Tcheou.

Notes des chapitres : $\underline{\mathrm{I}}-\underline{\mathrm{II}}-\underline{\mathrm{III}}-\underline{\mathrm{IV}}$.

Table $\bullet$ 
Nom du document : memoires_historiques_t.I.doc

Dossier :

C:ICSS\Envoi021204lse_ma_tsien

Modèle :

C:IWINDOWS $\backslash$ Application

DatalMicrosoft $\backslash$ Modèles $\backslash$ Normal.dot

Titre :

Sujet :

Mémoires historiques, tome premier

Auteur :

série Chine

Mots clés :

Se-ma Ts' ien

Ch' ien, Sstma Ch' ien, Ssima Ch' ien, Sima Qian, Historiographie

chinoise, Annales historiques, histoire de la Chine, China history,

Historical records, Records of the grand historian, astrologie chinoi

Commentaires : iences_sociales/index.html

http://www.uqac.uquebec.ca/zone30/Classiques_des_sc

Date de création : $\quad$ 17/09/04 08:52

$\mathrm{N}^{\circ}$ de révision : $\quad 212$

Dernier enregistr. le : 28/11/04 20:53

Dernier enregistrement par : Pierre Palpant

Temps total d' édition4 509 Minutes

Dernière impression sur : $\quad$ 05/12/04 13:42

Tel qu' à la dernière impression

Nombre de pages : 203

Nombre de mots : 104752 (approx.)

Nombre de caractères : 597088 (approx.) 